\title{
INCIPIENT MOTION OF RIPRAP ON STEEP SLOPES
}

\author{
by \\ Kai Rainer Langmaak \\ Thesis presented in fulfilment of the requirements for the degree of \\ Master of Engineering at Stellenbosch University
}

Supervisor: Prof GR Basson

December 2013 


\section{DECLARATION}

By submitting this thesis electronically, I declare that the entirety of the work contained therein is my own, original work, that I am the sole author thereof (save to the extent explicitly otherwise stated), that reproduction thereof by Stellenbosch University will not infringe any third party rights and that I have not previously in its entirety or in part submitted it for obtaining any qualification.

Signature:

Date:

Copyright () 2013 Stellenbosch University

All rights reserved 


\section{ABSTRACT}

Riprap is commonly used as an erosion protection measure around the world. In some cases, for example when constructing bed arrestors, riprap has to be designed to be stable on steep slopes. The literature shows that the problem of incipient motion is reasonably well understood, but existing hydraulic design methods are found to be largely unreliable.

The main objective of this study is to improve the understanding of the different factors affecting incipient motion in order to furnish the prospective design engineer with a reliable method for sizing riprap on steep slopes adequately.

Eight existing theories dealing with the threshold of incipient motion are reviewed, of which Liu's work (1957) seems most promising. Naturally, the required median rock diameter of the riprap is reasonably large (due to the steep slopes), with high particle Reynolds numbers. However, little data is available for these flow conditions.

Data collected from 12 large scale laboratory tests carried out for this research indicate that the dimensionless Movability Number is in fact constant for large particle Reynolds numbers. For design purposes, the recommended Movability Number which emerged from this study is 0.18 , provided that the steep bed slope is taken into account, and that the theoretical settling velocity is calculated using an accurate drag coefficient and the $d_{90}$ sieve size.

A comparison of the laboratory data with design equations showed that a large variety of results are obtained, which supports the need for this study.

Finally, it was shown that a calibrated one dimensional hydrodynamic model can be used by the practicing engineer to extract the hydraulic properties needed for applying Liu's theory. It was found that the ratio $k_{s} / d_{90}=0.81$ may be applied to estimate the bed roughness for the grading used in this study. 


\section{OPSOMMING}

Stortklip is 'n metode wat wêreldwyd gebruik word om erosie te voorkom. In sommige gevalle, byvoorbeeld vir die konstruksie van erosietrappe, moet stortklip teen steil hellings spesifiek ontwerp word om stabiliteit te verseker. Die literatuur beskryf die probleem van aanvanklike beweging redelik goed, maar dit is bevind dat die bestaande ontwerpmetodes grotendeels onbetroubaar is.

Die hoofdoelwit van hierdie ondersoek was om die faktore wat beweging van stortklip veroorsaak, beter te verstaan en 'n betroubare metode te ontwikkel wat 'n ingenieur kan aanwend om stortklipbeskerming wat op steil hellings geplaas word te ontwerp.

Agt verskillende metodes wat die begin van beweging beskryf is bestudeer, en dit wil voorkom asof die Liu teorie van 1957 die grootste potensiaal het. As gevolg van die steil hellings wat ondersoek word, is die benodigde klipgroote redelik groot wat weereens die oorsaak is vir ' $\mathrm{n}$ hoë deeltjie Reynolds getal is. In die literatuur kon geen data gevind word vir so " $n$ vloeitoestand nie.

Daarom is 12 laboratoriumtoetse gedoen en daar is gevind dat die Mobiliteitsgetal redelik konstant is vir groot deeltjie Reynoldsgetalle. Vir onwerpdoeleindes word 'n Mobiliteitsgetal van 0.18 aanbeveel, met die voorwaarde dat die bodemhelling in ag geneem word, en dat die teoretiese valsnelheid bereken word met die $d_{90}$ klipgroote en 'n akkurate sleurkoëffisiënt.

Verder is gevind dat die labaratorium data die voorspellings van die bestaande ontwerpvergelykings nie bevredigend pas nie. Dit ondersteun die behoefte vir hierdie studie.

Om die bogenoemde bevindings vir praktiese probleme bruikbaar te maak, is daar gewys dat ' $n$ gekalibreerde een dimensionale hydrodinamiese rekenaarmodel gebruik kan word om die nodige hidrouliese eienskappe te verkry om die Liu teorie toe te pas. Dit is bevind dat die verhouding $k_{s} / d_{90}=0.81$ 'n goeie benadering vir die hidrouliese ruheid kan voorsien. 


\section{TABLE OF CONTENTS}

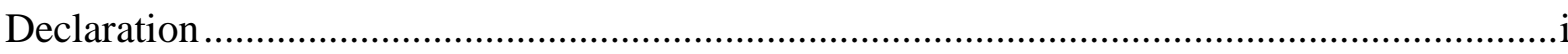

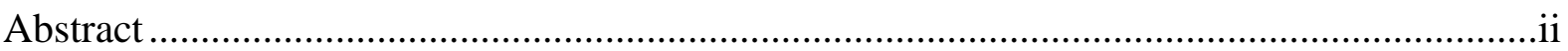

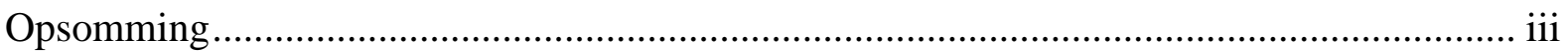

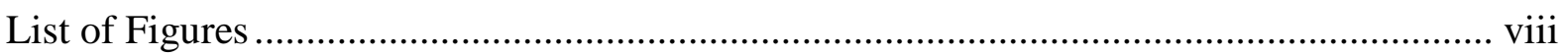

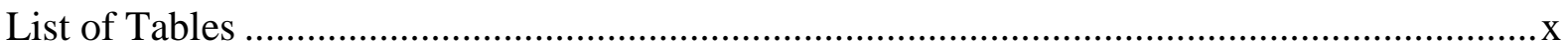

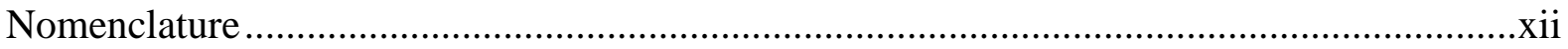

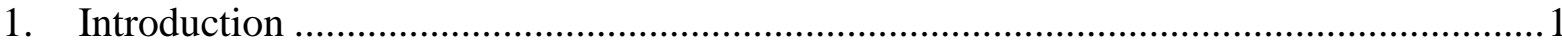

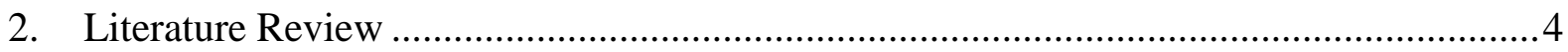

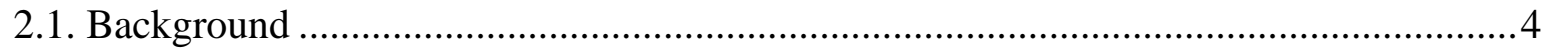

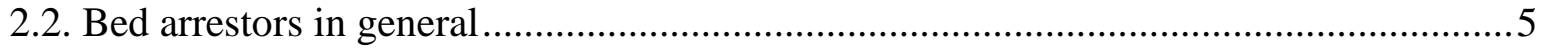

2.3. Physical Characteristics of Armourstone ....................................................................

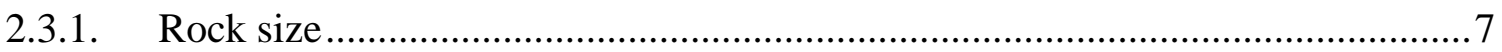

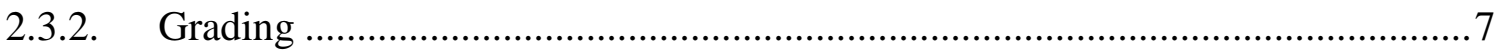

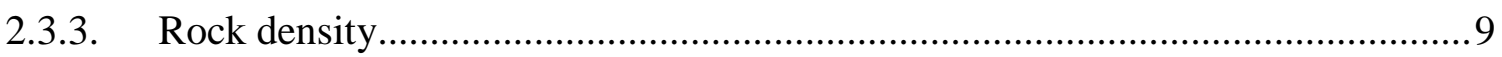

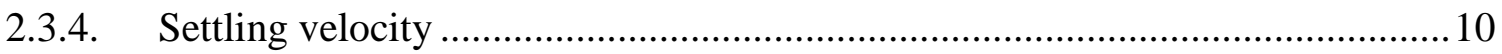

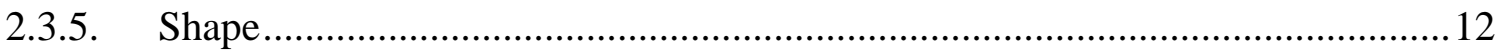

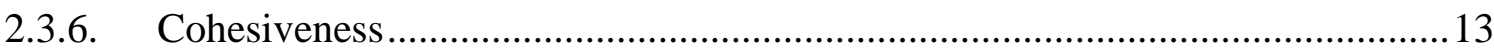

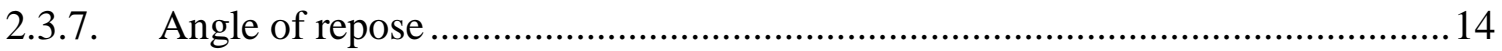

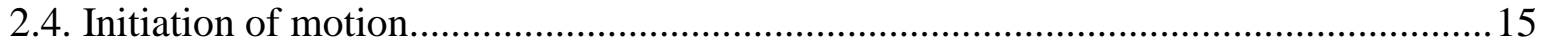

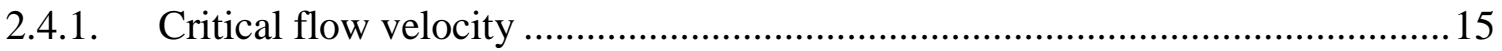

2.4.2. Shields's critical shear stress approach............................................................. 17

2.4.3. Lui's stream power approach .......................................................................20

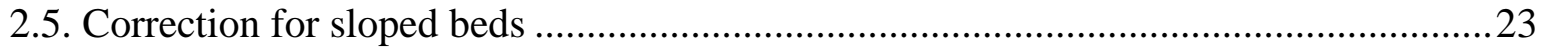

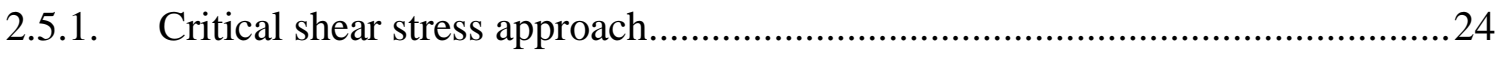

2.5.2. Flow velocity approach ............................................................................25 


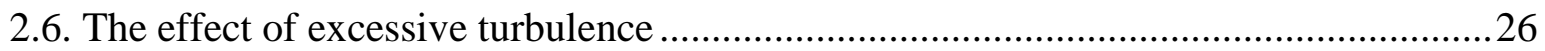

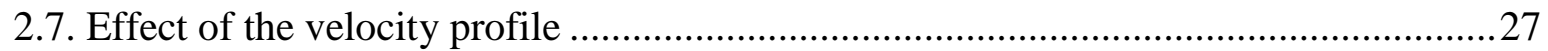

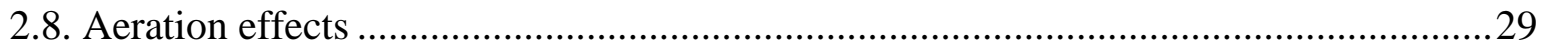

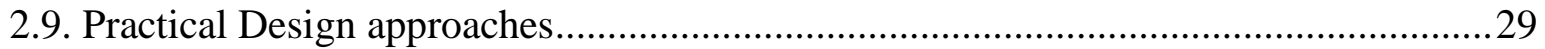

2.9.1. General Design Equation (CIRIA et al., 2007) ............................................ 30

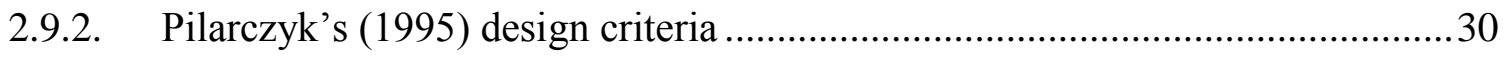

2.9.3. Escarameia and May's design equation (CIRIA et al., 2007)........................... 31

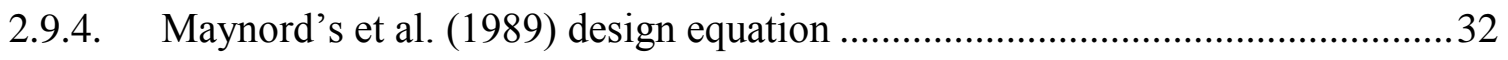

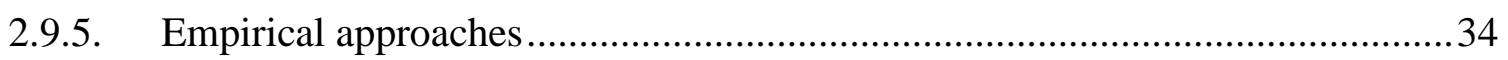

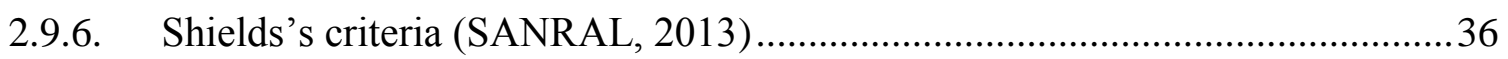

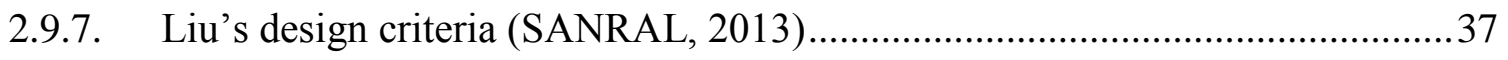

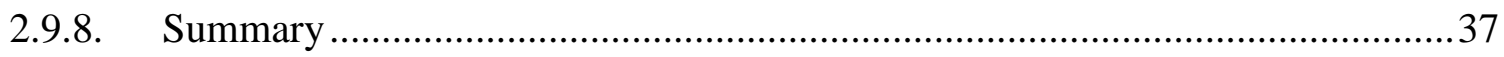

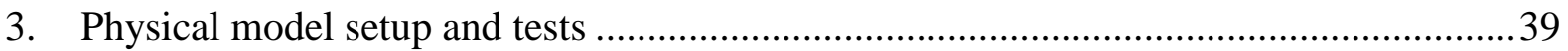

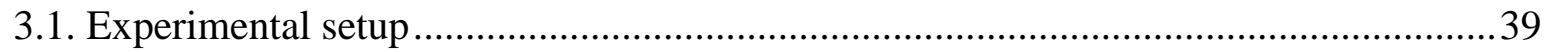

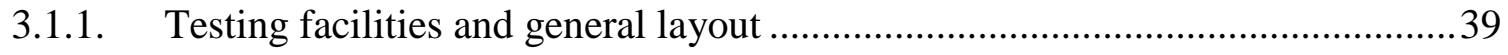

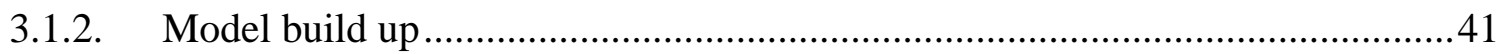

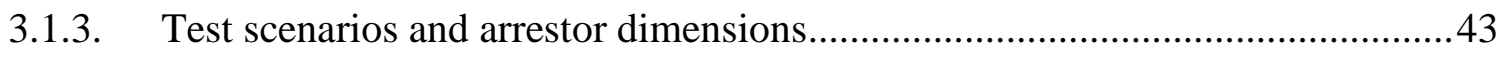

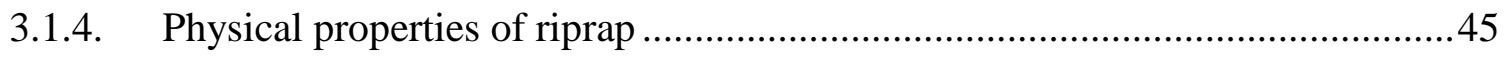

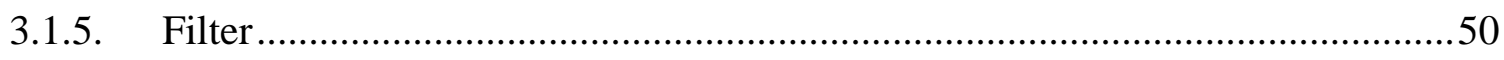

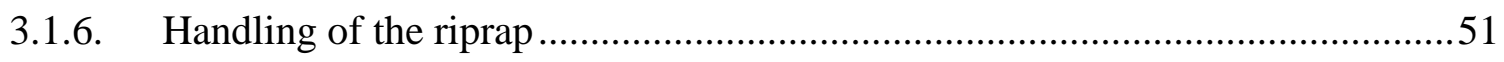

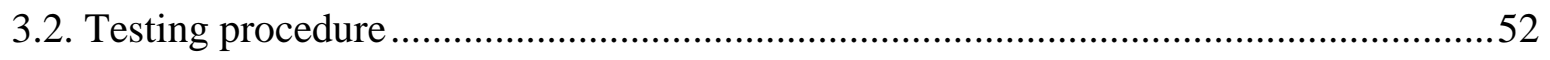

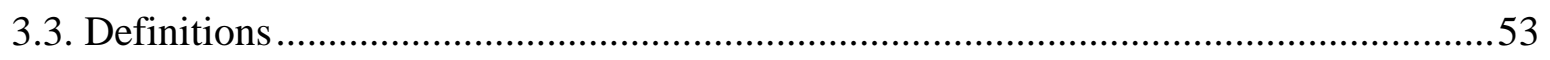

3.3.1. Definition of incipient motion under laboratory conditions .............................53

3.3.2. Definition of structure failure under laboratory conditions ..............................53

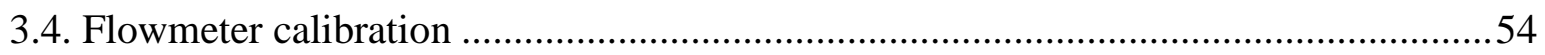

4. Experimental determination of Drag coefficient for particle settling velocity ................59 


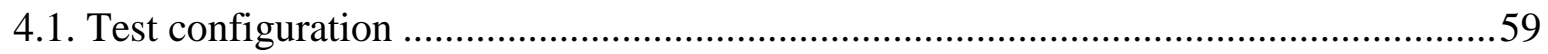

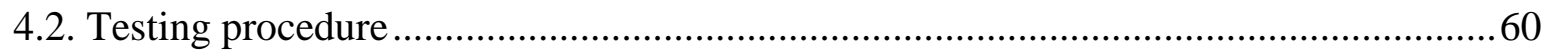

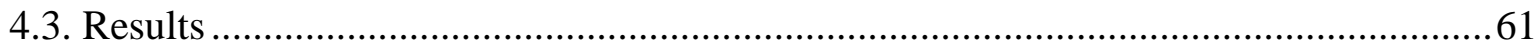

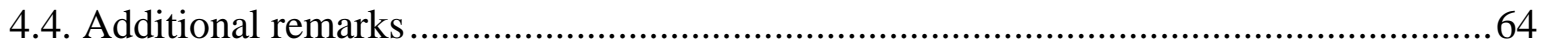

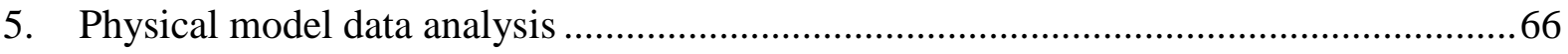

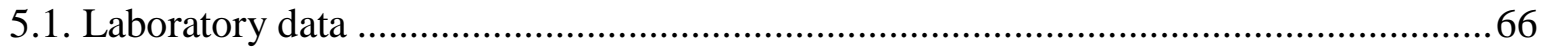

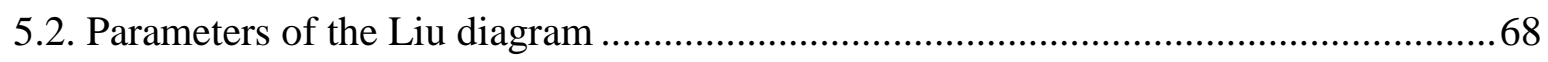

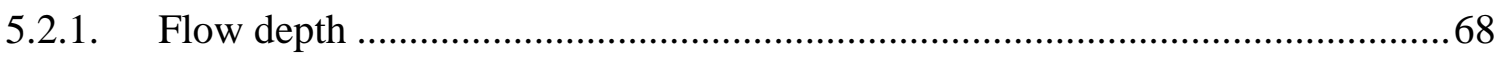

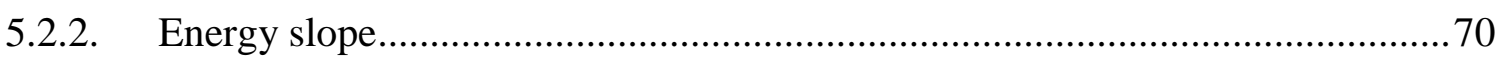

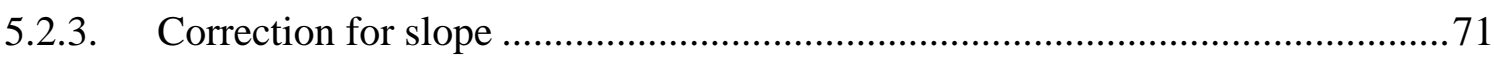

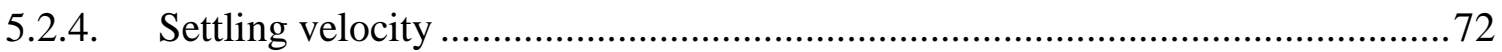

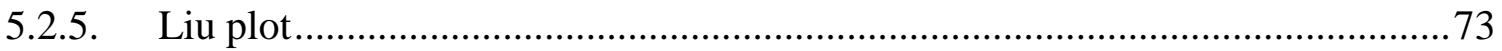

5.3. Comparison of incipient motion criteria of common design practices .........................75

5.3.1. General Design Equation (CIRIA et al., 2007) ............................................ 76

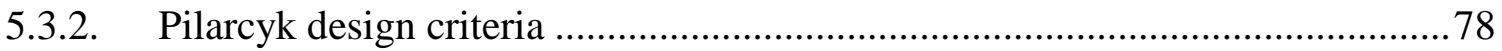

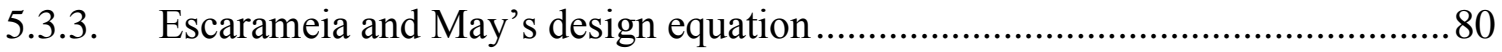

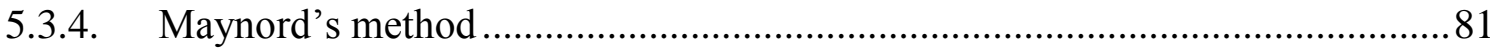

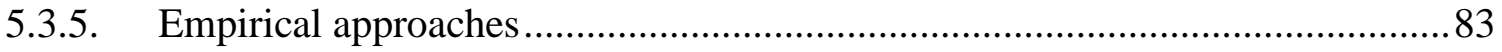

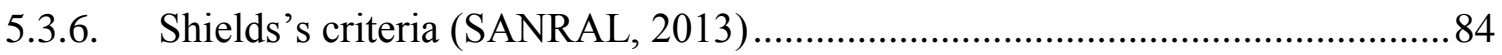

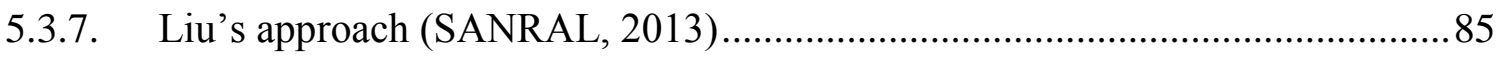

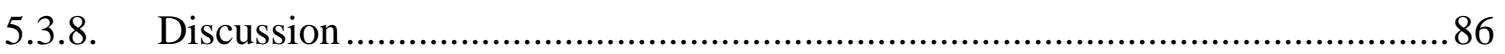

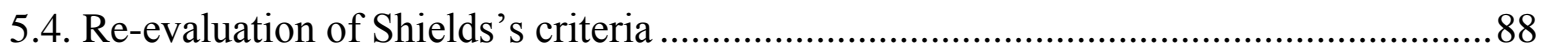

6. Development of a design methodology using one dimensional hydrodynamic modelling..

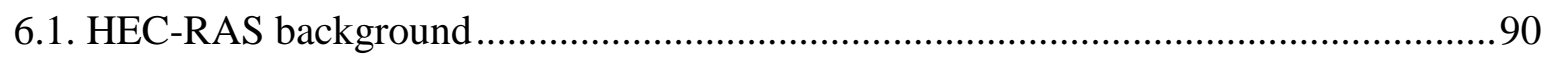

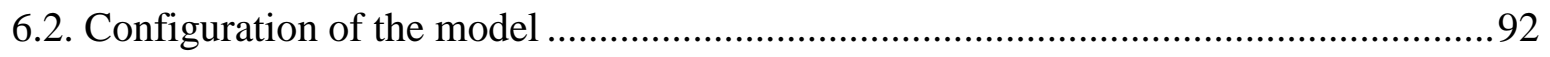

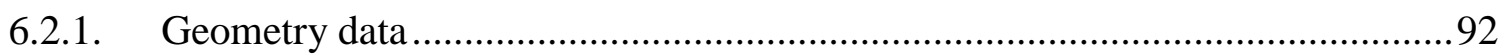




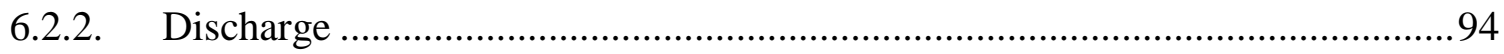

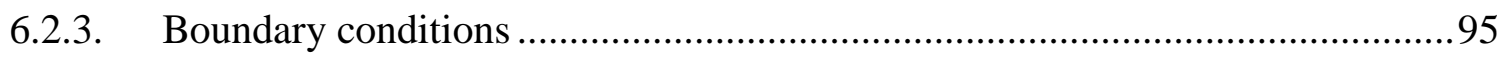

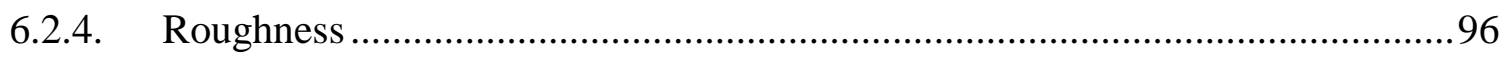

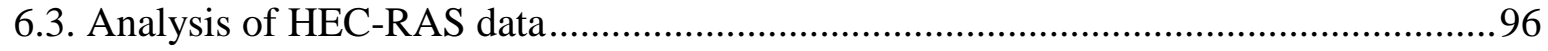

6.3.1. Approach to determining roughness coefficient ..........................................96

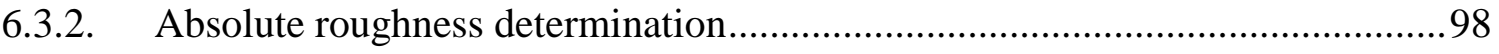

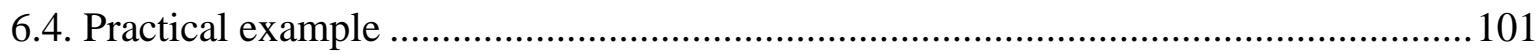

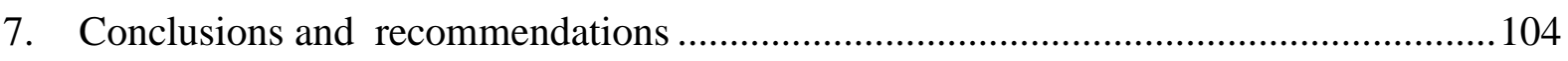

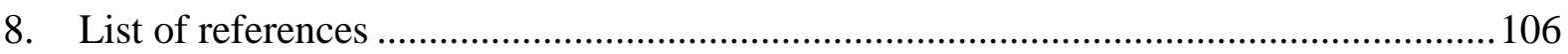

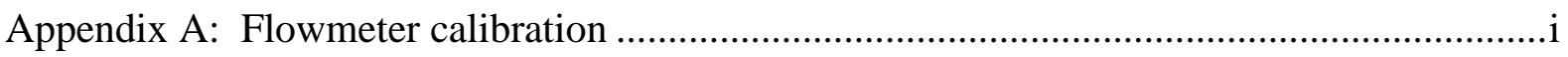

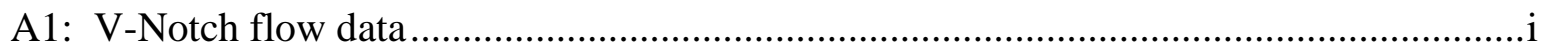

A2: Rectangular contracted weir flow data.................................................................ii

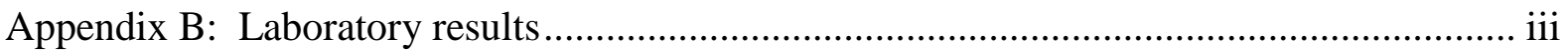

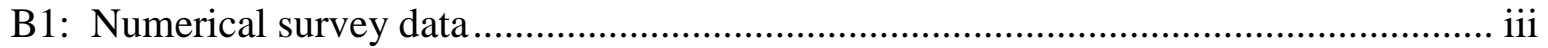

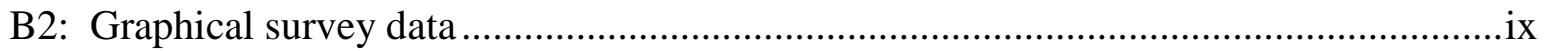

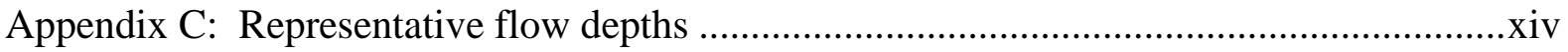

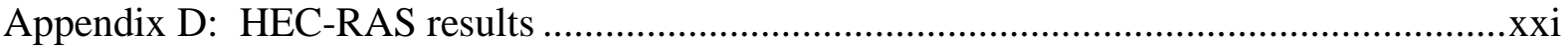




\section{LIST OF FIGURES}

Figure 2-1: Typical riprap arrestors in laboratory setup (Institute for Water and Environmental Engineering, 2012) ..........................................................6

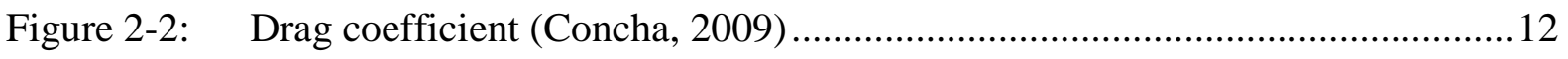

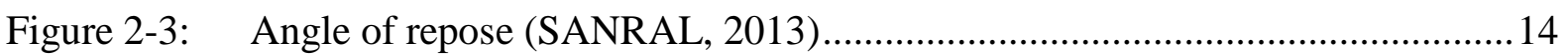

Figure 2-4: Threshold of motion (Raudkivi, 1998) as determined by Shields and other researchers

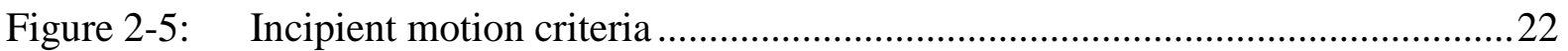

Figure 2-6: Vertical velocity profile (CIRIA et al., 2007) ….........................................28

Figure 3-1: Conceptual plan view of laboratory setup ................................................ 40

Figure 3-2: $\quad$ Uniform flow approaching the arrestor in the laboratory setup .....................41

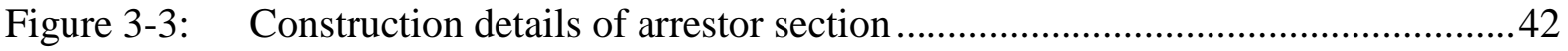

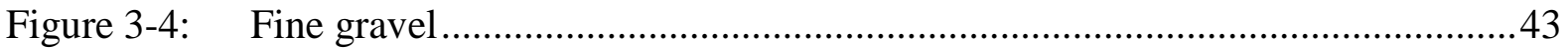

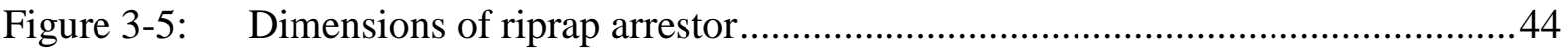

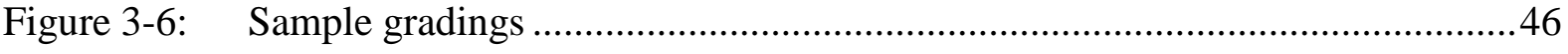

Figure 3-7: $\quad$ Rock sample (hornfels left, sandstone right) ......................................... 47

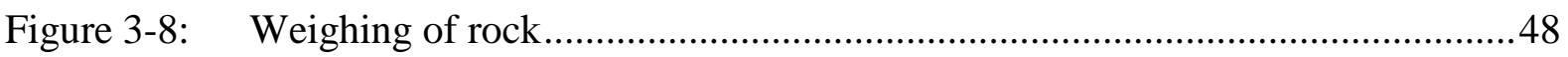

Figure 3-9: $\quad$ Measuring the displacement of a rock in the large beaker .............................. 48

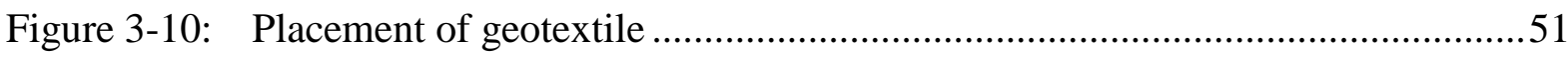

Figure 3-11: Example of failed arrestor structure, looking upstream (Test 131).................54

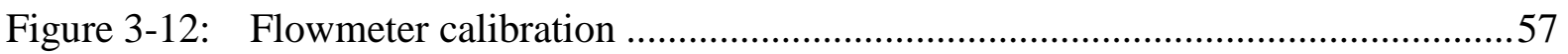

Figure 4-1: $\quad$ Steel tank used for determining settling velocity .......................................60

Figure 4-2: $\quad$ Snapshot of video recording as seen through window ...................................61

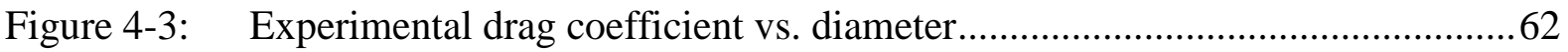

Figure 4-4: $\quad$ Experimental drag coefficient vs. particle Reynolds number .........................63

Figure 4-5: $\quad$ Experimental drag coefficient vs. shape factor ...........................................64 


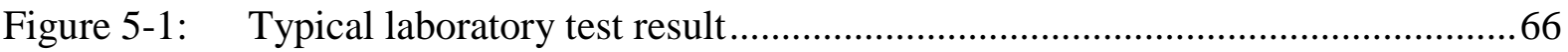

Figure 5-2: $\quad$ Exaggerated shape of structure just after incipient motion .............................69

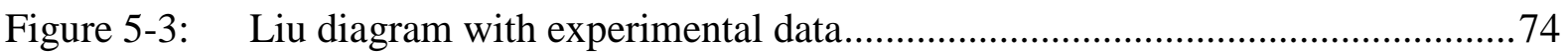

Figure 5-4: $\quad$ Liu diagram with experimental data (detailed) ......................................... 74

Figure 5-5: Layer thickness coefficient (Province of British Columbia Ministry of Environment, Lands and Parks , 2000) ........................................................ 82

Figure 5-6: Experimental data plotted on the Shields diagram ...................................... 89

Figure 6-1: Components of the Bernoulli equation (SANRAL, 2013) .............................91

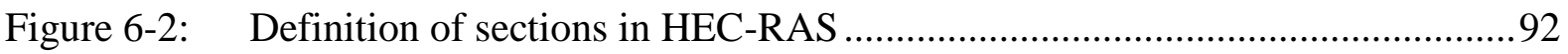

Figure 6-3: $\quad$ Typical layout of cross sections in HEC-RAS ............................................ 94

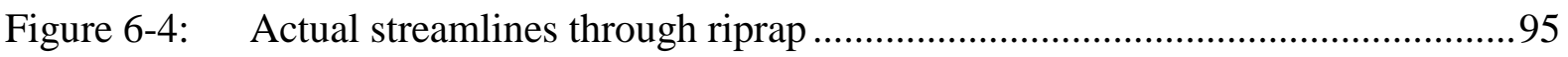

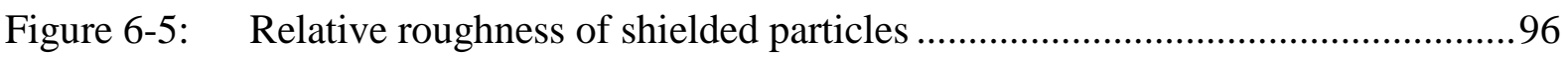

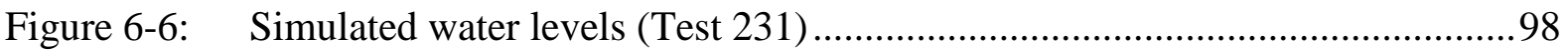

Figure 6-7: $\quad$ Experimental vs. calibrated HEC-RAS data .................................................. 101 


\section{LIST OF TABLES}

Table 2-1: $\quad$ Riprap classification (Simons \& Sentürk, 1992) ..............................................

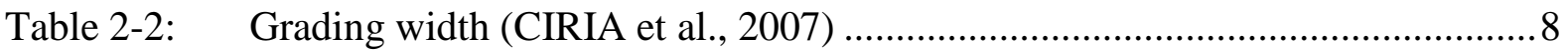

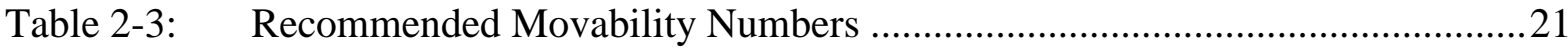

Table 2-4: $\quad$ Recommended $r$ values at $0.1 y$ above bed (CIRIA et al., 2007) .....................27

Table 2-5: Correction factors for velocity profile (CIRIA et al., 2007) for rough

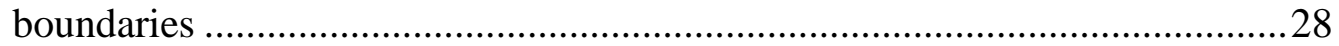

Table 2-6: $\quad$ Recommended values for Stability correction factor (CIRIA et al., 2007)......31

Table 2-7: Velocity distribution coefficients for Maynord's formula ...............................33

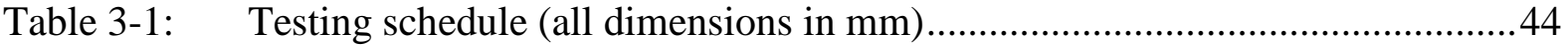

Table 3-2: $\quad$ Density determination of rock sample ....................................................... 49

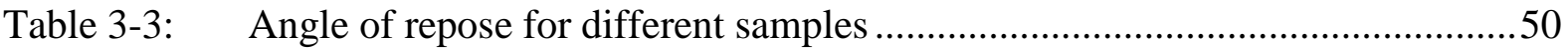

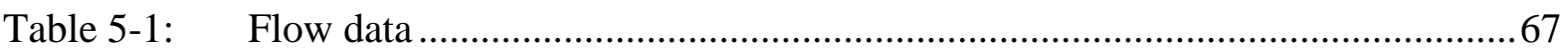

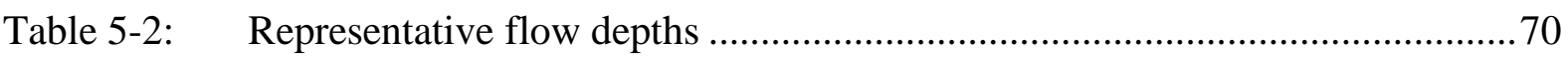

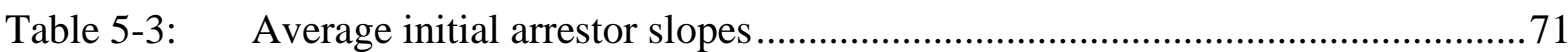

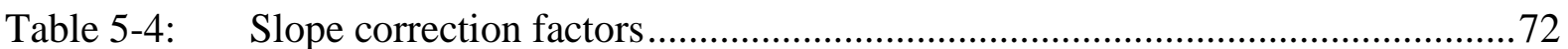

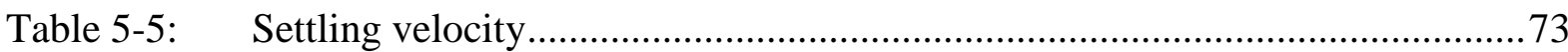

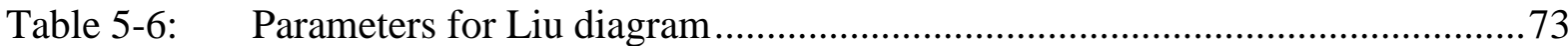

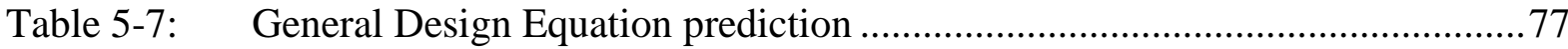

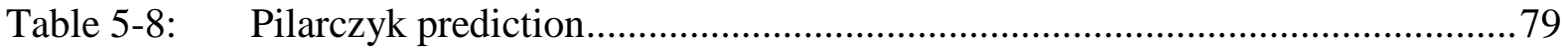

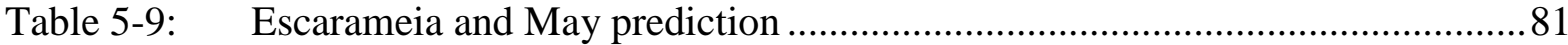

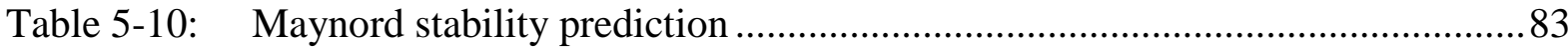

Table 5-11: Empirical methods to estimate riprap stability.............................................. 84

Table 5-12: $\quad$ Shields's stability prediction, as stipulated by SANRAL (2013).................... 85

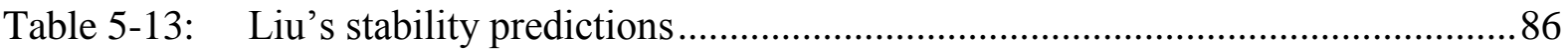

Table 5-14: Summary of riprap stability prediction techniques ….................................... 87 


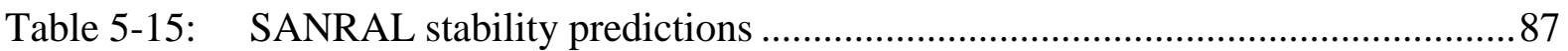

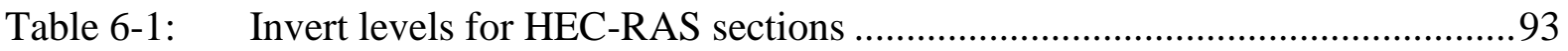

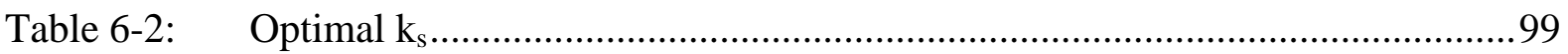

Table 6-3 : $\quad$ Parameters for Liu diagram using calibrated HEC-RAS model ..................... 100

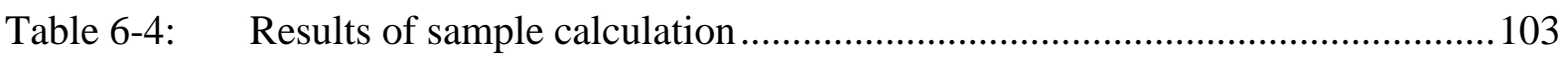




\section{NOMENCLATURE}
$A$
Flow area $\left(\mathrm{m}^{2}\right)$

$a, b, c$

Mutually perpendicular axes of particle, $a$ being the longest, $c$ the shortest (m)

$A_{p} \quad$ Exposed surface area of particle $\left(\mathrm{m}^{2}\right)$

$B$

Flow width (m)

$B$

Flowmeter calibration coefficient

$C_{d}$

Contraction coefficient

$C_{D}$

Drag coefficient

$C_{e}$

Effective discharge coefficient

$C_{s t}$

Stability coefficient

$C_{T}$

Blanket thickness coefficient

$C_{t}$

Turbulence coefficient

$C_{v}$

Velocity distribution coefficient

$D$

Flow depth (m)

$d$

Particle size, Sieve size (m)

$d_{50}$

Median particle sieve size (m)

$d_{n 50}$

Median nominal particle sieve size (m)

$d_{y}$

Sieve size of particle that exceeds y $\%$ of stone size (m)

$F_{D}$

Drag force exerted on a particle $(\mathrm{N})$

$f_{g} \quad$ Grading width, gradation factor 
Gravitational acceleration $\left(=9.81 \mathrm{~m} / \mathrm{s}^{2}\right)$

H

Energy head (m)

$h_{c}$

Expansion and contraction losses (m)

$h_{e}$

Energy head loss (m)

$h_{f}$

Friction loss (m)

$H_{l e}$

Corrected energy head (m)

$k_{h}$

Velocity profile factor

$K_{L}$

Empirical constant (m)

$k_{s}$

Chezy's roughness (m)

$k_{s l}$

Side slope factor

$k_{t}$

Turbulence amplification factor

$k_{\beta}, k_{\alpha}$

Slope reduction factors

$L$

Distance between magnetic poles (m)

$L$

Measured length of weir (m)

$L$

Reach length (m)

$L_{\text {Arr }}$

Horizontally measured arrestor length (m)

$L_{e}$

Effective length (m)

$m$

Mass (kg)

$n$

Manning's roughness coefficient $\left(\mathrm{s} / \mathrm{m}^{1 / 3}\right)$

$p$

Porosity of rock particle

$P_{S}$

Protrusion height of weir (m) 


\begin{tabular}{|c|c|}
\hline$Q$ & Discharge $\left(\mathrm{m}^{3} / \mathrm{s}\right)$ \\
\hline$Q_{f}$ & Discharge at which failure of structure occurs $(1 / s)$ \\
\hline$Q_{m}$ & Discharge at which incipient motion is initiated $(1 / \mathrm{s})$ \\
\hline$q$ & Unit discharge $\left(\mathrm{m}^{3} / \mathrm{s} . \mathrm{m}\right)$ \\
\hline$q_{\text {design }}$ & Design unit discharge $\left(\mathrm{m}^{3} / \mathrm{s} . \mathrm{m}\right)$ \\
\hline$q_{f}$ & Unit discharge at which slope failure occurs $\left(\mathrm{m}^{3} / \mathrm{s} . \mathrm{m}\right)$ \\
\hline$r$ & Depth averaged relative fluctuation intensity due to turbulence \\
\hline$R$ & Centreline radius of bend $(\mathrm{m})$ \\
\hline$R$ & Hydraulic radius (m) \\
\hline$R^{2}$ & Coefficient of determination \\
\hline $\operatorname{Re}$ & Reynolds number \\
\hline$R e^{*}$ & Particle Reynolds number \\
\hline$S_{0}$ & Bed slope $(\mathrm{m} / \mathrm{m})$ \\
\hline$S_{\text {Arr }}$ & Slope of the downstream part of the arrestor $(\mathrm{m} / \mathrm{m})$ \\
\hline$S_{f}$ & Energy slope $(\mathrm{m} / \mathrm{m})$ \\
\hline$S_{F}$ & Safety factor \\
\hline$S_{p}$ & Corey shape factor \\
\hline$S_{r}$ & Degree of saturation $(\%)$ \\
\hline$S_{w}$ & Water level slope $(\mathrm{m} / \mathrm{m})$ \\
\hline$t$ & Layer thickness (m) \\
\hline$t_{1}, t_{2}, t_{3}$ & Arrestor dimensions (mm) \\
\hline
\end{tabular}




\begin{tabular}{|c|c|}
\hline$V$ & Average flow velocity $(\mathrm{m} / \mathrm{s})$ \\
\hline$V$ & Voltage reading $(\mathrm{V})$ \\
\hline$V$ & Volume $\left(\mathrm{m}^{3}\right)$ \\
\hline$V^{*}$ & Particle shear velocity $(\mathrm{m} / \mathrm{s})$ \\
\hline$V_{0, c r}$ & Critical bed shear velocity on a sloped bed $(\mathrm{m} / \mathrm{s})$ \\
\hline$V_{0, c r, 0}$ & Critical bed shear velocity on a horizontal bed $(\mathrm{m} / \mathrm{s})$ \\
\hline$V_{b}$ & Near bed velocity $(\mathrm{m} / \mathrm{s})$ \\
\hline$V_{c}$ & Average critical flow velocity $(\mathrm{m} / \mathrm{s})$ \\
\hline$V_{s s}$ & Particle settling velocity $(\mathrm{m} / \mathrm{s})$ \\
\hline$W_{y}$ & Weight of stone that exceeds y $\%$ of stone size $(\mathrm{N})$ \\
\hline$y$ & Distance above bed (m) \\
\hline$y_{0}$ & Reference level near bed (m) \\
\hline$\alpha$ & Canal side slope $\left(^{\circ}\right)$ \\
\hline$\alpha$ & Cross sectional velocity variation coefficient \\
\hline$\alpha_{c e}, \beta_{c e}$ & Equation coefficients for discharge coefficient \\
\hline$\beta$ & Horizontal bed slope $\left(^{\circ}\right)$ \\
\hline$\Delta$ & Relative rock density \\
\hline$\theta$ & Angle of V-Notch $\left(^{\circ}\right)$ \\
\hline$\theta$ & Bed slope $\left(^{\circ}\right)$ \\
\hline$\kappa$ & Von Karman's constant $(\kappa=0.4)$ \\
\hline$\Lambda_{h}$ & Velocity profile factor \\
\hline
\end{tabular}


$\rho_{r}$

$\rho_{w}$

$\sigma$

$\tau$

$\tau_{0}$

$\tau_{0, c r}$

$\tau_{0, c r, 0}$

$\tau_{c r}$

$\phi$

$\phi_{s c}$

$\psi$

$\psi_{c r}$

$\psi_{p}$
Kinematic viscosity $\left(\mathrm{m}^{2} / \mathrm{s}\right)$

Density $\left(\mathrm{kg} / \mathrm{m}^{3}\right)$

Apparent rock density $\left(\mathrm{kg} / \mathrm{m}^{3}\right)$

Rock density $\left(\mathrm{kg} / \mathrm{m}^{3}\right)$

Density of water $\left(\sim 1000 \mathrm{~kg} / \mathrm{m}^{3}\right)$

Mean volume of water per unit mixture volume

Shear stress $\left(\mathrm{N} / \mathrm{m}^{2}\right)$

Bed shear stress $\left(\mathrm{N} / \mathrm{m}^{2}\right)$

Critical bed shear stress on a sloped bed $\left(\mathrm{N} / \mathrm{m}^{2}\right)$

Critical bed shear stress on a horizontal bed $\left(\mathrm{N} / \mathrm{m}^{2}\right)$

Critical bed shear stress $\left(\mathrm{N} / \mathrm{m}^{2}\right)$

Angle of repose $\left(^{\circ}\right)$

Stability correction factor

Shields parameter

Critical Shields parameter

Sphericity 


\section{INTRODUCTION}

The design and construction of measures to prevent excessive erosion of certain sections of a watercourse often form part of a hydraulic engineering project.

There are a number of causes of erosion of river beds. These include:

- a decrease in sediment supply;

- an increase in bed slope;

- an increase in channel velocities (typically due to a constriction in the channel, i.e. bridges, berms); and

- an increase in discharge.

Erosion control often makes up a large part of the total construction costs of hydraulic structures, such as canals, berms, culverts etc. There are a number of different methods to choose from to inhibit erosion, such as lining the affected area with concrete, the placement of Armorflex or Reno mattresses, or the construction of some sort of bed arrestors, which are protected steps with flatter unprotected reaches between the arrestors.

Many of these measures include the use of armourstone, such as dumped riprap. Riprap is often preferred over other erosion protection measures for a number of non-technical reasons:

- it is aesthetically pleasing since it uses natural materials;

- its environmental impact is often limited in comparison to other alternatives like concrete structures or the placing of Armorflex; and

- it is economical if the required rock size is available in a nearby quarry.

However, due to the high level of uncertainty involved in the design of riprap structures in turbulent and non-uniform conditions, extensive laboratory studies are needed, or overly conservative designs are proposed, leading to unnecessary expense.

The aim of this thesis is to investigate methods to reliably calculate the riprap rock size needed when large diameter riprap is placed on hydraulically steep slopes. 
The concept of incipient motion is of primary interest in this study, since it defines the point where particle movement is initiated, whereas the rate of transport is of less interest in this investigation.

Liu's (1957) theory of the 'Movability Number' parameter (indicating incipient motion) is studied in particular. Some researchers (e.g. Rooseboom, 1992; Stoffberg, 2005; Van der Walt, 2005; Armitage \& Rooseboom, 2010; Przedwojski et al., 1995) claim that Liu's theory is an appropriate method for identifying the point of incipient motion of non-cohesive particles in natural rivers. The validity of the application of this theory to steep slopes with non-uniform flow conditions is the focus of this investigation.

The objectives of this study were:

- to develop an understanding of the processes leading to incipient motion in noncohesive particles;

- to investigate the suitability of Liu's theory for the design of steep riprap structures by utilising data from a physical model;

- to compare different design guidelines with the laboratory results and comment on the appropriateness of the different methods in order to determine the relevance of each; and

- to develop a method which accurately calculates the point of incipient motion and can be used for design purposes.

Chapter 2 deals with the available literature in the field of incipient motion. In this chapter special reference is made to parameters affecting the point at which motion is initiated. In addition, a number of different theories and design practices are assessed. Laboratory tests conducted in this study (aimed at collecting data about incipient motion under laboratory conditions) are discussed in Chapter 3.

The laboratory results are analysed in Chapters 4 and 5, and are compared to the predictions of various design guidelines. Liu's theory is revisited and its appropriateness for predicting incipient motion is investigated.

In Chapter 6 a one dimensional hydrodynamic model is used to develop guidelines for applying Liu's theory for practical design purposes. 
Finally, in Chapter 7, the conclusions drawn from the study and recommendations for future research are discussed. 


\section{LITERATURE REVIEW}

\subsection{Background}

In order to estimate the stability of rocks of different sizes, densities, shapes and gradings, the processes by which they are moved must be fully understood.

A number of factors, identified by Armitage (2002) and Stoffberg (2005), affect the movement of a particle:

- Boundary conditions. For practical applications, the bottom boundary, or bed for the flow will most likely be uneven. Even for relatively smooth beds, the size, position and orientation of the surrounding particles will influence the flow regime in the vicinity of the particle, all of which will influence the stability of the particle.

- Contact points. All particles are in contact with each other at a number of points. The properties of these contact points influence the mechanics that allow or inhibit rotation, displacement (or a combination of the two) of a particle.

- Non-uniformity of particles. All naturally occurring sediments are graded to a certain extent. A process called armouring takes place when smaller particles are washed away, leaving larger, more stable ones behind and thus affecting the stability of the particles. Also, the particles' exposure to flow varies, due to smaller particles being hidden behind larger ones.

- Small-scale coherent flow structures. Unsteady flow patterns due to turbulence expose particles to very intense and rapidly changing forces. According to Armitage (2002), several researchers were able to correlate the appearance of turbulent bursts with sediment transport near the bed.

- Slope of the bed. The slope of the bed will affect the gravity component acting on particles.

Researchers used different approaches to tackle the problem of incipient motion. For example, Shields (1936) defined a critical shear stress as the threshold shear stress at which particle movement is initiated. If the applied shear stress is lower than the critical value, no particle motion is initiated. Hence, the particle is considered to be stable. When shear stresses are larger than the critical value, particles will start to erode. 
A similar approach, but using a critical shear velocity instead of a critical shear stress, was proposed by Liu (1957). Later, Armitage (2002) defined the dimensionless Mobility Number in terms of the shear velocity and the settling velocity of the particle and found that the stability of the particle can be related to the magnitude of the Movability Number.

Various authors (e.g. Chadwick et al., 2004; CIRIA et al. 2007) suggest that the erosive capacity of a stream can be estimated using the shear stress $(\tau)$ and the average flow velocity $(V)$. Annandale (2006) in turn states that the flow velocity or shear stress exerted on the bed is not always sufficient to estimate the required rock size.

A number of authors (Annandale, 2006; Chadwick et al., 2004; CIRIA et al., 2007; Maynord et al., 1987; Simons \& Sentürk, 1992) stress the unreliability of the available design methods and recommend that laboratory tests should be done wherever possible to verify the theoretical calculations.

Due to the complex nature of the turbulent flow pattern in general streams, it is virtually impossible to quantify the flow velocity very close to the boundary, which is in essence the driving force of particle erosion. It is therefore common practice to relate the flow velocity at a certain depth to the shear stress that the fluid exerts on the flow boundary (Annandale, 2006; CIRIA et al., 2007).

\subsection{Bed arrestors in general}

Reducing the slope of the river is a very effective method of decreasing the erosive capacity of the stream (Annandale, 2006). The construction of arrestors in river beds is aimed at reducing the slope between the arrestors. The height difference between the upstream and downstream arrestors is adjusted so that the desired slope (typically a stable or near stable slope) between the arrestors is achieved.

Arrestors are typically constructed perpendicular to the flow direction. If correctly designed, the structures work as follows (Przedwojski et al., 1995):

- the crests of the structures form a series of hydraulic controls in the river bed in order to inhibit erosion further upstream;

- erosion of the natural bed between the arrestors will continue until an equilibrium level is reached; and 
- energy is dissipated at the structures.

A typical set of arrestor structures in a laboratory study are shown Figure 2-1.

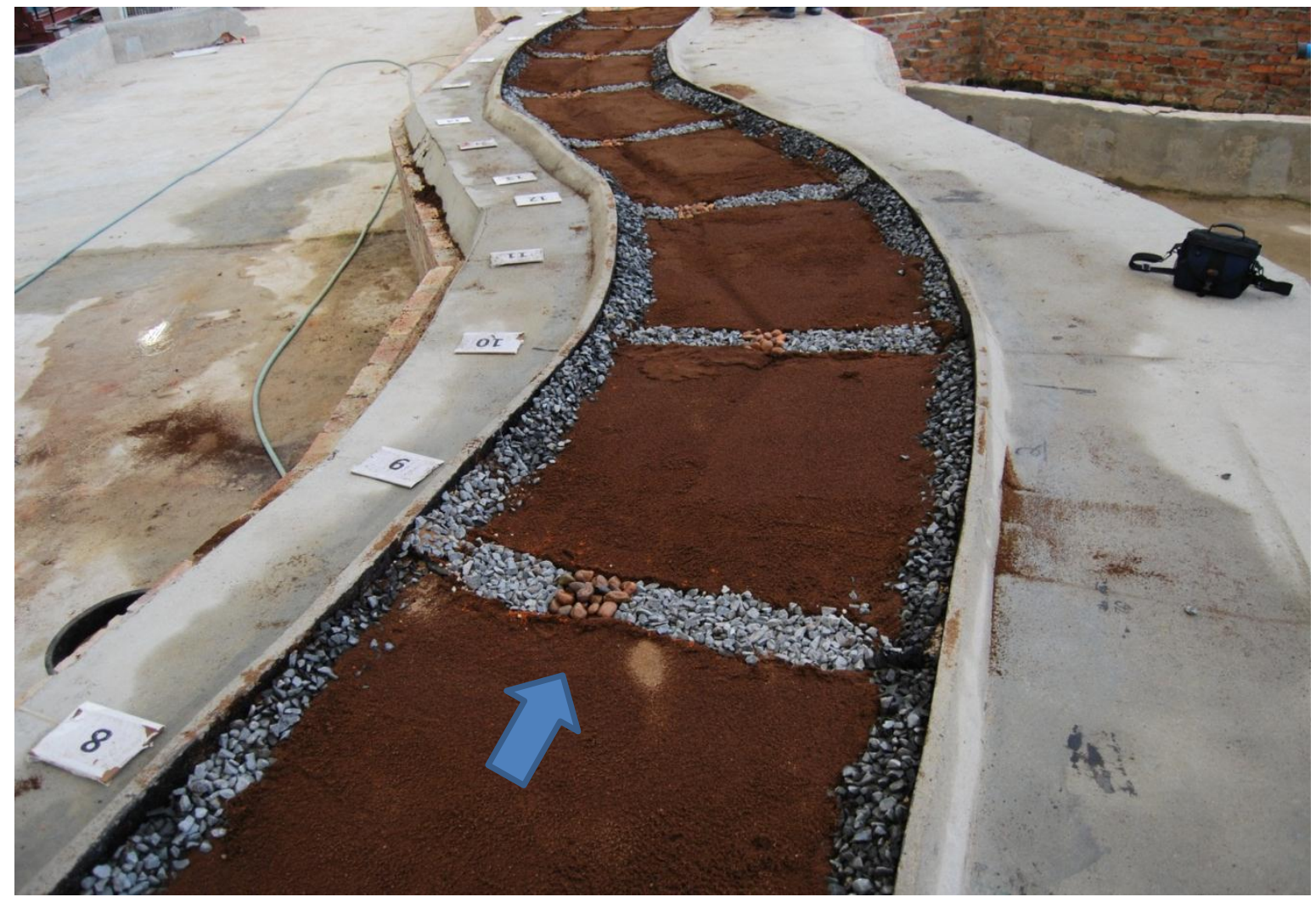

Figure 2-1: Typical riprap arrestors in laboratory setup (Institute for Water and Environmental Engineering, 2012)

In terms of functionality, the most important arrestor parameters that need to be considered are the crest height and the distance between the structures (Przedwojski et al., 1995). In practice, these parameters can be obtained by trial and error, making use of the available criteria for stable slopes (Hoffmans \& Verheij, 1997).

Previous research by De Almeida and Martin-Vide (2009) shows that the required riprap sizes tends to be underestimated when design methods for continuous riprap are used. They furthermore claim that the length of the riprap, as well as the protrusion height of the structure, play a significant role. According to Abt and Johnsons (1991), the ability of riprap to resist a certain flow is a function of the stone size, the hydraulic gradient and the discharge.

The following parameters of the arrestors will be investigated closely in this study:

- length of the arrestor in the flow direction $\left(L_{A r r}\right)$;

- downstream slope of the arrestor $\left(S_{\text {Arr }}\right)$; and 
- the median rock size $\left(d_{50}\right)$ of the riprap.

\subsection{Physical Characteristics of Armourstone}

\subsection{1. $\quad$ Rock size}

The rock size distribution of the riprap sample is one of the most important design parameters to consider. It is often the only parameter that can be selected by the engineer and used to predict the particle behaviour (Simons \& Sentürk, 1992).

A widely accepted classification of rock sizes is shown in Table 2-1.

Table 2-1: Riprap classification (Simons \& Sentürk, 1992)

\begin{tabular}{|c|c|}
\hline Size $(\mathrm{mm})$ & Class \\
\hline $4000-2000$ & Very large boulders \\
\hline $2000-1000$ & Large boulders \\
\hline $1000-500$ & Medium boulders \\
\hline $500-250$ & Small boulders \\
\hline $250-130$ & Large cobbles \\
\hline
\end{tabular}

A single rock size is expressed in terms of the sieve size $d$. For a sample of rocks, the diameter $d_{y}$ is more applicable, where the subscript $y$ denotes the percentage of the sample by mass, passing through a sieve size. The median sieve size, $d_{50}$ is commonly used.

Some guidelines make use of the median nominal diameter, termed $d_{n 50}$. This measure of rock size is based on a circular opening through which particles pass, while the previously mentioned $d_{50}$ is based on a rectangular sieve opening.

Based on laboratory tests, Laan (1981) proposed Equation 2-1 which allows conversion between the two parameters:

$$
d_{n}=0.84 d
$$

Equation 2-1

This conversion is also recommended by CIRIA et al. (2007).

\subsubsection{Grading}

The grading of rocks refers to how well smaller and larger rocks are distributed across the sample. A well graded sample does not contain any significant gaps throughout the grading width. In contrast, gap graded material contains a large number of rocks of a certain range, but very little of other sizes. 
The literature is mostly in agreement that riprap should be well graded for optimum performance. In physical terms, a good grading ensures the interlocking of the individual particles and maximum internal friction. This yields a stable attack surface (Annandale, 2006) of the top layer of the riprap. However, the correct grading width (defined as the ratio $d_{85} / d_{15}$ and commonly denoted as $f_{g}$ ) needed for riprap is a debatable topic: it has also been argued (e.g. Abt \& Johnson, 1991; Robinson et al., 1998) that in the case of an excess of fine material, the fines will simply be eroded, leaving the larger particles behind. Ultimately this yields less resistance to flow.

An indication of the required grading is often given in terms of the grading width, as presented in Table 2-2.

Table 2-2: Grading width (CIRIA et al., 2007)

\begin{tabular}{|c|c|}
\hline Grading width & $d_{85} / d_{15}$ \\
\hline Narrow & $<1.5$ \\
\hline Wide & $1.5-2.5$ \\
\hline Very wide & $2.5-5.0$ \\
\hline
\end{tabular}

CIRIA et al. (2007) recommend a wide grading for riprap and armourstone. Apart from the grading width, they also provide a detailed description of the different available requirements for standardising grading.

Another widely accepted grading method is presented by Simons and Sentürk (1992):

- $d_{100} \geq 2 d_{50}$

- $d_{20} \geq 0.5 d_{50}$

- $d_{\operatorname{Min}} \geq 0.2 d_{50}$

If the above guidelines are interpolated linearly on a logarithmic scale for the values of $d_{85}$ and $d_{15}$, a grading width $\left(d_{85} / d_{15}\right)$ of about 3.6 is obtained. It thus falls into the "very wide" category.

Thus, CIRIA et al. (2007) recommend a narrower grading width than Simons and Sentürk (1992).

Further, Przedwojski et al. (1995) recommend $d_{60} / d_{10} \geq 2.15$ for riprap with overtopping flow. Alternatively, they refer to the US Army Corps of Engineers' riprap design guidelines of 1985. These guidelines are presented in terms of the weight of the particle (termed $W_{y}$ ), 
unlike many other guidelines where reference is made to the sieve size. A dimensional analysis yields the following relation between the Mass and diameter of the rocks:

$$
W_{y}=\Delta d_{n y}^{3}
$$

Equation 2-2

where $\Delta$ is the relative rock density.

Using Equation 2-2, the US Army Corps of Engineers guidelines have been rewritten to yield the following relations:

- $1.26 d_{50} \leq d_{100} \leq 2 d_{50}$

- $0.74 d_{50} \leq \mathrm{d}_{15} \leq \mathrm{d}_{50}$

These guidelines are similar to those proposed by Simons and Sentürk (1992).

The grading is also a critical parameter for filter design. Filters are generally designed to be geometrically tight, implying that the particles in the lower layer are sized as to prevent them from penetrating the upper layer. Although this method tends to be impractical as it requires many layers, its efficiency is not dependent on the hydraulic loading on the structure, which is often difficult to determine (CIRIA et al., 2007; Przedwojski et al., 1995), but is often considered as the crucial advantage.

Two sources (CIRIA et al., 2007; Przedwojski et al., 1995) suggest that a uniformity criterion is applicable for filters. This is given by:

$$
\frac{d_{60}}{d_{10}}<10
$$

Przedwojski et al. (1995) refers to a retention criterion which ensures a stable interface between two layers of granular materials. The grading of the base and the filter material (denoted $b$ and $f$ respectively) should satisfy the following:

$$
\frac{d_{15 f}}{d_{85 b}}<5
$$

\subsubsection{Rock density}

The rock density $\left(\rho_{r}\right)$ of a riprap sample is an important parameter for stability calculations. In general the rock density does not vary significantly for different rock types. A good 
estimate for riprap density in general seems to be in the order to $2650 \mathrm{~kg} / \mathrm{m}^{3}$ (CIRIA et al., 2007; Annandale, 2006; Simons \& Sentürk, 1992; Przedwojski et al., 1995; SANRAL, 2013).

A convenient way to express the density is in terms of the unit less relative buoyant density $(\Delta)$ and is defined as:

$$
\Delta=\frac{\rho_{r}}{\rho_{w}}-1
$$

The relative buoyant density can be interpreted as the relative density of a particle under water. The density of water $\left(\rho_{w}\right)$ is commonly taken as $1000 \mathrm{~kg} / \mathrm{m}^{3}$.

According to CIRIA et al. (2007), the so called apparent rock density $\left(\rho_{\text {app }}\right)$ is more applicable for design purposes. It is given by Equation 2-4.

$$
\rho_{a p p}=\rho_{r}(1-p)+\rho_{w} p S_{r}
$$

Equation 2-4

where

$p \quad$ is the porosity of the rock particle, defined as the volume of the pore volume to the total volume; and

$S_{r} \quad$ is the degree of saturation, defined as the volume of the water in the pores to the volume of the pores.

Interestingly, there is no mention of the use of $\rho_{\text {app }}$ in any of the other literature reviewed. It seems however possible that the effect of the porosity of the rocks becomes significant once the rocks have been submersed under water for an extended period of time. For applications where the material is submerged for short periods only, there is not enough time for water to fill the voids. Thus, $p \sim 0$, implying that $\rho_{a p p} \sim \rho_{r}$.

\subsubsection{Settling velocity}

The settling velocity $\left(V_{s s}\right)$ of a particle describes the terminal velocity that a particle reaches in quiescent water conditions.

The settling velocity of a particle depends on a number of factors for example the shape, size, weight, surface roughness of the particle, and many other parameters. However, the majority of these loose significance as the particles increase in size (Simons \& Sentürk, 1992). 
When a particle reaches its settling velocity, the drag force $\left(F_{D}\right)$, the buoyancy force and the weight are in equilibrium. These forces can generally be determined with reasonable accuracy. The general drag force equation is given by:

$$
F_{D}=C_{D} \rho_{w} A_{p} \frac{V_{S S}^{2}}{2}
$$

where

$C_{D} \quad$ Drag coefficient; and

$A_{p} \quad$ Projected surface area of the particle.

Assuming that the particle under consideration is in equilibrium, the drag force and the gravitational forces $(F=m g)$ are equal. Thus, Equation 2-5 becomes

$$
C_{D} \rho_{w} A_{p} \frac{V_{S S}^{2}}{2}=m g
$$

Equation 2-6

where

$$
\begin{aligned}
& m \quad \text { Mass of the particle; and } \\
& g \quad \text { Gravitational acceleration }=9.81 \mathrm{~m} / \mathrm{s}^{2} \text {. }
\end{aligned}
$$

Assuming that the particles have spherical shape with a diameter $d$, the right hand side of Equation 2-6 becomes

$$
m g=\left(\rho_{r}-\rho_{w}\right)\left(\frac{1}{6} \pi d^{3}\right) g
$$

Finally, the projected surface area is expressed in terms of the particle diameter. Following some algebraic manipulation and simplification, the expression for $V_{s s}$ becomes

$$
V_{S S}^{2}=\frac{4}{3}\left(\frac{\rho_{r}-\rho_{w}}{\rho_{w}}\right) \frac{d g}{C_{D}}
$$

Equation 2-8

The main difficulty for computing Equation 2-8 is determining the drag coefficient $C_{D}$. Several researchers have proposed useful methods for determining $C_{D}$ for near spherical shaped particles. 
According to Concha (2009) and Simons and Sentürk (1992), several researchers found that for large Reynolds numbers $(R e)$, non-spherical particles rotate and vibrate, causing complex water-particle interactions that affect the velocity of the particle. This movement is highly dependent on the shape of the particle, as can be seen in Figure 2-2.

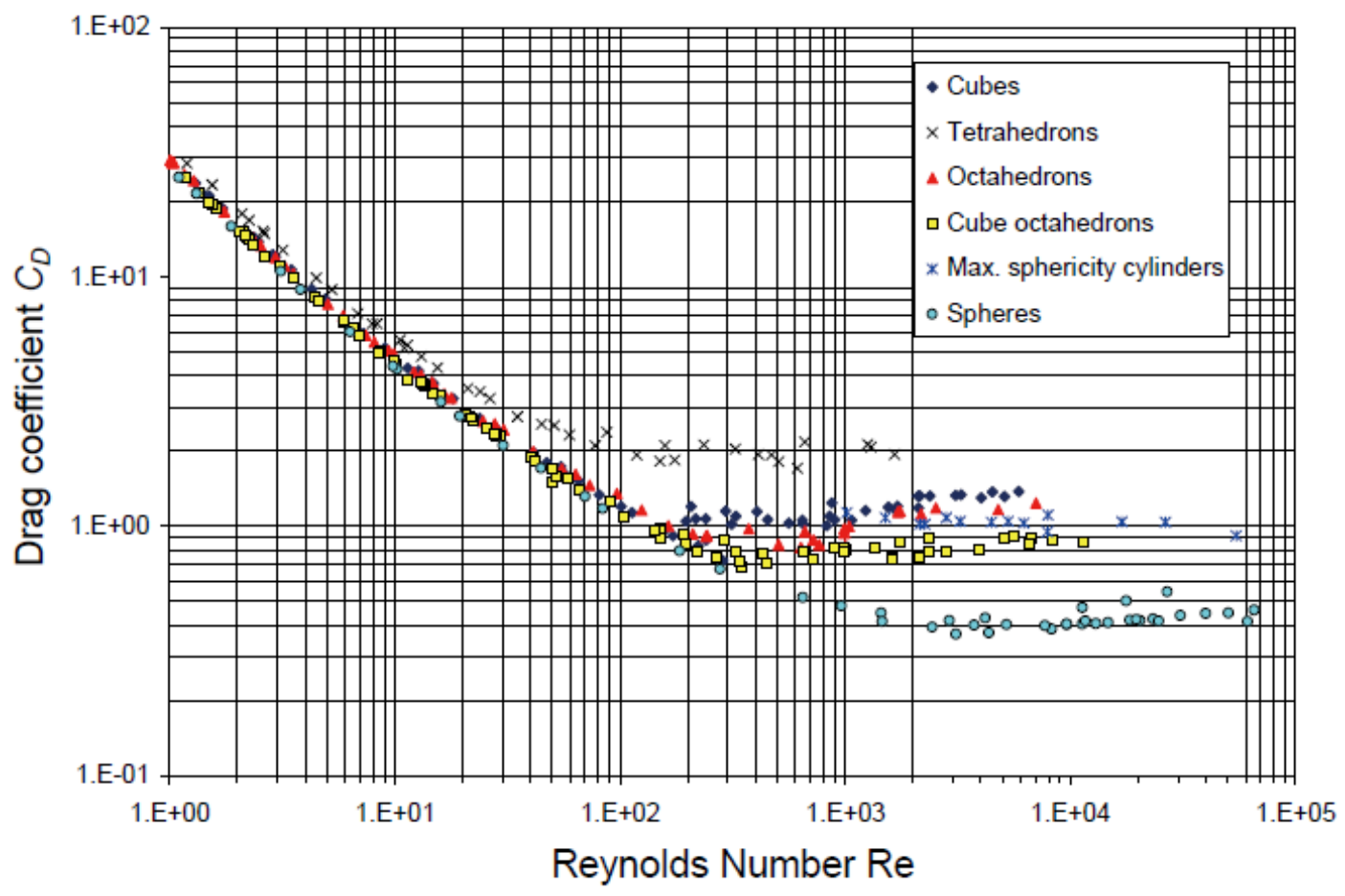

Figure 2-2: Drag coefficient (Concha, 2009)

The reader should note that the vertical scale is logarithmic, and that in the region where $R e>1000, C_{D}$ varies between about 0.4 and 2 (depending on the shape of the particle).

\subsubsection{Shape}

The shape of a particle refers to the overall geometric dimensions and is independent of the size and physical composition of the particle. Strictly speaking the shape of the particle is a complex interaction of geometric properties. It is therefore highly unlikely that different particles have the same shape. Simons and Sentürk (1992) suggest that particles that have very different shapes but equal volume and density can display similar behaviour in fluids.

Simons and Sentürk (1992) suggest that Corey's formula (Equation 2-9) yields a useful expression of shape:

$$
S_{p}=\frac{c}{\sqrt{a b}}
$$


where

$a, b$ and $c$ are measured along perpendicular axes with " $a$ " being the longest dimension, " $b$ " an intermediate and " $c$ " the shortest dimension.

It is furthermore suggested that the $S_{p}$ for a worn quartz particle is about 0.7 .

CIRIA et al. (2007) and Simons and Sentürk (1992) also mention some sort of a length to thickness LT (referred to as LT in CIRIA et al., 2007) which is a useful parameter to quantify the shape of the particles. They recommend the limitation of the proportion of particles with a LT > 3 to $5 \%$ for heavy armourstone in cover layers. This ensures a reasonable interlock of the particles. In general, long flat particles are considered to be less stable than particles with roughly the same dimensions along $a, b$ and $c$.

Simons and Sentürk (1992) and Concha (2009) introduce an additional parameter which is particularly useful for describing the relative motion between the falling particle and the fluid. This parameter is termed the sphericity and is given by Equation 2-10.

$$
\psi_{p}=\frac{\text { surface area of sphere of equal volume }}{\text { actual surface area of particle }}
$$

The closer the sphericity is to unity, the more the particles resemble the shape of a sphere. Concha (2009) shows in his paper that this ratio can be used to obtain a realistic value for $C_{D}$ since it can be theoretically linked to the approximate shape of the particle, as shown in Figure 2-2. However, he also realised the difficulty of determining the value of $\psi_{p}$ in practice.

Research by Abt and Johnson (1991) and Robinson et al. (1998) showed that the particle shape can affect the maximum allowable discharge before failure occurs by as much as $40 \%$, since round particles have less interlocking potential than angular ones.

\subsubsection{Cohesiveness}

The principles and methodology of armourstone design presented in this thesis are developed for non-cohesive material only.

It is widely accepted that cohesive forces between particles are a function of the surface area to weight ratio. The higher this ratio, the more cohesive the material is. An example of a 
cohesive material is clay. This study, however, is exclusively focused on larger particles like rocks and boulders. The study of incipient motion for cohesive particles is a completely different subject.

\subsubsection{Angle of repose}

The angle of repose $(\phi)$ is the steepest angle at which particles can rest on a heap of material without experiencing a loss of stability.

In Figure 2-3 (sourced from SANRAL, 2013), the angle of repose (referred to as slope angle) for a given angularity and particle size can be determined.

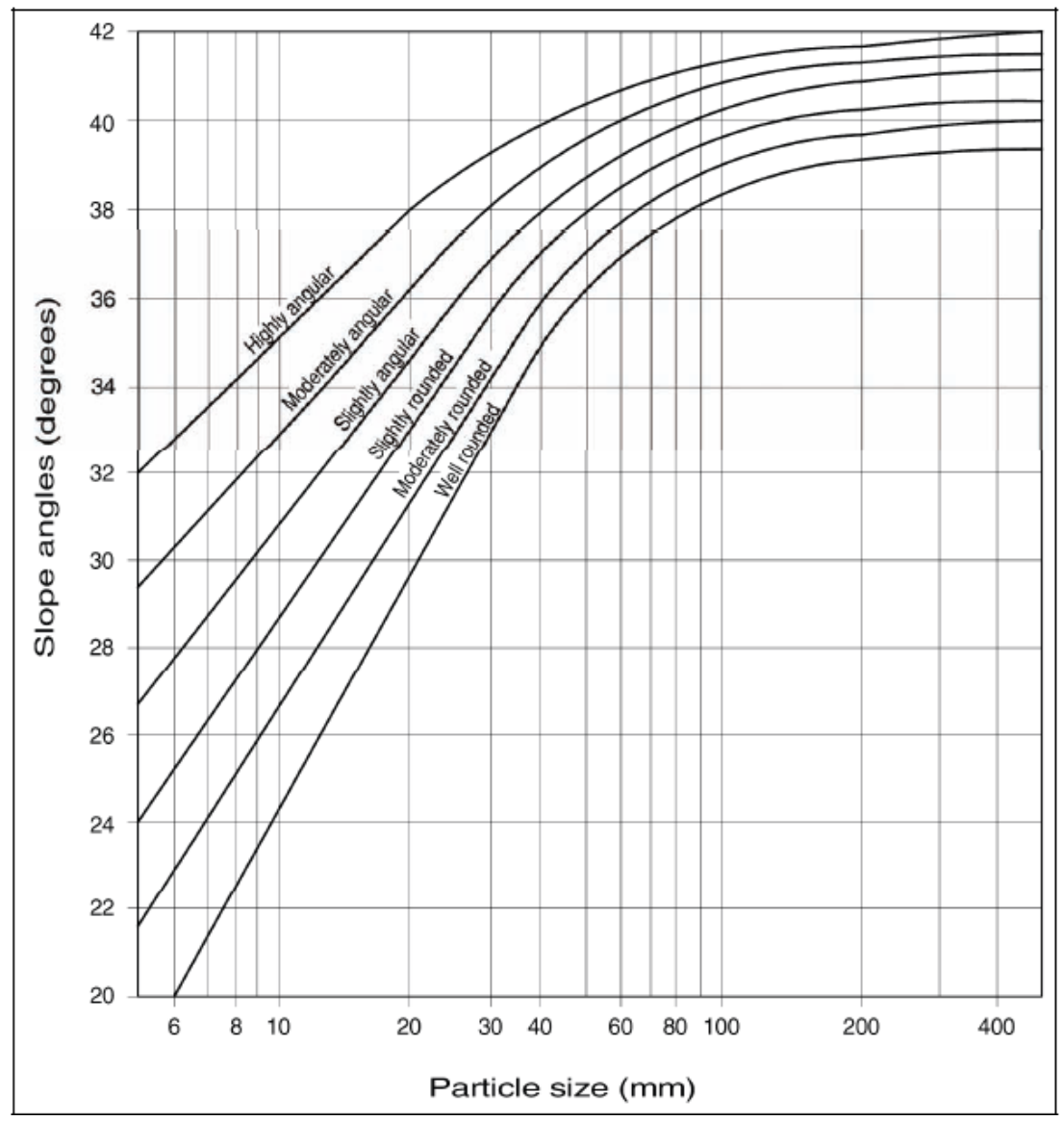

Figure 2-3: Angle of repose (SANRAL, 2013)

CIRIA et al. (2007) recommend that the angle of repose should be between 30 and $35^{\circ}$ for coarse sand, and up to $45^{\circ}$ for angular material. 


\subsection{Initiation of motion}

The concept of incipient motion has been extensively researched by pioneering researchers such as Shields (1936) and Liu (1957).

Other work, such as that of Rooseboom (1992) and Armitage (2002), made valuable contributions. Thus, the associated processes involved are reasonably well understood. In this section, the theoretical background of the concept of incipient motion is explored.

Researchers agree that incipient motion is initiated by oscillating eddy currents in the vicinity of the particles. Due to the complexity of such eddy currents, a mathematical description thereof is almost impossible. Instead, the hydraulic parameters of the flow in the vicinity of the particle are considered.

Although the existence of different states of motion is highly debated, it is clear that the definition of the initiation of movement is of critical importance for the success of laboratory tests. Kramer identified three types of motion in bed material (Simons \& Sentürk, 1992, Wu et al., 2000):

- Weak movement: A small number of particles in motion. The particles "moving on one square centimetre of the bed can be counted".

- Medium movement: The $d_{50}$ grains start to move.

- General movement: The entire mixture is in motion. All parts of the bed are affected.

In practice, the limited movement of riprap elements is sometimes acceptable. However, in many cases movement of the rocks can cause the structure to fail (for example when riprap is used to protect water pipelines) (Stoffberg, 2005).

Armitage (2002), CIRIA et al. (2007), Garde and Ranga Raju (2000) and Simons and Sentürk (1992) all identified the definition of when exactly incipient motion occurs as the greatest source of controversy in the various research papers.

\subsubsection{Critical flow velocity}

The critical flow velocity method is based on the idea that a particle becomes unstable if the flow velocity in the vicinity of the particle reaches a certain threshold. 
The main advantage of this method is that, unlike methods using shear stress or stream power, it makes use of velocity concepts. Therefore the visualisation and interpretation of velocity is facilitated (Armitage, 2002).

There is a substantial amount of theoretical support for the method. However, as the method requires definition of the velocity of the water in the vicinity of the particle, the method is limited in its applicability. The hydraulic conditions near the particles are often characterised by very high velocity gradients and are therefore exceptionally difficult to obtain. The stability of particles is thus not a function of the average stream velocity, but of the velocity distribution in the vicinity of the particle.

Yang (1973) for example developed the following piecewise defined function describing the critical condition of incipient motion:

$$
\begin{array}{lll}
\frac{V_{c}}{V_{s s}}=\frac{2.5}{\log \left(R e^{*}\right)}+0.66 & \text { for } 0<R e^{*}<70 & \text { Equation } 2-11 \\
\frac{V_{c}}{V_{s s}}=2.05 & \text { for } R e^{*}>70 & \text { Equation } 2-12
\end{array}
$$

where

$V_{c} \quad$ Average critical flow velocity $(\mathrm{m} / \mathrm{s}) ;$ and

$R e^{*}$ Particle Reynolds number, given by Equation 2-13.

$$
R e^{*}=\frac{V_{S S} d}{v}
$$

where

$v \quad$ is the kinematic viscosity. For water it is equal to approximately $1.13 \times 10^{-6}$ $\mathrm{m}^{2} / \mathrm{s}$ at $15^{\circ} \mathrm{C}$.

According to Yang (1973), particle motion is only initiated once $R e^{*}>70$, but Armitage (2002) claims that this formulation is not accepted by all researchers.

Certain literature contain tables populated with allowable average velocities and can be substituted for $V_{c}$ (i.e. SANRAL, 2013; Annandale, 2006; CIRIA et al., 2007). 
Another well-known equation was proposed by Izbash and Khaldre (1970):

$$
\text { Constant }=\frac{V_{c}^{2}}{2 g d_{50} \Delta}
$$

Equation 2-14

where

the constant is dependent on the application (typically, values of 0.7 and 1.4 are used for exposed stone and embedded stone respectively) (CIRIA et al., 2007).

If the depth averaged velocity across the canal $(V)$ is typically compared to the critical velocity; if $V>V_{c}$, the particles will start to erode.

Izbash and Khaldre (1970) originally developed this equation to estimate the stability of rocks in flowing water; this is particularly useful when a rockfill dam is constructed in flowing water. Graded rocks are dumped in the flowing water, gradually changing the hydraulics of the flow, until the flow is closed off completely. At some point, the dumped riprap acts as a hydraulic control (Abt \& Johnson, 1991), causing the flow to have similar hydraulic properties as those being investigated here. The relevance of Izbash's and Khaldre's (1970) work to this study is thus obvious.

In addition, Izbash and Khaldre (1970) imposed a limitation on their work, namely that Equation 2-14 is only valid for water depths $(D)$ between $0.3-3 \mathrm{~m}$ and a $D / d$ ratio between 5 and 10.

Theoretically, $V_{c}$ is exceptionally difficult (if not impossible) to determine analytically. For practical applications, however, guidelines for determining $V_{c}$ are available (CIRIA et al., 2007; Izbash \& Khaldre, 1970). These values are typically given as a function of the water depth and the median particle size of the bed. It is further interesting to note that Equation 214 is explicitly independent of the flow depth of the stream.

From the foregoing it is obvious that, although the methods were derived from solid theoretical principles, the flow velocity is not a suitable parameter.

\subsubsection{Shields's critical shear stress approach}

Shields (1936) developed a widely accepted theory for determining the point of incipient motion. In order for a particle to start moving, the drag force that the water exerts on the 
particle needs to overcome the resistive force. The resistive force is exerted by neighbouring particles on the particle under consideration.

Shields performed a dimensional analysis relating $F_{d}$ to the bed shear stress $\left(\tau_{0}\right)$ and is expressed below:

$$
F_{D} \propto \frac{\tau_{0} d^{2}}{A_{p}}
$$

At the threshold of movement, the critical bed shear stress $\left(\tau_{c r}\right)$ must be equal to the bed shear stress (i.e. $\tau_{0}=\tau_{c r}$ ), so that Equation 2-15 can be written as

$$
\frac{\tau_{0} d^{2}}{A_{p}} \propto\left(\rho_{s}-\rho\right) g \frac{\pi d^{3}}{6} S_{0}
$$

Equation 2.16

where

$S_{0} \quad$ Bed slope $(\mathrm{m} / \mathrm{m})$

Rearranging Equation 2-16 yields the dimensionless relation:

$$
\frac{\tau_{c r}}{\left(\rho_{r}-\rho_{w}\right) g d} \propto \frac{\pi A_{p}}{6} S_{0}
$$

The left hand side of the equation is known as Shields's parameter (or the Entrainment function) and is commonly denoted as $\psi$.

Further, Shields argues that the particle entrainment is a function of the turbulent shear velocity, $V^{*}$. The literature is in agreement (e.g. Armitage, 2002; CIRIA et al., 2007; Simons \& Sentürk, 1992; Van der Walt, 2005; SANRAL, 2013; Stephenson, 1979) that this velocity can be computed as follows:

$$
V^{*}=\sqrt{g D S_{f}}
$$

Equation 2-18

where

$$
S_{f} \quad \text { Energy slope }(\mathrm{m} / \mathrm{m})
$$

Using the shear velocity, the Reynolds number around the particle $\left(R e^{*}\right)$ is computed as follows: 


$$
R e^{*}=\frac{V^{*} d}{v}
$$

Finally, Shields plotted his experimental data and showed that there is a well-defined range of results that relate to the threshold of motion. The shaded band in Figure 2-4 shows the spread of Shields data. The dashed lines in turn show the data envelope of other researchers.

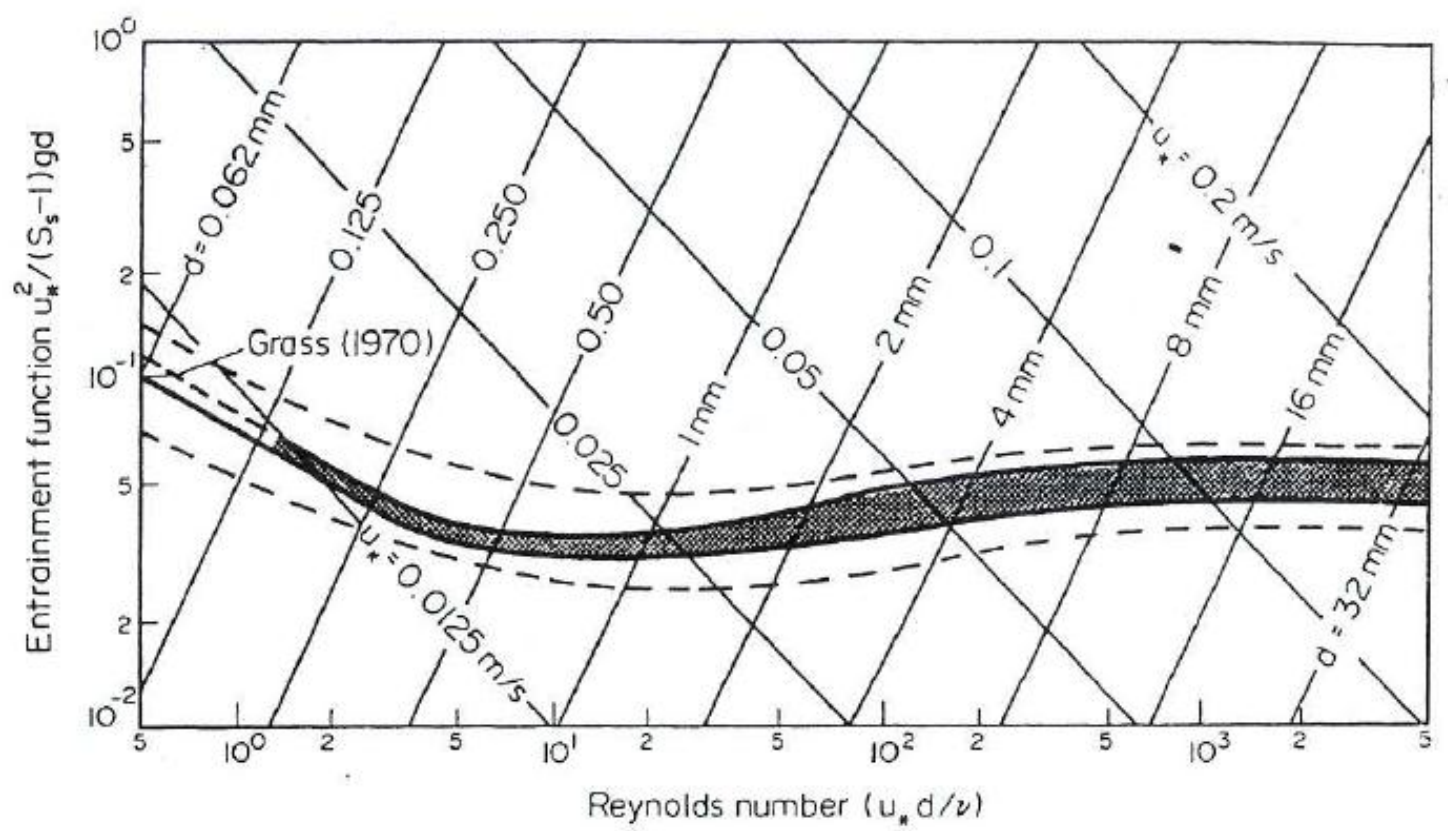

Figure 2-4: Threshold of motion (Raudkivi, 1998) as determined by Shields and other researchers

Shields's parameter is probably most widely used for engineering applications to define the critical shear stress at which particle movement is initiated. A convenient expression of Shields's theory is given as Equation 2-20.

$$
\psi=\frac{\tau_{c r}}{\left(\rho_{r}-\rho_{w}\right) g d}
$$

Equation 2-20

For design purposes, i.e. when rocks start moving, it is suggested that $\psi=0.03-0.035$ (CIRIA et al., 2007; Garge \& Ranga Raju, 2000; Przedwojski et al., 1995; SANRAL, 2013; Simons $\&$ Sentürk, 1992). These values correspond to rather conservative values of $\psi$, as seen in Figure 2-4.

However, Maynord et al. (1989) suggest that other researchers have undoubtedly proven that $\psi$ is not constant, but is in fact a function of the relative roughness (defined as the ratio particle size/flow depth). 


\subsubsection{Lui's stream power approach}

Numerous critics (especially Rooseboom, 1992 and Yang, 1973; Przedwojski et al., 1995) point out that Shields's approach has serious shortcomings. Rooseboom argues that the median particle size is not sufficient to describe incipient motion sufficiently. He argues that the settling velocity is a more suitable parameter.

In addition, Shields's approach does not take into account that some particles are more exposed to the flow than others, which relates to particle shape, grading and size (Simons \& Sentürk, 1992; Van der Walt, 2005; Przedwojski et al.,1995).

Also, Shields simplifies the problem by disregarding the vertical lift force, and considering the tangential force only. This lift force can however not be neglected, especially at high particle Reynolds numbers (Yang, 1973).

Liu (1957) agrees partly with Shields, concluding that the local velocities in the vicinity of the particle (and thus the drag force) are dependent on the particle Reynolds number, given by Equation 2-19.

However, Liu (1957) also found that there is a unique relationship between the particle Reynolds number $\left(R e^{*}\right)$ and the ratio of the shear velocity $\left(V^{*}\right)$ and the settling velocity of the particle $\left(V_{s s}\right)$. The latter term is referred to as the Movability Number. Liu (1957) derived the relationship by differentiating two different ways in which stream power is transferred, ultimately resulting in particles being displaced.

This difference refers to the distinction between laminar and turbulent flow. In laminar flow, power is transferred from faster moving layers of water to slower moving ones nearer to the bed. In turbulent flow, fast moving eddy currents transfer energy by colliding with slower moving water packets, decelerating themselves and accelerating the slower moving packets. In this way, energy is transferred.

Rooseboom (1992) showed that the applied power needed per unit volume to suspend a particle is given by

$$
\left(\rho_{s}-\rho_{w}\right) g V_{s s}
$$

He also determined that the power needed for motion in turbulent flow is proportional to 


$$
\frac{\rho g S_{f} D \sqrt{g D S_{f}}}{d}
$$

Rooseboom (1992) further argued that the stream will begin to entrain particles once the power needed to suspend the particle becomes greater than the power needed to maintain the status quo. Therefore,

$$
\left(\rho_{s}-\rho_{w}\right) g V_{s S} \propto \frac{\rho g S_{f} D \sqrt{g D S_{f}}}{d}
$$

Equation 2-21

Rearranging Equation 2-21 yields

$$
\frac{\left(\rho_{s}-\rho_{w}\right) d}{\rho S_{f} D} \propto \frac{\sqrt{g D S_{f}}}{V_{s s}}
$$

Equation 2-22

For turbulent flow in the vicinity of the particle (i.e. for large particles), $V_{s s}$ is a constant (see Section 2.3.4). Further, assuming that the flow is uniform and homogenous, the left hand side of the equation becomes constant for a certain flow condition and sediment size. Equation 2-22 (Rooseboom, 1992) can then be rewritten as

$$
\frac{\sqrt{g D S_{f}}}{V_{s s}}=\text { Constant }
$$

Different researchers proposed different values for the right hand side of Equation 2-23 as shown in Table 2-3.

Table 2-3: Recommended Movability Numbers

\begin{tabular}{|c|c|}
\hline Researcher & Critical Movability Number $\left(V^{*} / V_{s s}\right)$ \\
\hline $\begin{array}{c}\text { Rooseboom (1992), after data from } \\
\text { Yang (1973) }\end{array}$ & 0.12, for $R e^{*}>13$ \\
\hline Armitage (2002) & 0.17, for $R e^{*}>11.8$ \\
\hline Stoffberg (2005) & $\begin{array}{c}0.13, \text { (recommended for designing } \\
\text { riprap) }\end{array}$ \\
\hline SANRAL (2013) & 0.12, for $R e^{*}>13$ \\
\hline
\end{tabular}

For laminar flow, Equation 2-23 becomes (Rooseboom, 1992)

$$
\frac{\sqrt{g D S_{f}}}{V_{S S}}=\frac{1.6}{\frac{\sqrt{g D S_{f}}}{v} D}=\frac{1.6}{R e^{*}}
$$

Armitage (2002) in turn recommends that the right hand side of Equation 2-24 is equal to $2 / R e^{*}$. 
The value of $R e^{*}$ separating laminar and turbulent flow can be found by equating Equation 223 and 2-24 and finding the point of intersection. Depending on the criteria used, the analysis yields that for particle Reynolds numbers larger than 11.8 to 13, turbulent flow prevails, as shown in Figure 2-5. The experimental data compiled by Yang (1973) is also shown.

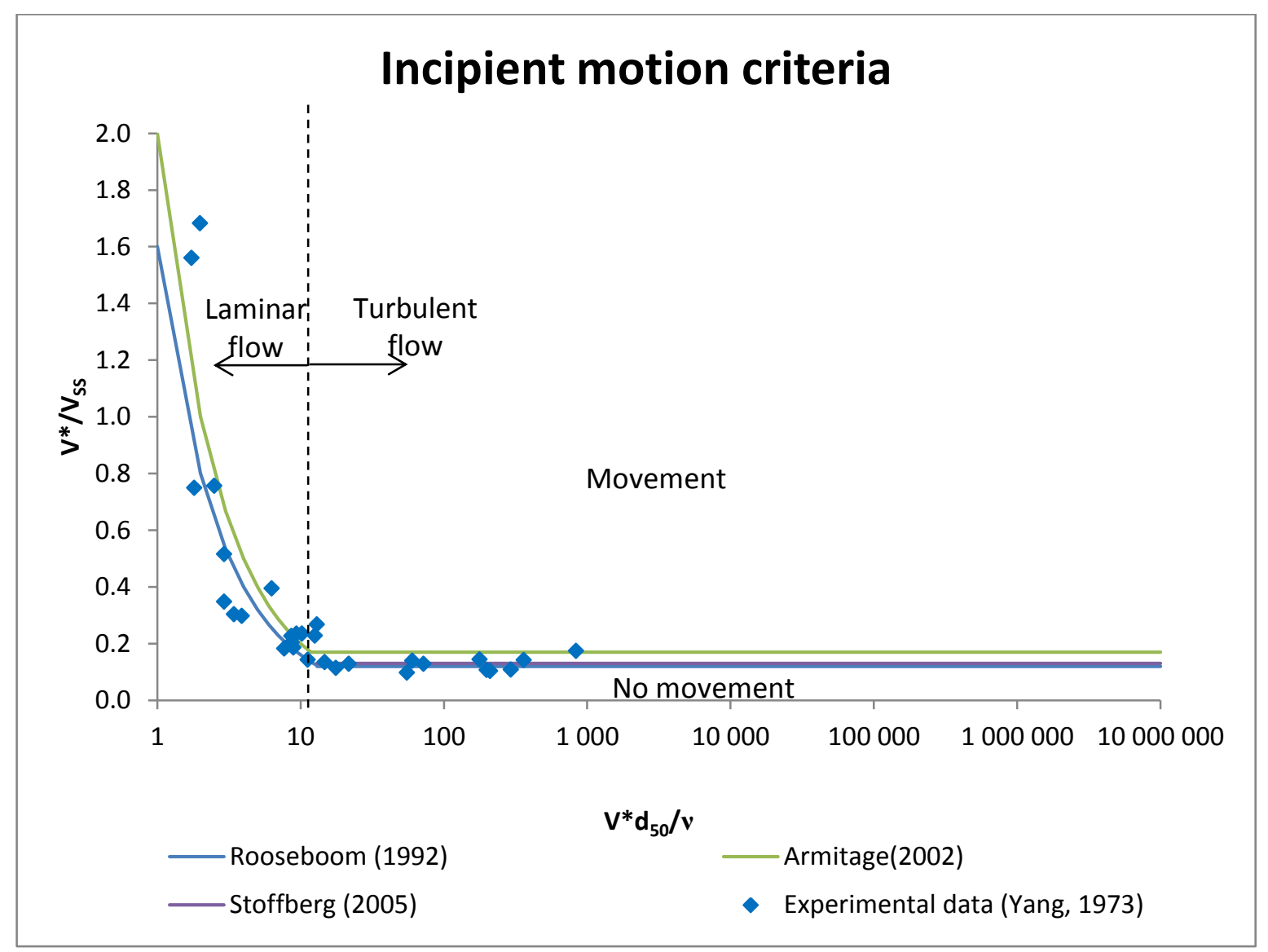

Figure 2-5: Incipient motion criteria

In this investigation, turbulent flow is of primary interest, since $R e^{*}$ is expected to be much larger than 13 due to the large sized riprap under consideration.

Both Shields and Liu base their theory on the assumption that the flow under consideration is uniform, implying that the slope of the water surface $\left(S_{w}\right), S_{0}$ and $S_{f}$ are parallel and thus equal. This should be kept in mind when the method is applied, since the flow over riprap arrestors analysed in this thesis is possibly non-uniform in nature. 


\subsection{Correction for sloped beds}

The discussions in the previous sections have all been limited to beds with small slopes. In this section, a correction factor is introduced that takes the effect of steep bed slopes into account.

Several researchers (Armitage, 2002; CIRIA et al., 2007; Stoffberg, 2005) distinguished between two types of slopes:

- Horizontal fall in the direction of the flow is represented as $\beta$ and is measured in degrees. If $\beta>0$, the nature of the slope causes the water to flow downhill and vice versa.

- Transverse slopes are denoted by $\alpha$ and are used to quantify the fall of the bed normal to the direction of flow. $\alpha=90^{\circ}$ when the flow is directed along the side slope and is 0 when the water flows perpendicular over the slope.

It should be noted that some research (e.g. Robinson et al., 1998; Peirson \& Cameron, 2006) suggests that air entrainment plays a significant role at slopes steeper than 1:10 (when $\beta$ > $5.71^{\circ}$ ). The following discussion ignores potential air entrainment in the flow. It only deals with particle stability issues as a result of a change in the direction of the gravity force.

The correction factors presented in the following sections are derived for shear stresses (i.e. $\psi$, or $\tau$ ). Since the following relation is true,

$$
\tau \propto V^{2} \text { or } \sqrt{\tau} \propto V
$$

Equation 2-25

the correction factors must be applied differently for shear stress criteria than for threshold velocity criteria.

CIRIA et al. (2007), Armitage (2002), Armitage \& Rooseboom.(2010), Stoffberg (2005) and others define $k_{\beta}$ and $k_{\alpha}$ as follows:

$$
\begin{aligned}
& k_{\beta}=\frac{\sin (\phi-\beta)}{\sin (\phi)} \\
& k_{\alpha}=\cos \beta \sqrt{\left(1-\left(\frac{\tan \beta}{\tan \phi}\right)^{2}\right)}
\end{aligned}
$$

Equation 2-26

Equation 2-27 
where

$k_{\beta} \quad$ Ratio of critical drag force for a longitudinally sloped bed to the critical drag force of the horizontal bed; and

$k_{\alpha} \quad$ Ratio of the critical drag force at a given transverse slope to the critical drag force of the normal bed.

Equations 2-26 and 2-27 have been derived by assuming equilibrium of the forces and moments acting on a particle. The steeper the slope, the less stable the particle.

The threshold of particle movement on stream wise sloping beds was studied by a number of researchers (Chiew \& Parker, 1994; Dey et al., 1999; Whitehouse \& Hardisty, 1988). Whitehouse and Hardisty (1988) and Dey et al. (1999) concluded that Equations 2-26 and 227 are indeed true, even for very steep slopes.

Maynord and Ruff (1987) argued that an increased stability of the riprap blanket can be expected for small slopes, since the downslope gravity component causes greater interlocking forces. The development of the correction factors $k_{\alpha}$ and $k_{\beta}$ in turn indicates a significant loss of stability on steep slopes, due to a change of direction of the gravity force exerted on the particle.

\subsubsection{Critical shear stress approach}

To compensate for the effects that the slope has on the shear stresses, the correction factors $\mathrm{k}_{\alpha}$ and $\mathrm{k}_{\beta}$ are introduced and defined as follows (Armitage, 2002, CIRIA et al., 2007):

$$
\begin{gathered}
\tau_{0, c r, \beta}=k_{\beta} \tau_{0, c r, 0} \\
\tau_{0, c r, \alpha}=k_{a} \tau_{0, c r, 0}
\end{gathered}
$$


where

$\tau_{0, c r, 0}$ Critical bed shear stress on a horizontal bed; and

$\tau_{0, c r} \quad$ Critical bed shear stress on a sloped bed.

Finally, a combination of the two correction factors is given as follows (Armitage, 2002; CIRIA et al., 2007):

$$
\tau_{0, c r}=k_{\beta} k_{\alpha} \tau_{0, c r, 0}
$$

Equation 2-30

For a bed that is horizontal in the longitudinal and transverse directions, the factors $k_{\beta}$ and $k_{\alpha}$ are equal to 1 .

\subsubsection{Flow velocity approach}

Considering the relations presented in Equations 2-25, 2-28 and 2-29 the following is true:

$$
V_{0, c r}=\sqrt{k_{\beta} k_{\alpha}} V_{0, c r, 0}
$$

Equation 2-31

where

$V_{0, c r, 0} \quad$ Critical bed shear velocity on a horizontal bed; and

$V_{0, c r} \quad$ Critical bed shear velocity on a sloped bed.

For example, the Movability Number for a sloped bed can be expressed as follows (Stoffberg, 2005; Armitage \& Rooseboom, 2010):

$$
\left(\frac{V *}{V_{s S}}\right)_{\beta, \alpha}=\sqrt{k_{\beta} k_{\alpha}}\left(\frac{V *}{V_{s S}}\right)_{0}
$$

Equation 2-32

where the subscript $\beta$ and $\alpha$ denotes a Movability Number for any given slope, while the subscript $O$ denotes a horizontal bed.

The left hand side of Equation 2-32 can thus be considered as being the Movability Number on a slope. 


\subsection{The effect of excessive turbulence}

In earlier discussions it has been established that the turbulence of the flow plays a significant role in the stability of particles, since turbulence is directly associated with large velocity gradients. Thus, a significant increase in turbulence can cause significant instability.

Turbulence cannot be quantified accurately by analytical methods. In most models, it is not taken into account (Mays, 1999). However, since most models are calibrated using experimental data, it seems reasonable to assume that most models inevitably take normal levels of turbulence into account.

In an attempt to quantify this effect, CIRIA et al. (2007) proposed a simplified approach to take excessive turbulence into account using the turbulence amplification factor $k_{t}$ given by Equation 2-33.

$$
k_{t}=\frac{1+3 r}{1.3}
$$

Equation 2-33

where $r$ is the depth averaged relative fluctuation intensity due to turbulence.

Unlike the correction factor for sloped beds, the factor $k_{t}$ relates to the velocity, not the involved shear stresses.

Normal turbulence is typically characterised by average relative fluctuation intensity in the order of 0.1 (CIRIA et al., 2007). Despite the claim of several sources (e.g. Annandale, 2006; Armitage, 2002; Mays, 1999; Przedwojski et al. 1995; Stoffberg, 2005) that it is extremely difficult, if not impossible, to attach a magnitude to the turbulence of the flow without extensive laboratory tests, CIRIA et al. (2007) state that $r=0.15$ is a typical value for flow above a rough bed (for example a bed lined with armourstone). For uniform flow in flat rivers with a low flow regime, a value of $r=0.10$ is more applicable.

Other recommended values for estimating the turbulence intensity are presented in Table 2-4. 
Table 2-4: Recommended $r$ values at $0.1 y$ above bed (CIRIA et al., 2007)

\begin{tabular}{|c|c|c|}
\hline Situation & Qualitative & $r$ \\
\hline Straight river of channel reaches & Normal (low) & 0.12 \\
\hline Edges of revetments in straight reaches & Normal (high) & 0.20 \\
\hline Bridge piers, caissons and spur-dikes; transitions & Medium-high & $0.35-0.50$ \\
\hline Downstream of hydraulic structures & Very high & 0.60 \\
\hline
\end{tabular}

These values should be used with care, since a large difference in results can be expected when the qualitative guidelines are assessed incorrectly. Also, in the opinion of the author, the classification spectrum presented in Table 2-4 is too wide for an accurate determination of the in-situ conditions.

\subsection{Effect of the velocity profile}

As has been discussed earlier, one of the biggest difficulties in sizing riprap is to obtain the flow velocity in the vicinity of the riprap.

For hydraulically rough and fully developed flow, the logarithmic velocity distribution can be fitted and is given by Equation 2-34.

$$
V=\frac{V^{*}}{\kappa} \ln \left(\frac{y}{y_{0}}\right)
$$

where

$$
\begin{aligned}
& \kappa \quad \text { Von Karman's constant }(=0.4) ; \\
& y \quad \text { Distance above bed }(\mathrm{m}) \text {; and } \\
& y_{0} \quad \text { Reference level near the bed and is typically given by Equation 2-35. }
\end{aligned}
$$

$$
y_{0}=0.033 k_{s} \text {. }
$$

Equation 2-35

where

$k_{s} \quad$ Chezy's roughness (m).

The shape of the profile described by Equation 2-34 is depicted in Figure 2-6. The equations shown in Figure 2-6 were slightly rearranged. 


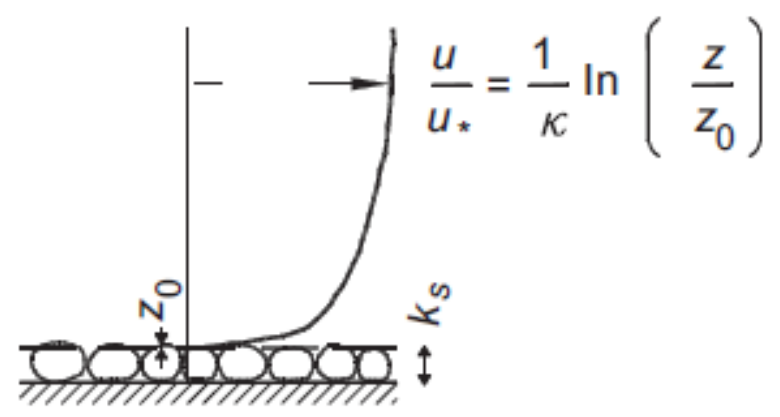

Figure 2-6: Vertical velocity profile (CIRIA et al., 2007)

Furthermore, a general equation to convert velocity to bed shear stress is given by:

$$
\tau_{0}=\rho V^{* 2}
$$

Equation 2-36

where

\section{$\rho \quad$ Density of medium under consideration $\left(\mathrm{kg} / \mathrm{m}^{3}\right)$}

The velocity profile factor $\left(\Lambda_{h}\right)$, introduced by CIRIA et al. (2007), is used in some of its design equations and is defined as $\Lambda_{h}=33 / k_{h}$.

Several practical equations were proposed, each applicable for a certain use. Table 2-5 presents a summary of the applicable formulae.

Table 2-5: Correction factors for velocity profile (CIRIA et al., 2007) for rough boundaries

\begin{tabular}{|l|c|c|l|}
\hline Equation & Velocity profile & Applicability & \\
\hline$\Lambda_{h}=\frac{18^{2}}{2 \mathrm{~g}} \log ^{2}\left(\frac{12 \mathrm{D}}{k_{s}}\right)$ & Fully developed & Large water depths, $\left(D / k_{s}>2\right)$ & Equation 2-37 \\
\hline$\Lambda_{h}=\frac{18^{2}}{2 \mathrm{~g}} \log ^{2}\left(1+\frac{12 \mathrm{D}}{k_{s}}\right)$ & Fully developed & Small water depth, $\left(D / k_{s}<2\right)$ & Equation 2-38 \\
\hline$\Lambda_{h}=\frac{33}{\left(1+D / d_{y}\right)^{0.2}}$ & Not fully developed & Short flow lengths & Equation 2-39 \\
\hline
\end{tabular}

where

$\Lambda_{h} \quad$ Velocity profile factor.

This approach is widely criticised (Maynord et al., 1989) since significant problems arise when the logarithmic relationship is applied to rough surfaces like riprap. 


\subsection{Aeration effects}

Aeration effects are known to play a role in cases where water is conveyed with a high velocity. Therefore, flow down steep rock slopes could possibly become a very complex process involving breaking of the flow surface and air entrainment.

The surface tension of water plays a prominent role in bubble entrainment. This implies that small scale laboratory tests cannot be simply scaled up to be representative of prototype conditions.

In a recent study, Pierson and Cameron (2006) found that aeration effects become prominent where the bed slope, $S_{0} \geq 0.1$. The intrusion of air deepens the flow depth and thus reduces the flow velocity. Consequently, the required rock for stable riprap size is decreased.

Pierson and Cameron (2006) found that when using conventional methods, the required rock sizes were overestimated by as much as $800 \%$. Pierson and Cameron (2006) proposed Equation 2-40 (based on Isbash's equation), which incorporates aeration effects.

$$
q_{f}=1.15 D \sqrt{\frac{2 g\left(\rho_{r}-\rho_{w}\right)}{\sigma \rho_{w}}} \sqrt{d_{50} \cos (\beta)} \sqrt{\tan \phi-\tan (\beta)} \quad \text { Equation 2-40 }
$$

where

$$
\begin{aligned}
& \sigma \quad \text { Mean volume of water per unit mixture volume; and } \\
& \phi \quad \text { Angle of repose. }
\end{aligned}
$$

The above approach is just one of many ways to estimate the stability of riprap if air entrainment plays a role.

\subsection{Practical Design approaches}

As shown in the previous section, there are different approaches that can be followed when estimating the particle stability under different flow conditions. Consequently, there are a number of design approaches based on the previous discussions.

A summary of some of the more commonly used and accepted methods found in literature follows in the next sections. 


\subsubsection{General Design Equation (CIRIA et al., 2007)}

CIRIA et al. (2007) developed the General Design Equation by considering a combination of some of the ideas proposed earlier.

Shields's critical shear stress was incorporated into the equation. The following values for Shields's parameter are recommended (CIRIA et al., 2007):

- $\quad$ 0.030-0.035 for a critical point where particles begin to move; and

- $0.050-0.055$ for limited movement of the particles.

In addition, the equation features elements based on Izbash and Khaldre's (1970) concept of critical velocity. Also, numerous correction factors are included. All these ideas were combined to arrive at the so called General Design Equation:

$$
\frac{V^{2} / 2 g}{\Delta d}=k_{\beta} k_{\alpha} k_{t}^{-2} k_{w}^{-1} \Lambda_{h} \psi_{c r}
$$

Equation 2-41

where

$\psi_{c r} \quad$ Critical Shields parameter; and

$k_{w} \quad$ Wave amplification factor (irrelevant for this study and is thus equal to unity).

\subsubsection{Pilarczyk's (1995) design criteria}

Pilarczyk (1995) modified Izbash's and Shields's equation by introducing additional correction factors. These factors take into account the effect of the transition areas between the consecutive layers of riprap, excessive turbulence, the side slope and the velocity distribution of the flow. The design equation is given by

$$
d_{n 50}=\frac{\phi_{s c}}{\Delta} \frac{0.035}{\psi_{c r}} k_{h}\left(k_{\alpha} k_{\beta}\right)^{-1} k_{t}^{2} \frac{V^{2}}{2 g}
$$

Equation 2-42 
where

$\phi_{s c} \quad$ Stability correction factor (given in Table 2-6); and

$k_{h} \quad$ Velocity profile factor, given as $33 / \Lambda_{h}$.

The stability correction factor makes provision for the fact that wherever transitions are induced, the hydraulic loading is affected. CIRIA et al. (2007) recommend the following values for $\phi_{s c}$.

Table 2-6: Recommended values for Stability correction factor (CIRIA et al., 2007)

\begin{tabular}{|c|c|}
\hline Hydraulic condition & Recommended $\phi_{s c}$ \\
\hline Exposed edges of gabions & 1.00 \\
\hline Exposed edges of riprap/armourstone & 1.50 \\
\hline Continuous rock protection & 0.75 \\
\hline Interlocked blocks and cables blockmats & 0.50 \\
\hline
\end{tabular}

2.9.3. Escarameia and May's design equation (CIRIA et al., 2007)

According to CIRIA et al. (2007), Escarameia and May's design equations are based on Izbash (see Equation 2-14). The equation has been modified to take the effect of turbulence into account. The design equation is given as:

$$
d_{n 50}=C_{t} \frac{V_{b}^{2}}{2 g \Delta}
$$

Equation 2-43

where

$C_{t} \quad$ Turbulence coefficient; and

$V_{b} \quad$ Near bed velocity (typically at a distance of $0.1 D$ from the bed).

Its similarity to Equation 2-14 should be noticed immediately. Equation 2-43 was applied successfully in areas with a high level of turbulence, for example around bridge piers, weirs and spillways.

The turbulence coefficient $C_{t}$ is given by Equation 2-44 for armourstone.

$$
C_{t}=12.3 r-0.2
$$

Equation 2-44

As stated earlier, it is very difficult to quantify turbulence due to its complex nature, making this method very difficult to apply in practice. 
It is also worthwhile to note that this method has been derived from experimental data and should be used with extreme care if the following requirements are not met (CIRIA et al., 2007):

- $\quad$ bed slope steeper than 1:2;

- $1 \leq D \leq 4 \mathrm{~m}$; and

- $5 \leq D / d \leq 10$.

This does not imply that the equations are incorrect for flow conditions outside these boundaries, but due to a limited range of laboratory data, the equation could not be verified outside these bounds.

\subsubsection{Maynord's et al. (1989) design equation}

Maynord et al. (1989) developed the US Army Corps of Engineers' preferred method for the design of riprap. Unlike the previously discussed method, Maynord's equation takes the thickness of a specific layer into account.

The underlying theory of this method is based on the idea that once the underlying material is exposed, the layer above it will fail. Maynord \& Ruff (1987) initially derived their equation for normal turbulence levels using a dimensional analysis. CIRIA et al. (2007) modified Maynord and Ruff's original equation by introducing a number of correction factors. Accordingly, Maynord and Ruff's modified design equation is given as (CIRIA et al, 2007):

$$
d_{50}=f_{g}^{0.32} S_{F} C_{s t} C_{v} C_{T} D\left(\frac{1}{\sqrt{\Delta}} \frac{V}{\sqrt{k_{s l} g D}}\right)^{2.5}
$$


where

$S_{F} \quad$ Safety factor (Recommended value between 1.1 and 1.2 (Prezedwojski et al., 1995; Maynord et al., 1989));

$C_{s t} \quad$ Stability coefficient, typically used as 0.3 for angular rock and 0.375 for rounded rock;

$C_{v} \quad$ Velocity distribution coefficient, given as unity for straight channels (see Table 2-7);

$C_{T} \quad$ Blanket thickness coefficient, typically given as unity; and

$k_{s l} \quad$ Side slope factor, given as $-0.672+1.492 \cot (\alpha)-0.449 \cot ^{2}(\alpha)+$ $0.045 \cot ^{3}(\alpha)$.

In an attempt to take the effect of the velocity distribution into account, Maynord and Ruff's equation makes use of the velocity distribution coefficient. Recommended values are given in Table 2-7 (CIRIA et al., 2007).

Table 2-7: Velocity distribution coefficients for Maynord's formula

\begin{tabular}{|c|c|}
\hline$C_{V}$ & Condition \\
\hline 1.0 & Straight channel \\
\hline $1.283-0.2 \log (R / B)$ & Inside of bends, \\
\hline 1.0 & Inside of bends, when $R / B>26$ \\
\hline 1.25 & End of dikes \\
\hline 1.25 & Downstream of concrete structures \\
\hline
\end{tabular}

where
$R \quad$ Centreline radius of bend $(\mathrm{m})$; and
$B \quad$ Flow width (m).

Maynord and Ruff (1989) explicitly stated that their original equation is only valid for grading widths between 1.8 and 4.6, and for a layer thickness $(t)$ of $2 d_{50}$. Although CIRIA et al. (2007) do not reveal details about the derivation of Equation 2-45, the correction factors are probably meant to correct for possible deviations from beyond these constraints. 


\subsubsection{Empirical approaches}

In the foregoing sections, design approaches were formulated mathematically using theoretical knowledge of the problem in combination with laboratory data. Additional consideration was given to other complicating factors (such as turbulence) by introducing correction factors.

The empirical methods presented in this section were derived independently from any theoretical understanding of the physical processes involved in incipient motion. Instead, a large number of laboratory tests were performed in order to arrive at a statistical regression model that fits observed laboratory test data.

Although the focus of this thesis is to investigate the stability of riprap structures that are purposely build for a certain hydraulic loading, it seems reasonable to assume that the hydraulic conditions are similar to those found on the downstream slope of overtopping rockfill embankments. Powledge et al. (1989) point out that although research projects dealing with overtopping embankments might yield somewhat valuable results, one should be well aware of the fact that the recommended equations are not intended for the purpose of designing arrestors.

Abt and Johnson (1991) performed a series of near prototype model studies and investigated the stability of riprap under overtopping conditions at different slopes, particle sizes, and layer thicknesses. They arrived at the Equation 2-46 (in American units) for angular rock, where $q_{\text {design }}$ is the unit discharge at which rocks start moving:

$$
d_{50}=5.23 S_{0}^{0.43} q_{\text {design }}^{0.56}
$$

Equation 2-46

Abt and Johnson (1991) suggest that no movement of the particle should be allowed when designing riprap. Przedwojski et al. (1995), however, argues that a more economical design can often be developed when limited movement of the rocks is allowed. He furthermore claims that movement does not necessarily lead to the failure of the arrestor.

Abt and Johnson (1991) used a number of data points obtained from laboratory data to fit the regression curve, given as Equation 2-46. Due to the scatter of the data, a safety factor of 1.2 was recommended. 
From laboratory tests, Abt and Johnson (1991) also proposed the following relation:

$$
q_{\text {design }}=1.35 q_{f}
$$

Equation 2-47

where

$q_{f} \quad$ Unit discharge at which the slope failed.

When compared to other methods, this method yielded satisfactory results for flatter embankments and smaller flow. An investigation by Abt and Johnson (1991) yielded too little data for slopes of 1,2 and $8 \%$. However, this does not seem to be a problem, since the slopes of interest in this investigation were between 20 and $40 \%$. Also, the $d_{50}$ used for the experiments ranged from 25 to $152 \mathrm{~mm}$. Abt and Johnson furthermore imposed the limitation of $1.5 \leq t / d_{50} \leq 3$ on their method due to a lack of data. In fact, their data is extremely valuable for this investigation, since a large number of tests were performed at a near prototype scale. Unfortunately, their data cannot be analysed further due to a lack of flow data in their work.

In an attempt to present a pertinent tool for the design of arrestors, Robinson et al. (1998) used the slope of the structure and the $d_{50}$ as variables in the prediction equation:

$$
\begin{aligned}
& q_{f}=9.7610^{-7}\left(1000 d_{50}\right)^{1.89} S_{0}^{-1.50} S_{0}<0.10 \\
& q_{f}=8.0710^{-6}\left(1000 d_{50}\right)^{1.89} S_{0}^{-0.58} 0.10 \leq S_{0}<0.40
\end{aligned}
$$

Equation 2-48

Equation 2-49

Powledge et al. (1989) describe some of the most common failure processes associated with riprap failure. They identified two zones prone to suffer the most damage.

Firstly, the area just downstream of the crest experiences negative pressures which tend to lift rocks out of position. This can be explained by the fact that the supercritical approaching water has a horizontal momentum, and cannot change direction very easily. Powledge et al. (1989) suggest that the arrestor should be shaped like an ogee to prevent this failure from happening. Robinson et al. (1998) used a radius of $40 d_{50}$ to create a smooth flow transition between the horizontal and the sloped part of the arrestor. 
Secondly, observations have shown that erosion mostly commences at the downstream interface of the inclined slope and the horizontal discharge channel. The incidence of such failures, however, has been strongly dependant on the tailwater level.

\subsubsection{Shields's criteria (SANRAL, 2013)}

The design guidelines presented by SANRAL (2013) are used by default by many practicing engineers in South Africa.

Shields's approach was simplified in the SANRAL guidelines (2013) to arrive at the following expression applicable to bed stability problems:

$$
d_{50}>11 D S_{0}
$$

Equation 2-50

Equation 2-50 is, according to SANRAL, valid for non-cohesive particles bigger than $6 \mathrm{~mm}$, with a relative density of 2.65 .

Equation 2-50 is derived from Equation 2-20 (repeated below)

$$
\psi=\frac{\tau_{c r}}{\left(\rho_{r}-\rho_{w}\right) g d}
$$

Assuming $\psi=0.056, \rho_{r}=2650 \mathrm{~kg} / \mathrm{m}^{3}$ and $\rho_{w}=1000 \mathrm{~kg} / \mathrm{m}^{3}$, Equation $2-20$ simplifies to

$$
0.056=\frac{\tau_{c}}{(2650-1000) g d}
$$

but

$$
\tau_{0}=\rho_{w} g d S_{0}
$$

so that Equation 2-51 becomes

$$
d=\frac{1000}{(0.056)(2650-1000)} D S_{0}=10.823 y S_{0} \sim 11 D S_{0}
$$

Equation 2-53

Finally, it can be assumed that $d=d_{50}$ and when substituting it into Equation 2-53 it becomes equal to Equation 2-50 (as required).

It is immediately noticeable that Shields's parameter is chosen very conservatively. The CIRIA et al. (2007) guidelines recommend much lower values $\left(\psi_{c} \sim 0.035\right)$. 
From the above discussion it is clear that Equation 2-50 should be used with caution, since it is only valid for uniform flow on flat slopes and riprap with a density of $2650 \mathrm{~kg} / \mathrm{m}^{3}$. Unfortunately, these assumptions are not stated explicitly in the guidelines.

\subsubsection{Liu's design criteria (SANRAL, 2013)}

According to SANRAL (2013), the relationships presented in Section 2.4 .3 can be used directly for design purposes.

SANRAL supports Rooseboom's criticism of Shields's theory, arguing that the particle size is not a representative measure of particles' transportability for non-cohesive particles. They thus recommend that the settling velocity of a particle is a more significant measure to quantify the transportability of particles.

Needless to say, Rooseboom's criteria (see Table 2-3) are recommended for design purposes.

\subsubsection{Summary}

The literature review proved that the processes relating to incipient motion are reasonably well understood. A number of different approaches have been developed by researchers such as Shields, Maynords and Liu.

Most of these theories were modified to varying degrees in order to make them usable for design purposes. Interestingly, there is little agreement between most of these methods as to what parameters are relevant for estimating the point of incipient motion.

Concern is expressed over the correction factors, in particular $k_{t}$ and $\Lambda_{h}$ which are included in the CIRIA et al. (2007) methods. It seems that the guidelines oversimplify the problems associated with determining these factors correctly. The theoretical background behind the equation is undermined if the oversimplified correction factors play a too dominant role in the final answer.

A number of equations, derived from laboratory data points by means of best fit lines, have been presented. A clear advantage of these methods lies in the exceptional ease with which these equations can be applied. However, since these methods are completely detached from theoretical descriptions of physical processes, they can only be applied in cases where the 
prototype conditions are very similar to the laboratory conditions for which they were derived.

Shields's method has been widely accepted among engineers, although it is criticised by many authors.

A considerable number of design approaches have been presented. It seems however that many of these standard procedures are not as failsafe as stipulated in sources like CIRIA et al. (2007) and SANRAL (2013). It is evident that many different design procedures may apply only over a limited range of conditions. These limitations are, however, poorly described (if at all) in these guidelines.

Although Liu's method is hardly encountered in the literature and not used very often in practice, the author is of the opinion that this method is promising due to its sound mathematical foundation. Thus, there is considerable scope for additional research to further improve the method. 


\section{PHYSICAL MODEL SETUP AND TESTS}

\subsection{Experimental setup}

Several tests were conducted in an undistorted physical model, implying that the model is scaled equally in the horizontal and vertical direction, to determine the stability of riprap. According to Przedwojski et al. (1995), a distorted scale should be avoided if possible and therefore the physical model was not distorted.

The tests were conducted in the Hydraulics Laboratory at the University of Stellenbosch.

\subsubsection{Testing facilities and general layout}

Due to the size of the model, the largest flume in the laboratory was utilised to perform the experiments. The flume is $30 \mathrm{~m}$ long, $1.25 \mathrm{~m}$ deep and $1 \mathrm{~m}$ wide. Its sides are lined with glass panels, which make observations from the side possible. In order to limit the possible effect of the flume walls on the flow pattern, the flow depth over the crest was limited to $0.3 \times$ flume width $=0.33 \mathrm{~m}$.

In addition, due to physical constraints, the water delivery was limited to about $300 \mathrm{l} / \mathrm{s}$. During the planning phase, a one dimensional computer model was used to estimate the flow conditions for the various tests. This information was then used to estimate flow at which incipient motion of the riprap is initiated $\left(Q_{m}\right)$. The Liu diagram method was used to ensure that the aims of the experiments were realised, given all these limitations. A schematic layout of the setup is shown in Figure 3-1. 


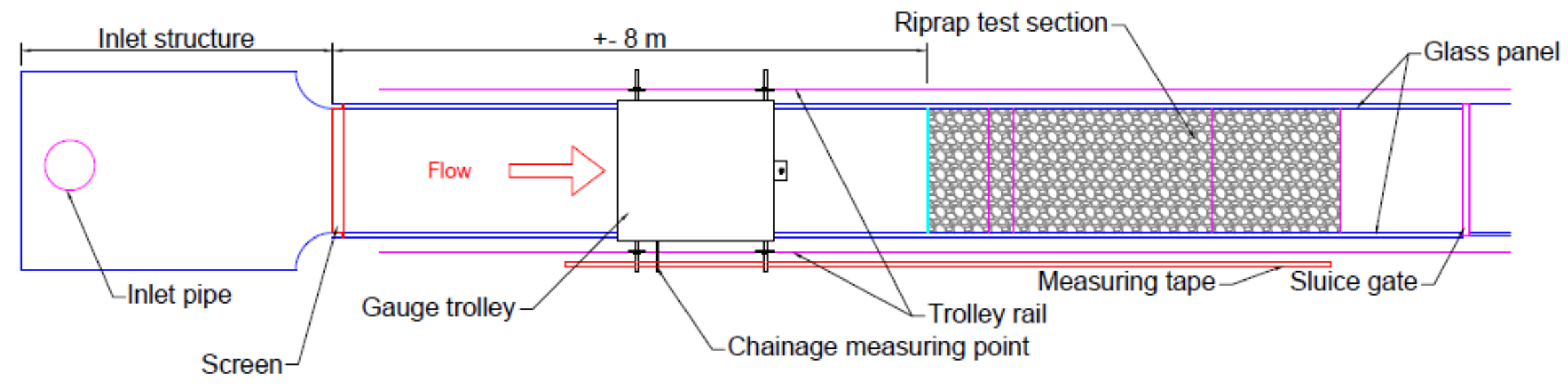

Figure 3-1: Conceptual plan view of laboratory setup 
The inlet structure was designed to ensure uniform flow in the flume upstream of the model. The edges of the inflow box were streamlined to avoid turbulence in the water. However, some wave formation inevitably occurred in the inlet structure as a result of the high velocity water entering the tank through the inlet pipe. Therefore, a screen made of shade-netting was installed at the entrance of the flume to prevent these waves from entering the flume. This was particularly useful during the tests involving low flows. Figure 3-2 shows the uniform flow approaching the structure.

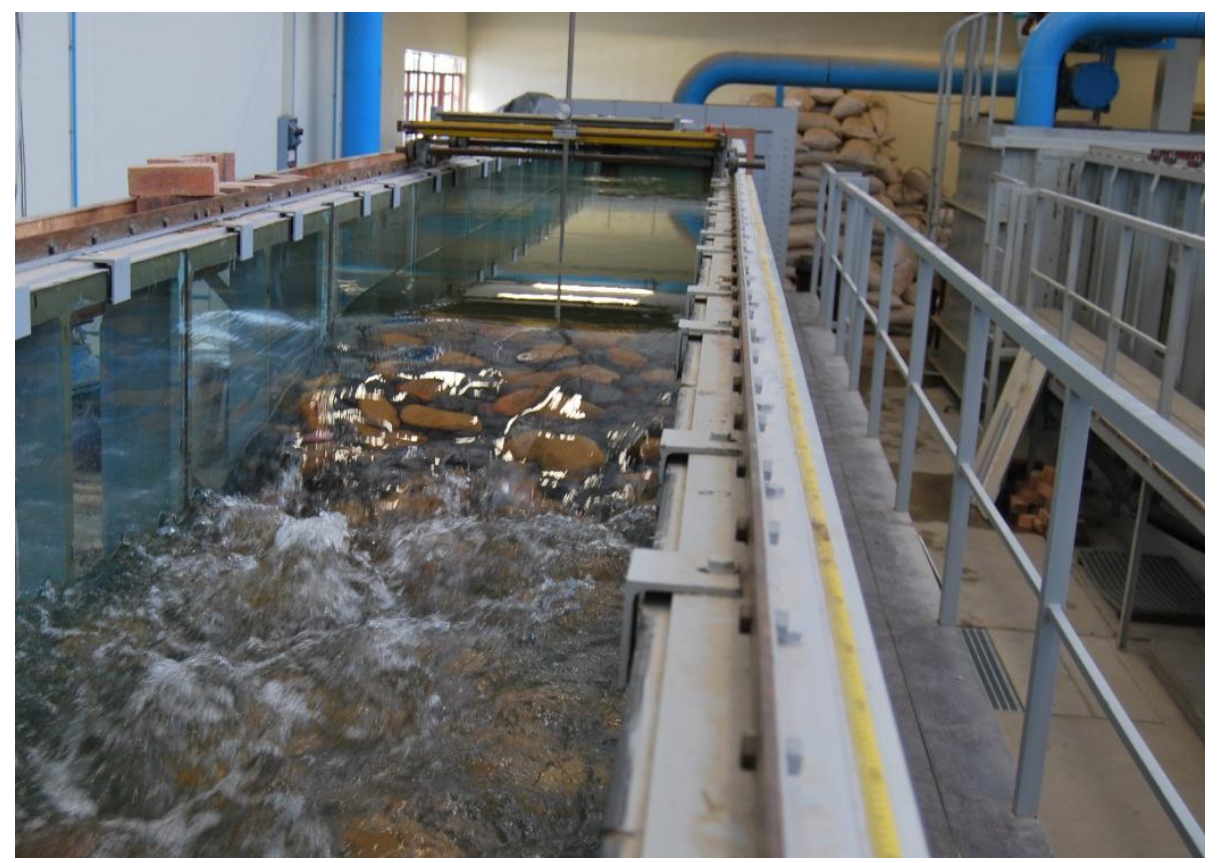

Figure 3-2: Uniform flow approaching the arrestor in the laboratory setup

The inlet pipe and the gauge trolley with the chainage measuring point can be seen in the background. The measuring tape and the trolley rail are also visible. A gauge used to measure water levels and to survey the structure is mounted on the trolley which can move along the tracks to measure water or bed levels at different chainages. The corresponding chainage was recorded for every level using a measuring tape glued to the side of the flume (seen as the yellow strip in the Figure 3-2).

\subsubsection{Model build up}

A section of the model depicting the different layers is shown in Figure 3-3. 


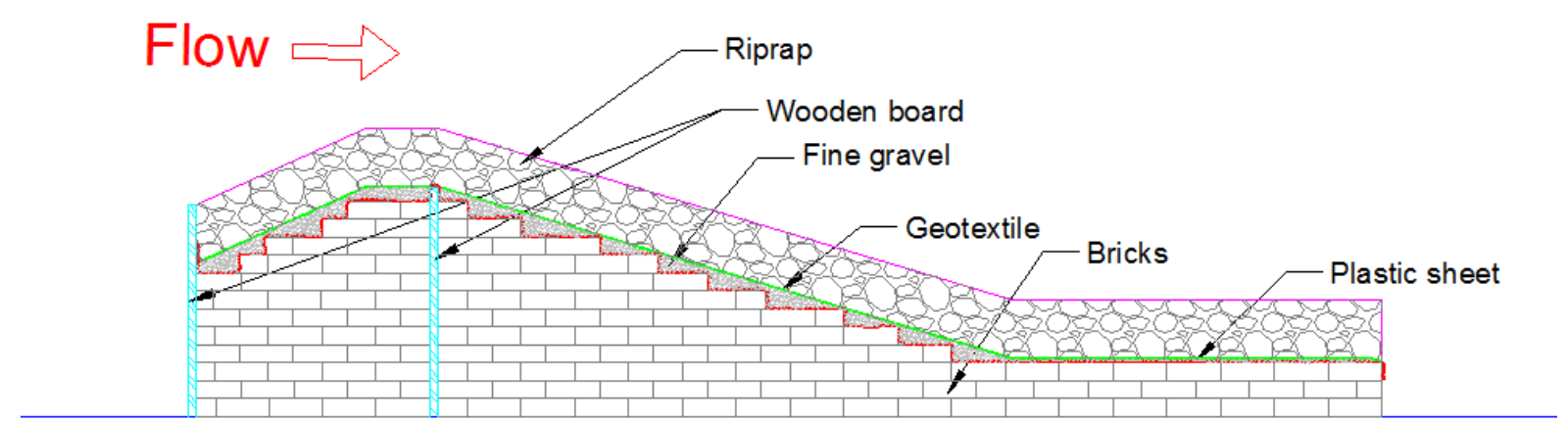

Figure 3-3: Construction details of arrestor section

Since the model had to be reconstructed after every test run, it was important to construct it in a way which minimised the disassembling and reconstruction time between the successive experiments.

An approximate shape of the arrestor was obtained by packing bricks as shown. They were arranged with a layer of varying thickness of fine gravel between the plastic sheet and the geotextile. The plastic sheet was placed directly on top of the bricks to prevent water movement in the voids between the bricks, with the ends of the plastic folded up. It is acknowledged that although this method does not prevent water from entering the voids, water is prevented from flowing between the bricks. This is one of the reasons why the flume was filled with water before the tests commenced, thus providing enough time for the voids between the bricks to fill with water and for the air to escape. The upstream wooden board shown in Figure 3-3 also prevented water from entering the brick matrix.

A second board was installed at the crest of the structure. The top of the board was regarded as a fixed reference point for surveying and construction purposes.

Since it is physically impossible to construct a smooth slope using the bricks alone, a fill material had to be used. Crushed hornfels aggregate with a $d_{50}$ of approximately $5 \mathrm{~mm}$ was used. It was placed on top of the plastic sheeting and filled the voids so that a smooth surface could be obtained. To ensure a similar roughness on the surface on which the geotextile was placed, the entire structure was covered with a minimum aggregate layer thickness of $5 \mathrm{~mm}$. Figure 3-4 shows the prepared surface. 


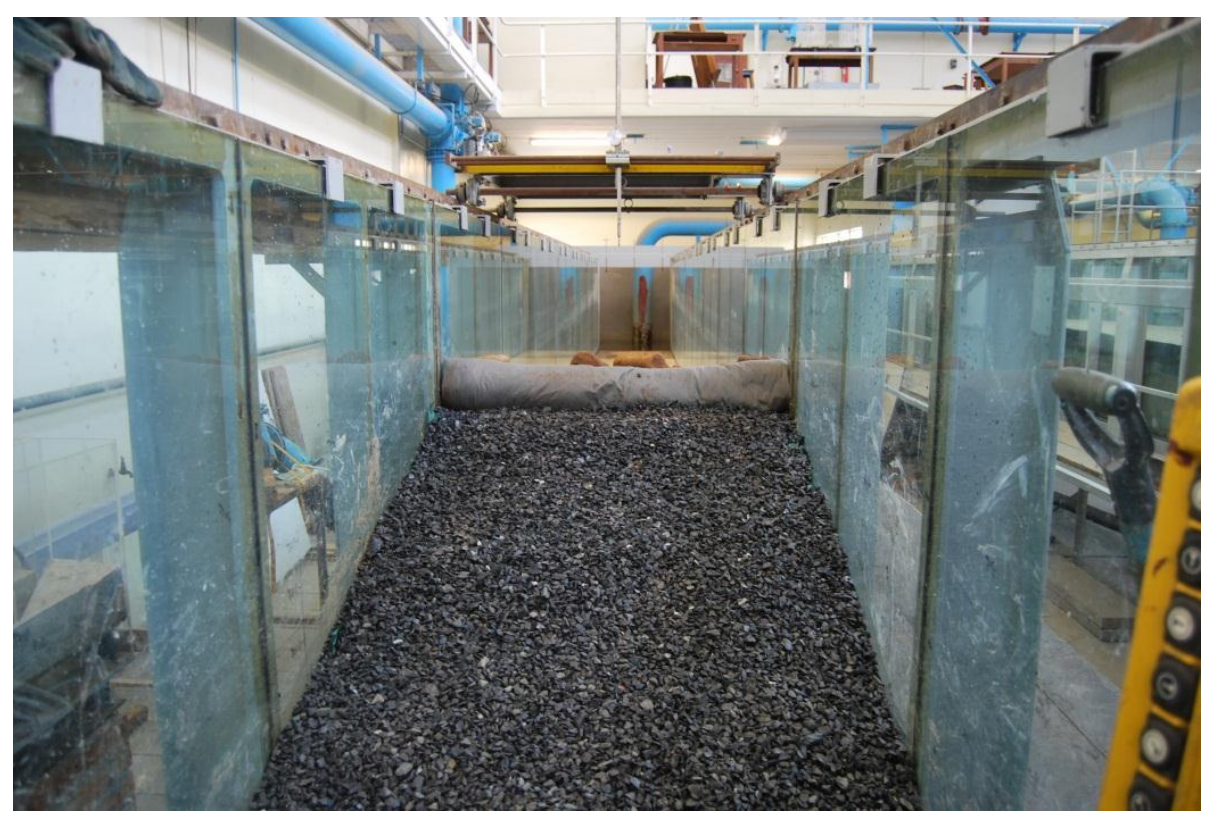

Figure 3-4: Fine gravel

In the background the roll of geotextile can be seen which was simply rolled down and placed over the slope. Finally, a riprap layer of a certain thickness was dumped on the geotextile.

\subsubsection{Test scenarios and arrestor dimensions}

Twelve different scenarios were tested in the laboratory. Three different slopes, two different lengths and two different $d_{50}$ riprap sizes were used. A three digit code was used to denote each of the tests. The first digit refers to the length of the arrestor, the second to the slope and the third to the $d_{50}$ rock size.

The effect of the length on the stability of the structure was studied by de Almeida and Martin-Vide (2009). They found that an increase in length increases the stability of the structure significantly. The literature presented earlier clearly showed that both the median stone diameter and the arrestor slope have a significant effect on the stability of the riprap.

A sketch of the arrestor is shown in Figure 3-5. 


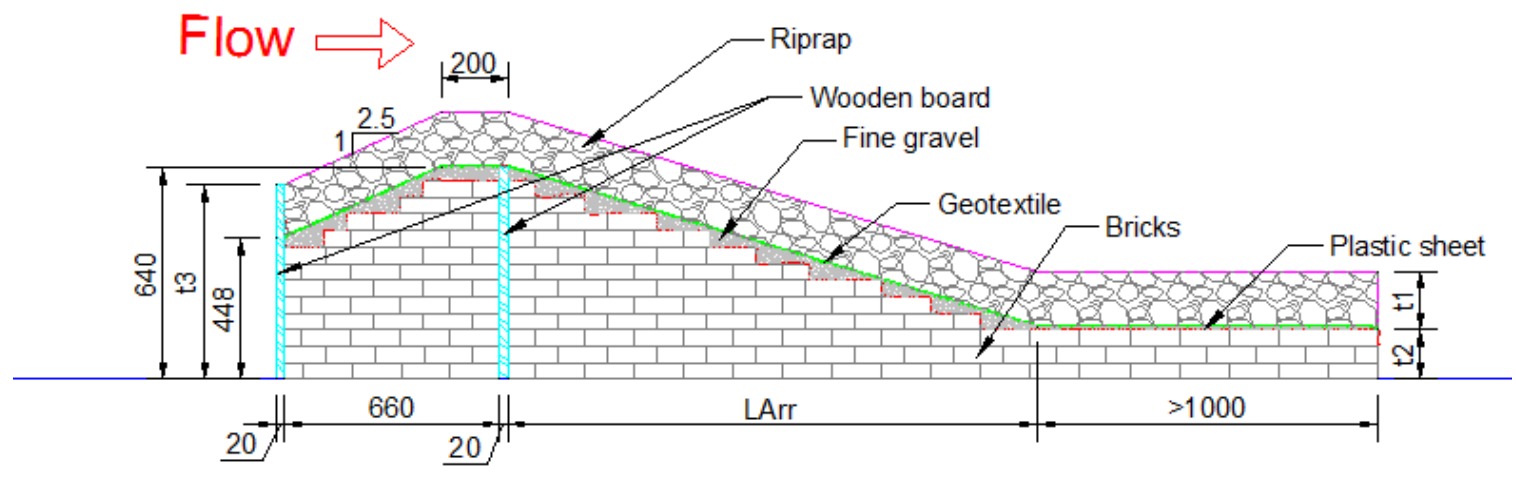

Figure 3-5: Dimensions of riprap arrestor

The dimensions $t_{1}, t_{2}$ and $t_{3}$ were varied, as shown in Table 3-1.

Table 3-1: Testing schedule (all dimensions in mm)

\begin{tabular}{|c|c|c|c|c|c|c|c|}
\hline Test & Code & $L_{\text {Arr }}$ & $S_{\text {Arr }}(1: \mathrm{x})$ & $d_{50}$ & $t_{1}$ & $t_{2}$ & $t_{3}$ \\
\hline 1 & 111 & 1600 & 5 & 67 & 168 & 320 & 588 \\
\hline 2 & 121 & 1600 & 3.3 & 67 & 168 & 155 & 588 \\
\hline 3 & 131 & 1600 & 2.5 & 67 & 168 & 0 & 588 \\
\hline 4 & 211 & 1000 & 5 & 67 & 168 & 440 & 588 \\
\hline 5 & 221 & 1000 & 3.3 & 67 & 168 & 337 & 588 \\
\hline 6 & 231 & 1000 & 2.5 & 67 & 168 & 240 & 588 \\
\hline 7 & 232 & 1000 & 2.5 & 100 & 250 & 240 & 670 \\
\hline 8 & 222 & 1000 & 3.3 & 100 & 250 & 337 & 670 \\
\hline 9 & 212 & 1000 & 5 & 100 & 250 & 440 & 670 \\
\hline 10 & 132 & 1600 & 2.5 & 100 & 250 & 0 & 670 \\
\hline 11 & 122 & 1600 & 3.3 & 100 & 250 & 155 & 670 \\
\hline 12 & 112 & 1600 & 5 & 100 & 250 & 320 & 670 \\
\hline
\end{tabular}

The length of the arrestor $\left(L_{A r r}\right)$ was chosen on the basis that it is the longest possible length that could be fitted into the flume, given the steepest slope of 1:2.5, the layer thickness of $2.5 d_{50}$ and the maximum flow depth over the crest.

For economic reasons, riprap arrestors are relatively steep structures. However, in order to keep the prototype rock diameters within practical limits, the arrestor slopes are typically not steeper than $1: 2.5(\mathrm{~V}: \mathrm{H})$.

In the literature study it was found that there is a significant lack of data for high particle Reynolds numbers. The data presented by Liu thus corresponds to relatively small particles. Therefore, reasonably large particles were selected for this investigation. 
In this study, the failure of the riprap on the sloped part downstream of the crest was of primary interest. The dimensions of the approach structure upstream of the crest were not altered during the tests. A slope of $1: 2.5(\mathrm{~V}: \mathrm{H})$ was used.

The purpose of the approach structure is to force the water into a supercritical state by creating a hydraulic control at the crest of the structure. The water accelerates further down the sloped part of the structure. Arrestors are typically designed so that the tailwater level in the outlet reach is sufficient to force a hydraulic jump in that area, causing energy to dissipate. Therefore, the outlet reach also requires erosion protection for a sufficient length. For any arrestor to function effectively, the water exiting the outlet reach should be subcritical.

In order to ensure a reliable hydraulic control, the crest width in the flow direction was made $200 \mathrm{~mm}=2$ times the $d_{50}$ of the larger sample. This ensures that even if a $d_{50}$ wide strip of riprap erodes on the crest, the control does not shift. Also, for the weir to behave hydraulically as a broad-crested weir, the weir width should at least be $3 H$ (Chadwick et al., 2004; SANRAL, 2013).

Robinson et al. (1998) found that the riprap size required for stability on the slope would also be stable in the outlet reach under supercritical flow conditions. Even so, it makes sense that supercritical flow in the outlet reach yields the worst possible conditions. Therefore, the downstream sluice gate of the flume was left open during the tests, causing a free outflow from the outlet reach, yielding mostly supercritical conditions in that area.

\subsubsection{Physical properties of riprap}

Since it is not feasible to procure riprap of a certain grading in such a comparatively small volume, the samples were mixed manually. Due to the unavailability of small and large rocks of the same type, two different types of rocks had to be used. The hornfels rock was available up to a size of about $75 \mathrm{~mm}$, which corresponds to the $d_{56}$ and $d_{35}$ fractions for Samples 1 and 2 respectively. Sandstone was used for the larger fractions. 


\subsubsection{Grading}

In order to produce a range of laboratory results, two different gradings were used for the study. The size distribution was done according to the requirements stipulated by Simons and Sentürk (1992).

Two sets of riprap were used, Sample 1 and Sample 2, with a $d_{50}$ of 0.067 and $0.1 \mathrm{~m}$ respectively. The desired size distribution for both samples is depicted in Figure 3-6.

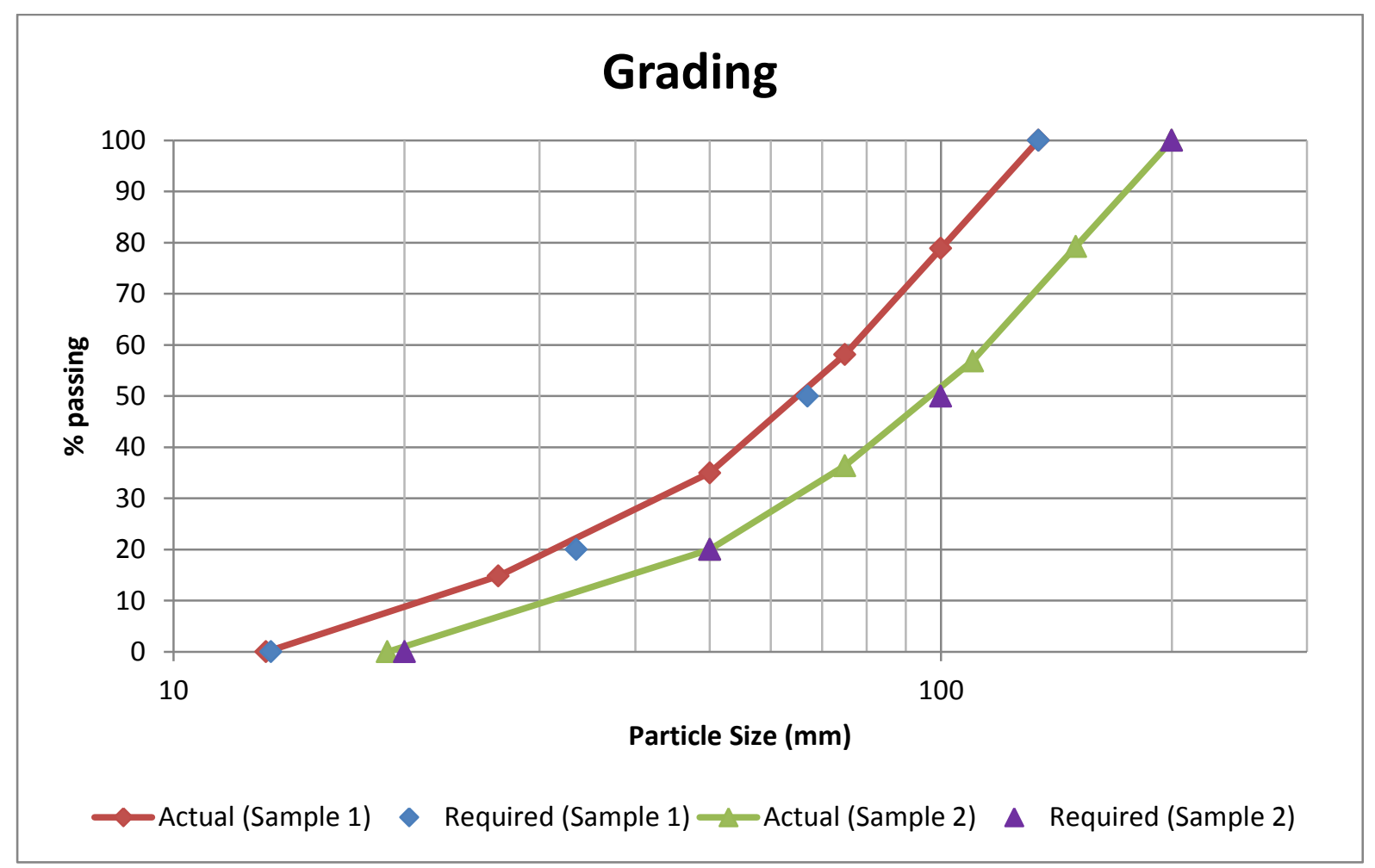

Figure 3-6: Sample gradings

Figure 3-6 shows that there is a good correlation between the Simon and Sentürk (1992) guidelines and the actual grading obtained in the laboratory.

The smaller fractions of the sample were sieved with standard sieve sizes. For rock sizes larger than $76 \mathrm{~mm}$, larger sieves were manufactured from steel squares with certain inner dimensions.

Rocks in a certain range of sizes were weighed and bagged. When enough rocks of each range were bagged, all the bags were carefully mixed. 


\subsubsection{Angularity}

The angularity of the sample was determined by inspection. Figure 3-7 shows the differences in angularity of both rock types in the sample.

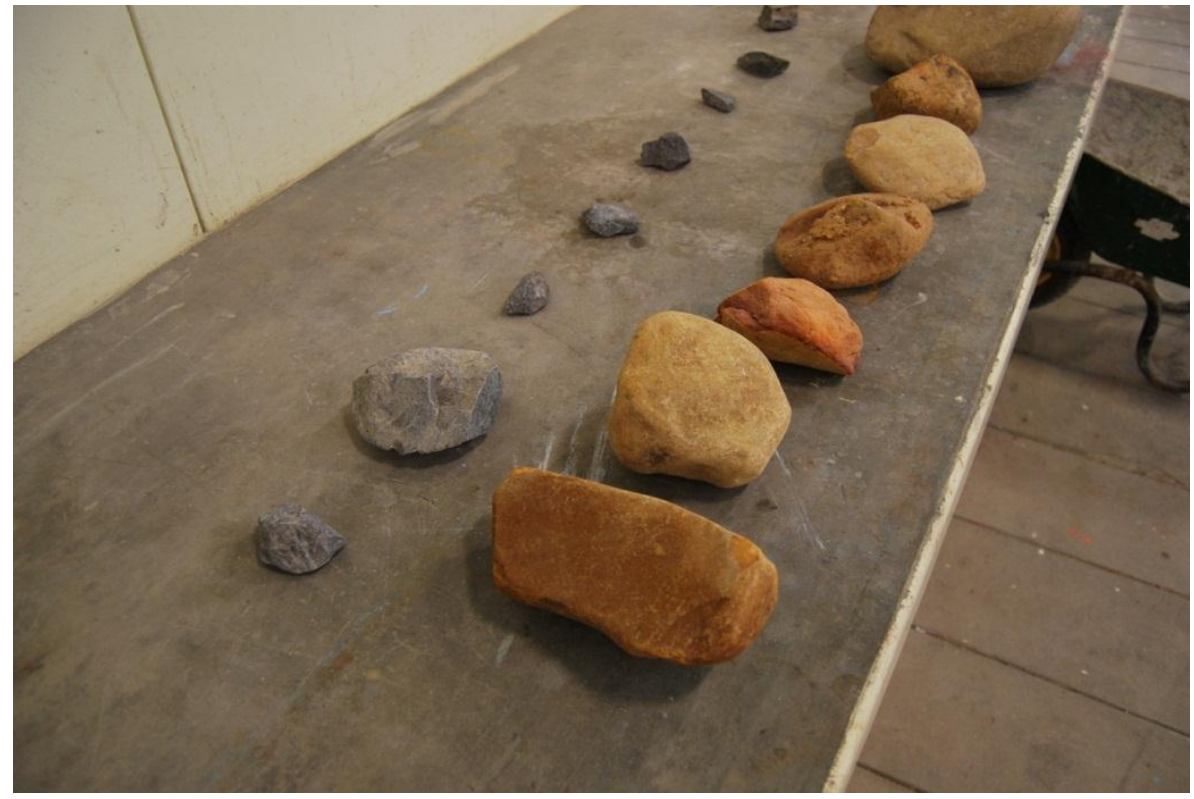

Figure 3-7: Rock sample (hornfels left, sandstone right)

It can be observed that the hornfels rock is slightly more angular than the alluvial sandstone. It was concluded that the hornfels rock can be classified as moderately angular, and the sandstone as slightly angular.

The difference in angularity was taken formally into account when the angle of repose was determined in Section 2.3.7.

\subsubsection{Rock density}

The density depends largely on the chemical composition of the particle and is thus a function of the type of rock.

Density is defined as follows:

$$
\rho=\frac{\text { Mass }}{\text { Volume }}=\frac{m}{V}
$$

Equation 3-1

The mass of an individual rock was determined by placing it on a calibrated digital scale as shown in Figure 3-8. Care was taken to ensure that the individual rocks were dry and free of dust. 


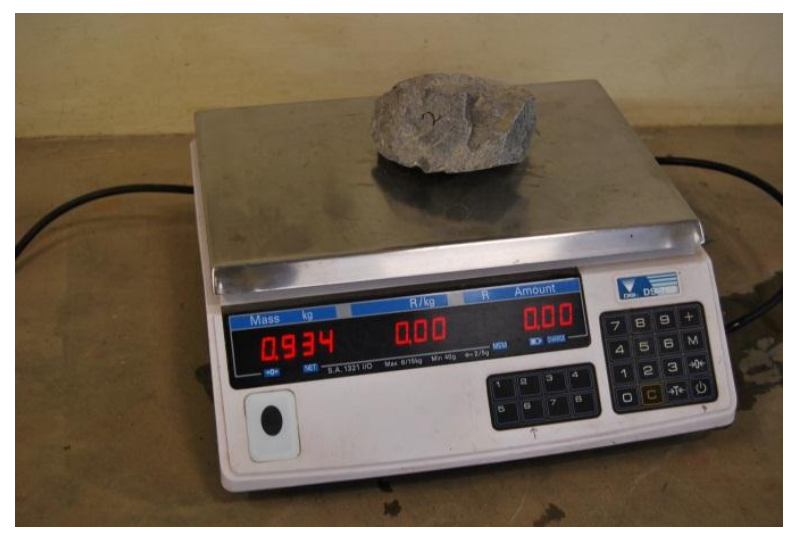

Figure 3-8: Weighing of rock

Due to the complex geometry of the rock particles, the volume could not be measured directly. Instead, the rocks were lowered one by one into a measuring beaker (making sure that the particles were completely submersed), and the before and after water levels recorded. The difference in the readings was equal to the volume they displaced.

For increased accuracy, the rocks were lowered into different sized beakers. Figure 3-9 shows the large beaker used to measure the displaced volume.

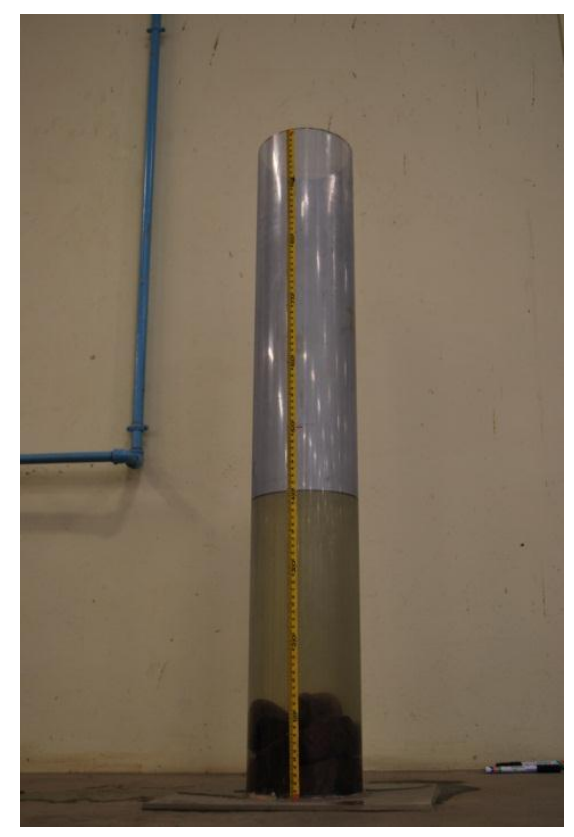

Figure 3-9: Measuring the displacement of a rock in the large beaker

For one of the samples, even the larger beaker (shown) was too small. In that case, a conventional bucket was used and the bucket was filled to about halfway before the rock was fully submersed in water. The water level was marked on the bucket before the rock was 
removed again. Using a beaker, the water that needed to be added to the bucket for the water to attain the level marked earlier was measured.

In an attempt to obtain a representative density across the sample, 10 rocks of each type were selected. The rocks were selected in a random order, whilst ensuring that rocks of many different sizes were represented in the sample.

Table 3-2 shows the masses, volumes and calculated densities of the sample.

Table 3-2: Density determination of rock sample

\begin{tabular}{|c|c|c|c|c|c|c|}
\hline Sample & Beaker & Type & Mass (g) & $V(\mathrm{ml})$ & $\rho_{r}\left(\mathrm{~kg} / \mathrm{m}^{3}\right)$ & Avg. $\rho_{r}\left(\mathrm{~kg} / \mathrm{m}^{3}\right)$ \\
\hline 1 & Small & Hornfels & 140 & 56 & 2500.0 & \multirow{10}{*}{2708} \\
\hline 2 & Large & Hornfels & 936 & 331 & 2832.0 & \\
\hline 3 & Small & Hornfels & 56 & 20 & 2800.0 & \\
\hline 4 & Small & Hornfels & 88 & 34 & 2588.2 & \\
\hline 5 & Small & Hornfels & 92 & 35 & 2628.6 & \\
\hline 6 & Small & Hornfels & 38 & 14 & 2714.3 & \\
\hline 7 & Small & Hornfels & 122 & 45 & 2711.1 & \\
\hline 8 & Small & Hornfels & 188 & 68 & 2764.7 & \\
\hline 9 & Small & Hornfels & 316 & 113 & 2796.5 & \\
\hline 10 & Small & Hornfels & 274 & 100 & 2740.0 & \\
\hline 11 & Large & Sandstone & 2292 & 863 & 2655.9 & \multirow{10}{*}{2661} \\
\hline 12 & Large & Sandstone & 2260 & 845 & 2675.8 & \\
\hline 13 & Large & Sandstone & 1050 & 386 & 2723.1 & \\
\hline 14 & Large & Sandstone & 1864 & 698 & 2671.5 & \\
\hline 15 & Large & Sandstone & 1758 & 679 & 2587.7 & \\
\hline 16 & Large & Sandstone & 1896 & 716 & 2647.7 & \\
\hline 17 & Bucket & Sandstone & 9595 & 3569 & 2688.2 & \\
\hline 18 & Large & Sandstone & 2448 & 900 & 2720.9 & \\
\hline 19 & Large & Sandstone & 3058 & 1175 & 2602.3 & \\
\hline 20 & Large & Sandstone & 1016 & 386 & 2634.9 & \\
\hline
\end{tabular}

As expected, the sandstone was slightly less dense than the hornfels. As mentioned earlier, a commonly accepted value for the density of natural rock is $2650 \mathrm{~kg} / \mathrm{m}^{3}$. From the results in Table 3-2, however, the density of the Hornfels sample seemed slightly higher. In the laboratory it could be observed that primarily hornfels particles were dislodged when exposed to the flow.

Thus, a value of $2700 \mathrm{~kg} / \mathrm{m}^{3}$ for $\rho_{r}$ seems more adequate to be used for further calculations. Even so, it is worthwhile noting that the difference between $2650 \mathrm{~kg} / \mathrm{m}^{3}$ and $2700 \mathrm{~kg} / \mathrm{m}^{3}$ is less than $2 \%$. Thus, the density cannot be regarded as a major source of error. 


\subsubsection{Angle of repose}

The angle of repose was determined according to the guidelines presented by SANRAL (2013).

The approximate ratios of the different rock types in the mix are shown in Table 3-3 as mass percentages. These ratios were used to linearly interpolate a point on Figure 2-3.

Table 3-3: Angle of repose for different samples

\begin{tabular}{|c|c|c|}
\cline { 2 - 3 } \multicolumn{1}{c|}{} & Sample 1 & Sample 2 \\
\hline$d_{50}(\mathrm{~m})$ & 0.067 & 0.100 \\
\hline \% Hornfels (by mass) & 58 & 36 \\
\hline \% Sandstone (by mass) & 42 & 64 \\
\hline$\phi\left({ }^{\circ}\right)$ & 39.8 & 40.7 \\
\hline$\phi(\mathrm{rad})$ & 0.698 & 0.716 \\
\hline
\end{tabular}

As can be seen in Table 3-3, the determination of $\phi$ is very insensitive to the different angularity classifications of the riprap. Consequently, the difference in $\phi$ presented in Table 3-3 is very small.

\subsubsection{Filter}

A filter is an important part of any riprap structure. Its primary purpose is to prevent finer material from being removed from below the riprap layer, as this would cause failure of the top layer of the riprap by undermining the bottom particles.

Since only the top layer of riprap was considered in this investigation, no filter layers were put in place. However, in order to prevent the underlying layer of the finer granular material (used as filler material) from being mixed with the top layer of riprap, a layer of geotextile was placed between the filler material and the riprap as shown in Figure 3-3.

The geotextile was only $0.5 \mathrm{~m}$ wide (versus the testing flume being $1 \mathrm{~m}$ wide). Therefore, three lanes of geotextile were placed along the length of the structure, the outer ones being placed first, with the edges along the glass folded up by approximately $50 \mathrm{~mm}$, as shown in Figure 3-10. The remaining middle lane was placed in the middle of the flume, thus covering the $100 \mathrm{~mm}$ wide strip in the middle and creating an overlap of roughly $200 \mathrm{~mm}$ on either side. 


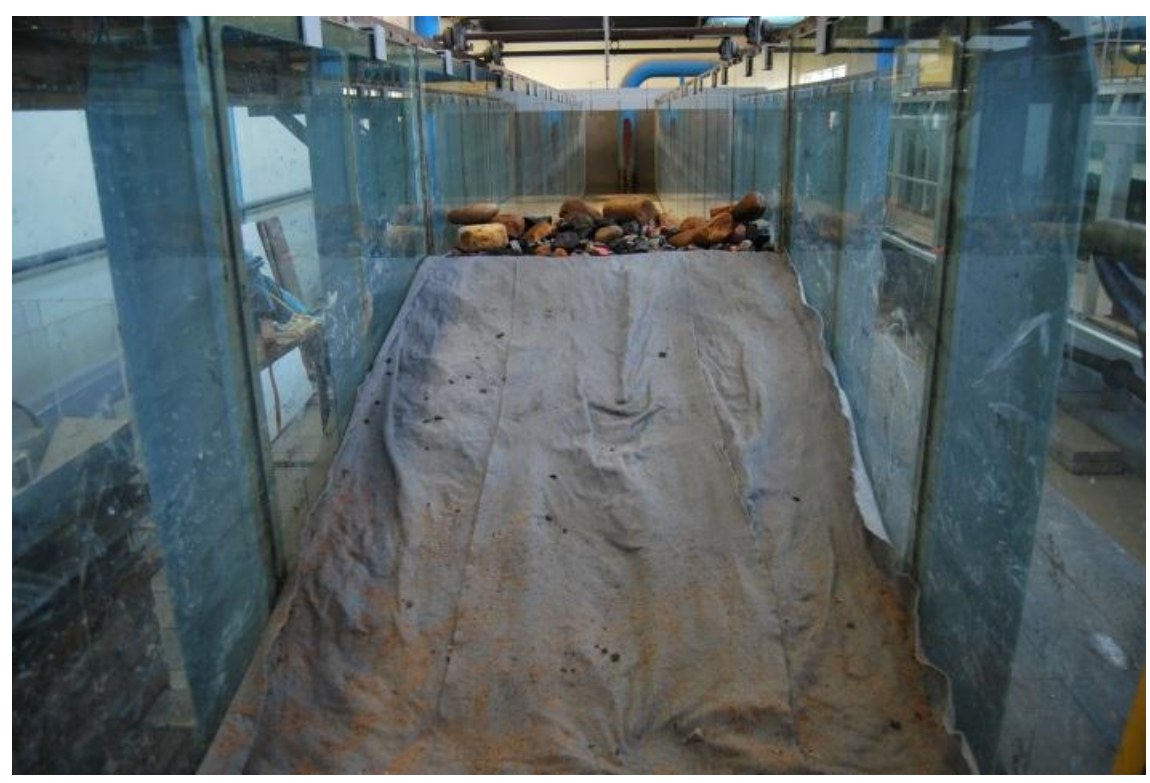

Figure 3-10: Placement of geotextile

The geotextile was of sufficient strength to resist damage under laboratory conditions. After every laboratory test, the geotextile was inspected for holes, tears or ruptures. The geotextile did not break during any of the tests, but was replaced as a precautionary measure after 6 tests.

\subsubsection{Handling of the riprap}

The foregoing discussions assume a random arrangement of different particles sizes (within the boundaries of the grading). In the context of the physical representation thereof, this assumption translates into dumping the riprap, rather than packing it. The smooth grading shown in Figure 3-6 had to be maintained in every packet of riprap material.

Since the riprap was repeatedly reused, precautions had to be taken to prevent the segregation of smaller particles, leaving the larger particles more exposed. After a test was completed, all the riprap downstream of the crest was removed and placed downstream of the structure (inside the flume), where it was mixed. Next the riprap was placed inside a drum, where it was lifted and transported to the desired position with an overhead crane. Starting at the most downstream part of the structure (to avoid the riprap from rolling downstream), the drum was tipped, so that the riprap could fall into its desired position.

In order to avoid flow concentrations and to achieve a relatively smooth surface, the riprap had to be levelled to some extent, especially in the areas close to the flume walls, where the 
drum was too bulky to reach the corners. Care was taken not cause significant segregation of the mix.

\subsection{Testing procedure}

The testing essentially involved two phases. The objective of the first phase was to determine the critical conditions under which incipient motion would occur. Secondly, the point at which the arrestor failed was determined. This was, however, not always possible since the maximum flow over the model was limited (see Chapter 3.3).

Once the construction of the model was completed, a small flow was discharged over the structure, typically in the range of 30-50 1/s, depending on the steepness of the structure. This was done for two reasons: firstly, any loose and exposed rocks would be washed down the slope to settle into a stable position. This was necessary to ensure that these movements would not be mistaken for the point of incipient motion during the actual tests. Secondly, the flow allowed the part of the flume between the sluice and the model to fill up, ensuring that the downstream water level could be controlled instantly when the actual testing phase commenced. Also, this allowed the voids between the bricks to fill up with water and allow the air to escape slowly. The flow was kept sufficiently small to not cause major movement of the riprap.

The structure was then surveyed with the needle gauge fixed to the trolley. Depending on the length of the structure, 12-15 points (spaced about $200 \mathrm{~mm}$ apart) were measured along the centre of the structure. Photos were taken in top and side views. This state of the arrestor is hereafter referred to as the initial condition.

The previous low flow was restored and then increased at a rate of $5 \mathrm{l} / \mathrm{s}$ per minute. The structure was carefully observed from the top and side of the flume until incipient motion was observed. The flow was immediately terminated once this was observed. This flow at which rock movement was observed is referred to as $Q_{m}$. A survey of the structure was conducted (at the same points as before) and photos were taken to document the movement of the particles.

Once complete, the downstream sluice was closed and the flume was slowly filled with water until the water level was close to the crest level of the structure. Then the flow was slowly 
increased (with the structure submersed) to $Q_{m}$, at which point the sluice was opened again. This method ensured that no rocks were moved while the $Q_{m}$ was restored. While still on $Q_{m}$, and the sluice open, water levels were measured.

The flow was then increased at a rate of $10 \mathrm{l} / \mathrm{s}$ per 5 min until the structure failed completely. A larger time step was selected to ensure that all particles that were unstable at a specific flow would indeed be dislodged. For flows smaller than $Q_{m}$, the condition of the rocks was time independent. The flow at which failure occurred was denoted as $Q_{f}$. Immediately after failure was observed, the water levels were recorded and the inlet valve was closed. The final surface was then surveyed. Finally, photos were taken in top and side view.

\subsection{Definitions}

\subsubsection{Definition of incipient motion under laboratory conditions}

As described before, the point of incipient motion was of primary interest and was documented carefully in terms of discharge, water levels and structure surveys.

From the literature study it is evident that the point of incipient motion is difficult to define in practice and involves a certain extent of subjective judgement. The point at which incipient motion was reached during the laboratory tests was when a limited number of particles started to erode. Typically, this movement occurred rather suddenly, and thus a definitive point could be determined. At this point, some material had been repositioned, but the entire slope remained stable.

This failure occurred in a relatively consistent manner. The movement of overly small particles was ignored for obvious reasons.

The point of incipient motion can be interpreted as a point at which the structure is still stable, although the layer thickness of the riprap has decreased slightly at local areas.

\subsubsection{Definition of structure failure under laboratory conditions}

As the flow rate reached its maximum stable discharge, it was observed that large stones would tilt into the flow and were transported downstream. These rocks typically caused a chain reaction by dislodging additional material. Failure was considered to be the flow condition that exposed the underlying geotextile. 
In practice, the prolonged exposure to oscillating eddy currents would tear up the geotextile once exposed, causing excessive undermining and almost immediate failure of the entire structure. Figure 3-11 shows an example of a failed slope, exposing the geotextile. The failure occurred directly below the crest.

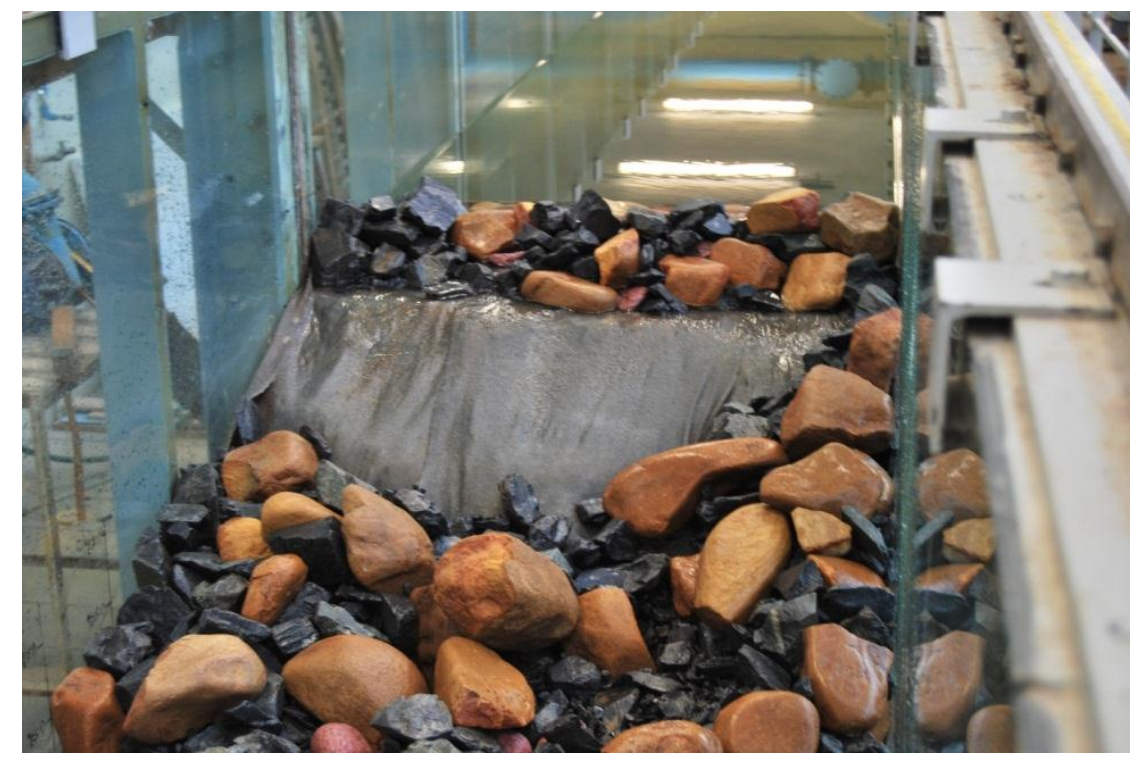

Figure 3-11: Example of failed arrestor structure, looking upstream (Test 131)

For the tests with the smaller rock sample (Sample 1), a rapid failure occurred as all the particles below the crest simultaneously slid down when enough particles were removed along the slope of the structure. For the larger sample, the failure occurred only locally and was thus not necessarily picked up by the survey.

\subsection{Flowmeter calibration}

In order to measure the flow over the model, an electric flowmeter was used. The flowmeter was calibrated with a $\mathrm{V}$-Notch for smaller flow and a rectangular weir for the larger flow.

The flowmeter utilises electric power to induce a magnetic field. Flux is created if water flows through the magnetic field and induces a Voltage $(V)$. This voltage was measured with a calibrated voltmeter. Faraday's law is utilised to convert voltage to discharge $(Q)$. The relationship is given by Equation 3-2 (in SI units).

$$
Q=\frac{V}{L} B A
$$

Equation 3-2 
where

$L \quad$ Distance between the magnetic poles (which is equal to the pipe diameter $D$ in pipes);

$B \quad$ Calibration constant; and

A Flow area.

The inner diameter of the flowmeter housing is, according to the manufacturer, $0.3 \mathrm{~m}$. Thus $L=D=0.3 \mathrm{~m}$.

Since the value of $B$ was unknown, it had to be determined experimentally, using discharge measured with weirs as a reference. A V-Notch is slightly more accurate than a rectangular weir (Chadwick et al., 2004) for flow measurements. However, due to geometric constraints in the flume, the V-Notch could only be used for flows up to about 50 1/s. For larger flows a contracted rectangular weir was used.

The calibration was conducted in the same flume as shown in Figure 3-1, without the arrestor setup. The flowmeter was situated near the inlet of the flume, while the weirs were installed about half way in the flume. The flow was increased gradually, while recording the Voltage reading and the Water level at a distance of $5 H$ upstream of the weir. Water levels could be measured to an accuracy of $0.1 \mathrm{~mm}$.

Equation 3-3 was used to convert the water levels to a discharge for the V-Notch weir.

$$
Q=C_{d} \frac{8}{15} \sqrt{2 g} \tan \left(\frac{\theta}{2}\right) H^{5 / 2}
$$


where

$C_{d} \quad$ Contraction coefficient $=0.59$ for $90^{\circ} \mathrm{V}$-notch weirs (Chadwick et al., 2004);

$\theta \quad$ Angle of the $\mathrm{V}$-notch $=90^{\circ}$; and

$H \quad$ Energy head measured a distance of $5 H$ upstream of the weir, with the lowest point on the weir being the datum.

The Kindsvater and Carter equation (United States Department of the Interior Bureau of Reclamation, 2012), given as Equation 3-4 was used to compute the discharge over the contracted rectangular weir, with the geometric properties and energy head known.

$$
Q=C_{e} L_{e} H_{l e}^{3 / 2}
$$

Equation 3-4

According to the United States Department of the Interior Bureau of Reclamation (2012), the parameters in Equation 3-4 can be defined as follows:

$C_{e} \quad$ Effective discharge coefficient (see Equation 3-6);

$L_{e} \quad$ Effective length, which is the width of the weir plus the empirical constant $\mathrm{K}_{\mathrm{L}}$, given by the polynomial in Equation 3-5; and

$H_{l e} \quad$ Energy head, measured above the weir crest, plus an empirical constant of $0.001 \mathrm{~m}$.

$$
K_{L}=-0.106098 \frac{L^{4}}{B}+0.1922 \frac{L^{3}}{B}-0.11417 \frac{L^{2}}{B}+0.028182 \frac{L}{B}-0.00006
$$

Equation 3-5

with

L Measured length of the weir crest (m);

The effective discharge coefficient $\left(C_{e}\right)$ is given as the following:

$$
C_{e}=\alpha_{c e}\left(\frac{H}{P_{s}}\right)+\beta_{c e}
$$


where

$$
\begin{array}{cc}
\alpha_{c e}, \beta_{c e} \quad \text { Equation coefficient (given as Equations 3-7 and 3-8 respectively); and } \\
P_{s} \quad \text { Protrusion height of weir }(\mathrm{m}) . & \\
\alpha_{c e}=\frac{0.030365 \frac{L}{B}-0.00470432}{1-1.76542 \frac{L}{B}+0.879917\left(\frac{L}{B}\right)^{2}} & \text { Equation 3-7 } \\
\beta_{c e}=1.724+0.04789 \frac{L}{B} & \text { Equation 3-8 }
\end{array}
$$

Appendix A contains the experimental data and the computation of flows with Equations 3-3 and 3-4. The maximum flow over the V-Notch was limited to about $120 \mathrm{l} / \mathrm{s}$, due to geometric constraints, as shown in Appendix A1.

The contracted rectangular weir was limited by a certain minimum flow that would be necessary for accurate water level measurements. The minimum accurate water level could be measured at a discharge of 51 1/s (see Appendix A).

Finally, the flowmeter could be formally calibrated. Figure 3-12 shows the experimental relationship between $\mathrm{Q}$ and $\mathrm{V}$.

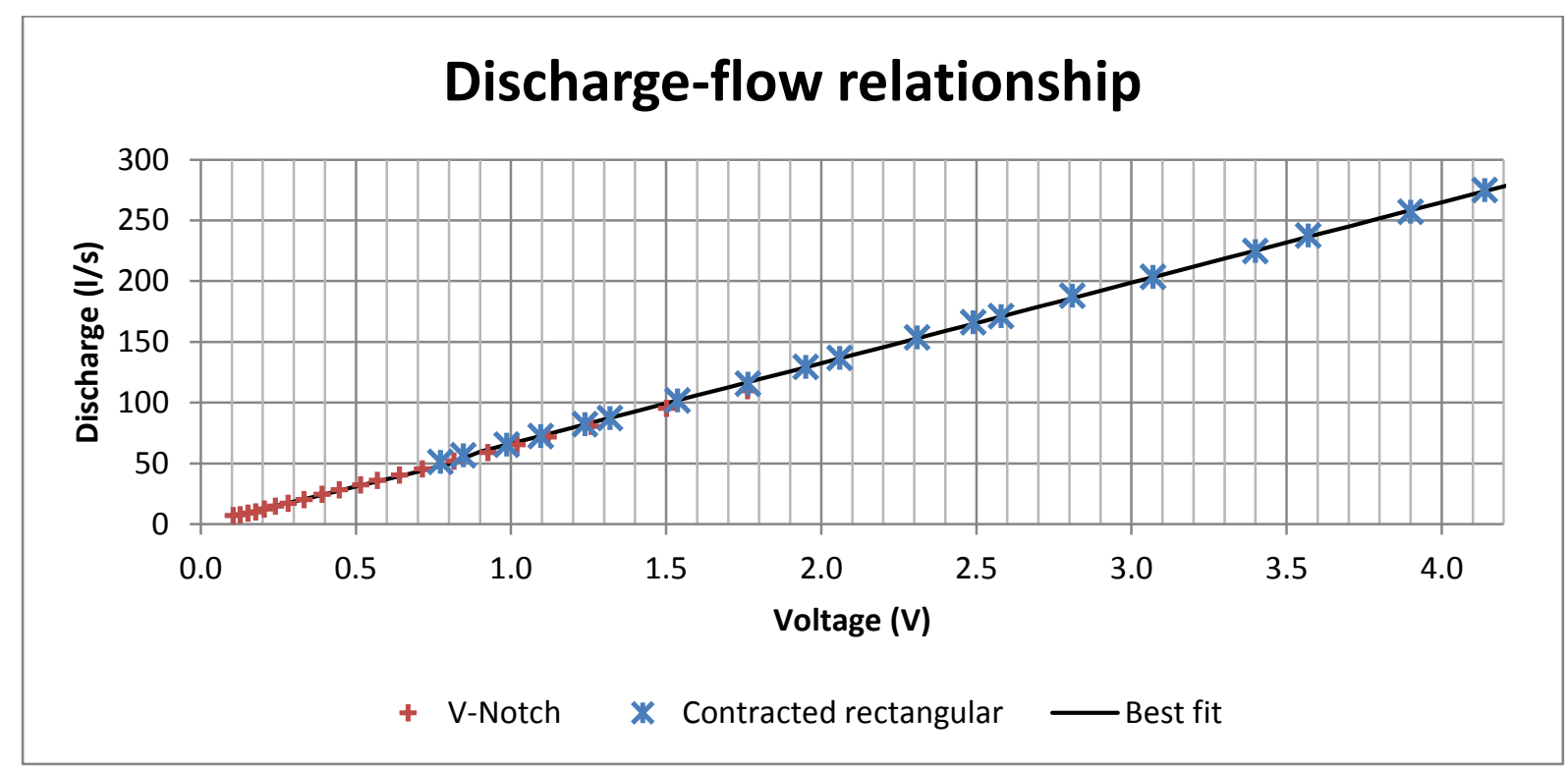

Figure 3-12: Flowmeter calibration

Figure 3-12 shows a near linear relationship between $V$ and $Q$, which is consistent with Faraday's law. At around $Q=50 \mathrm{l} / \mathrm{s}$, the data from the V-Notch seems to deviate slightly 
from the best fit line. Therefore, it was decided to define the relationship between $Q$ and $V$ piece wise.

Taking the minimum and maximum flow constraints of the different weirs into account, it was decided to use the flow from the V-Notch for flows up to 50 1/s. Larger flows would be calibrated with the data from the contracted rectangular weir so that a certain consistency was guaranteed in the calibration.

The linear equation representing the data is given in the form of Equation 3-2, which is repeated here

$$
Q=\frac{V}{L} B A
$$

with $L$ and $A$ being known and constant, the calibration constant $B$ is defined piecewise as shown below.

$$
B=\left\{\begin{array}{l}
0.262, \text { if } 12<Q \leq 50 \\
0.281, \text { if } 50<Q \leq 290
\end{array}\right.
$$




\section{EXPERIMENTAL DETERMINATION OF DRAG COEFFICIENT FOR PARTICLE SETTLING VELOCITY}

From the literature study it is apparent that the determination of the settling velocity of the

particles is not as straight-forward as it seems. Although Equation 2-8 (shown below) is derived from a solid theoretical basis, its application in practice is difficult, as the drag coefficient is unknown.

$$
V_{S S}^{2}=\frac{4}{3}\left(\frac{\rho_{r}-\rho_{w}}{\rho_{w}}\right) \frac{d g}{C_{D}}
$$

Equation 2-8

From the discussion in Section 3.1.4, the following parameters are true:

$$
\begin{array}{ll}
\rho_{r} \quad=2700 \mathrm{~kg} / \mathrm{m}^{3} \\
\rho_{w} \quad \sim 1000 \mathrm{~kg} / \mathrm{m}^{3} \\
d \quad=\text { sieve size } \sim \text { length of } b \text {-axis }(\mathrm{m})
\end{array}
$$

In order to obtain a drag coefficient that is representative of the riprap used in the laboratory studies, it was decided to determine this experimentally.

\subsection{Test configuration}

The experiments were conducted in a steel tank in the laboratory. The tank (shown in Figure 4-1) was $5.85 \mathrm{~m}$ high, with a diameter of $1.5 \mathrm{~m}$, and was filled with water. 


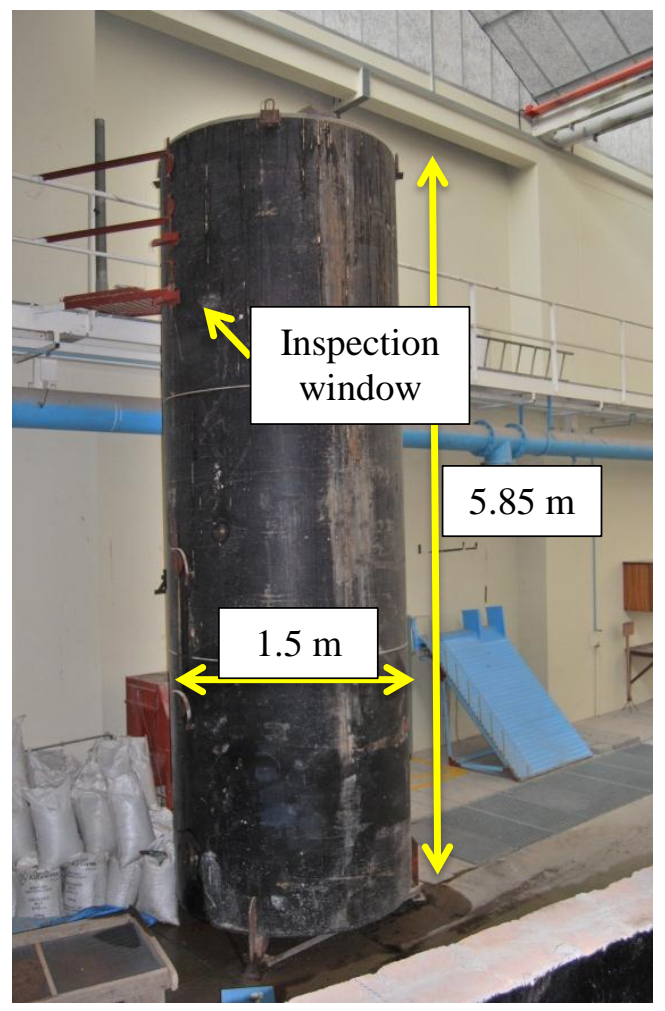

Figure 4-1: Steel tank used for determining settling velocity

The tank was also fitted with a $50 \mathrm{~mm}$ inspection window, at a distance of $0.955 \mathrm{~m}$ from the brim of the tank. A video camera was installed in front of the window, so that the inside of the tank could be seen. The lens of the camera was positioned so that it was aligned horizontally to the centre of the inspection window.

\subsection{Testing procedure}

A large number of rocks ( 82 in total), varying in mass and size were selected from the riprap samples used in the previous tests. For each rock, the parameters $\mathrm{a}, \mathrm{b}$ and $\mathrm{c}$ were determined. These parameters represent the longest, intermediate and shortest mutually perpendicular axes of a particle respectively. Also, the mass and type of rock were recorded.

While the camera in front of the window was recording, the rocks were released into the top of the tank. Since the tank is made of steel, the sound of the particles hitting the bottom of the tank was audible on the video recordings.

When releasing a particle from a stationary position, it will accelerate until it reaches terminal velocity, which is of primary interest. It was assumed that $0.955 \mathrm{~m}$ was sufficient for the particle to accelerate to terminal velocity. 
The time difference between the point where the particle was seen in the centre of the window in the video recording and the impact sound of the particle on the tank bottom was determined. A typical snapshot from the video recording of a rock is shown in Figure 4-2.

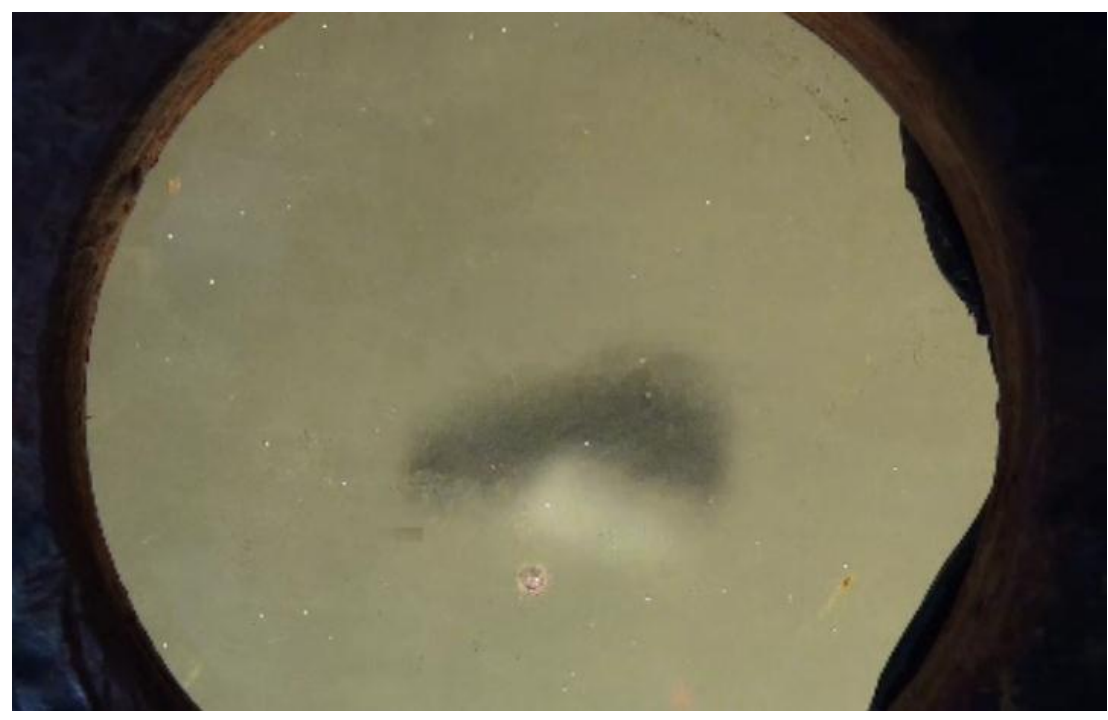

Figure 4-2: Snapshot of video recording as seen through window

Since the distance that the particle travelled was constant (i.e. $5.850-0.955=4.895 \mathrm{~m}$ ), the settling velocity could be determined using Equation 4-1.

$$
V_{\text {sS }}=\frac{4.895}{\text { Time difference }(s)}
$$

The video camera used recorded 25 frames per second, which implied that a maximum error of 0.08 seconds (i.e. the duration of 2 consecutive frames) could be associated with the determination of the time difference.

\subsection{Results}

It should be noted that the data recorded for many of the rocks could not be used for determining the settling velocity. The reasons were as follows:

- the rocks did not pass the window, therefore they could not be traced on the video;

- the rocks made contact with the inner wall of the tank, thus slowing down the particle and affecting the results; and

- the sound of some of the very light particles hitting the tank bottom was not audible on the video recording.

Of the 82 particles dropped, only 27 produced usable results. 
With all the parameters of Equation 2-8 known, $C_{D}$ could be determined. Figure 4-3 shows the results.

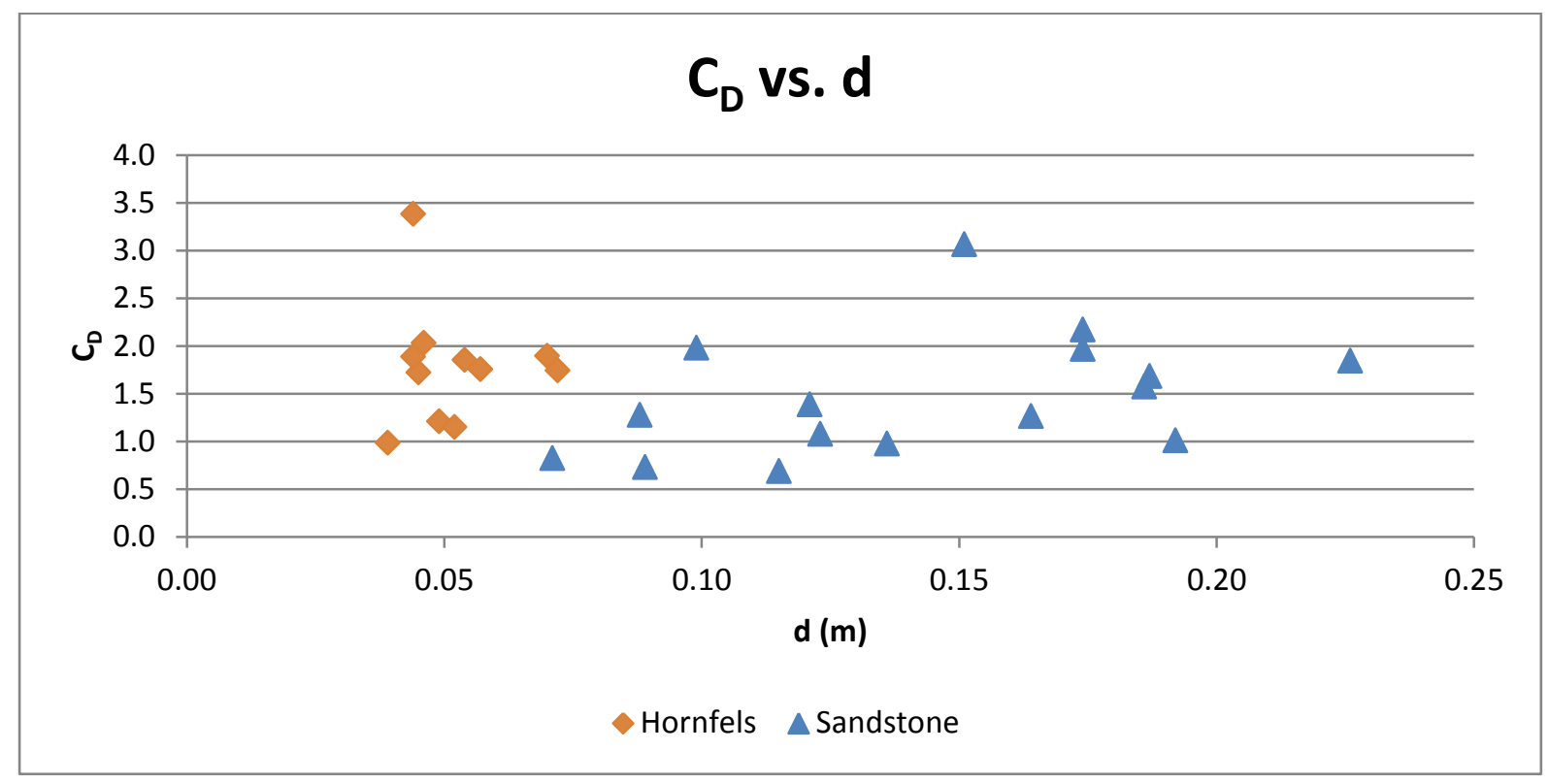

Figure 4-3: Experimental drag coefficient vs. diameter

Figure 4-3 shows that $C_{D}$ does not vary significantly with the rock diameter. This is consistent with Concha (2009), who showed that the drag coefficient is similar for particles of similar shapes. The sandstone data is slightly more scattered. This can be explained by a greater variety of shapes corresponding with the hornfels sample. The standard deviations are 0.145 and 0.150 for the hornfels and sandstone, respectively. The two outliers $\left(C_{D} \sim 3\right.$ and 3.5) can be associated with a comparatively small Corey shape factor (See Equation 2-9).

As a validation, the data was compared to Simons and Sentürk's (1992) and Concha's (2009) work. Figure 4-4 shows experimental data as a function of the particle Reynolds number. 


\section{$C_{D}$ vs. Re*}

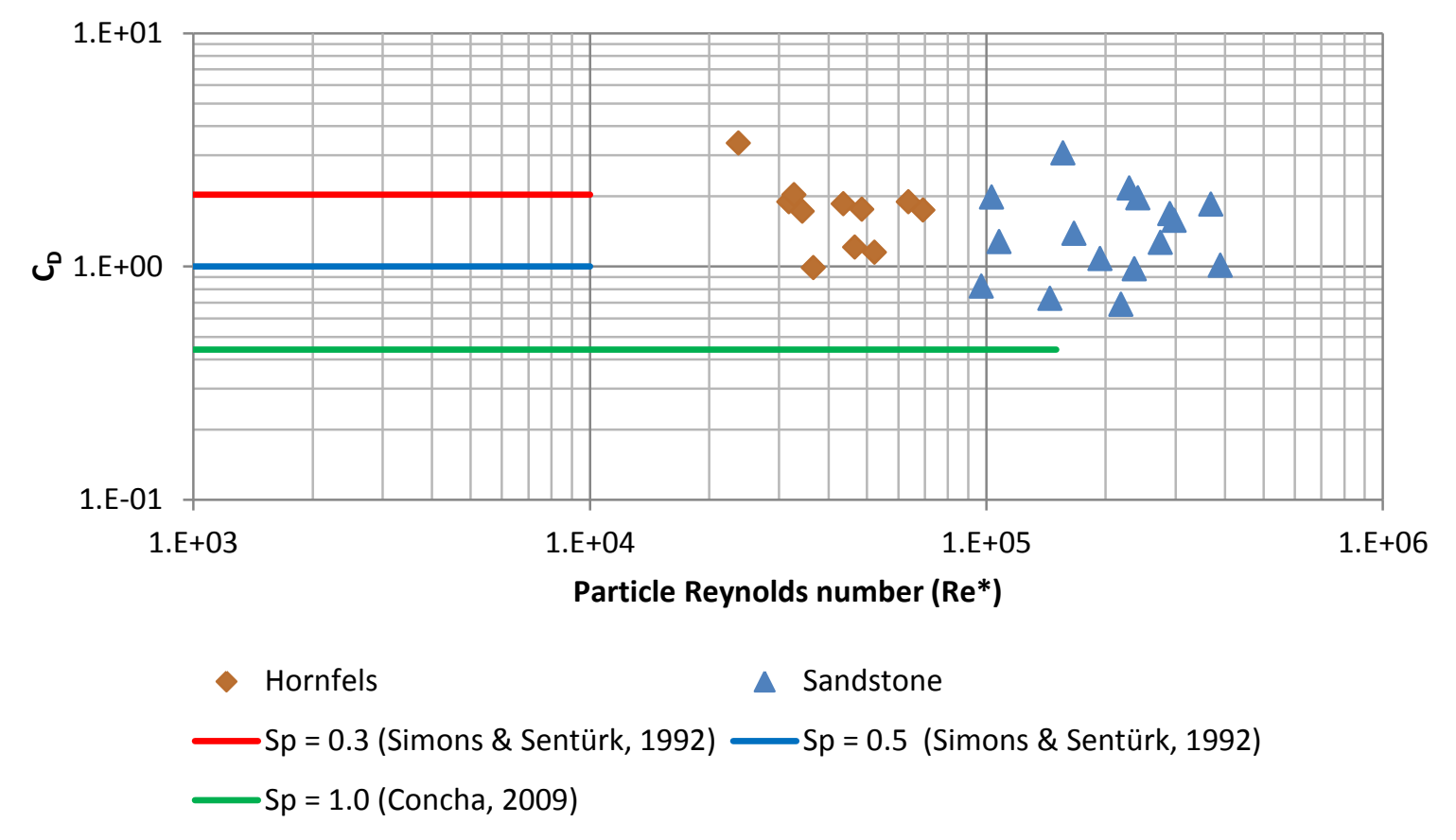

Figure 4-4: Experimental drag coefficient vs. particle Reynolds number

The laboratory data seems to confirm predictions in the literature. The shape factors of the particles plotted in Figure 4-4 vary between 0.31 and 0.86, with an average of 0.60.

It should be noted that the drag coefficients in the literature are limited to particle Reynold numbers which are less than needed for this investigation, as indicated in Figure 4-4.

Finally, a suitable shape factor for the riprap sample used in the riprap stability tests had to be selected. From the previous discussion it is clear that the shape factor is a vital component in determining a realistic drag coefficient, and thus an accurate settling velocity.

As shown in Figure 4-5, a definite relationship exists between Corey's Shape factor and the drag coefficient. In an attempt to obtain a representative shape factor, a trend line of the data points was fitted. 


\section{$C_{D}$ vs. shape factor}

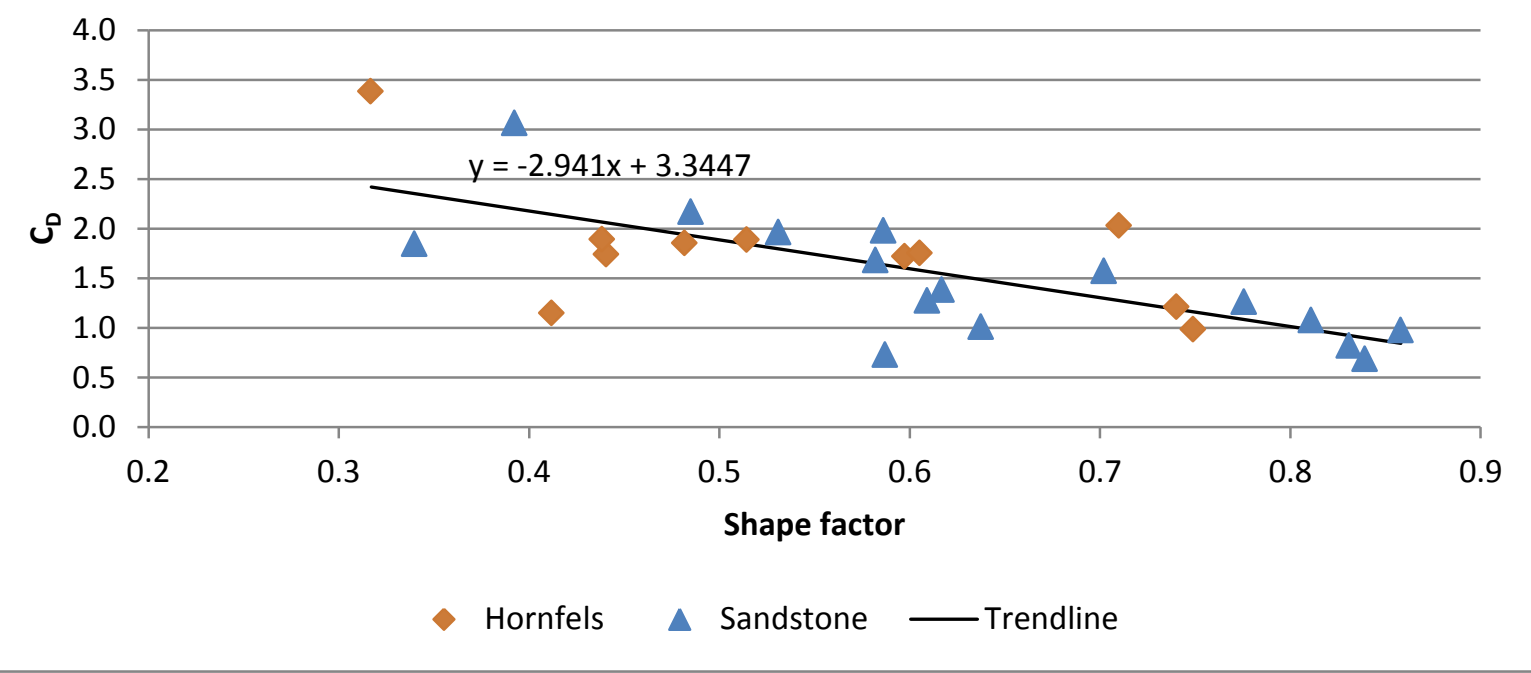

Figure 4-5: Experimental drag coefficient vs. shape factor

Figure 4-5 also provides evidence that the drag coefficient of the different rock types does not vary substantially. Thus, it seems acceptable to use the average shape factor of the 84 samples as being representative. The average shape factor of 82 samples is 0.58 , which yields a drag coefficient of 1.66 .

\subsection{Additional remarks}

The drag coefficient value obtained experimentally was found to be much larger than that used by Stoffberg (2005).

Following his analysis of a study conducted overseas, Stoffberg (2005) used a constant drag coefficient of 0.4 and obtained very satisfactory results when he plotted his data on the Liu diagram. In that study, crushed rock of comparable size was used, thus yielding similar particle Reynolds numbers. The hornfels used in the laboratory study were also obtained from crushed rock. Therefore, the assumption that the shape factors of both samples should be approximately equal holds. Thus, technically speaking, Stoffberg's drag coefficient was not correct.

However, Stoffberg's work is fundamentally different to this study in the sense that he used the $d_{50}$ rock size, whereas the $d_{90}$ was used here to calculate the settling velocity. In combination with the incorrect drag coefficient, his results were satisfactory. However, a suitable correction should be defined for this use. 
It is also important to note that Equation 2-8 was derived for particles of spherical shapes. Therefore, the mass and the exposed area of the particle are inaccurate when the equation is used for non-spherical particles (i.e. when $S_{p}<1$ ). 


\section{PHYSICAL MODEL DATA ANALYSIS}

The data collected in the laboratory was processed and is discussed in this section.

\subsection{Laboratory data}

The data obtained from the laboratory tests is set out in numerical and graphical formats in Appendix B1 and B2 respectively. A typical example from Appendix B2 is shown in Figure $5-1$.

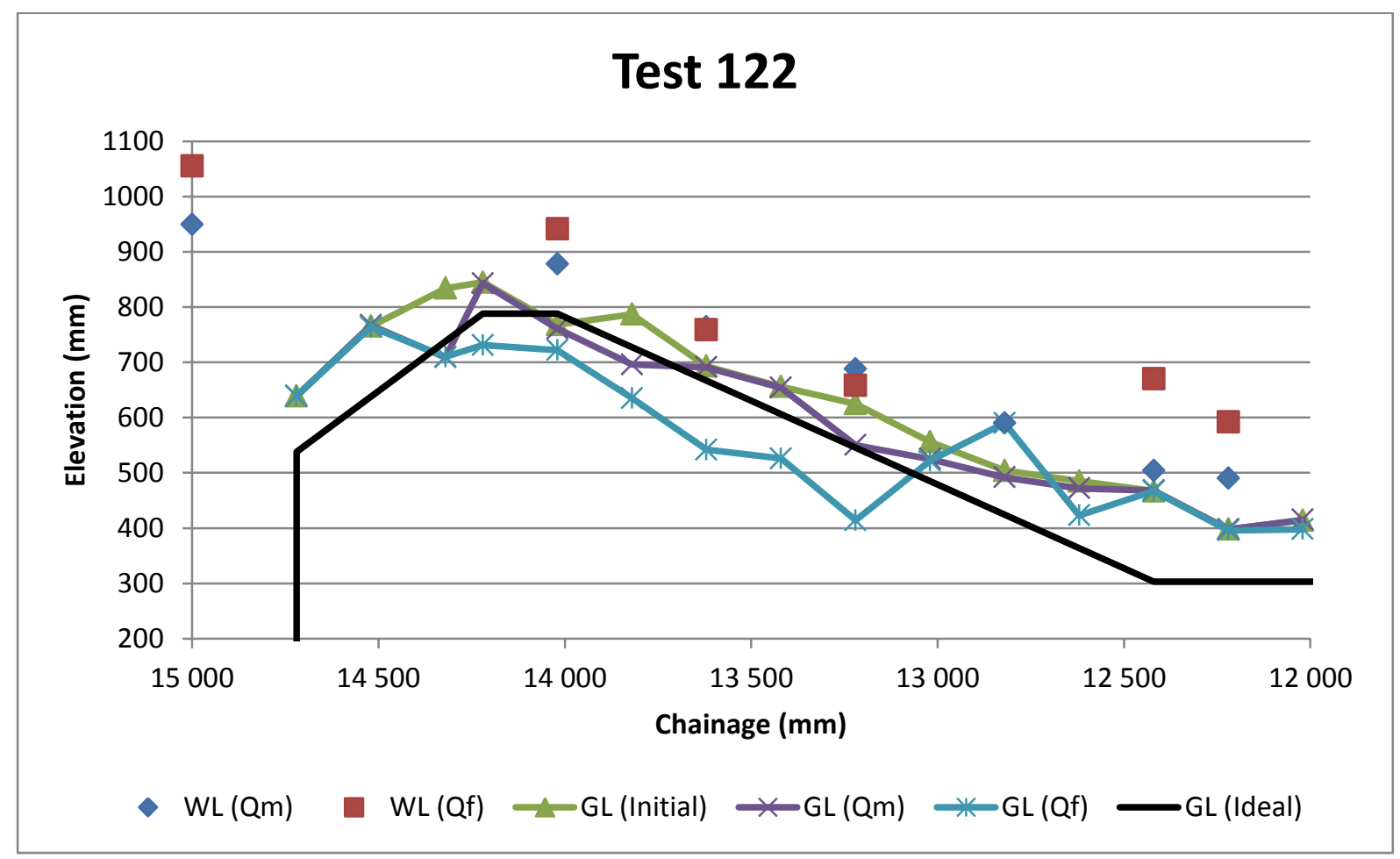

Figure 5-1: Typical laboratory test result

Water levels (WL) are shown for the respective flows as indicated in brackets. The surveyed riprap levels (GL) are also shown, and the flows after which the survey was done are indicated in brackets, with $Q_{m}$ being the flow at which the first movement of the riprap was observed, and $Q_{f}$ the flow at which failure occurred.

As expected, the initial survey generally plots above the $Q_{m}$ survey, since a small degree of erosion has already occurred at the time of the survey. The $Q_{f}$ survey obviously shows significantly more erosion, especially in the area just downstream of the crest. In most cases some deposition of material is evident in the outlet reach. 
At this point it must be noted that some difficulty was experienced in building a structure according to the dimensions originally intended. With the tests of the larger $d_{50}$ rocks in particular, it became increasingly difficult to achieve an acceptable shape of the structure, without compromising the local grading of the riprap. This problem was taken into account when the data was analysed.

During the laboratory tests it was often observed that rocks were dislodged at different locations along the length of the slope. The dislodged particles situated upstream rolled down the slope due to the loss of interlocking force at the toe of the mass, causing a deficit of material in the area upstream of the mass. Therefore failure was mostly observed in the area around the crest.

For the tests with larger diameter riprap, the point of failure was often not so immediately obvious. This is because smaller particles were dislodged, causing the geotextile to be exposed in a confined area. In such cases, the failure might not have been picked up by the survey, because the failure did not occur in the centre of the flume (where the structure was surveyed).

The discharges at which incipient motion occurred $\left(Q_{m}\right)$ and the discharges at which the structures failed $\left(Q_{f}\right)$ were recorded and are given in Table 5-1.

Table 5-1: Flow data

\begin{tabular}{|c|c|c|}
\hline Test & $Q_{m}(1 / \mathrm{s})$ & $Q_{f}(1 / \mathrm{s})$ \\
\hline 111 & 80.1 & 170.2 \\
\hline 121 & 74.8 & 95.4 \\
\hline 131 & 40.1 & 80.1 \\
\hline 211 & 111.3 & 175.5 \\
\hline 221 & 75.5 & 138.4 \\
\hline 231 & 60.3 & 80.8 \\
\hline 232 & 60.3 & 141.1 \\
\hline 222 & 100.0 & DNF \\
\hline 212 & 235.8 & DNF \\
\hline 132 & 58.9 & 141.1 \\
\hline 122 & 100.7 & 260.3 \\
\hline 112 & 170.9 & DNF \\
\hline
\end{tabular}

Due to the limited capacity of the pumps in the laboratory, the flow was not sufficient to cause failure of the structures in some cases, denoted as DNF (did not fail) in Table 5-1. 


\subsection{Parameters of the Liu diagram}

In Section 2.4.3, the background of the theory was explained. The laboratory data presented above was plotted on Liu's diagram to determine whether the theory holds for the given conditions.

In order to be able to plot a point on the diagram, the particle Reynolds number $\left(V^{*} d_{50} / v\right)$ and the Movability number $\left(V^{*} / V_{s s}\right)$ had to be evaluated. Due to the relatively large particle size, the Particle Reynolds number was expected to be large, implying highly turbulent flow in the vicinity of the particles. For large particle Reynold numbers, previous researchers found that the Movability Number was constant.

The kinematic viscosity (v) was taken as $1.13 \times 10^{-6} \mathrm{~m}^{2} / \mathrm{s}$, which corresponds to a water temperature of $15^{\circ} \mathrm{C}$. The determination of the settling velocity $\left(V_{s s}\right)$ was discussed in detail in Section 4.

The remaining parameters are discussed below.

\subsubsection{Flow depth}

In order to obtain the vertical position on the Liu diagram, the flow depth had to be determined. This was not an easy task, since the flow depth was relatively shallow and the flow is highly turbulent and non-uniform in nature due to the very high bed roughness.

The results of the surveys and the recorded water levels are shown in Appendix B. From these results, flow depths had to be determined which were representative of the flow conditions under which rock movement was initiated. The flow depth was calculated as the difference between the $Q_{m}$ Water Level and the post $-Q_{m}$ Ground Level.

The water levels just before the point of incipient motion were not available, only the ones after some erosion had already taken place (i.e. at $Q_{m}$ ). It was assumed that the erosion picked up in the post- $Q_{m}$ survey erosion was sufficiently small to not affect the readings of the $Q_{m}$ water levels excessively.

The flow depth was determined as follows: an area was identified where the erosion (or deposition) of material could be observed between the initial and the $Q_{m}$ survey. This 
indicated an unstable state of the particles in that vicinity of the model. The reader is referred to Appendix $\mathrm{C}$ for the exact location of these areas.

Where necessary, the water levels were interpolated linearly. To compensate for the slope of the structure, the flow depths were multiplied by $\cos \theta$, where $\theta$ is the representative slope of the structure after incipient motion was observed. Figure 5-2 shows these measurements schematically.

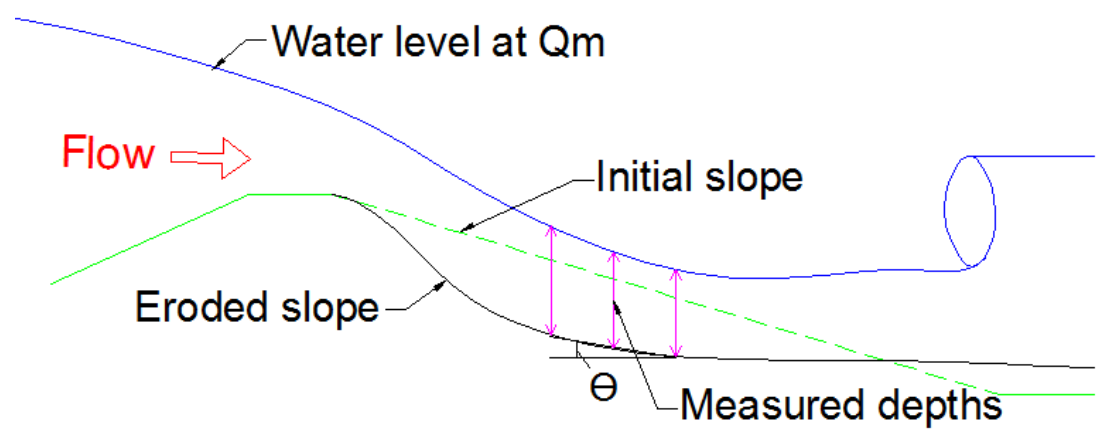

Figure 5-2: Exaggerated shape of structure just after incipient motion

As the discharge approaches critical conditions, isolated particles protruded from the slope and caused isolated water jets, which made the determination of the water level in that area meaningless for the purposes of this investigation. Therefore water levels could not always be measured at fixed intervals along the sloped part of the structure. Accordingly, the water level at another chainage (typically just up- or downstream) was measured together with the corresponding chainage.

In the case of a slightly fluctuating water surface, the minimum flow depth was measured. The flow depths along the length of the arrestor are given in Table 5-2. 
Table 5-2: Representative flow depths

\begin{tabular}{|c|c|c|c|c|c|c|c|c|c|c|}
\cline { 2 - 12 } \multicolumn{1}{c|}{} & \multicolumn{1}{|c|}{ Chainage $(\mathrm{mm})$} & \multicolumn{8}{|c|}{ Representative Flow depth $(\mathrm{m})$} \\
\hline Test & Begin & End & $\theta\left(^{\circ}\right)$ & 1 & 2 & 3 & 4 & 5 & Avg. $(\mathrm{m})$ & Std. dev \\
\hline 111 & 13620 & 13220 & 12.5 & 0.11 & 0.13 & 0.11 & & & 0.12 & 0.011 \\
\hline 121 & 14020 & 13820 & 20.1 & 0.06 & 0.09 & & & & 0.07 & 0.019 \\
\hline 131 & 14020 & 13620 & 26.6 & 0.03 & 0.02 & 0.05 & & & 0.03 & 0.018 \\
\hline 211 & 14020 & 13620 & 14.6 & 0.12 & 0.11 & 0.11 & & & 0.11 & 0.005 \\
\hline 221 & 13820 & 13420 & 15.2 & 0.08 & 0.10 & 0.10 & & & 0.10 & 0.010 \\
\hline 231 & 13520 & 13420 & 34.0 & 0.06 & 0.07 & & & & 0.07 & 0.013 \\
\hline 232 & 14020 & 13770 & 24.2 & 0.07 & 0.11 & 0.08 & & & 0.09 & 0.024 \\
\hline 222 & 14020 & 13520 & 15.1 & 0.11 & 0.11 & 0.11 & 0.08 & 0.09 & 0.10 & 0.014 \\
\hline 212 & 14020 & 13820 & 11.0 & 0.21 & 0.19 & & & & 0.20 & 0.010 \\
\hline 132 & 13220 & 12820 & 30.8 & 0.02 & 0.04 & 0.06 & & & 0.04 & 0.020 \\
\hline 122 & 13220 & 12820 & 8.3 & 0.14 & 0.11 & 0.10 & & & 0.12 & 0.020 \\
\hline 112 & 13420 & 13020 & 7.1 & 0.13 & 0.12 & 0.11 & & & 0.12 & 0.007 \\
\hline
\end{tabular}

As can be seen in Table 5-2, the flow depths were slightly inconsistent. This can be attributed to the turbulent flow conditions (and the consequent error in measuring the water level) and the effect of the uneven canal bed. Therefore, the average flow depth was used, rather than a single value.

\subsubsection{Energy slope}

It was not possible to determine a realistic energy gradient by using the laboratory data only. Taking into account the turbulent nature of the flow, the data was simply not sufficient to obtain representative velocities needed for the Energy equation.

During the analysis of the $Q_{m}$ laboratory data, it was found that the bed levels and the water levels in the critical areas were roughly parallel. At this point the reader is reminded that Liu assumed uniform flow conditions, implying that $S_{0}=S_{f}$.

In the light of the foregoing assumption, and the fact that the available data doesn't allow another more accurate method of calculating $S_{f}$, substituting the bed slope with the energy slope seems to be the best possible solution.

Thus, Equation 2-18 (to determine $V^{*}$ ) can be rewritten as

$$
V^{*}=\sqrt{g D S_{0}}
$$

Equation 5-1

The determination of a representative bed slope is described below. It was decided to utilise the data from the initial survey which represents the situation just before incipient motion occurred. 
In order to take into account the inaccurate construction of the arrestors, the slopes were taken as the best fit lines of the initial slopes of the structures. These are shown in Table 5-3.

Table 5-3: Average initial arrestor slopes

\begin{tabular}{|c|c|c|c|c|c|c|c|c|c|}
\hline & \multicolumn{2}{|c|}{ Chainage (mm) } & \multicolumn{6}{|c|}{ Equation of best fit line } & \multirow[b]{2}{*}{$R^{2}$} \\
\hline Test & Begin & End & $\mathrm{y}$ & $=$ & $S_{0}$ & $\mathrm{x}$ & + & $\mathrm{c}$ & \\
\hline 111 & 14020 & 12420 & $\mathrm{y}$ & $=$ & 0.1829 & $\mathrm{x}$ & + & -1852 & 0.94 \\
\hline 121 & 14020 & 12420 & 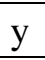 & $=$ & 0.2922 & $\mathrm{x}$ & 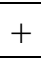 & -3351 & 0.97 \\
\hline 131 & 14020 & 12420 & $\mathrm{y}$ & $=$ & 0.3608 & $\mathrm{x}$ & + & -4323 & 0.98 \\
\hline 211 & 14020 & 13020 & $\mathrm{y}$ & $=$ & 0.1933 & $\mathrm{x}$ & + & -1963 & 0.97 \\
\hline 221 & 14020 & 13220 & $\mathrm{y}$ & $=$ & 0.2370 & $\mathrm{x}$ & $T$ & -2639 & 0.95 \\
\hline 231 & 14020 & 13020 & $\mathrm{y}$ & $=$ & 0.3920 & $\mathrm{x}$ & + & -4757 & 0.99 \\
\hline 232 & 14020 & 13020 & $\mathrm{y}$ & $=$ & 0.3870 & $\mathrm{x}$ & + & -4576 & 0.95 \\
\hline 222 & 14020 & 13020 & $\mathrm{y}$ & $=$ & 0.1495 & $\mathrm{x}$ & + & -1336 & 0.68 \\
\hline 212 & 14020 & 13020 & $\mathrm{y}$ & $=$ & 0.1951 & $\mathrm{x}$ & + & -1950 & 0.90 \\
\hline 132 & 14020 & 12420 & $\mathrm{y}$ & $=$ & 0.3564 & $\mathrm{x}$ & + & -4199 & 0.98 \\
\hline 122 & 14020 & 12420 & $\mathrm{y}$ & $=$ & 0.2157 & $\mathrm{x}$ & & -2235 & 0.97 \\
\hline 112 & 14020 & 12420 & $\mathrm{y}$ & $=$ & 0.2123 & $\mathrm{x}$ & + & -2138 & 0.96 \\
\hline
\end{tabular}

It should be noted that these slopes were not equal to the slopes at which the structures were originally intended to be constructed. The chainages shown indicate which sections of the structure could be considered as being sloped. For Test 221 the survey showed that the sloped part of the structure had already terminated at a length of $0.8 \mathrm{~m}$, and not at $1 \mathrm{~m}$ as shown in Table 3-1. This was purely a result of inaccurate construction.

The coefficient of determination $\left(R^{2}\right)$ for all the slopes was considered to be sufficiently close to 1 , indicating a good correlation between the best fit lines and the surveyed data points. Test 222, however, is the exception, due to a large irregularity of the bed.

\subsubsection{Correction for slope}

Due to the fact that the slopes were relatively steep, the values on the vertical axis were multiplied by the square root of the correction factors as given in Equation 2-32.

$$
\left(\frac{V *}{V_{s S}}\right)_{\beta, \alpha}=\sqrt{k_{\beta} k_{\alpha}}\left(\frac{V^{*}}{V_{s S}}\right)_{0}
$$

Equation 2-32

The factor $k_{\alpha}$ was taken as 1 , as there was no transverse slope in the structure. In Section 2.5 it was shown that $k_{\beta}$ is a function of the angle of repose and of the longitudinal slope of the canal. 
Table 5-4: Slope correction factors

\begin{tabular}{|c|c|c|c|c|}
\hline Test & $S_{f}(\mathrm{~m} / \mathrm{m})$ & $\beta(\mathrm{rad})$ & $k_{\beta}$ & $\sqrt{ } k_{\beta}$ \\
\hline 111 & 0.183 & 0.18 & 0.77 & 0.88 \\
\hline 121 & 0.292 & 0.28 & 0.63 & 0.79 \\
\hline 131 & 0.361 & 0.35 & 0.54 & 0.73 \\
\hline 211 & 0.193 & 0.19 & 0.76 & 0.87 \\
\hline 221 & 0.237 & 0.23 & 0.70 & 0.84 \\
\hline 231 & 0.392 & 0.37 & 0.50 & 0.70 \\
\hline 232 & 0.387 & 0.37 & 0.52 & 0.72 \\
\hline 222 & 0.150 & 0.15 & 0.82 & 0.90 \\
\hline 212 & 0.195 & 0.19 & 0.76 & 0.87 \\
\hline 132 & 0.356 & 0.34 & 0.56 & 0.75 \\
\hline 122 & 0.216 & 0.21 & 0.73 & 0.86 \\
\hline 112 & 0.212 & 0.21 & 0.74 & 0.86 \\
\hline
\end{tabular}

The magnitude of the correction factors should be noted; in practice these factors should not be disregarded, since they can reduce the Movability Number by up to $30 \%$.

\subsubsection{Settling velocity}

The equation for settling velocity was given in Equation 2-8.

$$
V_{S S}^{2}=\frac{4}{3}\left(\frac{\rho_{r}-\rho_{w}}{\rho_{w}}\right) \frac{d g}{C_{D}}
$$

Equation 2-8

The parameters have been defined as discussed above, whereas the choice of a representative rock diameter $(d)$ for the sample has not been discussed so far.

In Section 6.3.1 it is shown that there are indications that the larger particles in the grading dictate the stability of the riprap, due to hiding and exposure of particles. Therefore it makes sense to use a larger diameter than the $d_{50}$ in the equation. It was decided to use the $d_{90}$ value of the grading as the representative sieve size in Equation 2-8.

Using the experimental data for the rock density and the drag coefficient of 1.66 as described in Section 4.3, the settling velocities were calculated as shown in Table 5-5. 
Table 5-5: Settling velocity

\begin{tabular}{|c|c|c|c|c|}
\hline Sample & $d_{90}(\mathrm{~m})$ & $\Delta$ & $C_{D}$ & $V_{s s}(\mathrm{~m} / \mathrm{s})$ \\
\hline 1 & 0.124 & 1.66 & 1.66 & 1.27 \\
\hline 2 & 0.185 & 1.66 & 1.66 & 1.56 \\
\hline
\end{tabular}

\subsubsection{Liu plot}

The necessary parameters were processed so that they could be plotted on the Liu diagram.

Table 5-6 summarises the data.

Table 5-6: Parameters for Liu diagram

\begin{tabular}{|c|c|c|c|c|c|c|c|c|c|c|}
\hline Test & $\begin{array}{c}Q_{m} \\
(1 / \mathrm{s})\end{array}$ & $\begin{array}{c}S_{f} \\
(\mathrm{~m} / \mathrm{m})\end{array}$ & $\begin{array}{c}\text { Avg. } \\
D(\mathrm{~m})\end{array}$ & $\begin{array}{c}V_{s s} \\
(\mathrm{~m} / \mathrm{s})\end{array}$ & $C_{D}$ & $\begin{array}{c}V^{*} \\
(\mathrm{~m} / \mathrm{s})\end{array}$ & $\sqrt{ }_{\beta}$ & $d_{90}(\mathrm{~m})$ & $\begin{array}{c}\sqrt{k_{\beta} V^{*}} \\
V_{s s}\end{array}$ & $V^{*} d_{50} / v$ \\
\hline 111 & 80.1 & 0.183 & 0.119 & 1.27 & 1.66 & 0.46 & 0.88 & 0.124 & 0.32 & 50655 \\
\hline 121 & 74.8 & 0.292 & 0.072 & 1.27 & 1.66 & 0.45 & 0.79 & 0.124 & 0.28 & 49744 \\
\hline 131 & 40.1 & 0.361 & 0.032 & 1.27 & 1.66 & 0.34 & 0.73 & 0.124 & 0.19 & 37045 \\
\hline 211 & 111.3 & 0.193 & 0.115 & 1.27 & 1.66 & 0.47 & 0.87 & 0.124 & 0.32 & 51181 \\
\hline 221 & 75.5 & 0.237 & 0.095 & 1.27 & 1.66 & 0.47 & 0.84 & 0.124 & 0.31 & 51573 \\
\hline 231 & 60.3 & 0.392 & 0.065 & 1.27 & 1.66 & 0.50 & 0.70 & 0.124 & 0.28 & 54942 \\
\hline 232 & 60.3 & 0.387 & 0.087 & 1.56 & 1.66 & 0.57 & 0.72 & 0.185 & 0.27 & 93957 \\
\hline 222 & 100.0 & 0.150 & 0.099 & 1.56 & 1.66 & 0.38 & 0.90 & 0.185 & 0.22 & 62263 \\
\hline 212 & 235.8 & 0.195 & 0.198 & 1.56 & 1.66 & 0.62 & 0.87 & 0.185 & 0.35 & 100776 \\
\hline 132 & 58.9 & 0.356 & 0.043 & 1.56 & 1.66 & 0.39 & 0.75 & 0.185 & 0.18 & 63138 \\
\hline 122 & 100.7 & 0.216 & 0.115 & 1.56 & 1.66 & 0.49 & 0.86 & 0.185 & 0.27 & 80922 \\
\hline 112 & 170.9 & 0.212 & 0.118 & 1.56 & 1.66 & 0.50 & 0.86 & 0.185 & 0.27 & 81188 \\
\hline
\end{tabular}

As expected, the Particle Reynold numbers are relatively high $\left(R e^{*}>37000\right)$. This data was plotted on the Liu diagram and is shown in Figure 5-3 and Figure 5-4. 


\section{Liu diagram}

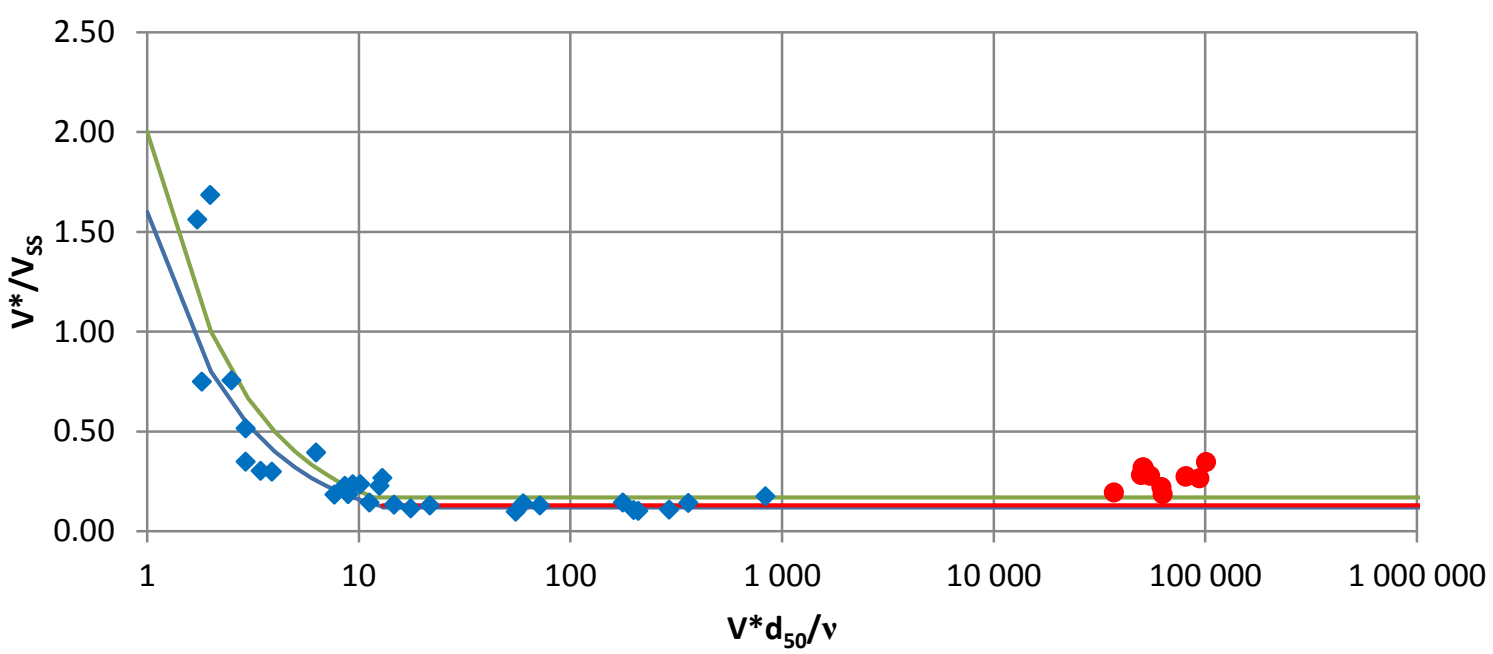

Rooseboom (1992)

- Armitage(2002)

Stoffberg (2005)

- Experimental data (Yang, 1973)

- Experimental data (This thesis)

Figure 5-3: Liu diagram with experimental data

A detailed plot of the tail end of Figure 5-3 is shown below.

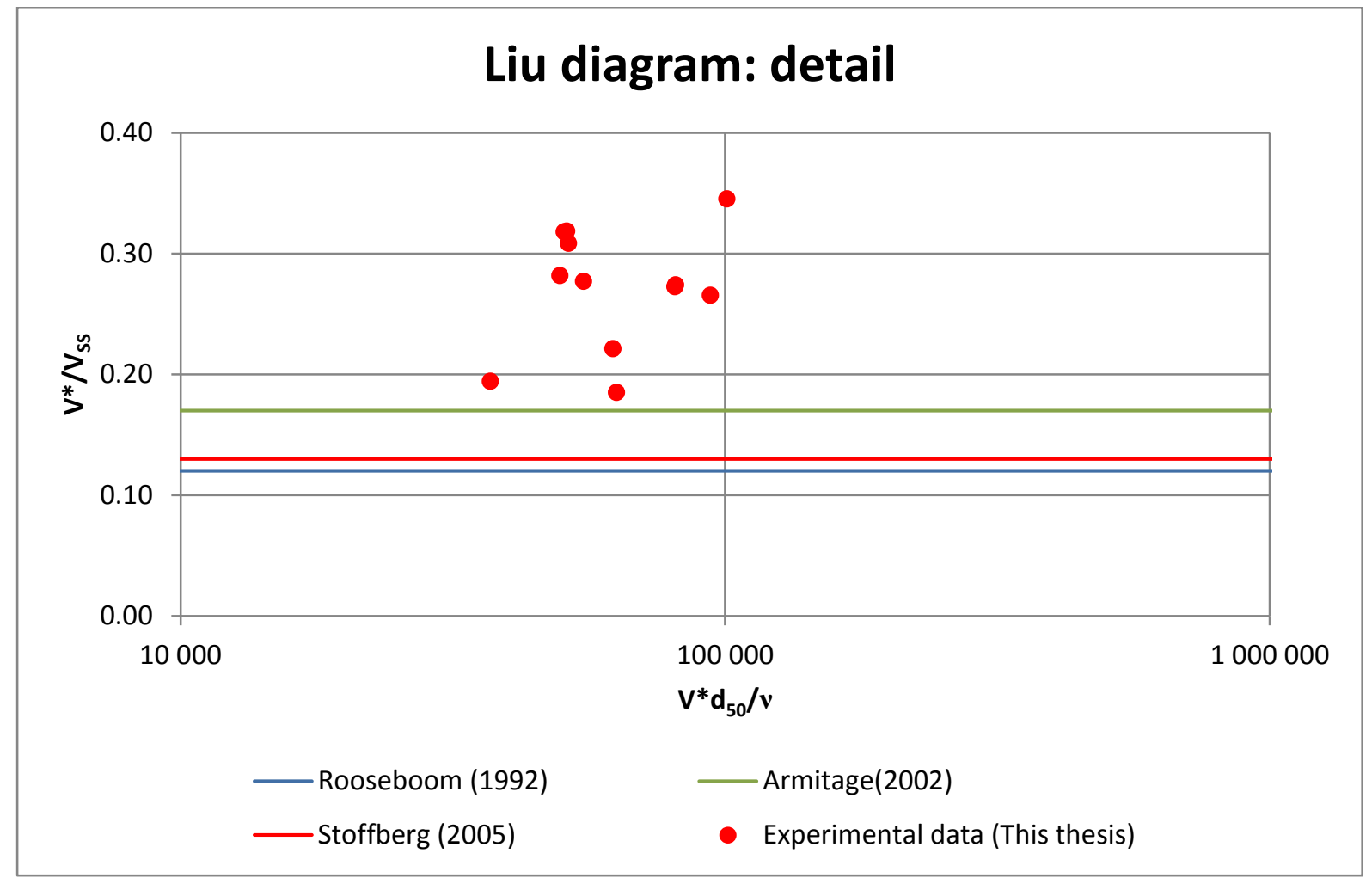

Figure 5-4: Liu diagram with experimental data (detailed) 
It should be noted that the laboratory measurements were taken close to, but probably not at the exact point of incipient motion. In fact, they were taken when the particles were already in an unstable state. Therefore, most of the data points plotted slightly higher than the values recommended by the various researchers.

At this point, it can be concluded that Liu's theory probably holds for the riprap placed in the laboratory. These laboratory conditions can be summarised as follows:

- $\quad$ steep slopes (between 0.18 and $0.36 \mathrm{~m} / \mathrm{m}$ );

- highly turbulent flow $\left(R e^{*}>37000\right)$; and

- non-uniform flow conditions.

For design purposes, the lowest observed Movability Number is applicable, since at this point the particles are the closest to incipient motion. Thus, a value of 0.18 is recommended. This corresponds almost exactly to the findings of Armitage (2002), who recommended a value of 0.17 .

\subsection{Comparison of incipient motion criteria of common design practices}

In Section 2.9 of this thesis, a number of guidelines from the available literature were to predict the stability of riprap. The literature study indicated that great uncertainty exists around existing incipient motion models. Therefore it was deemed necessary to compare the answers of different methods and see how they compare with the laboratory data.

Typically, the design equations yield a minimum $d_{50}$ rock size, given a certain flow condition. The continuity equation $(Q=V A)$ was utilised, using the observed $Q_{m}$ flows and the corresponding observed water depths.

An error was also calculated, which quantifies the difference between the maximum stable discharge predicted by the various theories and the laboratory findings (expressed as a percentage).

In order to keep the results comparable, no safety factors were incorporated in the calculations. 


\subsubsection{General Design Equation (CIRIA et al., 2007)}

CIRIA et al. (2007) recommends (amongst others) the General Design Equation (given as Equation 2-41) which is in essence a combination of Shields's and Izbash's theories.

$$
\frac{V^{2} / 2 g}{\Delta d}=k_{\beta} k_{\alpha} k_{t}^{-2} k_{w}^{-1} \Lambda_{h} \psi_{c r}
$$

Equation 2-41

The relative rock density $(\Delta)$ is given as

$$
\Delta=\frac{\rho_{a p p}}{\rho_{w}}-1
$$

Equation 2-3

It is reasonable to assume that $\rho_{a p p} \sim \rho_{r}=2700 \mathrm{~kg} / \mathrm{m}^{3}$, since the riprap was submersed in water for a short time only. Also, the density of water $\left(\rho_{w}\right)$ can be taken as $1000 \mathrm{~kg} / \mathrm{m}^{3}$. Therefore, $\Delta=1.7$.

Correction for the slope is incorporated in the factors $k_{\alpha}$ and $k_{\beta}$. Since the arrestors were not sloped in the transverse direction, $k_{\alpha}=1$. The values for $k_{\beta}$ are based on the initial slopes given in Table 5-3.

The correction factor for turbulence $\left(k_{t}\right)$ is included in the General Design Equation and is evaluated using Equation 2-33.

$$
k_{t}=\frac{1+3 r}{1.3}
$$

Equation 2-33

The turbulence intensity $(r)$ is very difficult (if not impossible) to determine analytically. CIRIA et al. (2007) recommend a value of 0.15 for a rough bed. According to CIRIA et al. (2007), this can be described as normal turbulence.

However, judging from the laboratory observations, the flow appeared to be very turbulent. Other descriptions of the condition, such as those presented in Table 2-4, do not seem applicable to the given problem. To make provision for the elevated turbulence, a value of 0.2 was selected. Equation 2-33 thus equals to 1.23.

The wave amplification factor was taken as unity, as per CIRIA et al. (2007).

The velocity profile factor is once again a difficult parameter to estimate. The layout of the laboratory was supposed to be sufficiently long for the flow to develop fully. Also, the flow 
depth was rather shallow; since $D / k_{s}$ was mostly $<2$ and therefore Equation $2-38$ was substituted.

$$
\Lambda_{h}=\frac{18^{2}}{2 g} \log ^{2}\left(1+\frac{12 D}{k_{s}}\right)
$$

Equation 2-38

The applicable roughness is largely a debate: CIRIA et al. (2007) recommends a roughness in the range of 1 to $3 d_{50}$. A bed roughness equal to the $d_{50}$ seems realistic, but is expected to be larger, as is discussed in Section 6.3.1 below. Therefore, both extremes were evaluated with Equation 2-41.

Finally, Shields's parameter had to be selected as described in Section 2.4.2. A critical value of around 0.035 was used to estimate the point at which the stones begin to move, which corresponds exactly to the methodology used for the first part of the laboratory testing.

Table 5-7 shows the parameters for Equation 2-41 as well as the predicted flow $\left(Q_{m}\right)$ at which this equation predicts that movement would occur. Also shown are the flows at which movement was observed in the laboratory, as well as the prediction errors.

Table 5-7: General Design Equation prediction

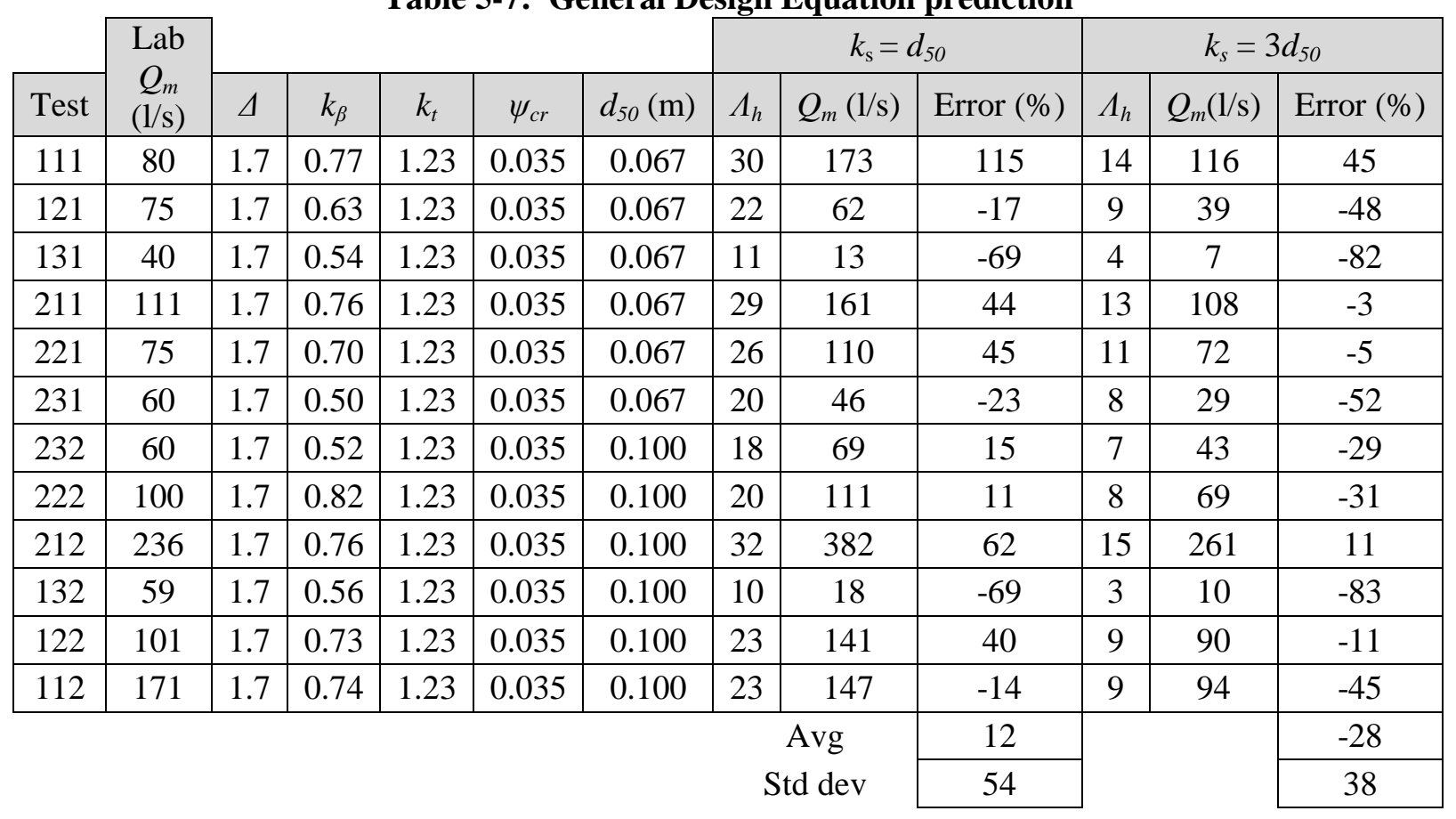

The error (in comparison to the measured $Q_{m}$ ) is shown. Negative values imply that the General Design Equation yields conservative results. Judging by the magnitude of the error, the results for $k_{s}=3 d_{50}$ deliver slightly better results. In general however, there is not good 
agreement between the laboratory findings and the prediction of the General Design Equation.

\subsubsection{Pilarcyk design criteria}

Pilarczyk proposed Equation 2-42:

$$
d_{n 50}=\frac{\phi_{s c}}{\Delta} \frac{0.035}{\psi_{c r}} k_{h}\left(k_{\alpha} k_{\beta}\right)^{-1} k_{t}^{2} \frac{V^{2}}{2 g}
$$

The parameters are the same as for the General Design Equation, with the exception of the introduction of $\phi_{s c}$, which corrects for inevitable transitions introduced when consecutive layers of riprap are placed on top of each other.

Due to the geometry of the arrestors and the descriptions presented in Table 2-6, the most applicable one is probably the "exposed edges of gabions". Therefore, a value for $\phi_{s c}$ of 1 is applicable, as the condition near the upstream and downstream ends of the sloped part of the arrestor can presumably resemble an exposed edge.

The velocity profile factor to be used in conjunction with the Pilarcyk's design criteria is expressed in terms of the factor $k_{h}$, which is given by $k_{h}=33 / \Lambda_{h}$.

Furthermore, CIRIA et al. (2007) recommend that the median characteristic size of the riprap $\left(d_{n 50}\right)$ can be represented by $0.84 d_{50}$.

Equation 2-42 was evaluated and the results are presented in Table 5-8. Again, due to the uncertainty associated with the choice of the roughness, two cases were evaluated. 
Table 5-8: Pilarczyk prediction

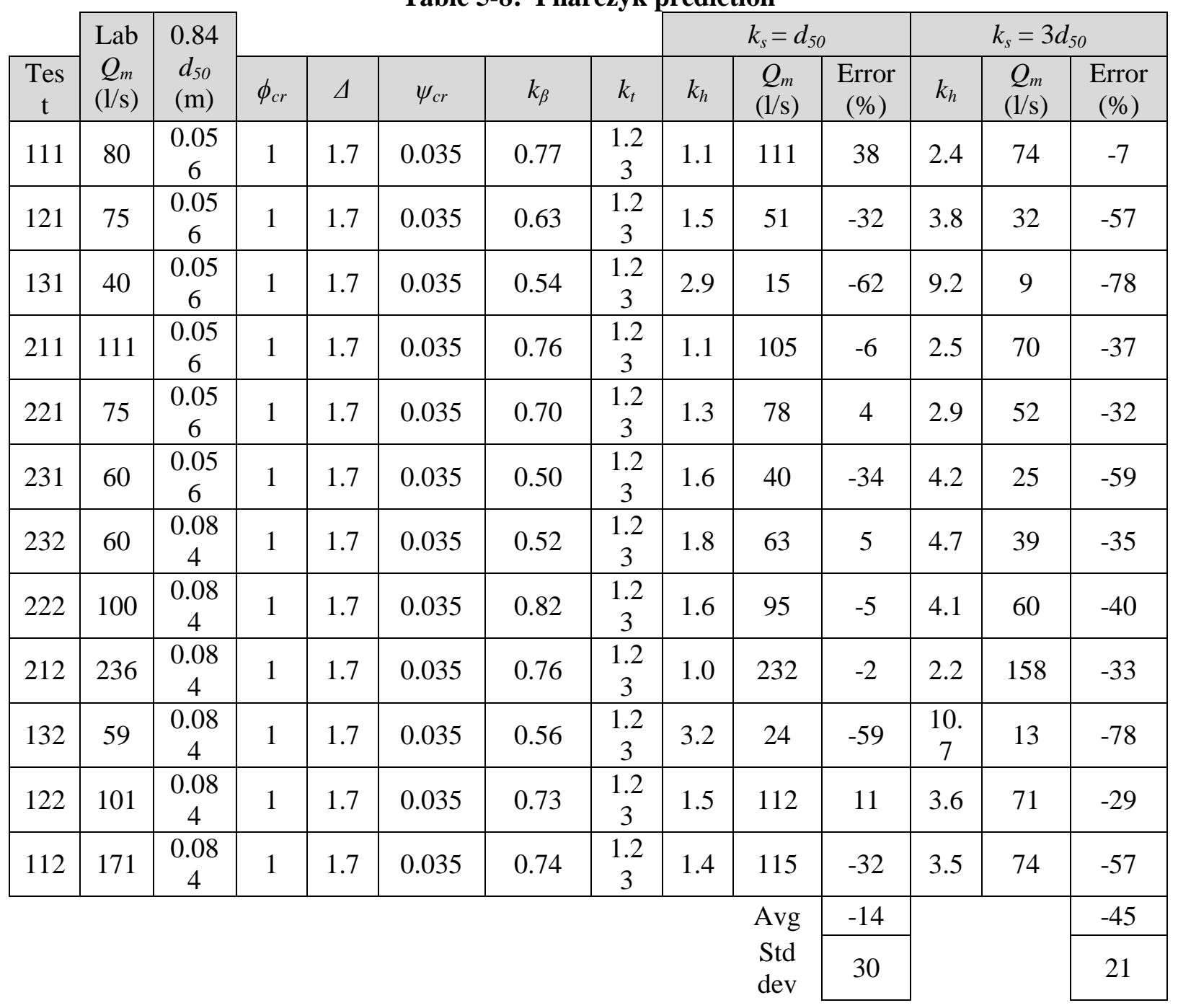

By inspection, the $k_{h}$ values appear to be quite high for the case where $k_{s}=3 d_{50}$. It must be kept in mind that these values function as a correction factor and should be in the vicinity of 1. The velocity profile correction factors for the case of $k_{s}=d_{50}$ seem more realistic.

It is also evident that, in general, conservative results with a comparatively small standard deviation were obtained, implying that the results are somewhat consistent.

Judging by the standard deviation of the error, the Pilarzyk design equation (Table 5-8) seems to yield slightly more consistent results than the General Design Equation (Table 5-7). The case where a roughness of $k_{s}=3 d_{50}$ assumed is a very conservative assumption and will probably yield a safe design. The maximum stable flows would be between 7 and $57 \%$ larger than designed for. 


\subsubsection{Escarameia and May's design equation}

Escarameia \& May (1992) adapted Izbash's equation for highly turbulent flow, given as Equation 2-43.

$$
d_{n 50}=C_{t} \frac{V_{b}^{2}}{2 g \Delta}
$$

Equation 2-43

Whether the flow over the arrestors can be classified as highly turbulent is questionable, since such classification inevitably requires subjective judgement. Nevertheless, the equation is said to have been successfully applied in a variety of areas with steep slopes. Also, the method is known to produce rather conservative results (CIRIA et al., 2007).

It is also important to note that the equation has only been tested against slopes not steeper than 1:2 and flow depths between 1 and $4 \mathrm{~m}$. The latter criterion is not met, since the observed flow depths in the laboratory ranged between 0.03 and $0.18 \mathrm{~m}$.

The factor $C_{t}$ (termed the turbulence coefficient) is given by Equation 2-44, which is a function of the turbulence intensity $(r)$. Previously, $r$ was estimated to be 0.2 and therefore Equation 2-44 evaluates to 2.26.

Finally, near bed velocity has to be determined. This velocity should be evaluated at $0.1 D$ above the bed. Theoretically a logarithmic flow distribution can be fitted (using Equation 234). However CIRIA et al. (2007) suggest that $V_{b} \sim 0.9 \mathrm{~V}$ should be used in cases where detailed data is lacking. For the purpose of this analysis, the latter approach was followed.

Table 5-9 summarises the predictions of the method. 
Table 5-9: Escarameia and May prediction

\begin{tabular}{|c|c|c|c|c|c|c|c|c|}
\hline Test & $\begin{array}{l}\text { Lab. } Q_{m} \\
\quad(1 / \mathrm{s})\end{array}$ & $C_{T}$ & $d_{50}(\mathrm{~m})$ & $\Delta$ & $D(\mathrm{~m})$ & $V_{b}(\mathrm{~m} / \mathrm{s})$ & $Q_{m}(1 / \mathrm{s})$ & $\begin{array}{c}\text { Error } \\
(\%)\end{array}$ \\
\hline 111 & 80 & 2.26 & 0.067 & 1.7 & 0.119 & 1.23 & 131 & 64 \\
\hline 121 & 75 & 2.26 & 0.067 & 1.7 & 0.072 & 1.23 & 79 & 6 \\
\hline 131 & 40 & 2.26 & 0.067 & 1.7 & 0.032 & 1.23 & 36 & -11 \\
\hline 211 & 111 & 2.26 & 0.067 & 1.7 & 0.115 & 1.23 & 127 & 14 \\
\hline 221 & 75 & 2.26 & 0.067 & 1.7 & 0.095 & 1.23 & 105 & 39 \\
\hline 231 & 60 & 2.26 & 0.067 & 1.7 & 0.065 & 1.23 & 72 & 20 \\
\hline 232 & 60 & 2.26 & 0.100 & 1.7 & 0.087 & 1.50 & 117 & 94 \\
\hline 222 & 100 & 2.26 & 0.100 & 1.7 & 0.099 & 1.50 & 133 & 33 \\
\hline 212 & 236 & 2.26 & 0.100 & 1.7 & 0.198 & 1.50 & 267 & 13 \\
\hline 132 & 59 & 2.26 & 0.100 & 1.7 & 0.043 & 1.50 & 57 & -3 \\
\hline 122 & 101 & 2.26 & 0.100 & 1.7 & 0.115 & 1.50 & 156 & 55 \\
\hline 112 & 171 & 2.26 & 0.100 & 1.7 & 0.118 & 1.50 & 159 & -7 \\
\hline \multirow{2}{*}{112} & & & & & & & Avg & 26 \\
\hline & & & & & & & Std dev & 32 \\
\hline
\end{tabular}

Considering the fact that the equation has been applied well beyond its recommended boundaries, this method yields reasonably acceptable results. However, the method is extremely sensitive to potential inaccuracies in the estimation of the near bed velocity, since the term is raised to the power of two in Equation 2-44.

\subsubsection{Maynord's method}

Maynord's (1995) approach to estimate the stability of riprap is unique in the sense that Equation 2-49 is based on the idea of not allowing the underlying material to be exposed.

$$
d_{50}=f_{g}^{0.32} S_{F} C_{s t} C_{v} C_{T} D\left(\frac{1}{\sqrt{\Delta}} \frac{V}{\sqrt{k_{s l} g D}}\right)^{2.5}
$$

Equation 2-45

The gradation factor $\left(f_{g}\right)$ is given as $d_{85} / d_{15}$ which is obtained from Figure 3-6 for the respective samples. The values of $f_{g}$ for the respective samples are equal to 3.58 .

CIRIA et al. (2007) recommend that a safety factor $\left(S_{F}\right)$ of at least 1.1 is used. However, it was taken as unity, for reasons mentioned previously.

The stability coefficient $\left(C_{s t}\right)$ of between 0.3 and 0.375 should be selected, depending on the angularity of the material. A larger value is needed for decreasing angularity. The riprap 
sample used in the laboratory consists of a mix of slightly and moderately angular rock. Thus, a value of 0.35 seems applicable.

Similar to the previous methods, the velocity distribution is also taken into account using the factor $C_{v}$. Maynord et al. (1989) recommends a value of 1 for straight channels.

The riprap thickness coefficient $\left(C_{T}\right)$ is given as unity in the CIRIA et al. (2007) design guidelines, since it yields the most conservative answer. However, Maynord (1995) and the Riprap Design and Construction Guide (Province of British Columbia Ministry of Environment, Lands and Parks , 2000) show that $C_{T}$ can be determined more accurately using Figure 5-5.

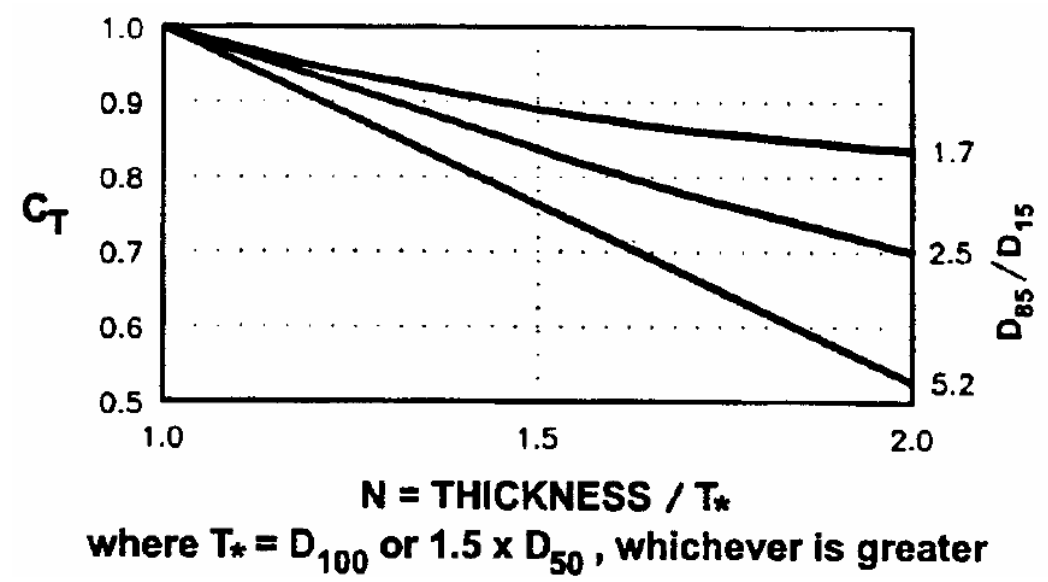

Figure 5-5: Layer thickness coefficient (Province of British Columbia Ministry of Environment, Lands and Parks , 2000)

With the riprap layer thickness of the laboratory setup being $2.5 d_{50}$ and $d_{100}=2 d_{50}, \mathrm{~N}$ evaluates to 1.25. The ratio $d_{85} / d_{15}$ can be determined from Figure 3-6 and is equal to 3.7. Thus, $C_{T}=0.9$.

Finally, the slope factor $\left(k_{s l}\right)$ can also be taken as unity, since arrestors are rectangular in section. Interestingly, the slope factor does not take the longitudinal slope into consideration. According to Maynord et al. (1989), the conventional factors $k_{\alpha}$ and $k_{\beta}$ give results that are too conservative. 
Table 5-10: Maynord stability prediction

\begin{tabular}{|c|c|c|c|c|c|c|c|c|c|c|c|c|c|}
\hline \multirow{2}{*}{ Test } & \multirow{2}{*}{$\begin{array}{c}\text { Lab. } \\
Q_{m} \\
(1 / s)\end{array}$} & & & & & & & & & & & & \\
\hline & & $\begin{array}{l}d_{50} \\
(\mathrm{~m})\end{array}$ & $f_{g}$ & $S_{F}$ & $C_{s t}$ & $C_{v}$ & $C_{T}$ & $\begin{array}{c}D \\
(\mathrm{~m})\end{array}$ & $\Delta$ & $k_{s l}$ & $\begin{array}{c}V \\
(\mathrm{~m} / \mathrm{s})\end{array}$ & $Q_{m}(1 / \mathrm{s})$ & $\begin{array}{c}\text { Error } \\
(\%)\end{array}$ \\
\hline 111 & 80 & 0.067 & 3.58 & 1 & 0.35 & 1 & 0.9 & 0.12 & 1.7 & 1 & 1.51 & 179 & 124 \\
\hline 121 & 75 & 0.067 & 3.58 & 1 & 0.35 & 1 & 0.9 & 0.07 & 1.7 & 1 & 1.43 & 103 & 37 \\
\hline 131 & 40 & 0.067 & 3.58 & 1 & 0.35 & 1 & 0.9 & 0.03 & 1.7 & 1 & 1.32 & 43 & 6 \\
\hline 211 & 111 & 0.067 & 3.58 & 1 & 0.35 & 1 & 0.9 & 0.11 & 1.7 & 1 & 1.50 & 173 & 55 \\
\hline 221 & 75 & 0.067 & 3.58 & 1 & 0.35 & 1 & 0.9 & 0.10 & 1.7 & 1 & 1.48 & 140 & 86 \\
\hline 231 & 60 & 0.067 & 3.58 & 1 & 0.35 & 1 & 0.9 & 0.07 & 1.7 & 1 & 1.42 & 93 & 54 \\
\hline 232 & 60 & 0.100 & 3.58 & 1 & 0.35 & 1 & 0.9 & 0.09 & 1.7 & 1 & 1.72 & 149 & 147 \\
\hline 222 & 100 & 0.100 & 3.58 & 1 & 0.35 & 1 & 0.9 & 0.10 & 1.7 & 1 & 1.74 & 171 & 71 \\
\hline 212 & 236 & 0.100 & 3.58 & 1 & 0.35 & 1 & 0.9 & 0.20 & 1.7 & 1 & 1.86 & 369 & 57 \\
\hline 132 & 59 & 0.100 & 3.58 & 1 & 0.35 & 1 & 0.9 & 0.04 & 1.7 & 1 & 1.60 & 68 & 15 \\
\hline 122 & 101 & 0.100 & 3.58 & 1 & 0.35 & 1 & 0.9 & 0.12 & 1.7 & 1 & 1.77 & 204 & 103 \\
\hline 112 & 171 & 0.100 & 3.58 & 1 & 0.35 & 1 & 0.9 & 0.12 & 1.7 & 1 & 1.77 & 209 & 22 \\
\hline & & & & & & & & & & & & Avg & 65 \\
\hline & & & & & & & & & & & & Std dev & 44 \\
\hline
\end{tabular}

The results clearly indicate that Maynord's equation yields overly non-conservative results. Table 5-10 clearly shows that Maynord's method yields unacceptable results, since the method generally overestimates the stability of the riprap, possibly resulting in the design of unstable riprap.

\subsection{5. $\quad$ Empirical approaches}

A number of empirical approaches were presented and discussed in the literature study. These expressions are in the form of a statistical regression, and only depend on the unit discharge, the median rock diameter and the slope of the structure.

The slope used for these equations was taken as the best fit straight line of the initial structure. The results are presented in a tabular format below: 
Table 5-11: Empirical methods to estimate riprap stability

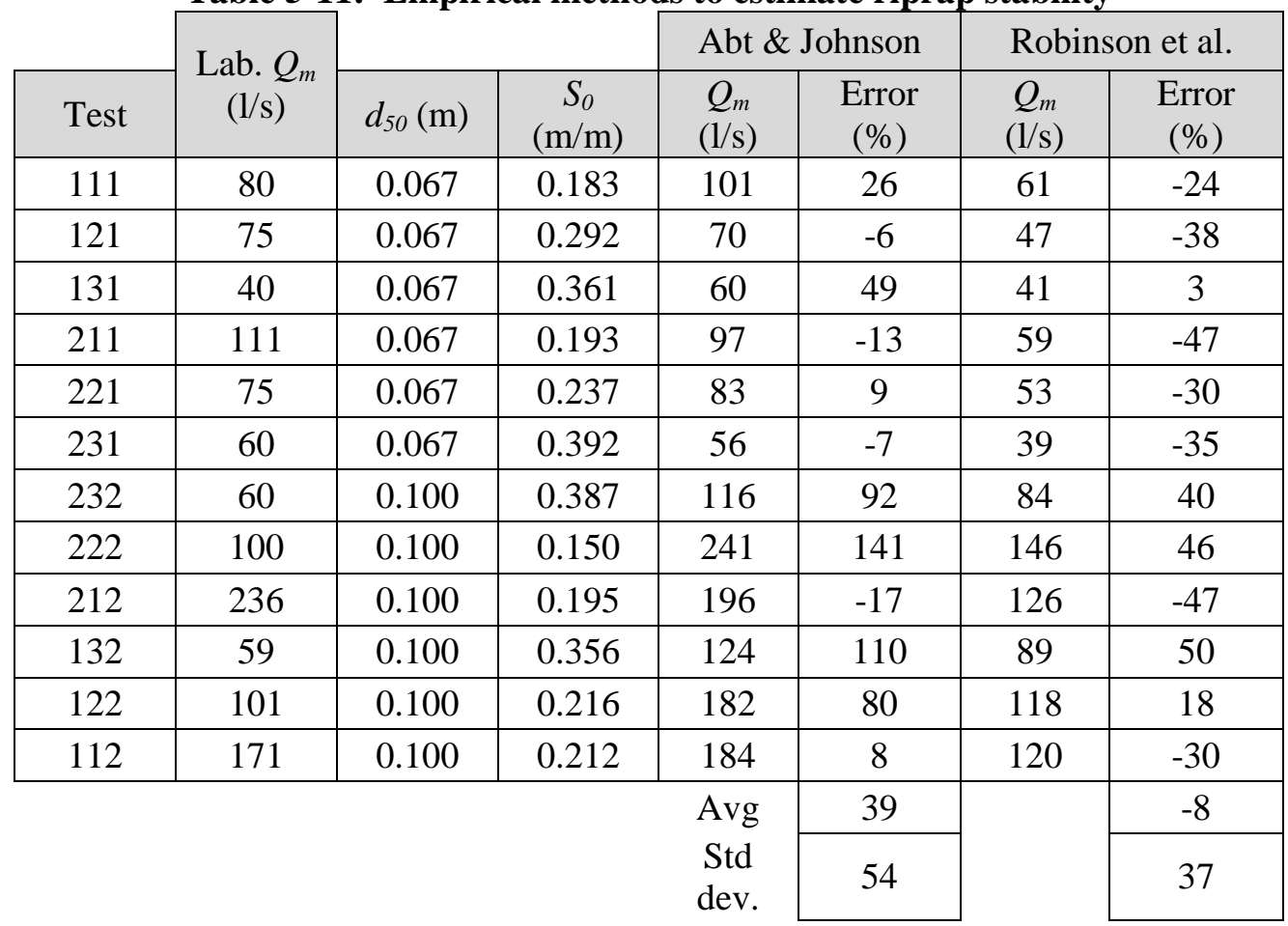

Both Abt and Johnson (1991) and Robinson et al.'s (1998) equations produced rather disappointing results, especially when considering the extensive testing that preceded the development of these equations. Unfortunately, the results were not interpreted in terms of the theoretical background. Therefore, considerable scatter of the data is expected.

\subsubsection{Shields's criteria (SANRAL, 2013)}

As discussed thoroughly in Section 2.9.6, SANRAL's approach is based on Shields's approach of incipient motion.

The bed slope $\left(S_{0}\right)$ is needed for the SANRAL methods. Since this comparison is aimed at representing the results of a practical design, it was decided to use the best fit initial slope as $S_{0}$.

The results are shown in Table 5-12. 
Table 5-12: Shields's stability prediction, as stipulated by SANRAL (2013)

\begin{tabular}{|c|c|c|c|c|c|c|}
\hline Test & Lab $Q_{m}(\mathrm{l} / \mathrm{s})$ & Lab. $d_{50}(\mathrm{~m})$ & $S_{0}(\mathrm{~m} / \mathrm{m})$ & $D(\mathrm{~m})$ & $d_{50 \text { min }}(\mathrm{m})$ & Error $(\%)$ \\
\hline 111 & 80 & 0.067 & 0.183 & 0.119 & 0.088 & 31 \\
\hline 121 & 75 & 0.067 & 0.292 & 0.072 & 0.230 & 244 \\
\hline 131 & 40 & 0.067 & 0.361 & 0.032 & 0.128 & 91 \\
\hline 211 & 111 & 0.067 & 0.193 & 0.115 & 0.244 & 264 \\
\hline 221 & 75 & 0.067 & 0.237 & 0.095 & 0.248 & 270 \\
\hline 231 & 60 & 0.067 & 0.392 & 0.065 & 0.281 & 320 \\
\hline 232 & 60 & 0.100 & 0.387 & 0.087 & 0.369 & 269 \\
\hline 222 & 100 & 0.100 & 0.150 & 0.099 & 0.162 & 62 \\
\hline 212 & 236 & 0.100 & 0.195 & 0.198 & 0.425 & 325 \\
\hline 132 & 59 & 0.100 & 0.356 & 0.043 & 0.167 & 67 \\
\hline 122 & 101 & 0.100 & 0.216 & 0.115 & 0.274 & 174 \\
\hline 112 & 171 & 0.100 & 0.212 & 0.118 & 0.276 & 176 \\
\hline
\end{tabular}

The critical flow at which the riprap is stable cannot be calculated directly from SANRAL's guidelines. Instead, the minimum median rock diameter needed was calculated and was used to evaluate the error.

The method yields rock sizes that are too small, and results in an unstable design. In addition, the standard deviation is substantial, indicating very inconsistent results.

\subsubsection{Liu's approach (SANRAL, 2013)}

Previously, the laboratory data was plotted on Liu's diagram to evaluate the relative plotting positions corresponding to the various laboratory tests. For comparison purposes however, the minimum $d_{50}$ was calculated, with all the other parameters known.

Further, uniform flow was assumed, so that $S_{f} \sim S_{0}$ (it was later verified by one dimensional modelling). A more accurate approximation of $S_{f}$ would require hydrodynamic computations, which require choosing a specific roughness $\left(k_{s}\right)$. Section 6.3 deals with approaches employed to circumvent the problem.

The settling velocity was calculated with Equation 2-8, using a drag coefficient of 0.4 and the median sieve size.

After verifying that the flow was indeed rough turbulent (i.e. $R e^{*}>13$ ), a value for $d_{50}$ was iterated so that the Movability Number is 0.12. The results are shown in Table 5-13. 
Table 5-13: Liu's stability predictions

\begin{tabular}{|c|c|c|c|c|c|c|c|c|c|}
\hline Test & $\begin{array}{c}\text { Lab. } \\
Q_{m}(1 / \mathrm{s})\end{array}$ & $d_{50}(\mathrm{~m})$ & $\begin{array}{c}V_{s s} \\
(\mathrm{~m} / \mathrm{s})\end{array}$ & $D(\mathrm{~m})$ & $\begin{array}{c}V^{*} \\
(\mathrm{~m} / \mathrm{s})\end{array}$ & $\begin{array}{c}S_{0} \\
(\mathrm{~m} / \mathrm{m})\end{array}$ & $\begin{array}{c}d_{50 \min } \\
(\mathrm{m})\end{array}$ & $V^{*} / V_{s s}$ & $\begin{array}{c}\text { Error } \\
(\%)\end{array}$ \\
\hline 111 & 80 & 0.067 & 1.93 & 0.104 & 0.232 & 0.183 & 0.030 & 0.12 & -55 \\
\hline 121 & 75 & 0.067 & 1.93 & 0.073 & 0.232 & 0.292 & 0.019 & 0.12 & -72 \\
\hline 131 & 40 & 0.067 & 1.93 & 0.034 & 0.232 & 0.361 & 0.015 & 0.12 & -77 \\
\hline 211 & 111 & 0.067 & 1.93 & 0.116 & 0.232 & 0.193 & 0.028 & 0.12 & -58 \\
\hline 221 & 75 & 0.067 & 1.93 & 0.091 & 0.232 & 0.237 & 0.023 & 0.12 & -66 \\
\hline 231 & 60 & 0.067 & 1.93 & 0.031 & 0.232 & 0.392 & 0.014 & 0.12 & -79 \\
\hline 232 & 60 & 0.100 & 2.36 & 0.061 & 0.283 & 0.387 & 0.021 & 0.12 & -79 \\
\hline 222 & 100 & 0.100 & 2.36 & 0.111 & 0.283 & 0.150 & 0.055 & 0.12 & -45 \\
\hline 212 & 236 & 0.100 & 2.36 & 0.183 & 0.283 & 0.195 & 0.042 & 0.12 & -58 \\
\hline 132 & 59 & 0.100 & 2.36 & 0.035 & 0.283 & 0.356 & 0.023 & 0.12 & -77 \\
\hline 122 & 101 & 0.100 & 2.36 & 0.118 & 0.283 & 0.216 & 0.038 & 0.12 & -62 \\
\hline 112 & 171 & 0.100 & 2.36 & 0.090 & 0.283 & 0.212 & 0.038 & 0.12 & -62 \\
\hline & & & & & & & & \multirow{2}{*}{$\begin{array}{c}\text { Avg } \\
\text { Std dev }\end{array}$} & -66 \\
\hline & & & & & & & & & 11 \\
\hline
\end{tabular}

Although the method seems to underestimate the required rock size on average by $66 \%$, the method yields reasonably consistent results. The standard deviation is small in comparison to the other methods.

This proves that Liu's method is in fact a valuable tool for estimating the stability of particles. However, for future designs, the following issues should be addressed:

- Modify the recommended Movability Number;

- Determining an exact value of the drag coefficient; and

- Correcting for the bed slope in the calculations. Table 5-13 clearly shows that the error increases for the tests with the steeper slopes.

\subsubsection{Discussion}

In order to get a better overview of the stability predictions of the various methods, all the results are shown in Table 5-14. Since the SANRAL methods are compared on the basis of the required minimum $d_{50}$, they are presented separately. 
Table 5-14: Summary of riprap stability prediction techniques

\begin{tabular}{|c|c|c|c|c|c|c|c|c|c|}
\hline & \multirow{3}{*}{ Lab } & \multirow{2}{*}{\multicolumn{2}{|c|}{$\begin{array}{c}\text { General } \\
\text { Design Eq. }\end{array}$}} & \multirow{2}{*}{\multicolumn{2}{|c|}{ Pilarcryk }} & \multirow{3}{*}{$\begin{array}{l}\text { Escarameia } \\
\text { \& May }\end{array}$} & \multirow{3}{*}{ Maynord } & \multirow{3}{*}{$\begin{array}{c}\text { Abt \& } \\
\text { Johnson }\end{array}$} & \multirow{3}{*}{$\begin{array}{c}\text { Robinson } \\
\text { et al. }\end{array}$} \\
\hline & & & & & & & & & \\
\hline & & $\begin{array}{l}k_{s}= \\
d_{50}\end{array}$ & $\begin{array}{l}k_{s}= \\
3 d_{50}\end{array}$ & $\begin{array}{l}k_{s}= \\
d_{50}\end{array}$ & $\begin{array}{l}k_{s}= \\
3 d_{50}\end{array}$ & & & & \\
\hline Test & $\begin{array}{c}Q_{m} \\
(1 / \mathrm{s})\end{array}$ & $\begin{array}{c}Q_{m} \\
(1 / \mathrm{s})\end{array}$ & $\begin{array}{c}Q_{m} \\
(1 / \mathrm{s})\end{array}$ & $\begin{array}{c}Q_{m} \\
(1 / \mathrm{s})\end{array}$ & $\begin{array}{c}Q_{m} \\
(1 / s)\end{array}$ & $Q_{m}(1 / \mathrm{s})$ & $Q_{m}(1 / \mathrm{s})$ & $Q_{m}(1 / \mathrm{s})$ & $Q_{m}(1 / \mathrm{s})$ \\
\hline 111 & 80 & 173 & 116 & 111 & 74 & 131 & 179 & 101 & 61 \\
\hline 121 & 75 & 62 & 39 & 51 & 32 & 79 & 103 & 70 & 47 \\
\hline 131 & 40 & 13 & 7 & 15 & 9 & 36 & 43 & 60 & 41 \\
\hline 211 & 111 & 161 & 108 & 105 & 70 & 127 & 173 & 97 & 59 \\
\hline 221 & 75 & 110 & 72 & 78 & 52 & 105 & 140 & 83 & 53 \\
\hline 231 & 60 & 46 & 29 & 40 & 25 & 72 & 93 & 56 & 39 \\
\hline 232 & 60 & 69 & 43 & 63 & 39 & 117 & 149 & 116 & 84 \\
\hline 222 & 100 & 111 & 69 & 95 & 60 & 133 & 171 & 241 & 146 \\
\hline 212 & 236 & 382 & 261 & 232 & 158 & 267 & 369 & 196 & 125 \\
\hline 132 & 59 & 18 & 10 & 24 & 13 & 57 & 68 & 124 & 88 \\
\hline 122 & 101 & 141 & 90 & 112 & 71 & 156 & 204 & 182 & 118 \\
\hline 112 & 171 & 147 & 94 & 115 & 74 & 159 & 209 & 184 & 119 \\
\hline
\end{tabular}

Table 5-15: SANRAL stability predictions

\begin{tabular}{|c|c|c|c|c|}
\cline { 4 - 5 } \multicolumn{1}{c|}{} & Lab. $Q_{m}(1 / \mathrm{s})$ & Lab. $d_{50}(\mathrm{~m})$ & Shields & Liu \\
\cline { 4 - 5 } Test & & & $d_{50 \min }(\mathrm{m})$ & $d_{50 \min }(\mathrm{m})$ \\
\hline 111 & 80 & 0.067 & 0.088 & 0.030 \\
\hline 121 & 75 & 0.067 & 0.230 & 0.019 \\
\hline 131 & 40 & 0.067 & 0.128 & 0.015 \\
\hline 211 & 111 & 0.067 & 0.244 & 0.028 \\
\hline 221 & 75 & 0.067 & 0.248 & 0.023 \\
\hline 231 & 60 & 0.067 & 0.281 & 0.014 \\
\hline 232 & 60 & 0.100 & 0.369 & 0.021 \\
\hline 222 & 100 & 0.100 & 0.162 & 0.055 \\
\hline 212 & 236 & 0.100 & 0.425 & 0.042 \\
\hline 132 & 59 & 0.100 & 0.167 & 0.023 \\
\hline 122 & 101 & 0.100 & 0.274 & 0.038 \\
\hline 112 & 171 & 0.100 & 0.276 & 0.038 \\
\hline
\end{tabular}

Table 5-14 and Table 5-15 imply that no single prediction procedure in either totally over or under estimations. This supports the observed data, since a certain trend in the prediction equations would mean that the laboratory data is faulty. 
With the exception of Liu's method, a great variation in the results of existing methods can be observed. This furthermore highlights the need for refining Liu's theory to obtain a more accurate method for the prediction of riprap stability.

A point worth noticing is the sensitivity of the CIRIA et al. (2007) methods to some of the parameters needed as input for the equations. Some parameters, like $r, k_{h}, C_{s t}$ and $C_{v}$ are parameters that typically cannot be determined accurately in practice. Although CIRIA et al. (2007) provide some guidelines on how these values should be chosen, they typically rely on the experience and interpretation of the engineer. For example, an under estimation of the stability coefficient by $25 \%$ in Escarameia and May's equation directly results in an underestimation of $25 \%$ of the rock size. This can have devastating effects in practice. The determinations of most of these values lack a practical scientific method to compute them.

The theory proposed by Liu does not entail choosing correction factors. Also, it has the advantage of being derived from a solid theoretical basis, making it more appropriate for designing riprap.

\subsection{Re-evaluation of Shields's criteria}

As mentioned earlier, Shields's criteria is regarded as the classic method for estimating riprap stability. The results obtained for the adapted Shields criteria from SANRAL were, however, disappointing. Therefore, it was decided to revisit the method and using the basic theory (rather than the simplified approach) to explain the poor results.

From previous discussions (see Section 2.9.6), Shields's method can be expressed as follows:

$$
\psi=k_{\beta} \frac{\rho D S_{0}}{\left(\rho_{r}-\rho_{w}\right) d}
$$

The laboratory data was then plotted on the Shields diagram as shown in Figure 5-6. 


\section{Shields diagram}

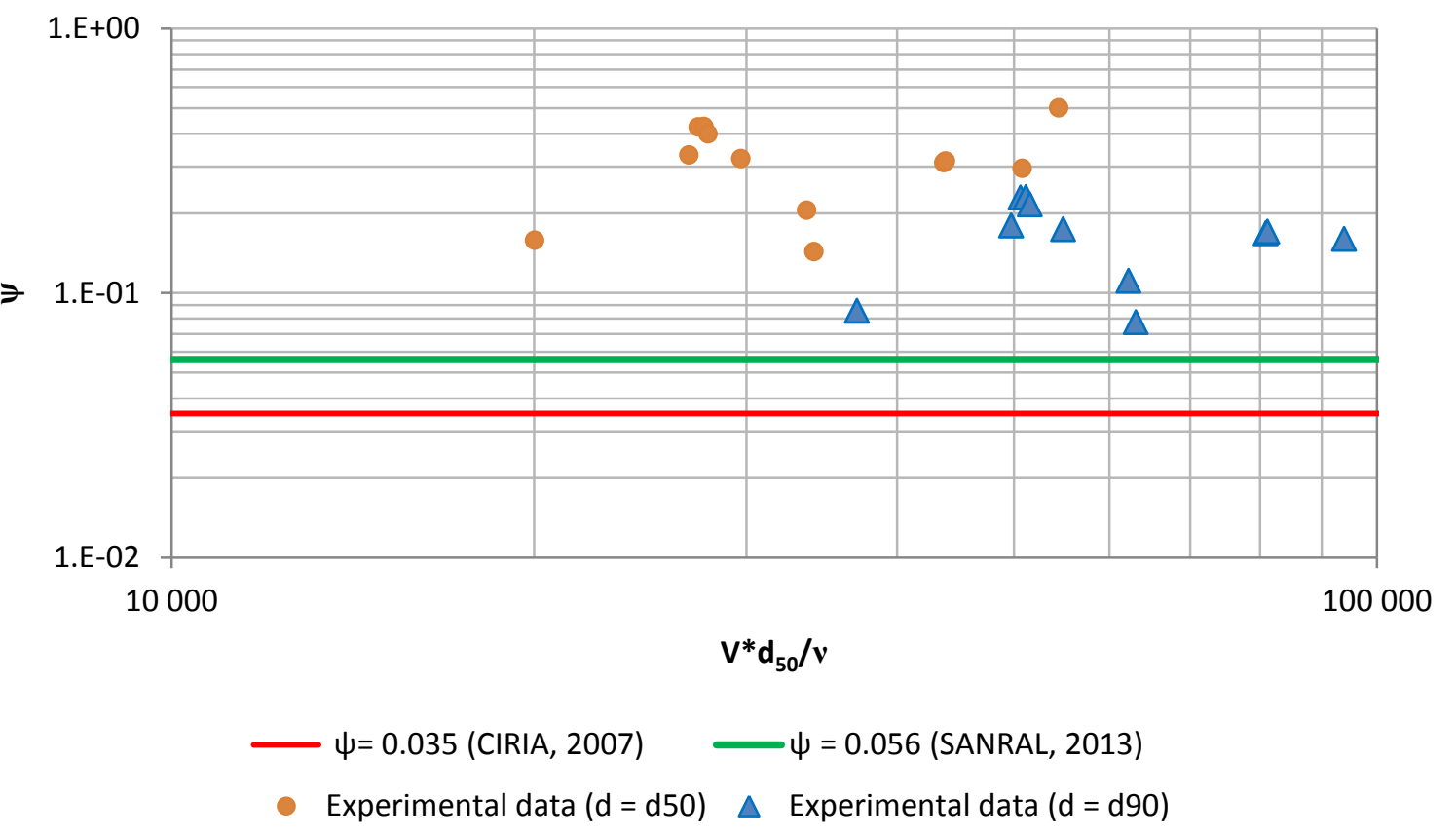

Figure 5-6: Experimental data plotted on the Shields diagram

Earlier it was found that the $d_{90}$ is the most applicable sieve size for analysing data points on Liu's diagram due to hiding and exposure effects. Therefore, the data points for both scenarios are shown. From Figure 5-6 the SANRAL values and the plot using the $d_{90}$ seems most applicable.

One would expect the data to plot above the recommended values, since the laboratory data points correspond to flow conditions in which some movement has already occurred.

The above findings show that the collected laboratory data is more or less in line with Shields's findings.

The reasons for the initial poor results (see Section 5.3.6) are undoubtedly due to the over simplification of Shield's criteria in the SANRAL (2013) guidelines. These include the effects of the bed slope, and the choice of a representative sieve size of the grading. 


\section{DEVELOPMENT OF A DESIGN METHODOLOGY USING ONE DIMENSIONAL HYDRODYNAMIC MODELLING}

From the discussion on the analysis of the laboratory data, it is evident that some parameters (especially the flow depth and energy slope) could not be determined very accurately. The vertical scatter observed on the Liu diagram can probably partly be attributed to these inaccuracies.

In this chapter attempts are made to improve the scatter of the data points on the Liu diagram. The laboratory data was used in combination with a calibrated one dimensional hydrodynamic computer model. Finally, this knowledge is used to develop a practical riprap design methodology for design engineers.

In traditional design procedures, the data available to the engineer is usually limited to the dimensions of the structure, the properties of the available riprap material and the design discharge.

\subsection{HEC-RAS background}

HEC-RAS is one dimensional flow modelling software which is capable of performing (amongst other) water surface profile calculations for steady, gradually varied flow in a subor supercritical state, or a combination thereof.

HEC-RAS utilises the standard step method, which involves solving the Bernoulli equation (Equation 6-1) between two consecutive cross sections. In an assembled model, there can be a large number of sections.

$$
\frac{\alpha V_{1}^{2}}{2 g}+D_{1} \cos \theta+Z_{1}=\frac{\alpha V_{2}^{2}}{2 g}+D_{2} \cos \theta+Z_{2}+h_{e}
$$


where
$\alpha \quad$ Coefficient to compensate for variation in velocity across a section; and
$h_{e} \quad$ Energy head loss.

The subscripts 1 and 2 denote the upstream and downstream cross sections respectively. The different terms of the Bernoulli equation are depicted in Figure 6-1.

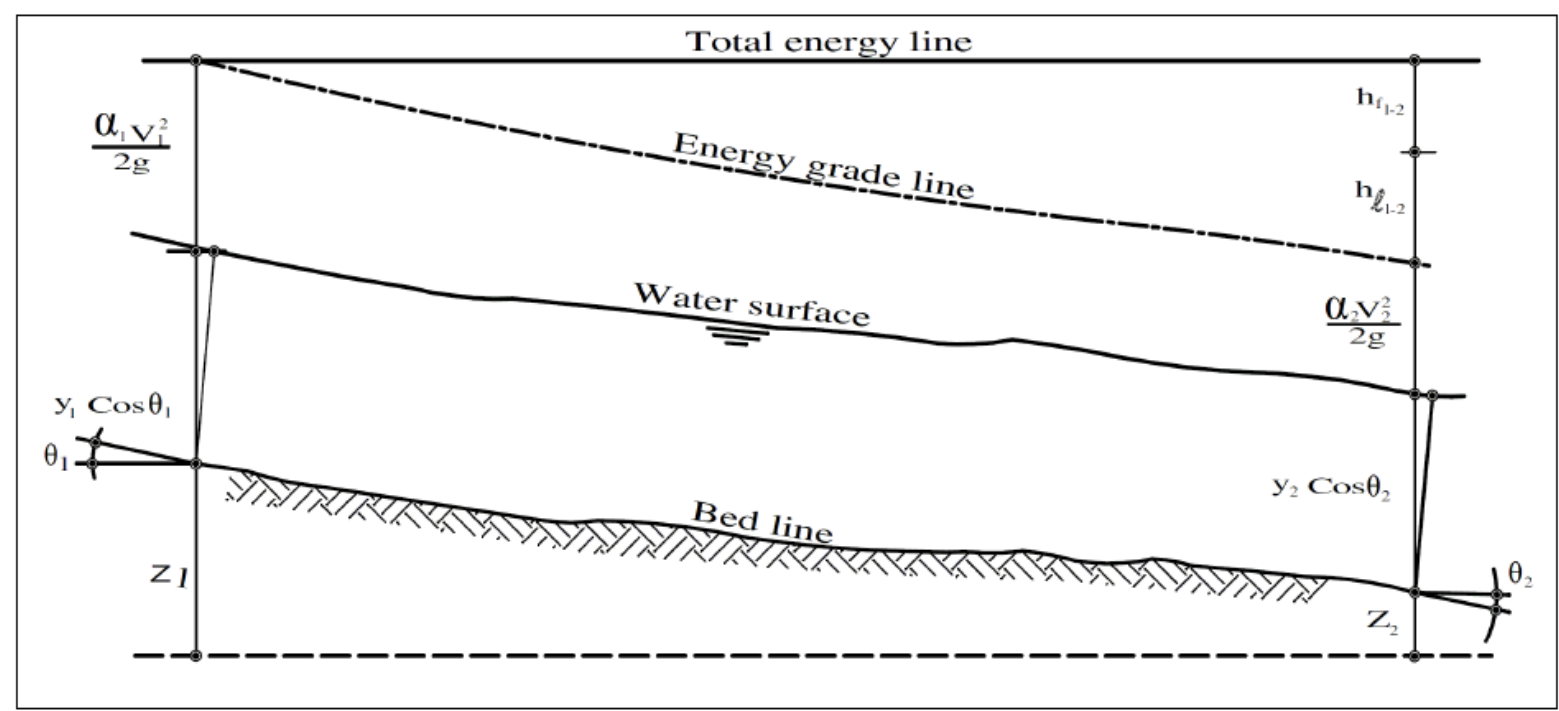

Figure 6-1: Components of the Bernoulli equation (SANRAL, 2013)

For all cases considered in this thesis, the model contains only profiles with a rectangular single channel, with $\alpha=1$.

The energy head loss term is made up of the sum of two components, namely contraction/expansion losses $\left(h_{c}\right)$ and friction losses $\left(h_{f}\right)$. Since the cross section is not subdivided along its width, the contraction and expansion losses are equal to zero. $h_{f}$ in turn is expected to play a significant role in these simulations (it will be seen later in this chapter that the roughness is relatively large). HEC-RAS uses a special formulation of Manning's equation (Equation 6-2) to estimate friction losses (US Corps of Engineers, 2010; SANRAL, 2013):

$$
h_{f}=L \frac{V^{2} n^{2}}{R^{4 / 3}}
$$


where

$L \quad$ Reach length between consecutive cross sections (m);

$R \quad$ Hydraulic radius (m); and

n Manning's roughness coefficient.

Since the simulation is treated as a slice of a structure with an infinite width, the wide channel approximation was assumed, implying that the hydraulic radius $(R)$ is approximately equal to the flow depth $(D)$.

\subsection{Configuration of the model}

As a first step in the process of developing a design methodology, the laboratory conditions had to be modelled as accurately as possible.

The required input data for the one dimensional model includes information about the geometry of the structure, discharge, roughness and the boundary conditions. A different model was created for each of the 12 laboratory tests.

\subsubsection{Geometry data}

The geometry data that was fed into the model originated from the laboratory surveys. Every simulation was built on seven cross sections, as shown in Figure 6-2. HEC-RAS uses a numbering convention where the most downstream section is numbered first, continuing in ascending order.

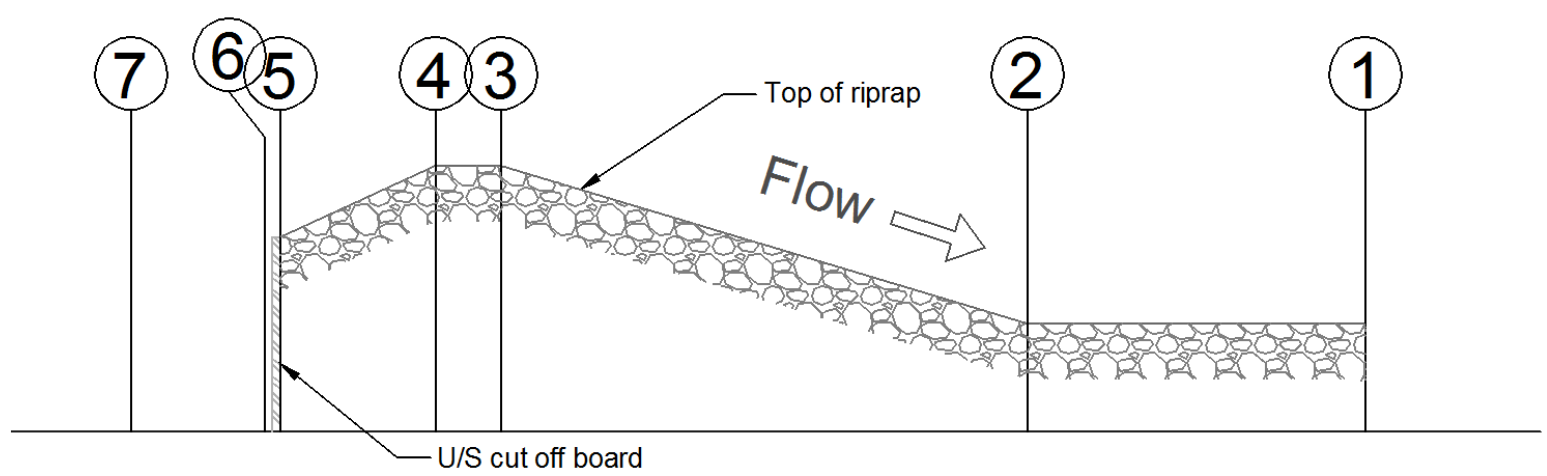

Figure 6-2: Definition of sections in HEC-RAS 
A cross section was required at the start and end of the model and at any point where the bed slope changes. Theoretically the distance between section 5 and 6 should be 0 to create a vertical step in the structure. However, HEC-RAS is unable to solve the Bernoulli equation with two sections being on top of each other. Therefore, a small distance of $0.05 \mathrm{~m}$ was specified. Although this will result in some inaccuracies in the vicinity, this is not considered as problematic, as the hydraulic parameters on the sloped part of the structure are of primary interest. The cross sections were made rectangular with a width of $1 \mathrm{~m}$, corresponding to the laboratory flume dimensions. They were made sufficiently high, so that water would not overtop the sides of the flume.

The invert levels of the different sections were determined as presented in Table 6-1.

Table 6-1: Invert levels for HEC-RAS sections

\begin{tabular}{|c|c|c|}
\hline Section & Invert Level & Comment \\
\hline 1 & Equal to Section 2 & To ensure a horizontal bed between (1) and (2) \\
\hline 2 & $\begin{array}{l}\text { Calculated from line } \\
\text { of best fit of surveyed } \\
\text { data }\end{array}$ & $\begin{array}{l}\text { Surveyed point at (2) does not necessarily lie on regression line. } \\
\text { Thus elevation had to be slightly adjusted to ensure representative } \\
\text { slope }\left(S_{0}\right) \text {. }\end{array}$ \\
\hline 3 & $\begin{array}{l}\text { As surveyed on crest } \\
\text { of riprap }\end{array}$ & \multirow{2}{*}{$\begin{array}{l}\text { Invert levels between (3) and (4) tend to differ considerably as a } \\
\text { result of inaccurate construction. Thus, the surveyed Invert Levels } \\
\text { were used to represent the structure more accurately. }\end{array}$} \\
\hline 4 & $\begin{array}{l}\text { As surveyed } 200 \mathrm{~mm} \\
\mathrm{U} / \mathrm{S} \text { of crest }\end{array}$ & \\
\hline 5 & $\begin{array}{l}\text { As surveyed on top of } \\
\text { cut-off board }\end{array}$ & Values equal for tests of equal $d_{50}$ \\
\hline 6 & $\begin{array}{l}\text { As surveyed on flume } \\
\text { floor }\end{array}$ & Values equal for all tests \\
\hline 7 & $\begin{array}{l}\text { As surveyed on flume } \\
\text { floor }\end{array}$ & Values equal for all tests \\
\hline
\end{tabular}

The surveyed data referred to in Table 6-1 originates from the survey conducted before testing commenced (i.e. the initial survey). This survey represents the condition of the structure that the designer originally designed for, and was thus applicable. As before, the initial best fit slope of the structure was used, as given in Table 5-3.

Since more calculation points were necessary on the sloped part of the structure (to obtain more accurate data of the flow conditions), nine additional cross sections were interpolated between sections 2 and 3. Figure 6-3 shows a three dimensional representation of the cross sections in HEC-RAS. 


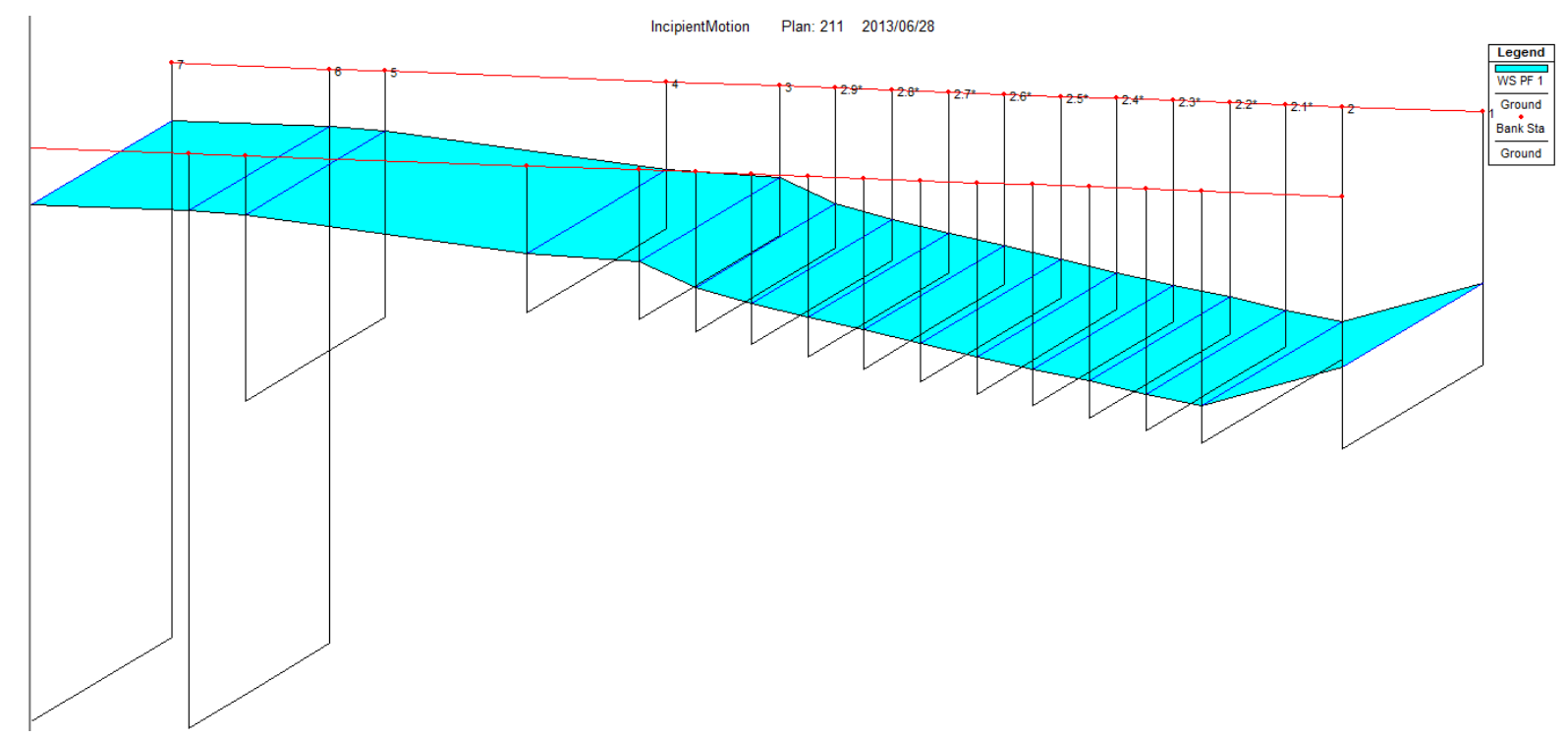

Figure 6-3: Typical layout of cross sections in HEC-RAS

The rectangular shapes show the cross sections at which HEC-RAS solves Equation 6-1, while the blue plane depicts the computed water surface. Figure 6-3 indicates that the water surface at the most downstream section appears to be increasing from the previous sections. In that area a hydraulic jump is formed. HEC-RAS is unable to determine the exact hydraulics around the jump; it can only detect the presence of a jump in that area.

\subsubsection{Discharge}

The HEC-RAS model was configured so that a flow equal to $Q_{m}$ passes over the structure. As previously described, this flow was determined in the laboratory as the critical flow that causes incipient motion. These flows are given in Table 5-1.

It is acknowledged that no provision for seepage through the structure is taken into account in the HEC-RAS model. The HEC-RAS model assumes that the outer layer of riprap is impermeable. However, in practice (since dumped riprap is a porous medium), some flow is expected to percolate through the riprap, as indicated in Figure 6-4. 


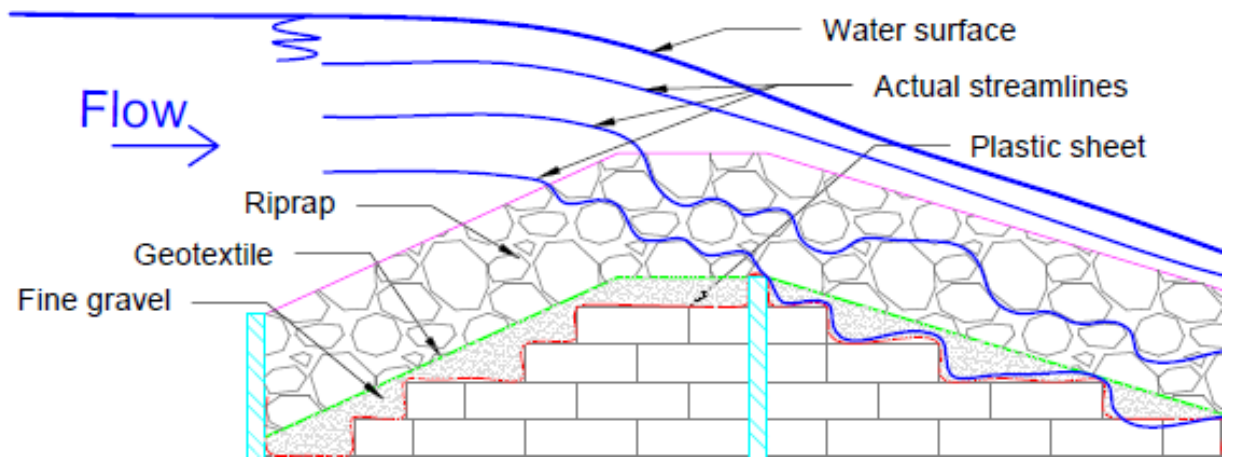

Figure 6-4: Actual streamlines through riprap

The water that percolates through the riprap does not contribute to the water depth that the riprap downstream experiences.

It should be noted, however, that the plastic sheeting limits the water from seeping in between the bricks, limiting the watercourse to the area above the plastic sheeting.

The results of this investigation are therefore limited to a certain rock size and grading, since the bulk granular porosity of dumped rock was mainly dependant on these two parameters. Also, a properly functioning geometrically tight filter was assumed, implying that failure of the top layer of the riprap did not occur as a result of failure of underlying layers.

\subsubsection{Boundary conditions}

HEC-RAS allows the user to define boundary conditions in terms of upstream and downstream water levels.

Once again the laboratory data was utilised: the water levels at Section 7 and Section 1 were used as upstream and downstream water levels (see Appendix B1 for laboratory data). In the laboratory these values could be measured with a high accuracy since the water was flowing relatively uniformly in these areas. Thus, these boundary conditions are reasonably accurate.

In practice, the upstream and downstream water levels can be determined using backwater calculations or any other applicable method, depending on the nature of the problem. 


\subsubsection{Roughness}

As discussed, HEC-RAS uses Manning's equation to quantify friction losses. However, since most literature utilises Chezys $k_{s}$, it seemed more appropriate to run the simulations in terms of roughness $k_{s}$, not in terms of Manning's roughness factor.

There is a function in HEC-RAS that allows the user to specify Chezy's roughness. A built in algorithm converts $k_{s}$ to Manning's n using Equation 6-3 (US Army Corps of Engineers, 2010).

$$
n=\frac{R^{1 / 6}}{18 \log \left(\frac{12.2 R}{k_{S}}\right)}
$$

Equation 6-3

Since Equation 6-3 did not appear in any other reviewed literature, it was verified by doing spot checks on the graphical representation of this conversion, as presented in SANRAL (2013).

The determination of a representative value for $k_{s}$ was the primary objective of the one dimensional model. Thus, different $k_{s}$ values, ranging from $k_{s}=0.05 \mathrm{~m}$ to $0.6 \mathrm{~m}$ were used.

\subsection{Analysis of HEC-RAS data}

\subsubsection{Approach to determining roughness coefficient}

In a study by Van der Walt (2005) it was found that the relative roughness, defined as $k_{s} / d_{y}$, is approximately constant for a rough turbulent reach in the Berg River in the Western Cape.

By definition the roughness $k_{s}$ is the diameter of the eddy currents formed near the boundary, as a result of the irregularity of the bed. The concept of relative roughness is illustrated schematically in Figure 6-5.

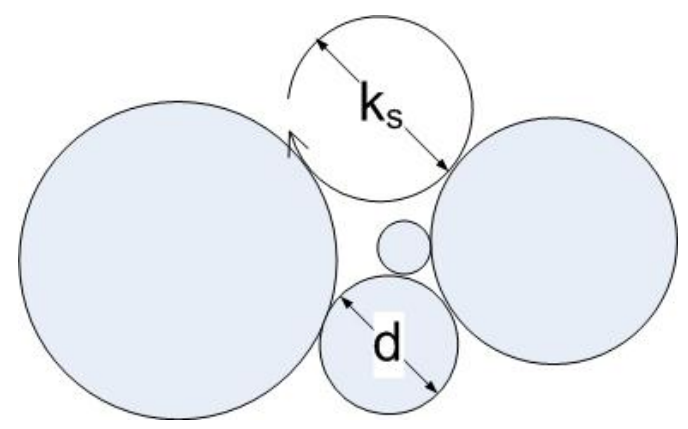

Figure 6-5: Relative roughness of shielded particles 
In the case of a graded material, smaller particles are hidden behind larger particles as seen in Figure 6-5 (Wu et al., 2000). This causes the hiding particles to experience a much higher relative roughness compared to a uniformly graded bed, where the absolute roughness is determined by the particle size. In other words, the roughness is a function of the larger particles in the grading (i.e. $d_{90}$ ).

Garde and Ranga Raju (2000) present a number of equations that have been developed by different researchers that take this "hiding" effect into account by using mostly empirical relations, but their practical application is very limited.

The grading of the bed in the laboratory tests is constant. Therefore, a constant ratio of $k_{s} / d_{y}$ is expected. In order to be consistent with the sieve size used in determining the settling velocity, the relative roughness was defined in terms of the $d_{90}$ rock size as:

$$
\text { Relative roughness }=\frac{k_{s}}{d_{90}}
$$

Equation 6-4

Van der Walt (2005) found that the relative roughness (with $d_{y}=d_{50}$ ) $\sim 5$ for a reach in the Berg River. The hydraulic conditions in the Berg River are of course considerably different to those in the laboratory flume, considering the slopes at which the tests are performed. Thus, the ratio he found to be applicable in the reach of the Berg River is probably not relevant for this research project. However, the idea of hiding and exposure of particles is exploited further.

Upon revisiting Figure 6-5, the following limits regarding the absolute roughness can be deduced:

- According to the grading of the samples, the largest particle in the sample $\left(d_{100}\right)$ is only slightly larger than the $d_{90}$. It can thus be reasoned that $k_{s} \leq d_{100}$, thus the relative roughness $\leq 1$.

- Also, from an earlier discussion it is clear that the larger particles define the roughness of the bed. If larger particles are defined as particles bigger or equal to the median rock diameter, $k_{s} \geq d_{50}$. Since $d_{90}<2 d_{50}, k_{s}>0.5 d_{90}$. Thus, the following bounds for the relative roughness are applicable: 


\subsubsection{Absolute roughness determination}

The HEC-RAS model was configured as described. A typical result of such simulations is shown in Figure 6-6. The reader is referred to Appendix D for the results of the other simulations.

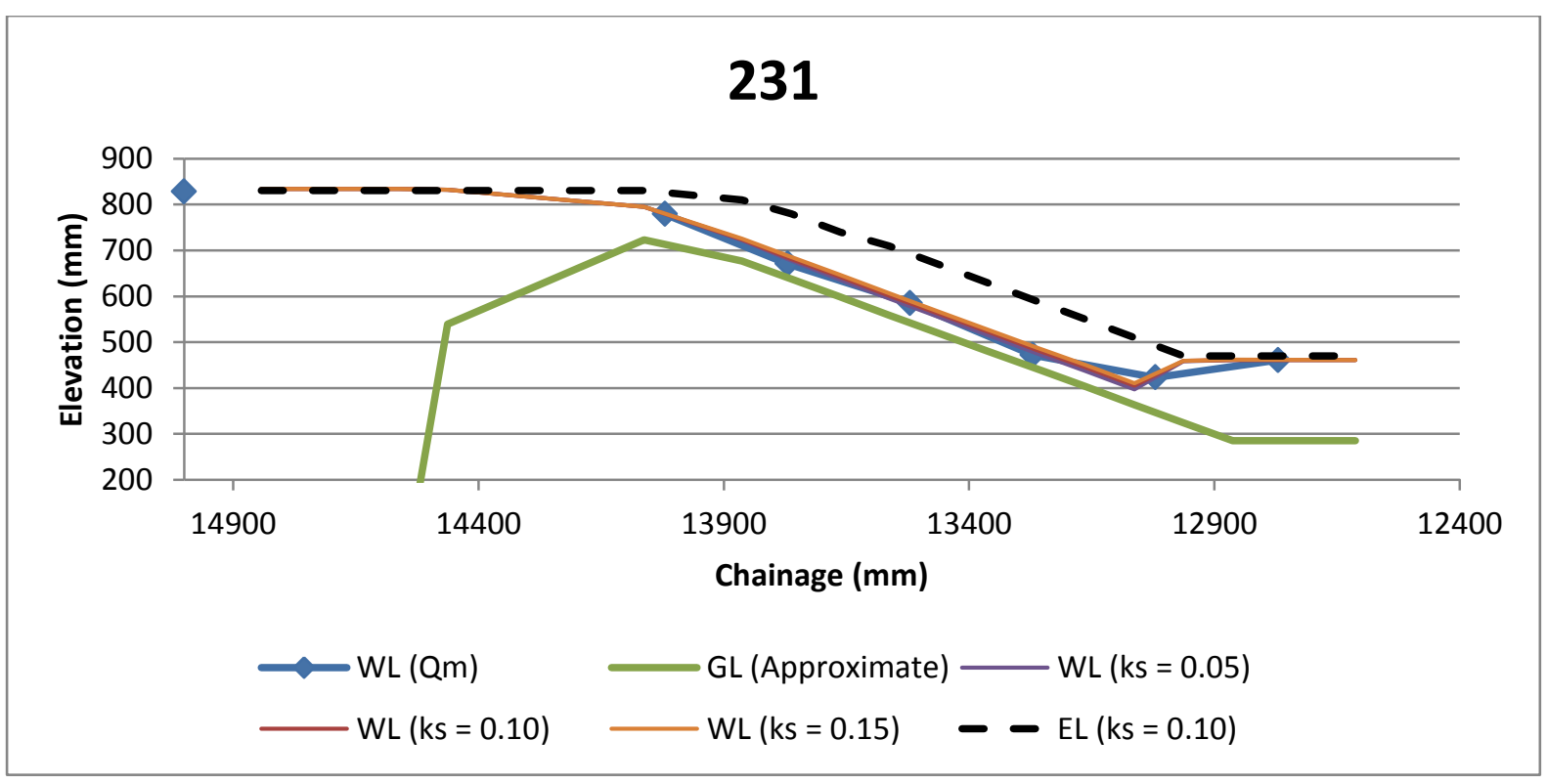

Figure 6-6: Simulated water levels (Test 231)

The water levels measured on the physical model as well as the simulated water levels for different values for $k_{s}$ are shown. Also, the energy line (EL) is given, corresponding to the roughness that fits the measured water levels best.

The roughness was iterated in steps of $0.05 \mathrm{~m}$. This seems to be a large interval, since the obtained roughness is merely in the order of 0.05-0.60 m. However, the difference in the water levels is too small to tell which of the results seems to fit best. Thus, determining the roughness that yields the best fit to the observed data is prone to subjective judgement.

From a previous discussion it is clear that the same $k_{s}$ can be expected for the same grading. Therefore, the ideal roughness was obtained by considering the same roughness for tests with the same $d_{90}$ and evaluating the collective error of the simulated water level and the observed water level. The roughnesses that were determined are shown in Table 6-2. 
Table 6-2: Optimal $\mathbf{k}_{\mathrm{s}}$

\begin{tabular}{|c|c|c|c|}
\hline Test & $k_{s}(\mathrm{~m})$ & $d_{90}(\mathrm{~m})$ & $k_{s} / d_{90}$ \\
\hline 111 & 0.10 & 0.124 & 0.81 \\
\hline 121 & 0.10 & 0.124 & 0.81 \\
\hline 131 & 0.10 & 0.124 & 0.81 \\
\hline 211 & 0.10 & 0.124 & 0.81 \\
\hline 221 & 0.10 & 0.124 & 0.81 \\
\hline 231 & 0.10 & 0.124 & 0.81 \\
\hline 232 & 0.15 & 0.185 & 0.81 \\
\hline 222 & N/A & 0.185 & N/A \\
\hline 212 & N/A & 0.185 & N/A \\
\hline 132 & 0.15 & 0.185 & 0.81 \\
\hline 122 & 0.15 & 0.185 & 0.81 \\
\hline 112 & 0.15 & 0.185 & 0.81 \\
\hline
\end{tabular}

Table 6-2 indicates that there is indeed a constant absolute roughness applicable to the flow. $\mathrm{A} k_{s} / d_{90}$ ratio of 0.81 is recommended.

Referring to Appendix D, a good correlation between the measured and simulated water levels for various magnitudes of roughness could be observed. However, the results of Test 222 and 212 were not satisfactory. The initial movement caused the bed to take on a circular shape, thus changing the flow conditions considerably so that no value of $k_{s}$ would result in water levels that match the observed data. Thus, $k_{s}$ could not be obtained.

The results of the laboratory data, using the calibrated $S_{f}$ and $D$ values, are presented in Table 6-3. 
Table 6-3 : Parameters for Liu diagram using calibrated HEC-RAS model

\begin{tabular}{|c|c|c|c|c|c|c|c|c|c|}
\hline Test & $\begin{array}{c}Q_{m} \\
(1 / \mathrm{s})\end{array}$ & $S_{f}(\mathrm{~m} / \mathrm{m})$ & $D(\mathrm{~m})$ & $V_{s s}(\mathrm{~m} / \mathrm{s})$ & $V^{*}(\mathrm{~m} / \mathrm{s})$ & $\sqrt{ } k_{\beta}$ & $d_{90}(m)$ & $\sqrt{ } k_{\beta} V^{*} / V_{s s}$ & $V^{*} d_{50} / v$ \\
\hline 111 & 80.1 & 0.184 & 0.056 & 1.27 & 0.32 & 0.88 & 0.124 & 0.22 & 34907 \\
\hline 121 & 74.8 & 0.273 & 0.048 & 1.27 & 0.36 & 0.79 & 0.124 & 0.22 & 39297 \\
\hline 131 & 40.1 & 0.356 & 0.033 & 1.27 & 0.34 & 0.73 & 0.124 & 0.19 & 37119 \\
\hline 211 & 111.3 & 0.166 & 0.069 & 1.27 & 0.33 & 0.87 & 0.124 & 0.23 & 36757 \\
\hline 221 & 75.5 & 0.222 & 0.052 & 1.27 & 0.34 & 0.84 & 0.124 & 0.22 & 36774 \\
\hline 231 & 60.3 & 0.370 & 0.039 & 1.27 & 0.38 & 0.70 & 0.124 & 0.21 & 41212 \\
\hline 232 & 60.3 & 0.369 & 0.044 & 1.56 & 0.40 & 0.72 & 0.185 & 0.19 & 65666 \\
\hline 222 & 100.0 & - & - & 1.56 & - & 0.90 & 0.185 & - & - \\
\hline 212 & 235.8 & - & - & 1.56 & - & 0.87 & 0.185 & - & - \\
\hline 132 & 58.9 & 0.340 & 0.045 & 1.56 & 0.39 & 0.75 & 0.185 & 0.19 & 63450 \\
\hline 122 & 100.7 & 0.242 & 0.066 & 1.56 & 0.40 & 0.86 & 0.185 & 0.22 & 65035 \\
\hline 112 & 170.9 & 0.196 & 0.092 & 1.56 & 0.42 & 0.86 & 0.185 & 0.23 & 68761 \\
\hline
\end{tabular}

The above data shows a minimum value of the vertical axis of 0.19 (compared to the initial laboratory data which produced a value of 0.18, as shown in Section 5.2.5). Since the points are expected to plot close to and above the threshold of incipient motion, the lowest Movability Number in the data set should be considered as safe for design purposes. Thus, a value of 0.18 is recommended for design purposes.

The above data is plotted on Liu's diagram as shown in Figure 6-7. 


\section{Liu diagram}

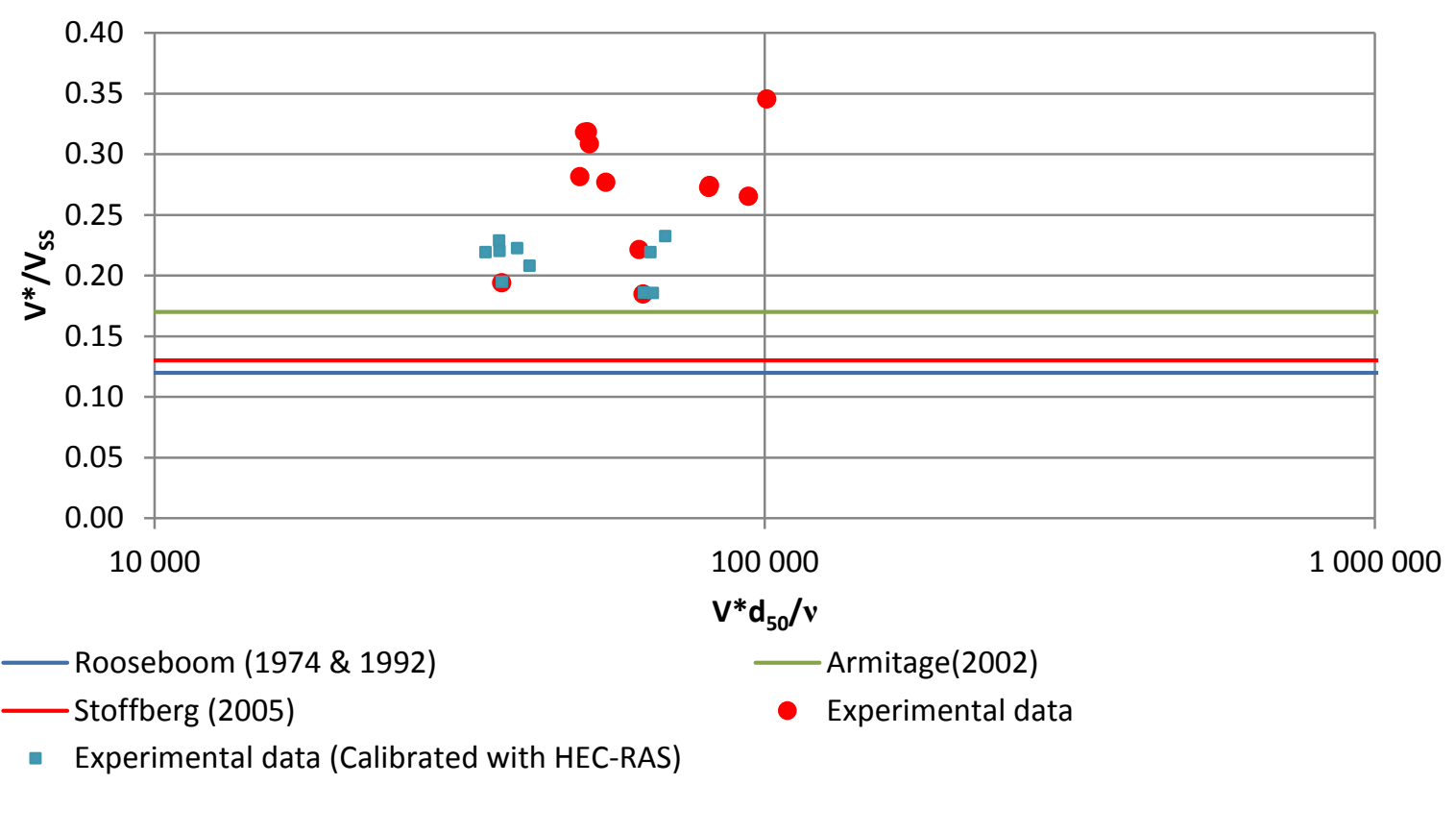

Figure 6-7: Experimental vs. calibrated HEC-RAS data

The scatter observed in the experimental data has decreased substantially by using the $S_{f}$ and $D$ values of the calibrated HEC-RAS model. The calibrated data points moved closer to the recommended values of the other researchers.

The reduction of the scatter can be explained by revisiting the numerical results of the initial and calibrated data (see Table 5-6 and Table 6-3 respectively). It can be seen that the energy slopes in both tables are very similar. Thus, the approximation $S_{0} \sim S_{f}$ does not cause a significant error. However, the obtained values for the flow depth $(D)$ do not compare very well. This can probably be ascribed to the difficulties involved in determining the flow depth in the laboratory, as discussed in Section 5.2.1.

\subsection{Practical example}

In order to illustrate the practical implications of the findings in this thesis, a practical example has been prepared. 
Consider the following problem: The top layer of a riprap lined spillway has to be designed. Assume Simons and Sentürk's (1992) recommended grading, and a layer thickness of $2.5 d_{50}$. Design for each of the following scenarios:

- $S_{0}$

$$
\begin{array}{cc}
\circ & 0.2(\mathrm{~m} / \mathrm{m}) \\
\circ & 0.4(\mathrm{~m} / \mathrm{m})
\end{array}
$$

- Unit discharge $(q)$
○ $0.8 \mathrm{~m}^{3} / \mathrm{s} . \mathrm{m}$
○ $1.4 \mathrm{~m}^{3} / \mathrm{s} . \mathrm{m}$
○ $2.0 \mathrm{~m}^{3} / \mathrm{s} . \mathrm{m}$

An angle of repose of $40^{\circ}$, a drag coefficient of 1.66 and a rock density of $2650 \mathrm{~kg} / \mathrm{m}^{3}$ can be assumed.

Considering the findings in this thesis, the steps followed to obtain an acceptable design are outlined below.

Step 1:

- Estimate the required $d_{90}$ rock size.

- Use the ratio of $k_{s} / d_{90}=0.81$ to obtain the roughness.

\section{Step 2:}

- Determine the critical combination of $S_{f}$ and $D$ in the area of interest. This can be done using one dimensional computer models, or alternatively the standard step method for hand calculations.

Step 3:

- Calculate the $d_{90}$, so that $\sqrt{k_{\beta}} V^{*} / V_{s s}=0.18$ (See Figure 6-7). Since the slopes are steep, the factor $\sqrt{k_{\beta}}$ (see Section 2.5.2) cannot be excluded.

- $\quad$ Check if $k_{s} / d_{90}=0.81$.

- If $k_{s} / d_{90} \neq 0.81$, adjust $d_{90}$ and go back to step 1 . 
As a final check, the particle Reynolds number $\left(R e^{*}\right)$ should be determined to make sure that flow is turbulent (i.e. $R e^{*}>13$ ).

Using this methodology, the $d_{90}$ rock diameters were determined, as shown in Table 6-4. With the grading of the sample known, the $d_{50}$ can simply be interpolated.

Table 6-4: Results of sample calculation

\begin{tabular}{|c|c|c|c|c|c|c|c|}
\hline ID & $q\left(\mathrm{~m}^{3} / \mathrm{s} . \mathrm{m}\right)$ & $S_{0}(\mathrm{~m} / \mathrm{m})$ & $D(\mathrm{~m})$ & $S_{f}(\mathrm{~m} / \mathrm{m})$ & $V_{s s}(\mathrm{~m} / \mathrm{s})$ & $k_{s}(\mathrm{~m})$ & $d_{90}(\mathrm{~m})$ \\
\hline 001 & 0.3 & 0.20 & 0.15 & 0.19972 & 2.60 & 0.41 & 0.51 \\
\hline 002 & 0.9 & 0.20 & 0.31 & 0.20102 & 3.76 & 0.85 & 1.06 \\
\hline 003 & 1.4 & 0.20 & 0.42 & 0.20062 & 4.35 & 1.14 & 1.42 \\
\hline 004 & 0.3 & 0.40 & 0.14 & 0.39937 & 2.82 & 0.48 & 0.59 \\
\hline 005 & 0.9 & 0.40 & 0.28 & 0.40007 & 4.07 & 1.00 & 1.23 \\
\hline 006 & 1.4 & 0.40 & 0.38 & 0.40023 & 4.72 & 1.35 & 1.66 \\
\hline
\end{tabular}

The above table illustrates the sensitivity of the slope and discharge on the method. It makes sense that for a steeper slope, larger rocks are needed. The same applies to riprap exposed to higher discharges. 


\section{CONCLUSIONS AND RECOMMENDATIONS}

The investigation of the stability of riprap on steep slopes yielded valuable information. It is clear that the processes involving incipient motion are reasonably well understood and documented.

It is reasoned that the core objective of this study was achieved by equipping the design engineer with tools to design stable large diameter riprap on steep slopes, without being too conservative. Liu's theory could not be improved significantly, but it is felt that valuable insight was gained regarding the practical application thereof.

The findings in this thesis can be summarised as follows:

- By comparing the predictions of the existing design methods with the observed laboratory data, it was found that the existing methods yield a wide variety of results, with no particular method yielding reasonably acceptable results.

- Although Liu's theory was derived for uniform flow on very flat slopes with uniform sediment sizes, it was shown that his prediction fits the laboratory data very well. The importance of including the slope correction factor $\left(\sqrt{k_{\beta}}\right)$ in the calculations when bed slopes are steep is stressed.

- In comparison to the data proposed by other researchers, the data points of this thesis plot in an area of a very high particle Reynolds number. Therefore, the Movability Numbers proposed here can be used for large diameter riprap.

- The settling velocity (needed to calculate the Movability Number) should be calculated using the $d_{90}$ diameter to take into account the hiding effects of a nonuniform riprap bed.

- Ideally, the drag coefficient should be determined experimentally. In the absence of laboratory data, the drag coefficient should be determined in accordance with an average shape factor of the sample. The success of applying Liu's theory depends very much on the accuracy of the settling velocity. 
- Liu's critical Movability Number for incipient motion can be taken as 0.18 for design purposes. This presupposes turbulent flow conditions and the use of the same grading as stipulated by Simons and Sentürk (1992), with $d_{100}=2 d_{50}, d_{20}=0.5 d_{50}$ and a layer thickness of $2.5 d_{50}$.

- An absolute roughness ratio $\left(k_{s} / d_{90}\right)$ of 0.81 seems to be applicable for the grading used in this thesis. This is particularly useful to estimate the roughness needed to obtain the hydraulic parameters like flow depth and the energy slope.

From the study, the importance of the correct determination of the settling velocity should be obvious. It seems, however, that there is a lack of data available for large particles (i.e. high particle Reynolds numbers). This poses an obvious problem for the practicing designer. Thus, additional research is needed to equip the designer with methods to estimate the settling velocity accurately.

It was pointed out that some error is acceptable in the one dimensional computer simulations, because the bulk granular porosity of the riprap medium is not taken into account. Therefore, the results of this study are limited to a certain grading. There is certainly considerable scope for future research, as the effect thereof could not be quantified in this thesis. 


\section{LIST OF REFERENCES}

Abt, S. \& Johnson, T.L. 1991. Riprap design for overtopping flow. Journal of Hydraulic Engineering, 117(8): 959-972.

Annandale, G.W. 2006. Scour technology: Mechanics and engineering practice. New York: McGraw-Hill.

Armitage, N.P. 2002. A unit stream power model for the prediction of local scour in rivers. Doctoral dissertation. Stellenbosch: University of Stellenbosch.

Armitagte, N.P. \& Rooseboom, A. 2010. The link between movability number and incipient motion in river sediments. Water SA, 36(1): 89-96.

Chadwick, A., Morfett, J. \& Borthwick, M. 2004. Hydraulics in civil and environmental engineering. London: Spon Press.

Chiew, Y.M. \& Parker, G. 1994. Incipient sediment motion on non-horizontal slopes. Journal of Hydraulic Research, 35(5): 649-660.

CIRIA, CUR \& CETMEF. 2007. The rock manual: The use of rock in hydraulic engineering (2nd edition). London: CIRIA.

Concha, F. 2009. Settling velocities of particulate systems. KONA Powder and Particle Journal, (27): 18-37.

De Almeida, G.A.M. \& Martín-Vide, J.P. 2009. Riprap stability: Transverse and longitudinal versus continuous protections. Journal of Hydraulic Engineering, 135(6): 447-456.

Dey, S., Dey Sarker, H.K. and Debnath, K. 1999. Sediment Treshold on Stream-Wise Bed Slopes. Paper presented at 26th National Conference on Fluid Mechanics and Fluid Power. Kharagpur, India.

Escarameia, M. \& May, R.W.P. 1992. Channel Protection: Turbulence Downstream of Structures. HR Report SR 313. 
Garde, R.J. \& Ranga Raju, K.G. 2000. Mechanics of sediment transportation and alluvial stream problems. New Delhi: New Age International Publishers.

Hoffmans, G.J.C.M. \& Verheij, H.J. 1997. Scour manual. Rotterdam, Netherlands: A.A. Balkema.

Institute for Water and Environmental Engineering. 2012. Sir Lowry's Pass River Upgrade Hydraulic Model Study.

Izbash, S.V. and Khaldre, K.Y. 1970. Hydraulics of River Channel Closure. Butterworths.

Laan, G. 1981. The Relation between Shape and Weight of Pieces of Rock. Report MAW-R81079.

Liu, H.K. 1957. Mechanics of sediment-ripple formation. Journal of the Hydraulics Division, (83)2: 1-23.

Maynord, S.T., Ruff, J. \& Abt, S. 1989. Riprap design. Journal of Hydraulic Engineering, 115(7): 937-949.

Maynord, S.T. 1995. Corps Riprap Design for Channel Protection.

Maynord, S.T. and Ruff, J.F. 1987. Riprap Stability on Channel Side Slopes. Paper presented at Hydraulic Engineering. Proceedings of the 1987 National Conference.

Mays, L.W. 1999. Hydraulic design handbook. New York: Mc Graw Hill.

Peirson, W. \& Cameron, S. 2006. Design of rock protection to prevent erosion by water flows down steep slopes. Journal of Hydraulic Engineering, 132(10): 1110-1114.

Pilarczyk, K.W. 1995. Simplified unification of stability formulae for revetments under current and wave attack, River, coastal and shoreline protection. New York: Wiley and Sons.

Powledge, G., Ralston, D., Miller, P., Chen, Y., Clopper, P. \& Temple, D. 1989. Mechanics of overflow erosion on embankments. II: Hydraulic and design considerations. Journal of Hydraulic Engineering, 115(8): 1056-1075. 
Province of British Columbia Ministry of Environment, Lands and Parks. 2000. Riprap design and construction guide.

Przedwojski, B., Blazejewski, R. \& Pilarczyk, K.W. 1995. River training techniques : Fundamentals, design and applications. Rotterdam: Balkema Publishers.

Raudkivi, A.J. 1998. Loose boundary hydraulics. Rotterdam. Balkema

Robinson, K., Rice, C. \& Kadavy, K. 1998. Design of rock chutes. American Society of Agricultural Engineers, 41(3): 621-626.

Rooseboom, A. 1992. Sediment Transport in Rivers and Reservoirs - A Southern African Perspective. Paper presented at Water Research Commission Report No. 297/1/92 Department of Environmental Affairs, Pretoria.

SANRAL. 2013. Drainage manual (6th edition). Pretoria: The South African National Road Agency

Shields, A. 1936. Anwendungen der Ähnlichkeitsmechanik und der Turbulenzforschung auf die Geschiebebewegung. Technischen Hochschule Berlin. Doctoral dissertation

Simons, D.B. \& Sentürk, F. 1992. Sediment transport technology : Water and sediment dynamics. Littleton, Colorado., USA: Water Resources Publications.

Stephenson, D.A. 1979. Rockfill in hydraulic engineering. Amsterdam: Elsevier Scientific Publishing Company.

Stoffberg, F.W. 2005. Evaluation of incipient motion criteria for rock in reno mattresses and rip rap. Masters Thesis. Stellenbosch: University of Stellenbosch.

United States Department of the Interior Bureau of Reclamation. 2012. Water measurement manual: A water resources technical publication. [Online]. Available: http://www.usbr.gov/pmts/hydraulics_lab/pubs/wmm/chap07_06.html [2013, January 24]

US Army Corps of Engineers. 2010. HEC-RAS River Analysis System: Hydraulic Reference Manual (Version 4.1). 
van der Walt, S.C. 2005. Mathematical modelling of sediment transport dynamics in the berg river considering current and future water resources development scenarios. Stellenbosch: University of Stellenbosch, 2005. Masters Thesis.

Whitehouse, R. \& Hardisty, J. 1988. Experimental assessment of two theories for the effect of bed slope on the threshold of bed-load transport. Marine Geology, 79(2): 135-139.

Wu, W.,Wang, S.Y.W. \& Jia, J. 2000. Nonuniform sediment transport in alluvial rivers. Journal of Hydraulic Research, 38(6):427-434.

Yang, C.T. 1973. Incipient motion and sediment transport. Journal of the Hydraulics Division, 99(10): 1679-1704. 


\section{APPENDIX A: FLOWMETER CALIBRATION}

\section{A1: V-Notch flow data}

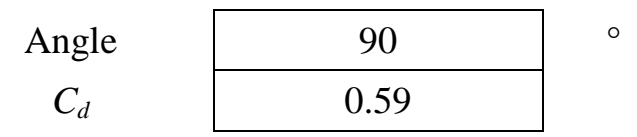

\begin{tabular}{|c|c|c|c|c|}
\hline Increment & Reference $(\mathrm{mm})$ & WL Reading $(\mathrm{mm})$ & $H(\mathrm{~m})$ & $Q(\mathrm{l} / \mathrm{s})$ \\
\hline 1 & 351.3 & 470.5 & 0.1192 & 6.8 \\
\hline 2 & 351.3 & 474.8 & 0.1235 & 7.5 \\
\hline 3 & 351.3 & 484.0 & 0.1327 & 8.9 \\
\hline 4 & 351.3 & 490.2 & 0.1389 & 10.0 \\
\hline 5 & 351.3 & 501.1 & 0.1498 & 12.1 \\
\hline 6 & 351.3 & 512.4 & 0.1611 & 14.5 \\
\hline 7 & 351.3 & 522.8 & 0.1715 & 17.0 \\
\hline 8 & 351.3 & 534.4 & 0.1831 & 20.0 \\
\hline 9 & 351.3 & 549.1 & 0.1978 & 24.3 \\
\hline 10 & 351.3 & 561.2 & 0.2099 & 28.1 \\
\hline 11 & 351.3 & 572.9 & 0.2216 & 32.2 \\
\hline 12 & 351.3 & 582.2 & 0.2309 & 35.7 \\
\hline 13 & 351.3 & 593.6 & 0.2423 & 40.3 \\
\hline 14 & 351.3 & 605.5 & 0.2542 & 45.4 \\
\hline 15 & 351.3 & 619.3 & 0.2680 & 51.8 \\
\hline 16 & 351.3 & 633.4 & 0.2821 & 58.9 \\
\hline 17 & 351.3 & 645.2 & 0.2939 & 65.3 \\
\hline 18 & 351.3 & 656.2 & 0.3049 & 71.5 \\
\hline 19 & 351.3 & 670.8 & 0.3195 & 80.4 \\
\hline 20 & 351.3 & 693.2 & 0.3419 & 95.3 \\
\hline 21 & 351.3 & 713.1 & 0.3618 & 109.7 \\
\hline 22 & 351.3 & 726.0 & 0.3747 & 119.8 \\
\hline
\end{tabular}


A2: Rectangular contracted weir flow data

\begin{tabular}{|c|c|c|c|c|}
\hline & & \multirow{5}{*}{$\begin{array}{l}\mathrm{m} \\
\mathrm{m} \\
\mathrm{m}\end{array}$} & $L / B$ & 0.8 \\
\hline$B$ & 1 & & $\alpha_{c e}$ & 0.1299 \\
\hline$L$ & 0.8 & & $\beta_{c e}$ & 1.7623 \\
\hline \multirow[t]{2}{*}{$P_{s}$} & 0.511 & & $K_{L}$ & 0.004365 \\
\hline & & & $K_{H}$ & 0.001 \\
\hline
\end{tabular}

\begin{tabular}{|c|c|c|c|c|c|c|c|c|}
\hline Increment & $\begin{array}{c}\text { Reference } \\
(\mathrm{mm})\end{array}$ & $\begin{array}{c}\text { WL Reading } \\
(\mathrm{mm})\end{array}$ & $H(\mathrm{~m})$ & $C_{e}$ & $\begin{array}{c}L_{e} \\
(\mathrm{~m})\end{array}$ & $h_{e}(\mathrm{~m})$ & $\begin{array}{c}Q \\
(1 / \mathrm{s})\end{array}$ & Volts \\
\hline 1 & 460.3 & 460.3 & 0.0000 & 1.762 & 0.804 & 0.001 & 0.0 & 0.000 \\
\hline 2 & 460.3 & 567.5 & 0.1072 & 1.790 & 0.804 & 0.108 & 51.2 & 0.774 \\
\hline 3 & 460.3 & 574.8 & 0.1145 & 1.791 & 0.804 & 0.115 & 56.5 & 0.847 \\
\hline 4 & 460.3 & 586.0 & 0.1257 & 1.794 & 0.804 & 0.127 & 65.0 & 0.987 \\
\hline 5 & 460.3 & 595.2 & 0.1349 & 1.797 & 0.804 & 0.136 & 72.3 & 1.096 \\
\hline 6 & 460.3 & 607.1 & 0.1468 & 1.800 & 0.804 & 0.148 & 82.2 & 1.239 \\
\hline 7 & 460.3 & 612.9 & 0.1526 & 1.801 & 0.804 & 0.154 & 87.1 & 1.320 \\
\hline 8 & 460.3 & 629.3 & 0.1690 & 1.805 & 0.804 & 0.170 & 101.7 & 1.538 \\
\hline 9 & 460.3 & 644.1 & 0.1838 & 1.809 & 0.804 & 0.185 & 115.5 & 1.765 \\
\hline 10 & 460.3 & 658.1 & 0.1978 & 1.813 & 0.804 & 0.199 & 129.2 & 1.950 \\
\hline 11 & 460.3 & 665.5 & 0.2052 & 1.814 & 0.804 & 0.206 & 136.6 & 2.060 \\
\hline 12 & 460.3 & 681.7 & 0.2214 & 1.819 & 0.804 & 0.222 & 153.3 & 2.310 \\
\hline 13 & 460.3 & 693.5 & 0.2332 & 1.822 & 0.804 & 0.234 & 166.0 & 2.490 \\
\hline 14 & 460.3 & 698.1 & 0.2378 & 1.823 & 0.804 & 0.239 & 171.0 & 2.580 \\
\hline 15 & 460.3 & 713.1 & 0.2528 & 1.827 & 0.804 & 0.254 & 187.8 & 2.810 \\
\hline 16 & 460.3 & 726.5 & 0.2662 & 1.830 & 0.804 & 0.267 & 203.2 & 3.070 \\
\hline 17 & 460.3 & 744.4 & 0.2841 & 1.835 & 0.804 & 0.285 & 224.5 & 3.400 \\
\hline 18 & 460.3 & 754.9 & 0.2946 & 1.837 & 0.804 & 0.296 & 237.4 & 3.570 \\
\hline 19 & 460.3 & 770.4 & 0.3101 & 1.841 & 0.804 & 0.311 & 256.9 & 3.900 \\
\hline 20 & 460.3 & 784.3 & 0.3240 & 1.845 & 0.804 & 0.325 & 274.8 & 4.140 \\
\hline
\end{tabular}




\section{APPENDIX B: LABORATORY RESULTS}

\section{B1: Numerical survey data}

Table B1-1: Water and bed levels for Test 111

\begin{tabular}{|c|c|c|c|c|c|c|}
\hline \multicolumn{3}{|c|}{ Water level $(\mathrm{mm})$} & \multicolumn{5}{|c|}{ Bed level $(\mathrm{mm})$} \\
\hline Chainage & $@ Q_{m}$ & $@ Q_{f}$ & Chainage & Initial & Post $Q_{m}$ & Post $Q_{f}$ \\
\hline 15000 & 870 & 889 & 14720 & 539 & 538 & 539 \\
\hline 14020 & 804 & 726 & 14520 & 612 & 636 & 608 \\
\hline 13620 & 710 & 678 & 14320 & 712 & 712 & 684 \\
\hline 13220 & 618 & 737 & 14220 & 699 & 699 & 717 \\
\hline 12820 & 594 & 592 & 14020 & 725 & 719 & 598 \\
\hline 12420 & 530 & 531 & 13820 & 671 & 670 & 544 \\
\hline 12120 & 524 & & 13620 & 662 & 593 & 549 \\
\hline & & 13420 & 585 & 530 & 564 \\
\hline & 13220 & 547 & 504 & 600 \\
\hline & 13020 & 519 & 507 & 514 \\
\hline & 12820 & 471 & 491 & 450 \\
\hline & 12620 & 510 & 522 & 412 \\
\hline & 12420 & 409 & 476 & 420 \\
\hline & 12220 & 480 & 484 & 444 \\
\hline & 12020 & 439 & 450 & 470 \\
\hline
\end{tabular}

Table B1-2: Water and bed levels for Test 121

\begin{tabular}{|c|c|c|c|c|c|c|}
\hline \multicolumn{3}{|c|}{ Water level (mm) } & \multicolumn{5}{|c|}{ Bed level (mm) } \\
\hline Chainage & $@ Q_{m}$ & $@ Q_{f}$ & Chainage & Initial & Post $Q_{m}$ & Post $Q_{f}$ \\
\hline 15000 & 855 & 851 & 14720 & 539 & 539 & 539 \\
\hline 14020 & 785 & 706 & 14520 & 629 & 629 & 628 \\
\hline 13700 & 714 & 652 & 14320 & 727 & 726 & 726 \\
\hline 13520 & 682 & & 14220 & 715 & 713 & 657 \\
\hline 13380 & & 552 & 14020 & 724 & 723 & 585 \\
\hline 13060 & 514 & 528 & 13820 & 655 & 650 & 529 \\
\hline 12740 & 397 & 562 & 13620 & 667 & 668 & 502 \\
\hline & & 13420 & 600 & 637 & 470 \\
\hline & & 13220 & 502 & 503 & 443 \\
\hline & 13020 & 485 & 487 & 401 \\
\hline & 12820 & 378 & 377 & 411 \\
\hline & 12620 & 304 & 304 & 489 \\
\hline & 12420 & 284 & 330 & 337 \\
\hline & 12220 & 274 & 274 & 385 \\
\hline & 12020 & 240 & 256 & 334 \\
\hline
\end{tabular}


Table B1-3: Water and bed levels for Test 131

\begin{tabular}{|c|c|c|c|c|c|c|}
\hline \multicolumn{3}{|c|}{ Water level (mm) } & \multicolumn{4}{|c|}{ Bed level (mm) } \\
\hline Chainage & $@ Q_{m}$ & $@ Q_{f}$ & Chainage & Initial & Post $Q_{m}$ & Post $Q_{f}$ \\
\hline 15000 & 801 & 833 & 14720 & 538 & 538 & 539 \\
\hline 14020 & 761 & 671 & 14520 & 604 & 603 & 607 \\
\hline 13620 & 585 & 547 & 14320 & 592 & 626 & 621 \\
\hline 13220 & 515 & 574 & 14220 & 736 & 735 & 747 \\
\hline 12820 & 299 & 417 & 14020 & 728 & 728 & 614 \\
\hline 12420 & 187 & 330 & 13820 & 682 & 655 & 600 \\
\hline 12120 & 187 & 244 & 13620 & 587 & 528 & 474 \\
\hline & & & 13420 & 498 & 499 & 423 \\
\hline & & & 13220 & 490 & 490 & 544 \\
\hline & & & 13020 & 349 & 352 & 418 \\
\hline & & & 12820 & 259 & 252 & 377 \\
\hline & & & 12620 & 246 & 245 & 393 \\
\hline & & & 12420 & 174 & 175 & 281 \\
\hline & & & 12220 & 104 & 132 & 143 \\
\hline & & & 12020 & 108 & 107 & 106 \\
\hline
\end{tabular}

Table B1-4: Water and bed levels for Test 211

\begin{tabular}{|c|c|c|c|c|c|c|}
\hline \multicolumn{3}{|c|}{ Water level $(\mathrm{mm})$} & \multicolumn{4}{|c|}{ Bed level $(\mathrm{mm})$} \\
\hline Chainage & $@ Q_{m}$ & $@ Q_{f}$ & Chainage & Initial & Post $Q_{m}$ & Post $Q_{f}$ \\
\hline 15000 & 894 & 887 & 14820 & 538 & 538 & 539 \\
\hline 14020 & 845 & 729 & 14520 & 611 & 610 & 607 \\
\hline 13770 & 748 & 653 & 14320 & 678 & 682 & 637 \\
\hline 13520 & 720 & 584 & 14220 & 691 & 725 & 640 \\
\hline 13270 & 679 & 557 & 14020 & 758 & 720 & 596 \\
\hline 13020 & 654 & 567 & 13820 & 697 & 652 & 542 \\
\hline 12770 & 680 & 574 & 13620 & 655 & 616 & 470 \\
\hline & & 13420 & 645 & 651 & 440 \\
\cline { 3 - 6 } & & 13220 & 601 & 600 & 421 \\
\cline { 3 - 6 } & 13020 & 547 & 552 & 442 \\
\cline { 3 - 6 } & 12820 & 557 & 547 & 468 \\
\cline { 3 - 6 } & 12620 & 565 & 566 & 453 \\
\hline
\end{tabular}


Table B1-5: Water and bed levels for Test 221

\begin{tabular}{|c|c|c|c|c|c|c|}
\hline \multicolumn{3}{|c|}{ Water level $(\mathrm{mm})$} & \multicolumn{5}{|c|}{ Bed level $(\mathrm{mm})$} \\
\hline Chainage & $@ Q_{m}$ & $@ Q_{f}$ & Chainage & Initial & Post $Q_{m}$ & Post $Q_{f}$ \\
\hline 15000 & 850 & 848 & 14720 & 539 & 538 & 539 \\
\hline 14020 & 754 & 688 & 14520 & 625 & 623 & 624 \\
\hline 13770 & 671 & 648 & 14320 & 709 & 707 & 618 \\
\hline 13520 & 595 & 659 & 14220 & 722 & 723 & 608 \\
\hline 13270 & 591 & 694 & 14020 & 668 & 668 & 594 \\
\hline 13020 & 544 & 645 & 13820 & 640 & 601 & 515 \\
\hline 12770 & 536 & 566 & 13620 & 610 & 518 & 525 \\
\hline & & 13420 & 550 & 492 & 531 \\
\cline { 4 - 7 } & & 13220 & 476 & 502 & 528 \\
\cline { 3 - 7 } & 13020 & 481 & 485 & 465 \\
\cline { 3 - 7 } & 12820 & 482 & 478 & 491 \\
\cline { 3 - 7 } & 12620 & 412 & 485 & 457 \\
\cline { 3 - 6 }
\end{tabular}

Table B1-6: Water and bed levels for Test 231

\begin{tabular}{|c|c|c|c|c|c|c|}
\hline \multicolumn{3}{|c|}{ Water level $(\mathrm{mm})$} & \multicolumn{5}{|c|}{ Bed level $(\mathrm{mm})$} \\
\hline Chainage & $@ Q_{m}$ & $@ Q_{f}$ & Chainage & Initial & Post $Q_{m}$ & Post $Q_{f}$ \\
\hline 15000 & 828 & 834 & 14720 & 538 & 538 & 538 \\
\hline 14020 & 779 & 678 & 14520 & 611 & 612 & 616 \\
\hline 13770 & 671 & 623 & 14320 & 682 & 679 & 656 \\
\hline 13520 & 585 & 667 & 14220 & 731 & 731 & 646 \\
\hline 13270 & 472 & 540 & 14020 & 680 & 677 & 592 \\
\hline 13020 & 423 & 555 & 13820 & 664 & 660 & 535 \\
\hline 12770 & 461 & 554 & 13620 & 588 & 585 & 471 \\
\hline & & 13420 & 486 & 450 & 444 \\
\hline & & 13220 & 426 & 436 & 431 \\
\cline { 4 - 7 } & 13020 & 353 & 350 & 445 \\
\cline { 4 - 7 } & 12820 & 421 & 420 & 468 \\
\cline { 3 - 7 } & 12620 & 334 & 355 & 453 \\
\hline
\end{tabular}


Table B1-7: Water and bed levels for Test 232

\begin{tabular}{|c|c|c|c|c|c|c|}
\hline \multicolumn{3}{|c|}{ Water level (mm) } & \multicolumn{4}{|c|}{ Bed level (mm) } \\
\hline Chainage & $@ Q_{m}$ & $@ Q_{f}$ & Chainage & Initial & Post $Q_{m}$ & Post $Q_{f}$ \\
\hline 15000 & 951 & 1020 & 14720 & 639 & 639 & 639 \\
\hline 14020 & 901 & 846 & 14520 & 794 & 794 & 789 \\
\hline 13770 & 814 & 768 & 14320 & 803 & 799 & 823 \\
\hline 13520 & 682 & 754 & 14220 & 796 & 795 & 795 \\
\hline 13220 & 593 & 724 & 14020 & 828 & 826 & 704 \\
\hline 13020 & 600 & 725 & 13820 & 806 & 707 & 637 \\
\hline 12820 & 605 & 727 & 13770 & 788 & 728 & 623 \\
\hline & & & 13620 & 646 & 714 & 609 \\
\hline & & & 13520 & 667 & 628 & 549 \\
\hline & & & 13420 & 598 & 599 & 634 \\
\hline & & & 13220 & 532 & 551 & 558 \\
\hline & & & 13020 & 478 & 521 & 583 \\
\hline & & & 12820 & 485 & 475 & 609 \\
\hline & & & 12620 & 489 & 465 & 648 \\
\hline
\end{tabular}

Table B1-8: Water and bed levels for Test 222

\begin{tabular}{|c|c|c|c|c|c|c|}
\hline \multicolumn{3}{|c|}{ Water level $(\mathrm{mm})$} & \multicolumn{4}{|c|}{ Bed level (mm) } \\
\hline Chainage & $@ Q_{m}$ & $@ Q_{f}$ & Chainage & Initial & Post $Q_{m}$ & Post $Q_{f}$ \\
\hline 15000 & 957 & 1064 & 14720 & 639 & 639 & 639 \\
\hline 14020 & 865 & 922 & 14520 & 752 & 747 & 746 \\
\hline 13770 & 789 & 819 & 14320 & 775 & 775 & 748 \\
\hline 13520 & 705 & 737 & 14220 & 774 & 772 & 759 \\
\hline 13220 & 678 & 749 & 14020 & 812 & 756 & 679 \\
\hline 13020 & 691 & 806 & 13820 & 700 & 688 & 649 \\
\hline 12820 & 665 & 829 & 13770 & 704 & 679 & 631 \\
\hline & & & 13620 & 704 & 658 & 659 \\
\hline & & & 13520 & 698 & 610 & 577 \\
\hline & & & 13420 & 631 & 631 & 628 \\
\hline & & & 13220 & 621 & 580 & 497 \\
\hline & & & 13020 & 655 & 656 & 665 \\
\hline & & & 12820 & 581 & 566 & 669 \\
\hline & & & 12620 & 537 & 549 & 538 \\
\hline
\end{tabular}


Table B1-9: Water and bed levels for Test 212

\begin{tabular}{|c|c|c|c|c|c|c|}
\hline \multicolumn{3}{|c|}{ Water level (mm) } & \multicolumn{4}{|c|}{ Bed level (mm) } \\
\hline Chainage & $@ Q_{m}$ & $@ Q_{f}$ & Chainage & Initial & Post $Q_{m}$ & Post $Q_{f}$ \\
\hline 15000 & 1074 & 1110 & 14720 & 639 & 639 & 639 \\
\hline 14020 & 1007 & 1034 & 14520 & 682 & 682 & 680 \\
\hline 13770 & 940 & 967 & 14320 & 736 & 736 & 737 \\
\hline 13520 & 837 & 867 & 14220 & 782 & 785 & 781 \\
\hline 13220 & 786 & 808 & 14020 & 798 & 798 & 795 \\
\hline 13020 & 814 & 814 & 13820 & 759 & 759 & 801 \\
\hline 12820 & 852 & 851 & 13770 & 709 & 778 & 781 \\
\hline & & & 13620 & 704 & 698 & 668 \\
\hline & & & 13520 & 687 & 712 & 713 \\
\hline & & & 13420 & 645 & 645 & 645 \\
\hline & & & 13220 & 666 & 668 & 666 \\
\hline & & & 13020 & 579 & 578 & 576 \\
\hline & & & 12820 & 598 & 598 & 593 \\
\hline & & & 12620 & 609 & 604 & 603 \\
\hline
\end{tabular}

Table B1-10: Water and bed levels for Test 132

\begin{tabular}{|c|c|c|c|c|c|c|}
\hline \multicolumn{3}{|c|}{ Water level (mm) } & \multicolumn{4}{|c|}{ Bed level (mm) } \\
\hline Chainage & $@ Q_{m}$ & $@ Q_{f}$ & Chainage & Initial & Post $Q_{m}$ & Post $Q_{f}$ \\
\hline 15000 & 922 & 912 & 14720 & 639 & 639 & 639 \\
\hline 14020 & 827 & 731 & 14520 & 743 & 742 & 742 \\
\hline 13620 & 696 & 776 & 14320 & 807 & 807 & 727 \\
\hline 13220 & 586 & 621 & 14220 & 856 & 856 & 590 \\
\hline 12820 & 395 & 529 & 14020 & 788 & 787 & 609 \\
\hline 12420 & 299 & 408 & 13820 & 707 & 730 & 571 \\
\hline 12220 & 307 & 407 & 13620 & 654 & 655 & 670 \\
\hline & & & 13420 & 582 & 582 & 631 \\
\hline & & & 13220 & 549 & 560 & 585 \\
\hline & & & 13020 & 491 & 441 & 434 \\
\hline & & & 12820 & 344 & 322 & 510 \\
\hline & & & 12620 & 281 & 281 & 390 \\
\hline & & & 12420 & 216 & 220 & 292 \\
\hline & & & 12220 & 167 & 167 & 226 \\
\hline & & & 12020 & 216 & 214 & 236 \\
\hline
\end{tabular}


Table B1-11: Water and bed levels for Test 122

\begin{tabular}{|c|c|c|c|c|c|c|}
\hline \multicolumn{3}{|c|}{ Water level (mm) } & \multicolumn{4}{|c|}{ Bed level (mm) } \\
\hline Chainage & $@ Q_{m}$ & $@ Q_{f}$ & Chainage & Initial & Post $Q_{m}$ & Post $Q_{f}$ \\
\hline 15000 & 949 & 1055 & 14720 & 639 & 639 & 639 \\
\hline 14020 & 878 & 941 & 14520 & 765 & 767 & 764 \\
\hline 13620 & 764 & 759 & 14320 & 834 & 709 & 710 \\
\hline 13220 & 688 & 658 & 14220 & 845 & 843 & 731 \\
\hline 12820 & 590 & & 14020 & 768 & 761 & 722 \\
\hline 12420 & 504 & 670 & 13820 & 787 & 696 & 635 \\
\hline 12220 & 490 & 592 & 13620 & 693 & 691 & 542 \\
\hline & & & 13420 & 656 & 654 & 526 \\
\hline & & & 13220 & 625 & 550 & 414 \\
\hline & & & 13020 & 556 & 525 & 522 \\
\hline & & & 12820 & 504 & 492 & 590 \\
\hline & & & 12620 & 485 & 472 & 423 \\
\hline & & & 12420 & 467 & 468 & 467 \\
\hline & & & 12220 & 398 & 398 & 396 \\
\hline & & & 12020 & 414 & 415 & 398 \\
\hline
\end{tabular}

Table B1-12: Water and bed levels for Test 112

\begin{tabular}{|c|c|c|c|c|c|c|}
\hline \multicolumn{3}{|c|}{ Water level (mm) } & \multicolumn{4}{|c|}{ Bed level (mm) } \\
\hline Chainage & $@ Q_{m}$ & $@ Q_{f}$ & Chainage & Initial & Post $Q_{m}$ & Post $Q_{f}$ \\
\hline 15000 & 1021 & 1111 & 14720 & 639 & 639 & 639 \\
\hline 14020 & 963 & 1097 & 14520 & 687 & 687 & 686 \\
\hline 13620 & 837 & 880 & 14320 & 827 & 826 & 826 \\
\hline 13220 & 735 & 754 & 14220 & 801 & 803 & 805 \\
\hline 12820 & 709 & 730 & 14020 & 864 & 863 & 862 \\
\hline 12420 & 655 & 735 & 13820 & 809 & 812 & 809 \\
\hline 12220 & 667 & 734 & 13620 & 753 & 748 & 755 \\
\hline & & & 13420 & 661 & 660 & 636 \\
\hline & & & 13220 & 680 & 616 & 615 \\
\hline & & & 13020 & 612 & 610 & 608 \\
\hline & & & 12820 & 564 & 577 & 564 \\
\hline & & & 12620 & 554 & 604 & 594 \\
\hline & & & 12420 & 525 & 525 & 558 \\
\hline & & & 12220 & 520 & 544 & 517 \\
\hline & & & 12020 & 546 & 546 & 549 \\
\hline
\end{tabular}


B2: Graphical survey data

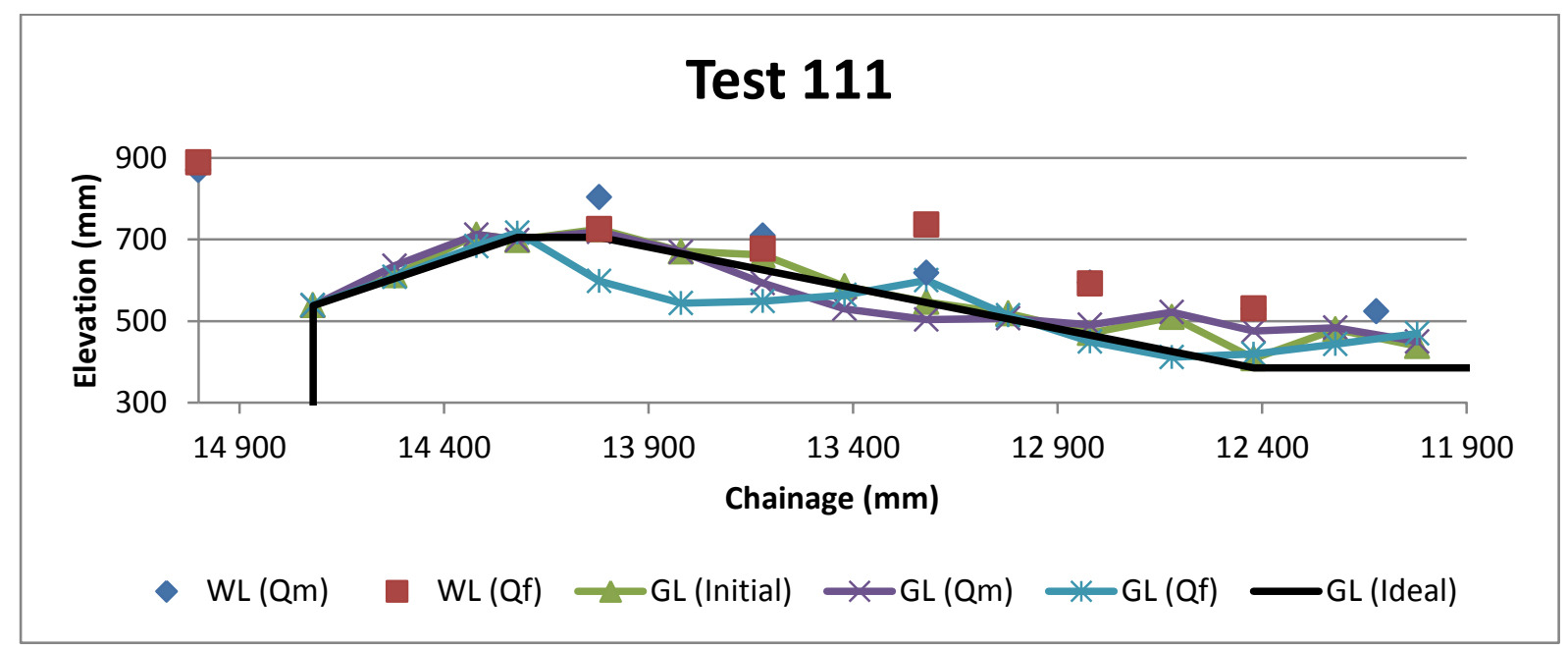

Figure B2-1: Experimental results for Test 111

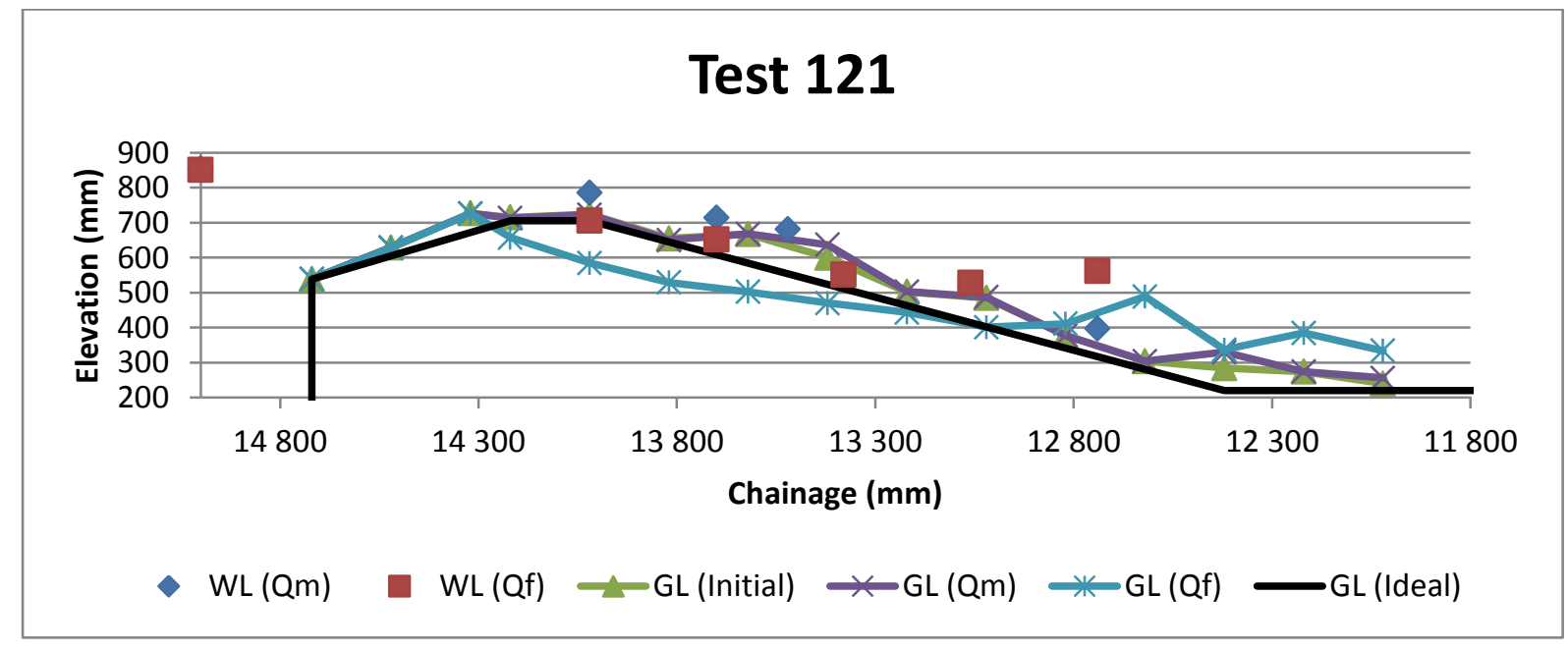

Figure B2-2: Experimental results for Test 121 


\section{Test 131}

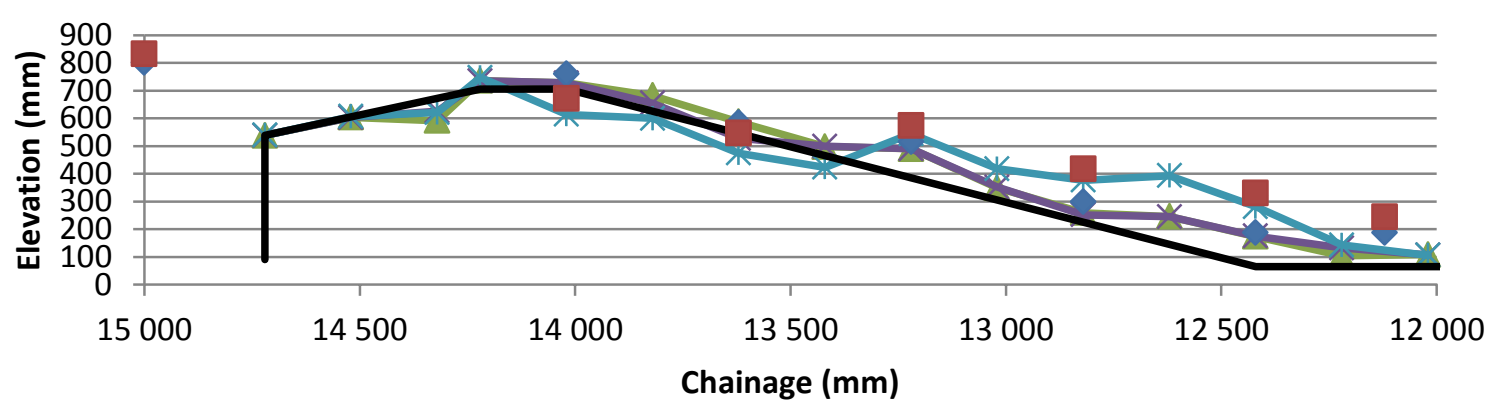

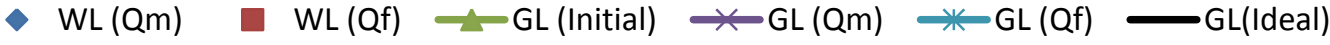

Figure B2-3: Experimental results for Test 131

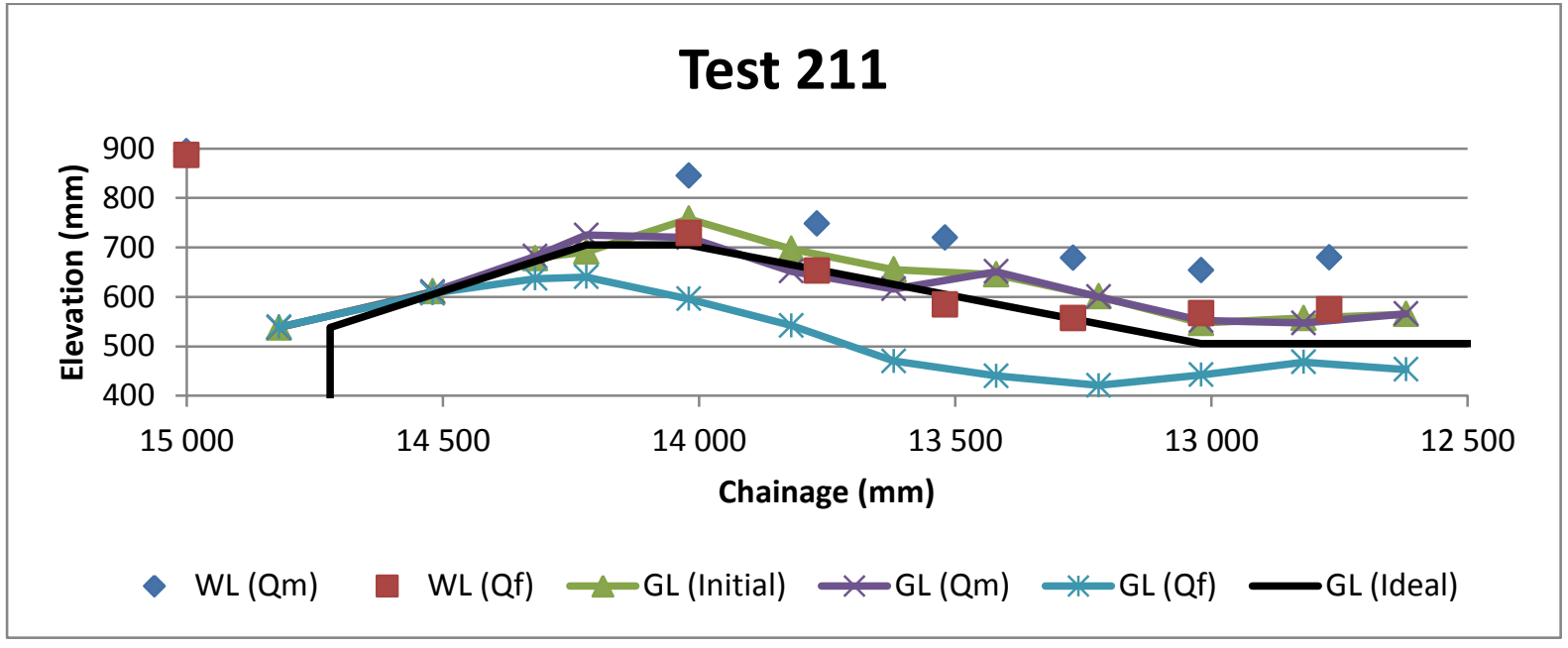

Figure B2-4: Experimental results for Test 211

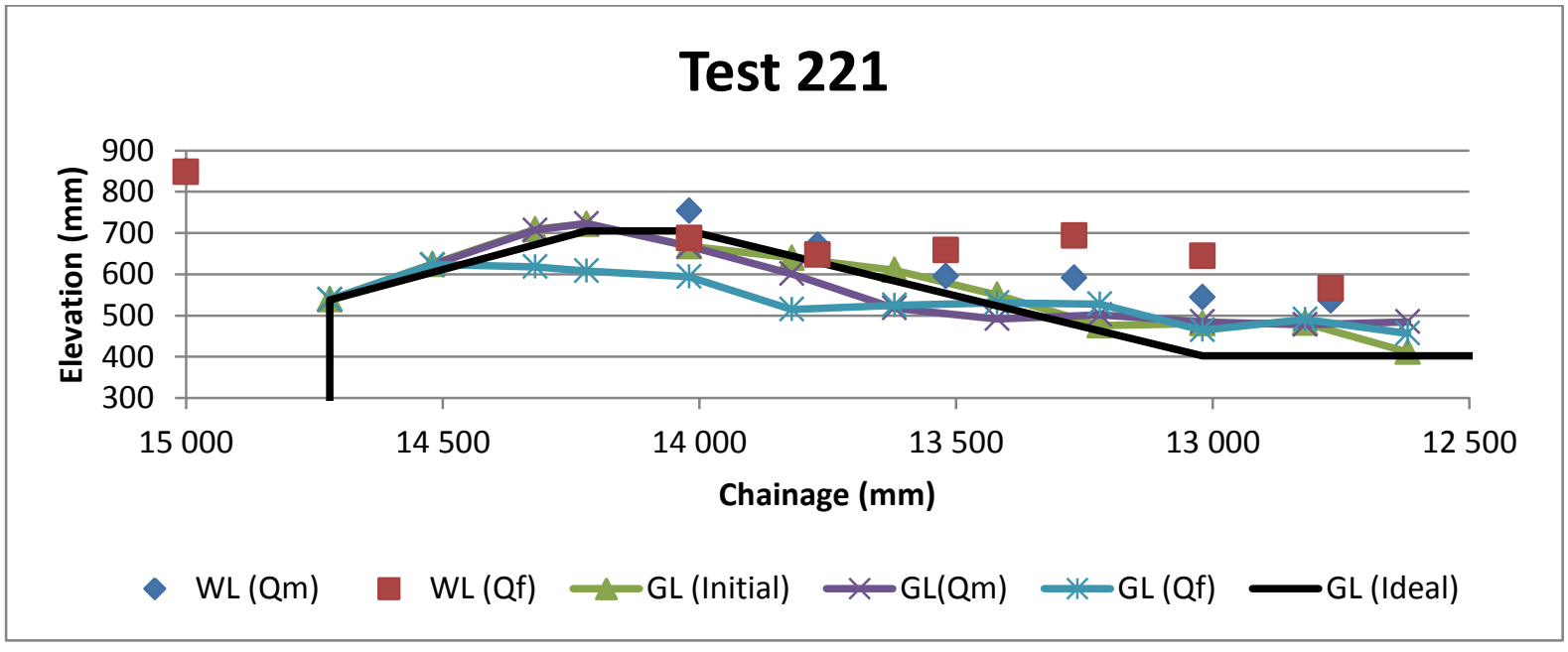

Figure B2-5: Experimental results for Test 221 


\section{Test 231}

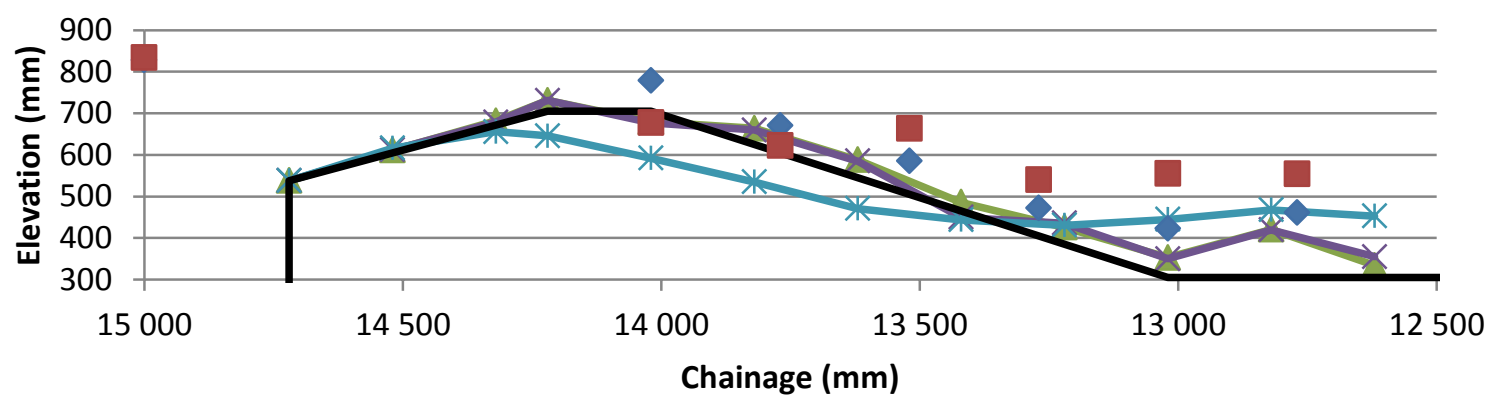

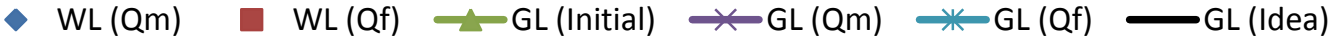

Figure B2-6: Experimental results for Test 231

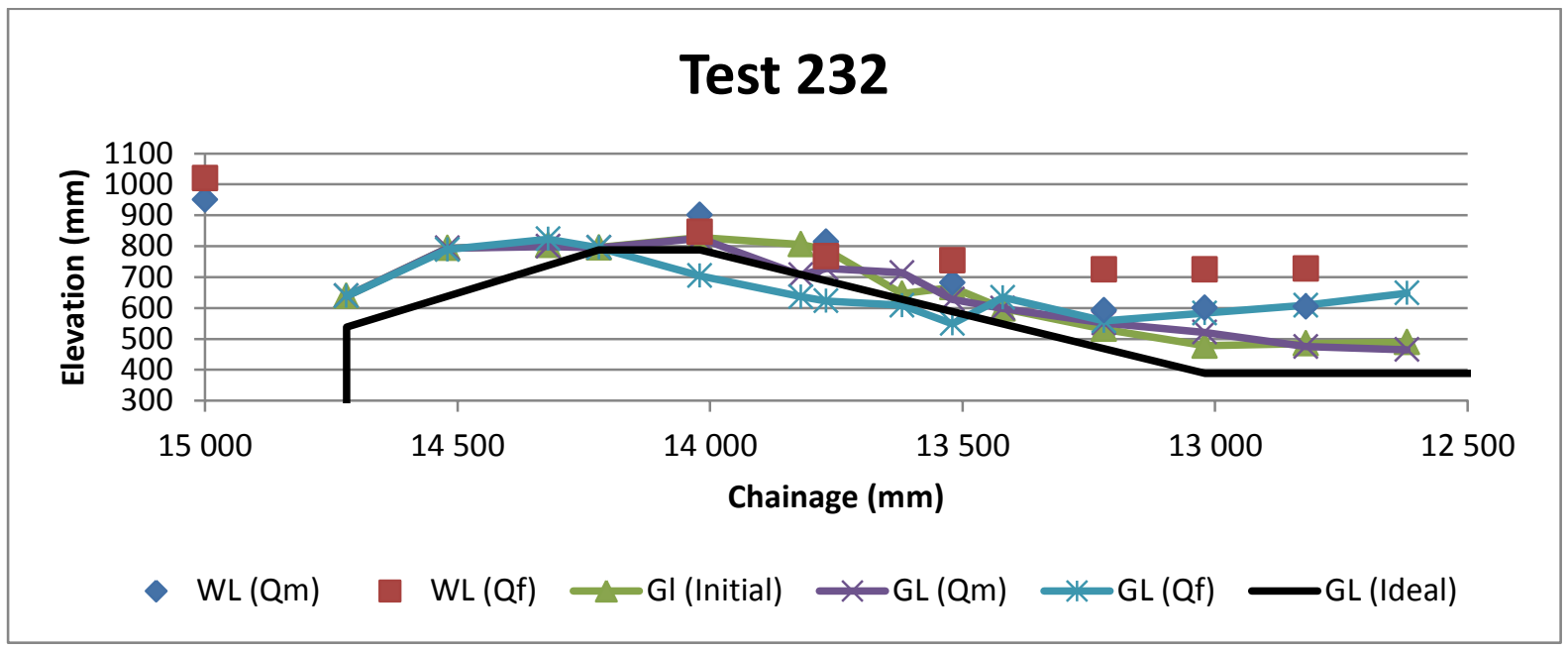

Figure B2-7: Experimental results for Test 231

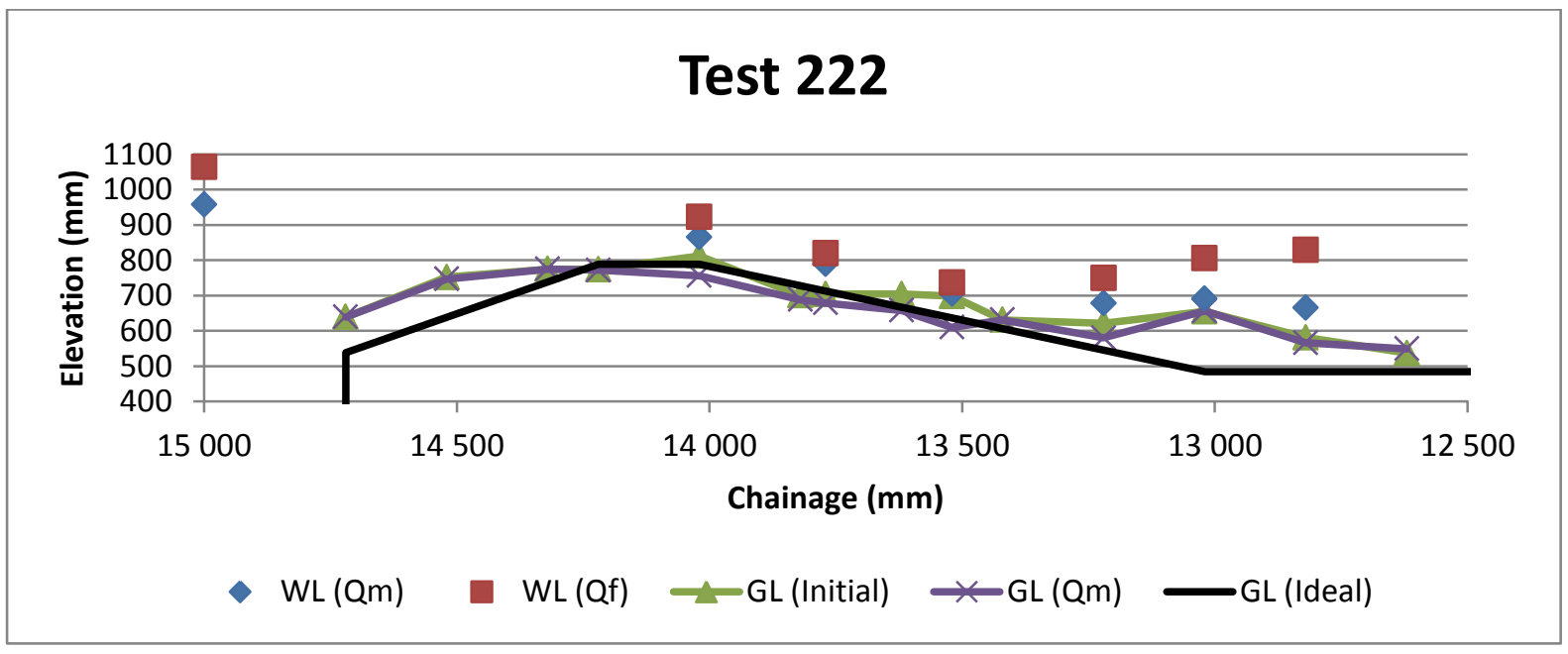

Figure B2-8: Experimental results for Test 222 


\section{Test 212}

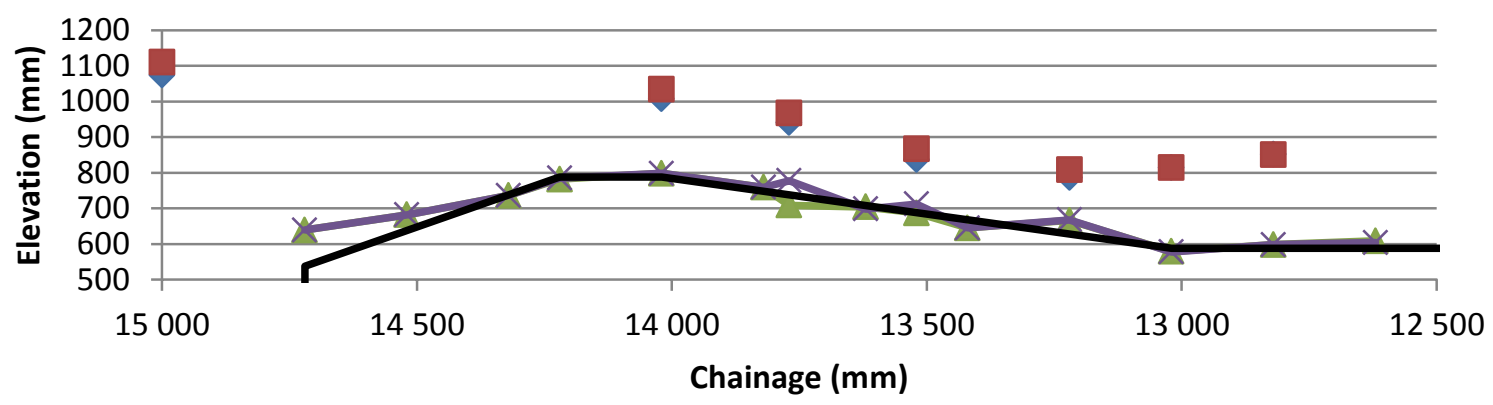

$\bullet \mathrm{WL}(\mathrm{Qm}) \quad \mathrm{WL}(\mathrm{Qf}) \leadsto \mathrm{GL}$ (Initial) $\longleftarrow \mathrm{GL}(\mathrm{Qm}) \rightleftharpoons \mathrm{GL}$ (Ideal)

Figure B2-9: Experimental results for Test 212

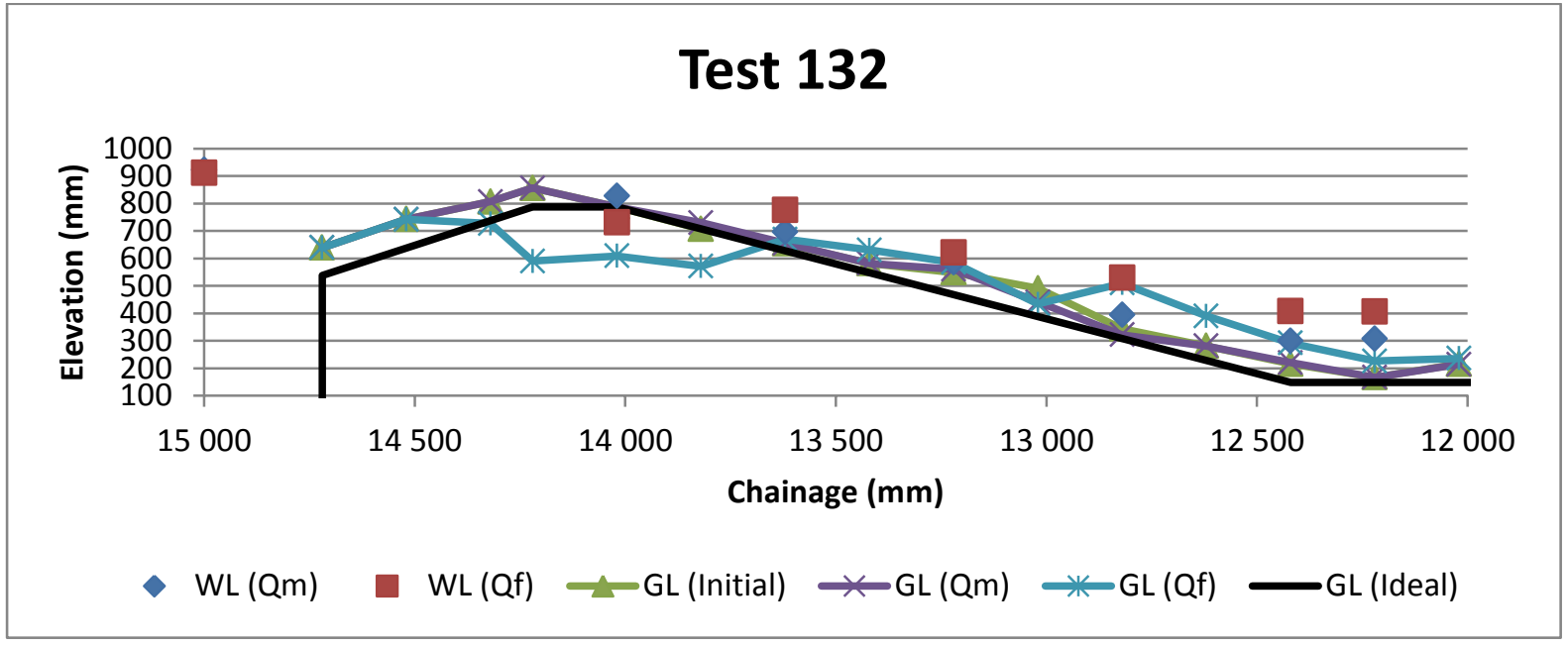

Figure B2-10: Experimental results for Test 132

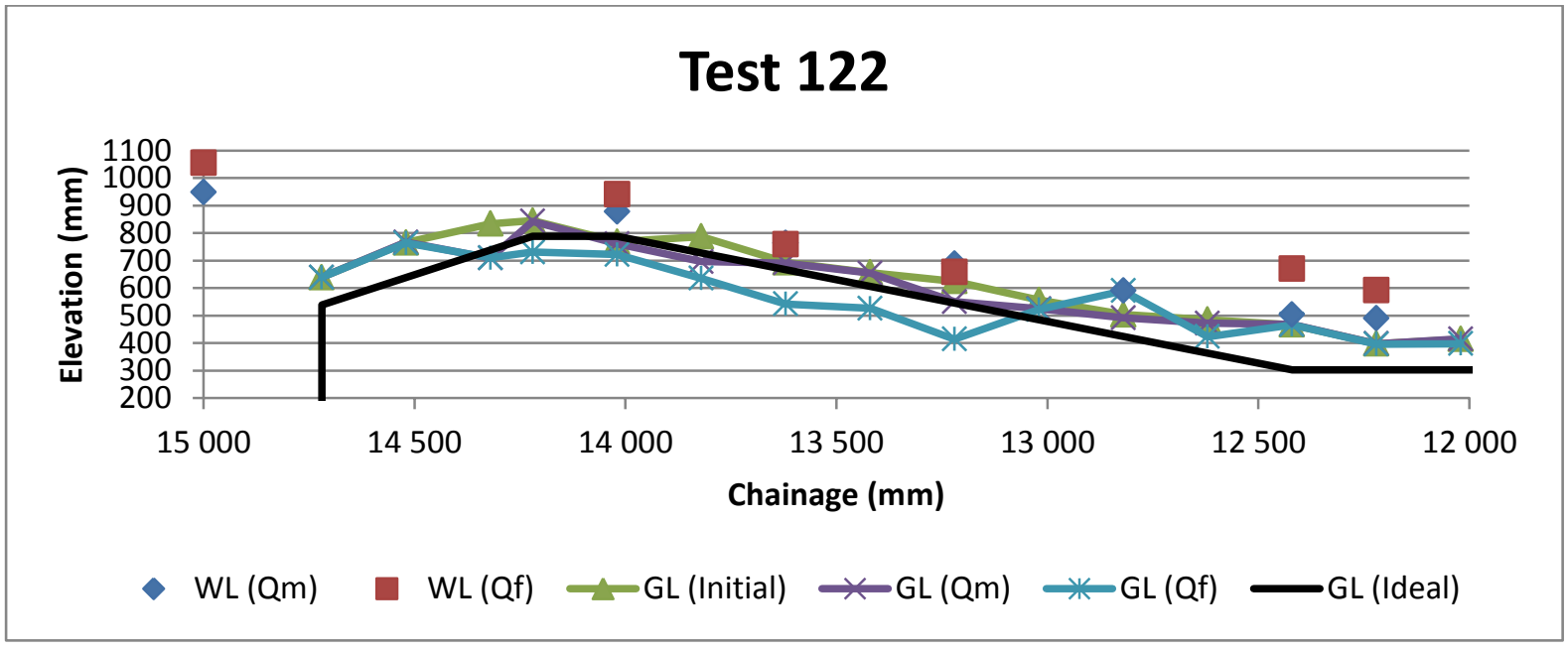

Figure B2-11: Experimental results for Test 122 
Test 112

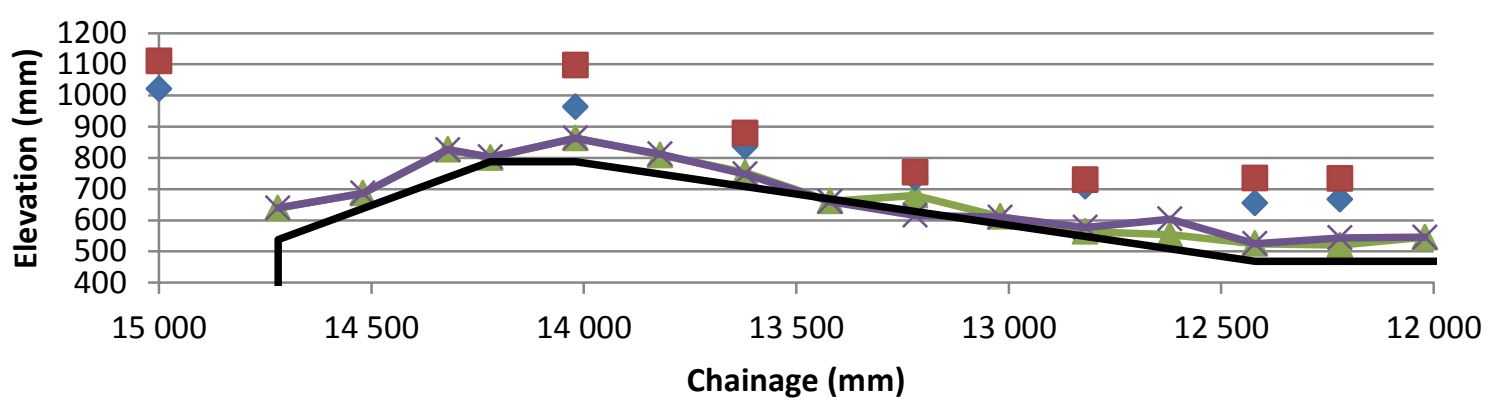

-WL (Qm) $\square \mathrm{WL}(\mathrm{Qf}) \multimap \mathrm{GL}$ (Initial) $\leftarrow \mathrm{GL}(\mathrm{Qm}) \rightleftharpoons \mathrm{GL}$ (Ideal)

Figure B2-12: Experimental results for Test 112 


\section{APPENDIX C: REPRESENTATIVE FLOW DEPTHS}

Note: The following figures depict the areas considered critical in terms of incipient motion. The orange arrows indicate the flow depth.

Test 121 and 212 were treated as follows: their critical area is not immediately obvious. The survey shows that some material deposited just below the indicated critical area. This implies that material had to be eroded from the upstream part, and thus this part is considered as critical.

In addition, two areas have been identified where erosion has occurred in Test 122, but the lower part was selected since the erosion seemed to be less severe, thus the water level is more accurate in that area. Also, more data points are available in that vicinity.

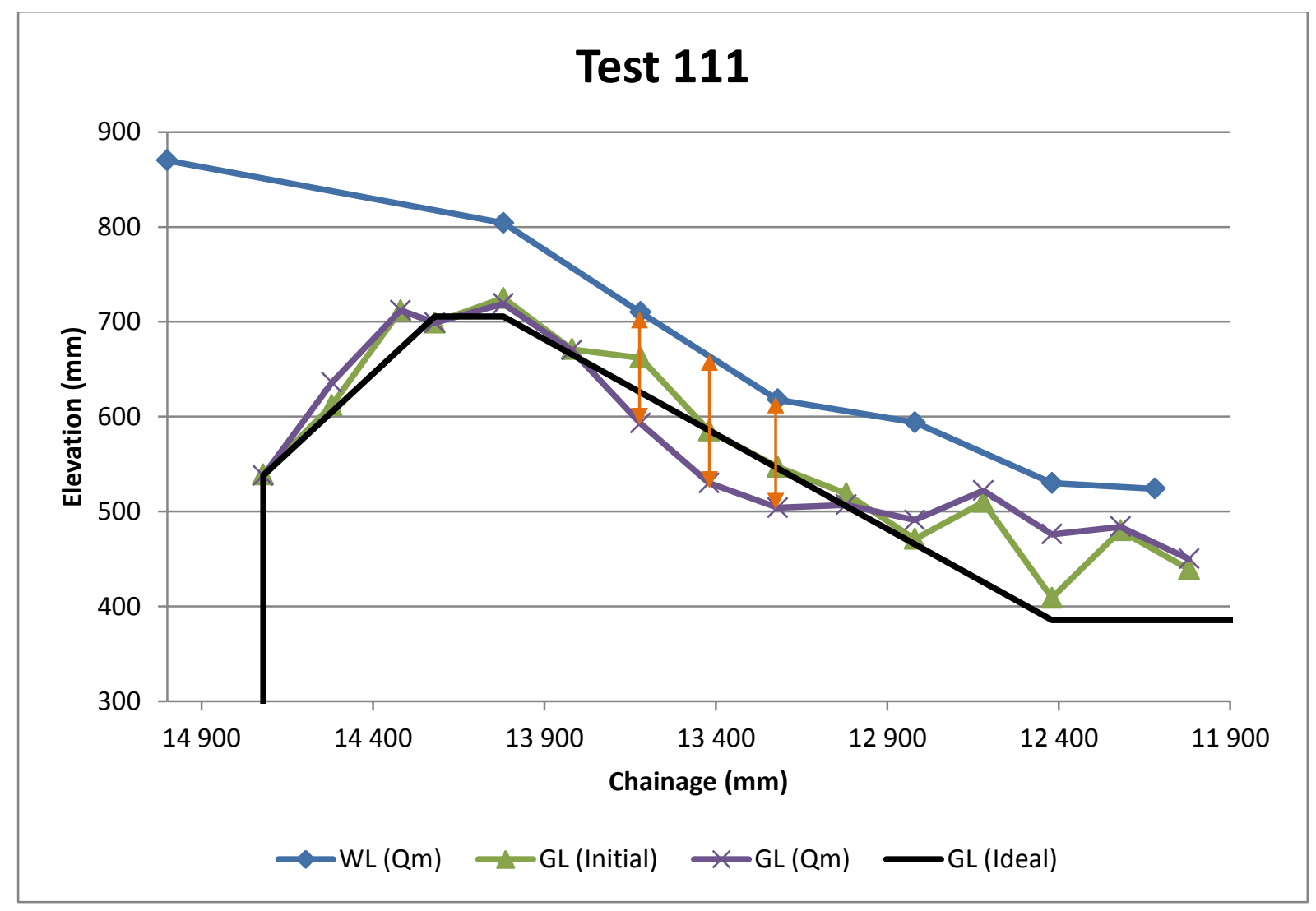

Figure C-1: Representative condition of incipient motion for Test 111 


\section{Test 121}

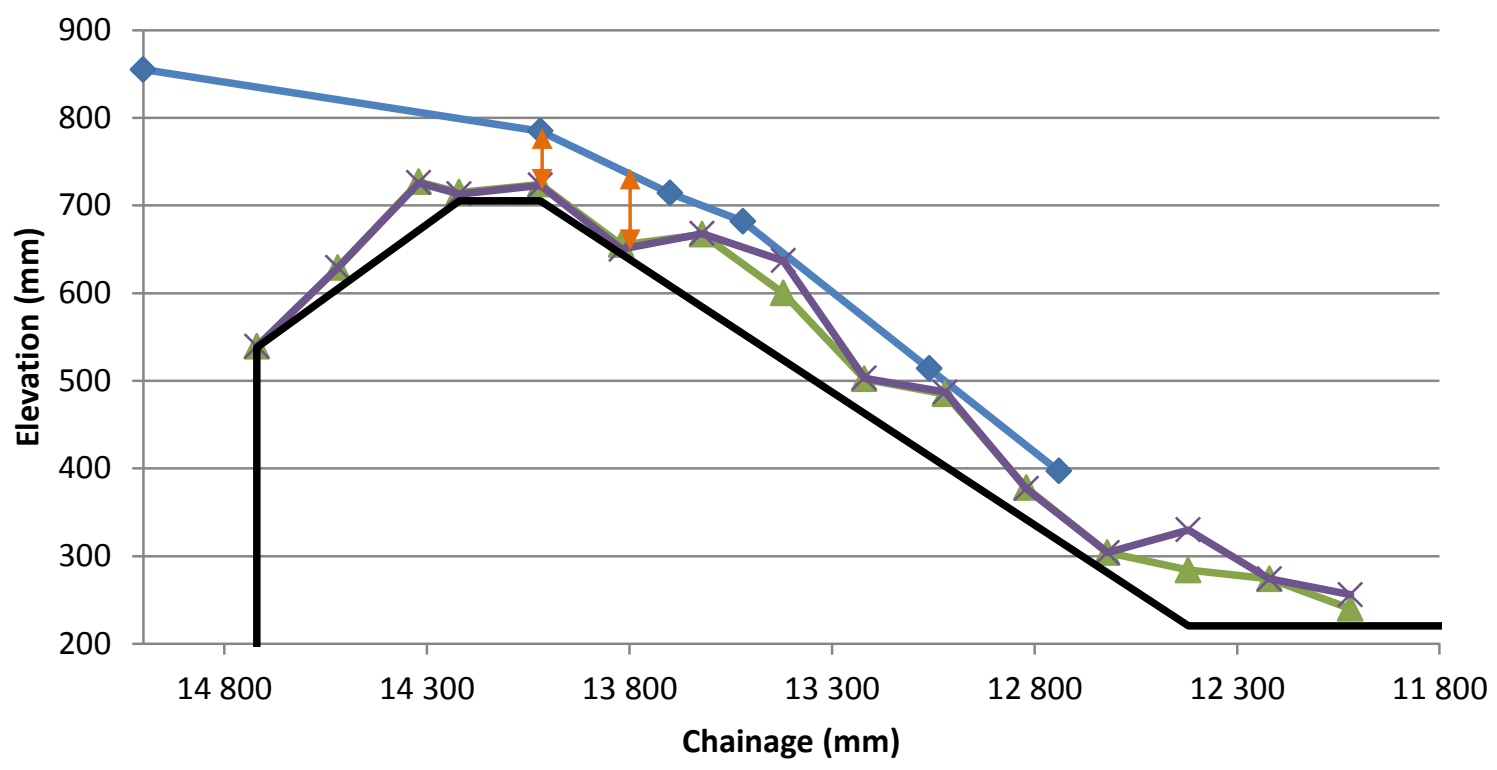

$\leadsto \mathrm{WL}(\mathrm{Qm}) \quad \mathrm{GL}$ (Initial) $\quad$ Ground $(\mathrm{Qm}) \multimap \mathrm{GL}$ (Ideal)

Figure C-2: Representative condition of incipient motion for Test 121

Test 131

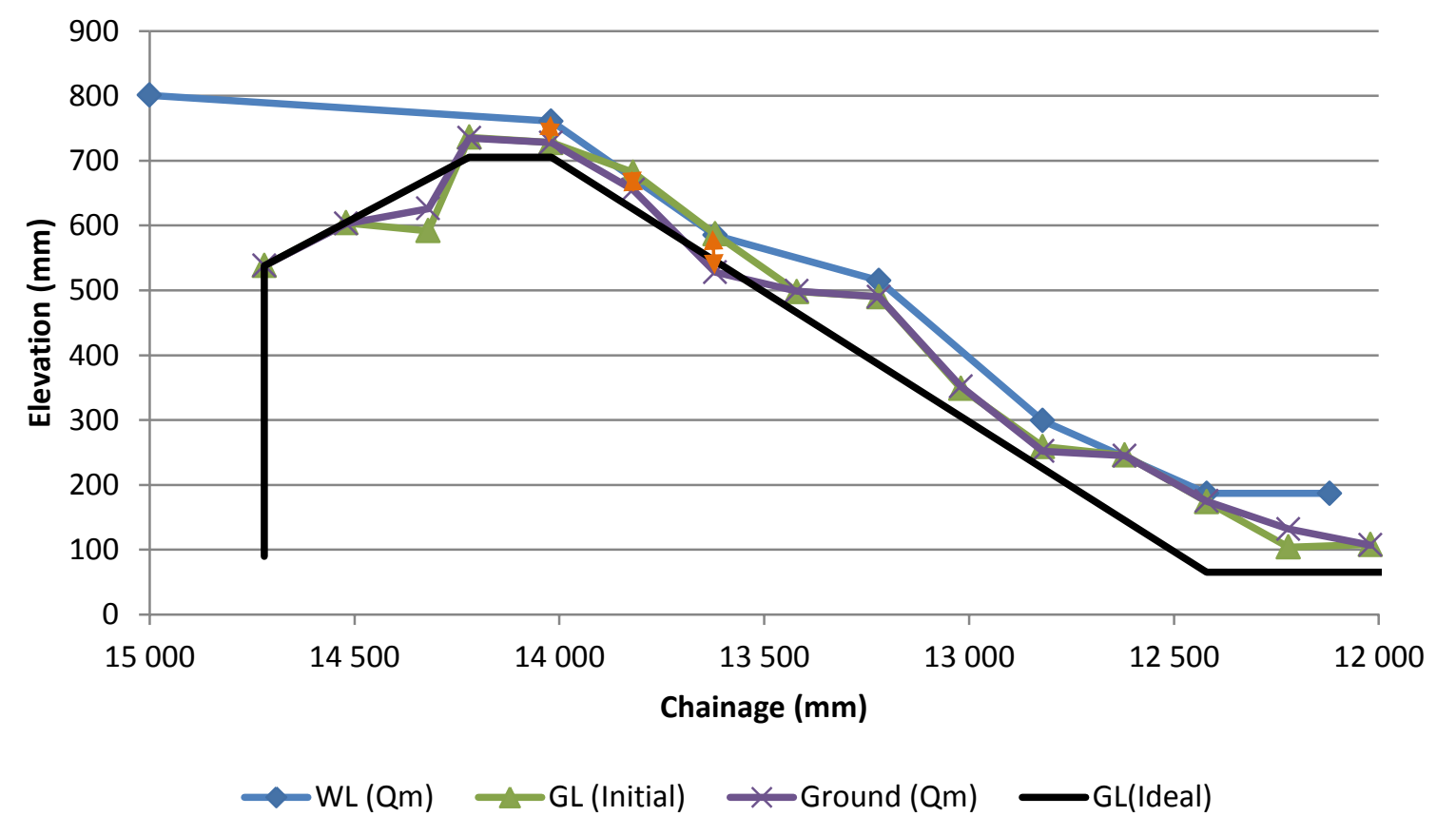

Figure C-3: Representative condition of incipient motion for Test 131 


\section{Test 211}

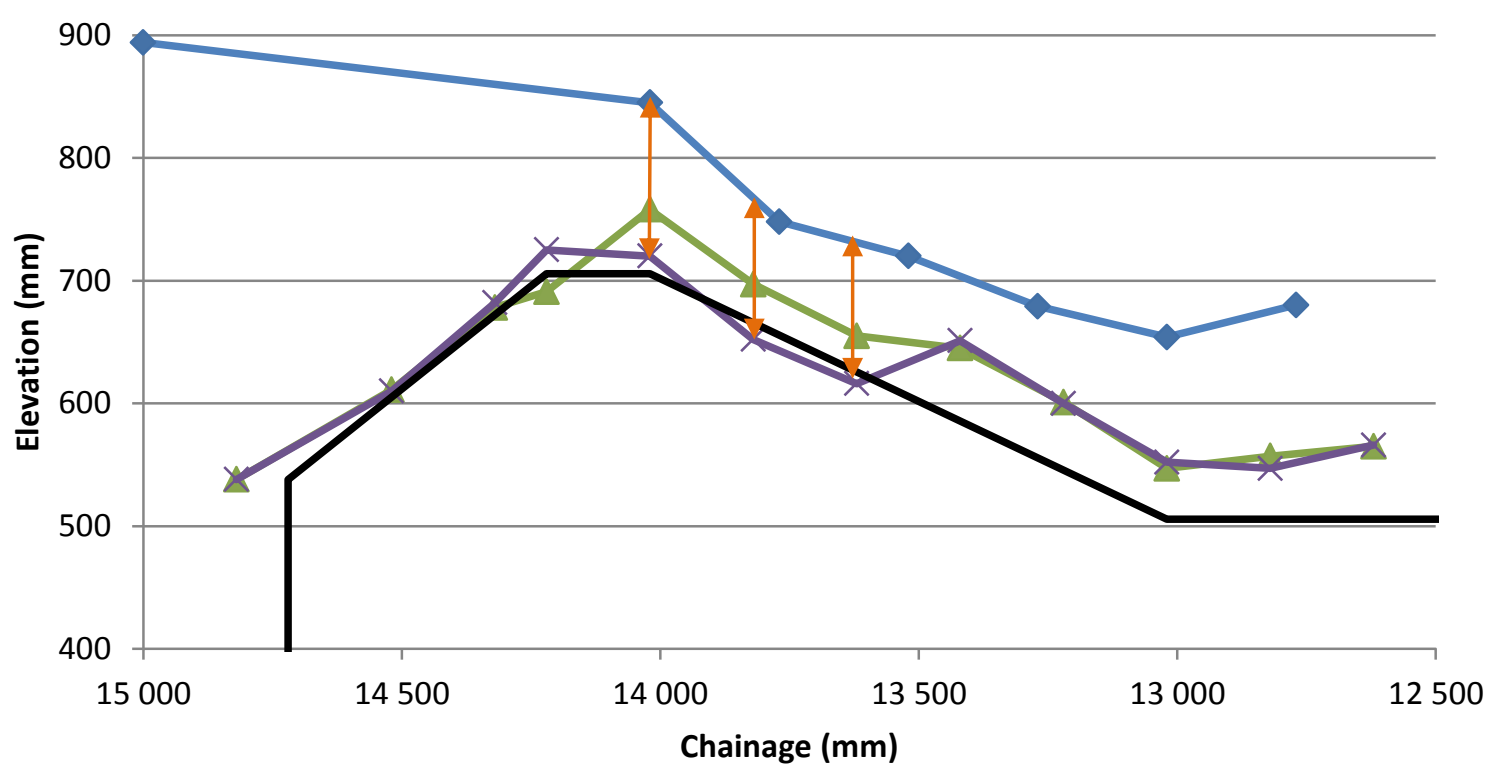

$\leadsto \mathrm{WL}(\mathrm{Qm}) \multimap \mathrm{GL}$ (Initial) $\quad$ Ground $(\mathrm{Qm}) \multimap \mathrm{GL}$ (Ideal)

Figure C-4: Representative condition of incipient motion for Test 211

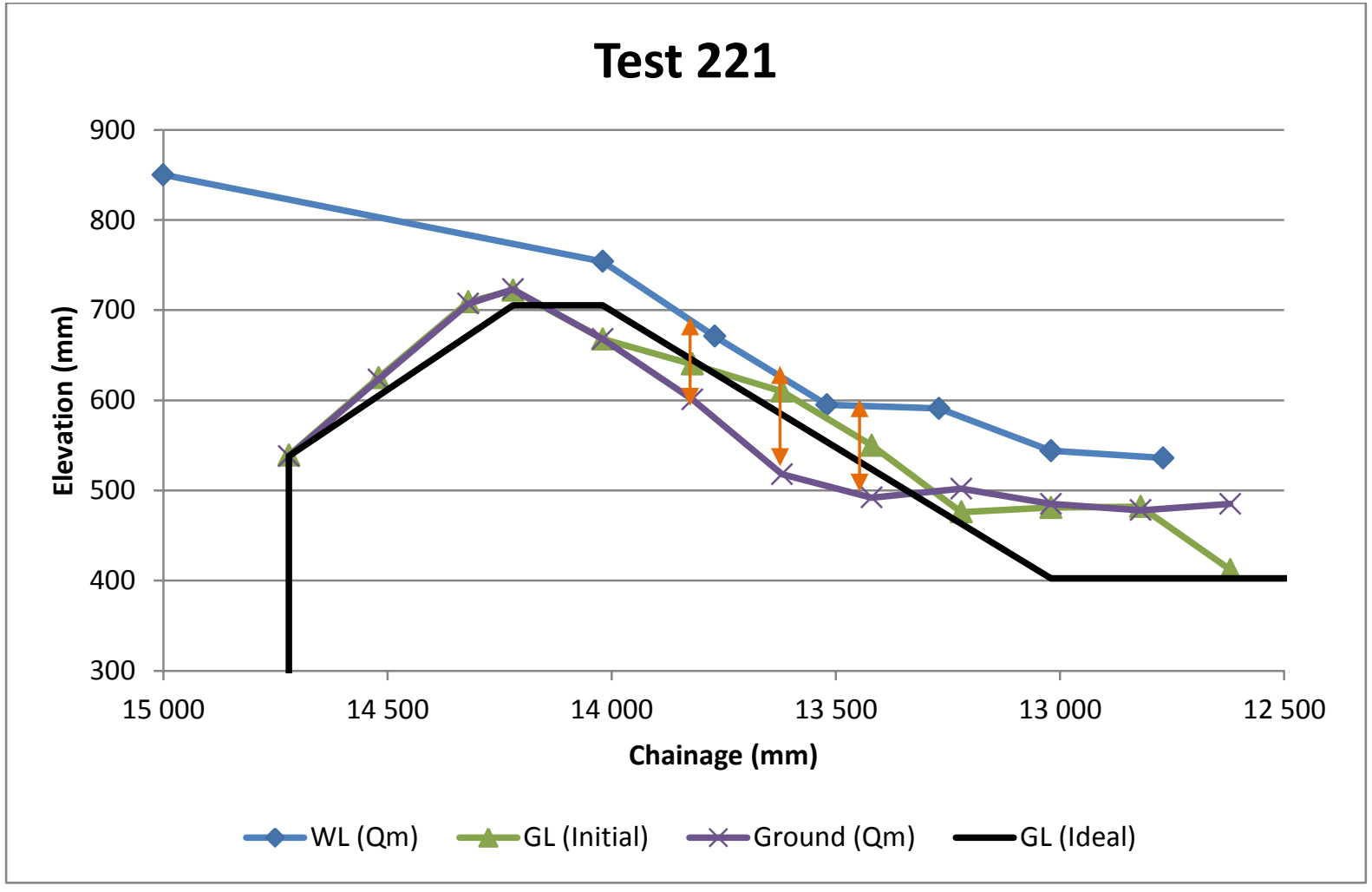

Figure C-5: Representative condition of incipient motion for Test 221 


\section{Test 231}

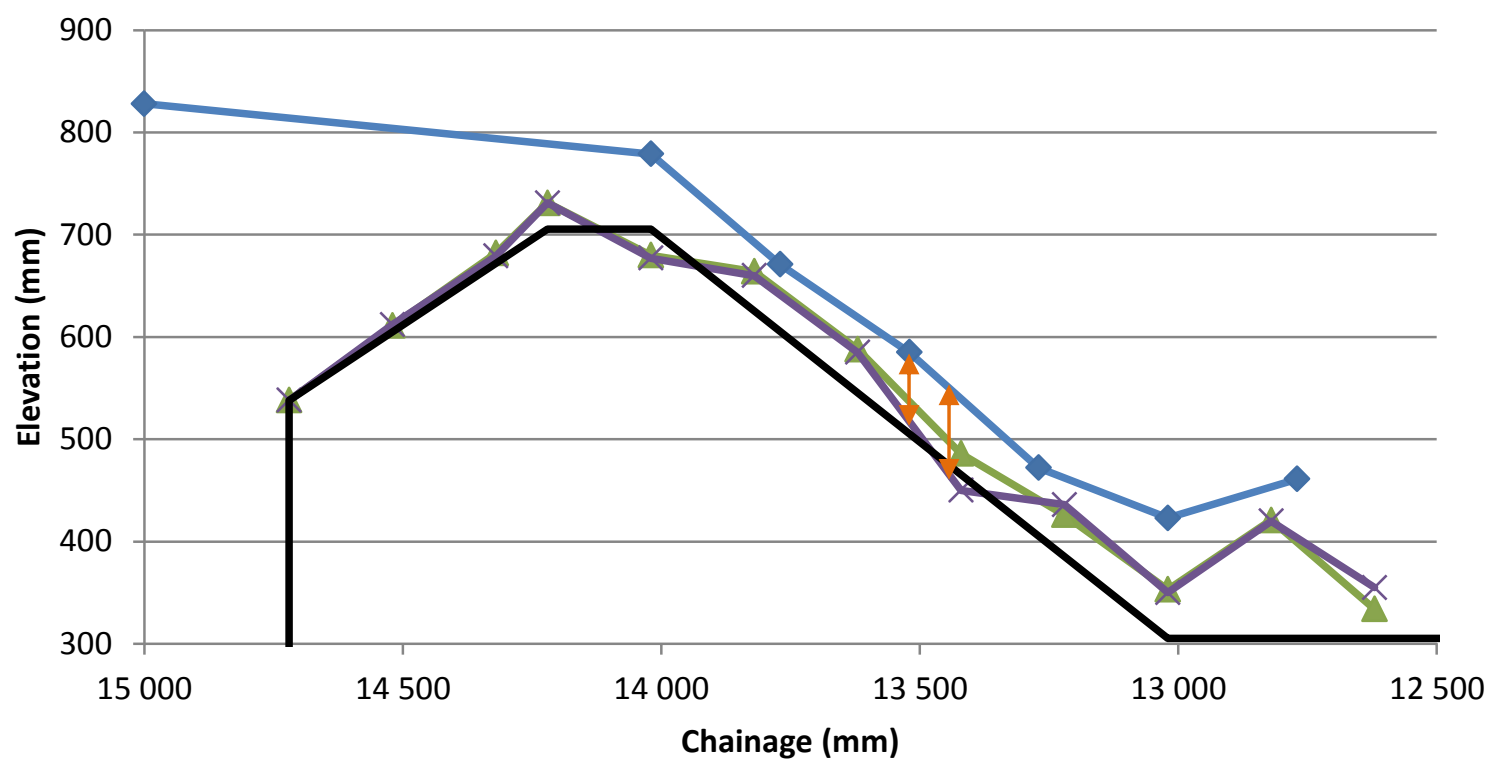

$\sim \mathrm{WL}(\mathrm{Qm}) \multimap \mathrm{GL}$ (Initial) $\longleftarrow$ Ground $(\mathrm{Qm}) \multimap \mathrm{GL}$ (Idea)

Figure C-6: Representative condition of incipient motion for Test 231

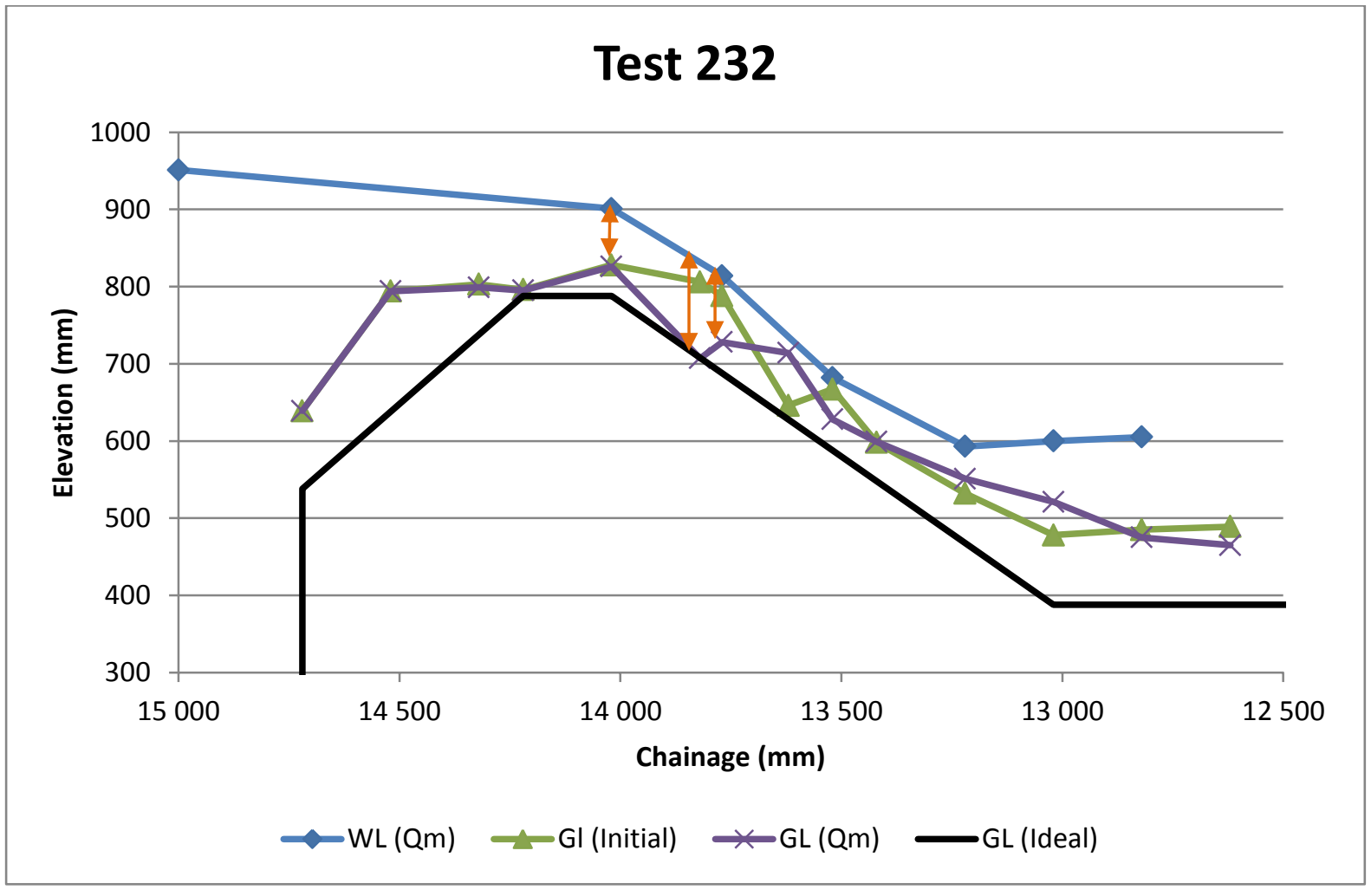

Figure C-7: Representative condition of incipient motion for Test 232 
Test 222

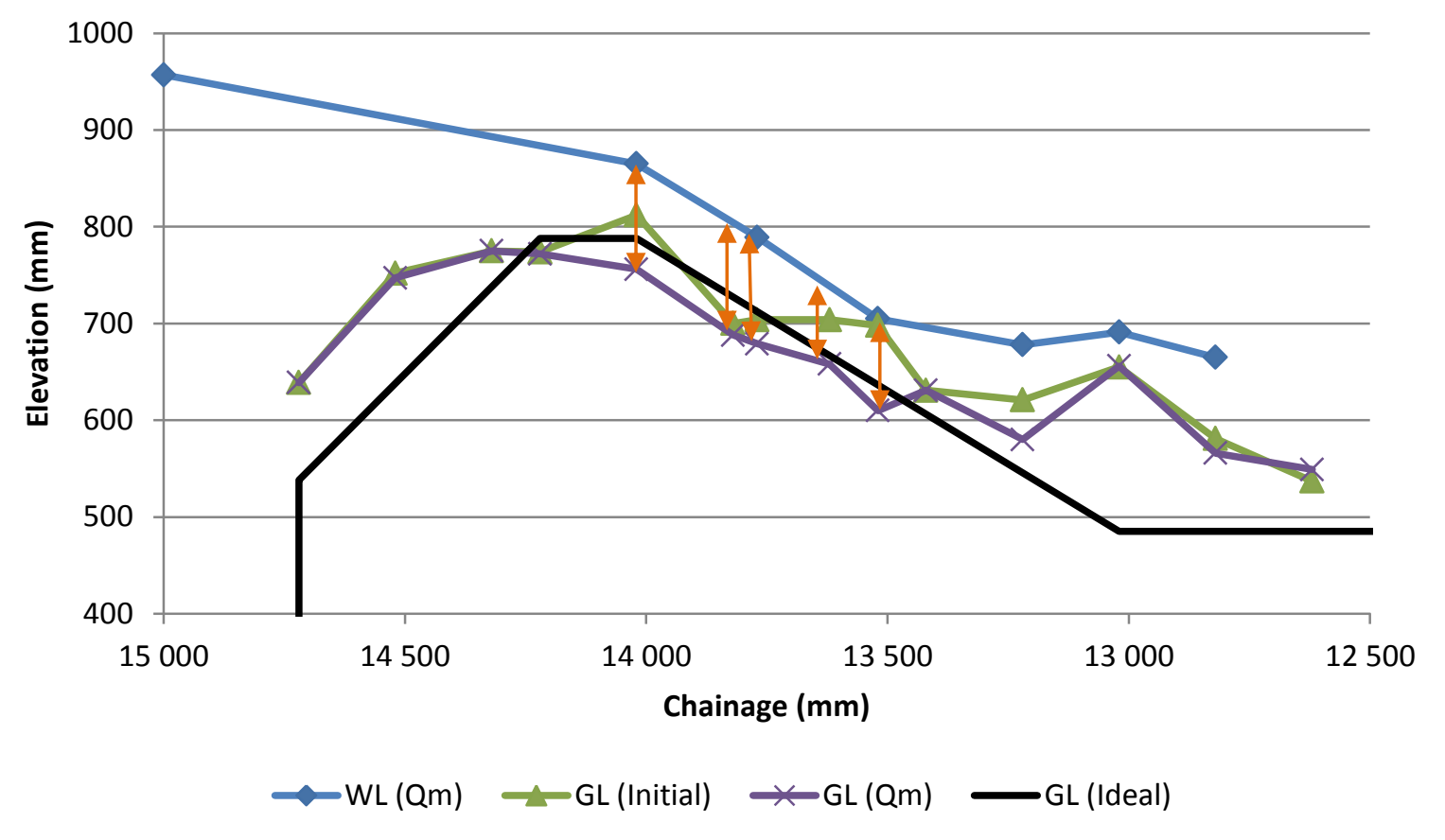

Figure C-8: Representative condition of incipient motion for Test 222

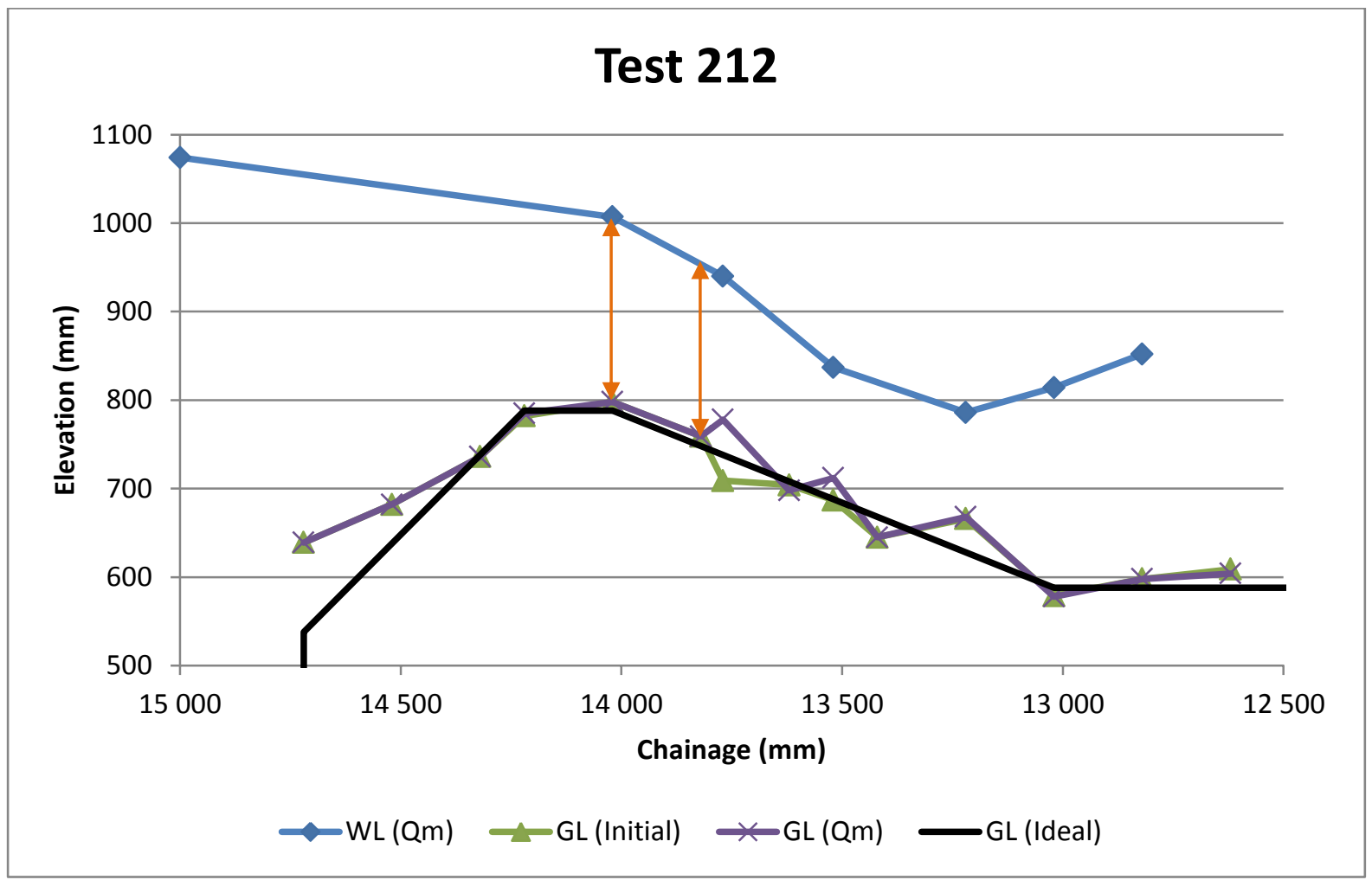

Figure C-9: Representative condition of incipient motion for Test 212 


\section{Test 132}

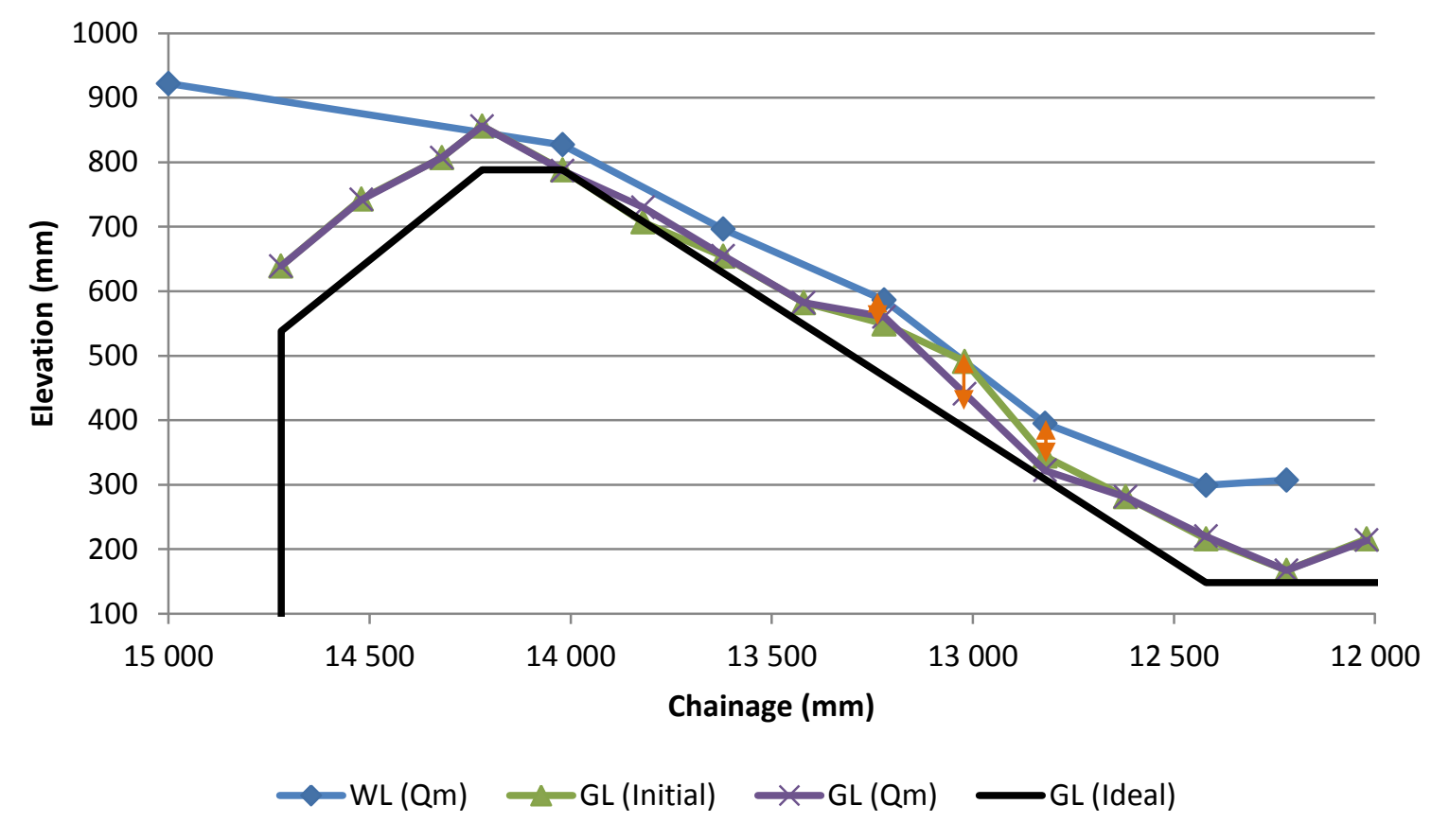

Figure C-10: Representative condition of incipient motion for Test 132

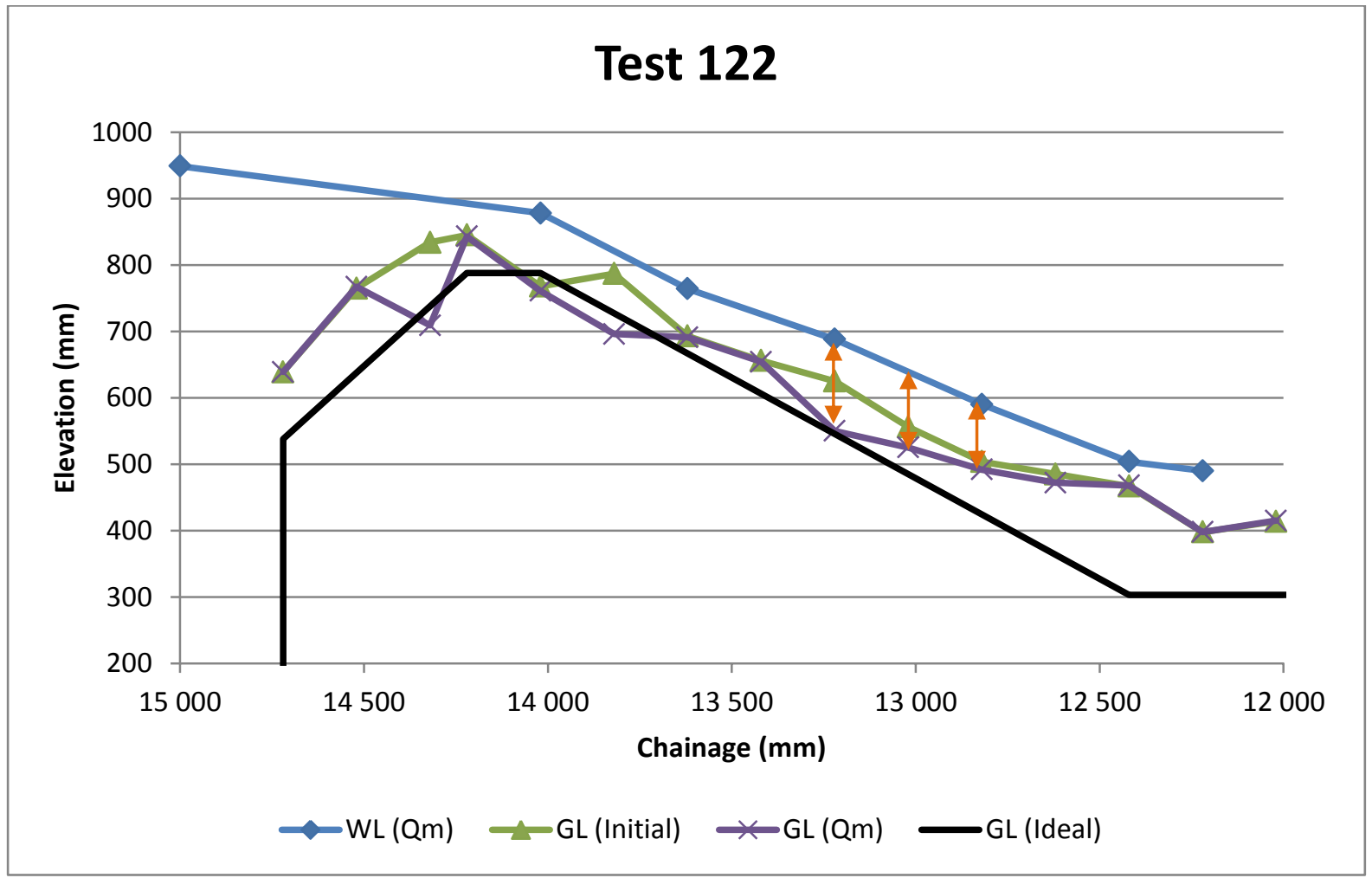

Figure C-11: Representative condition of incipient motion for Test 122 


\section{Test 112}

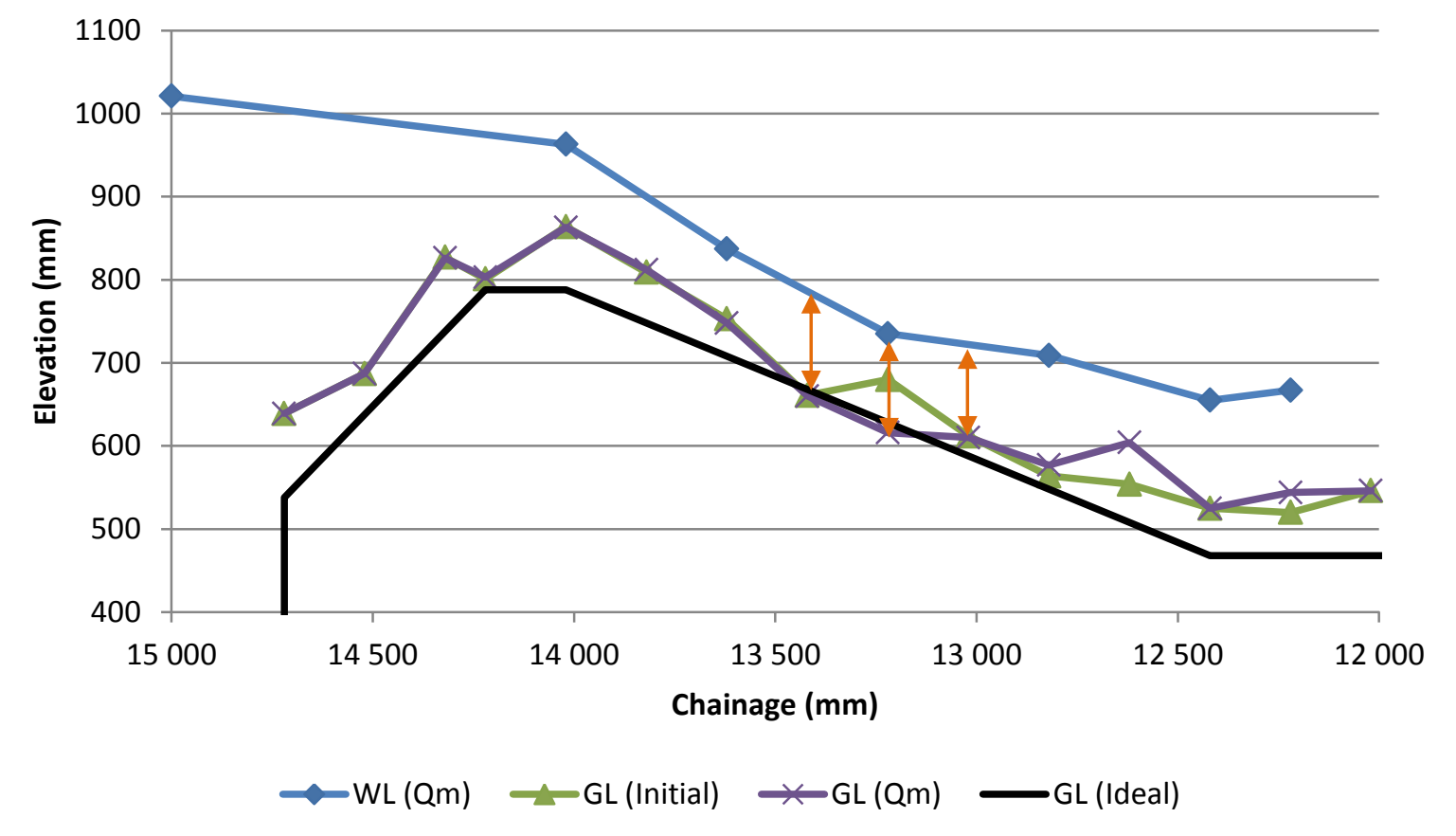

Figure C-12: Representative condition of incipient motion for Test 112 


\section{APPENDIX D: HEC-RAS RESULTS}

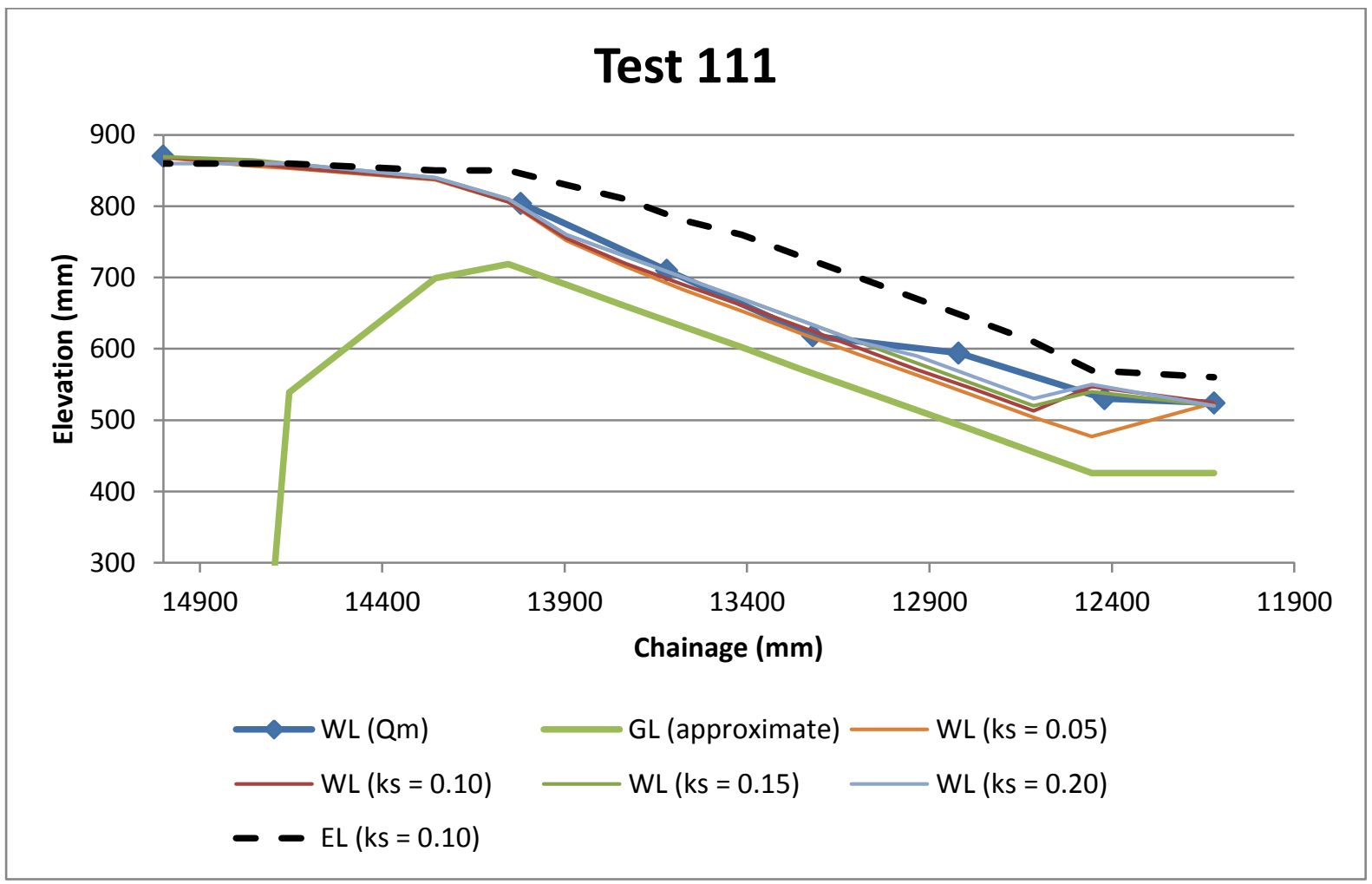

Figure D-1: Simulation results for Test 111 


\section{Test 121}

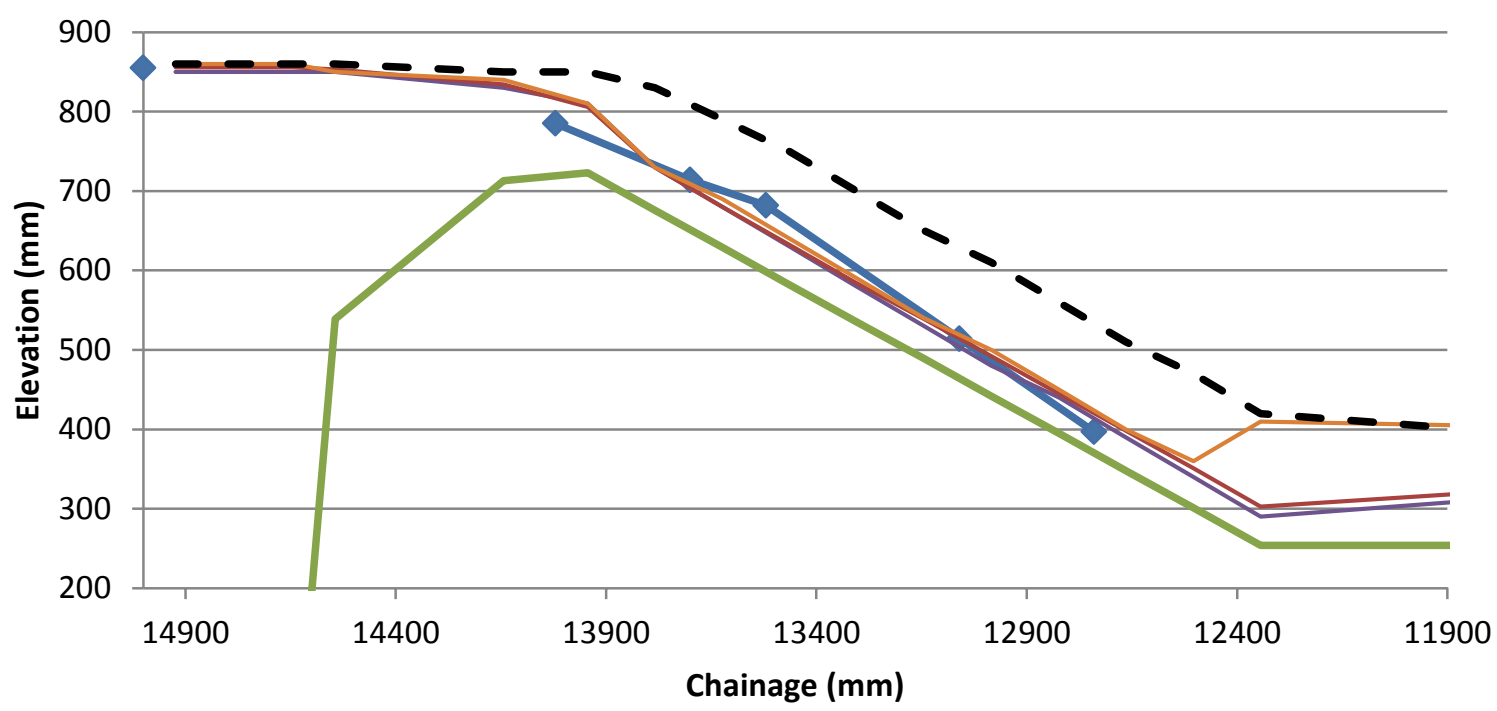
$\leadsto$ WL $(\mathrm{Qm})$
GL (approximate) - WL $(\mathrm{ks}=0.05)$
$\mathrm{WL}(\mathrm{ks}=0.10)$
$W L(k s=0.15) \quad-\quad-E L(k s=0.10)$

Figure D-2: Simulation results for Test 121

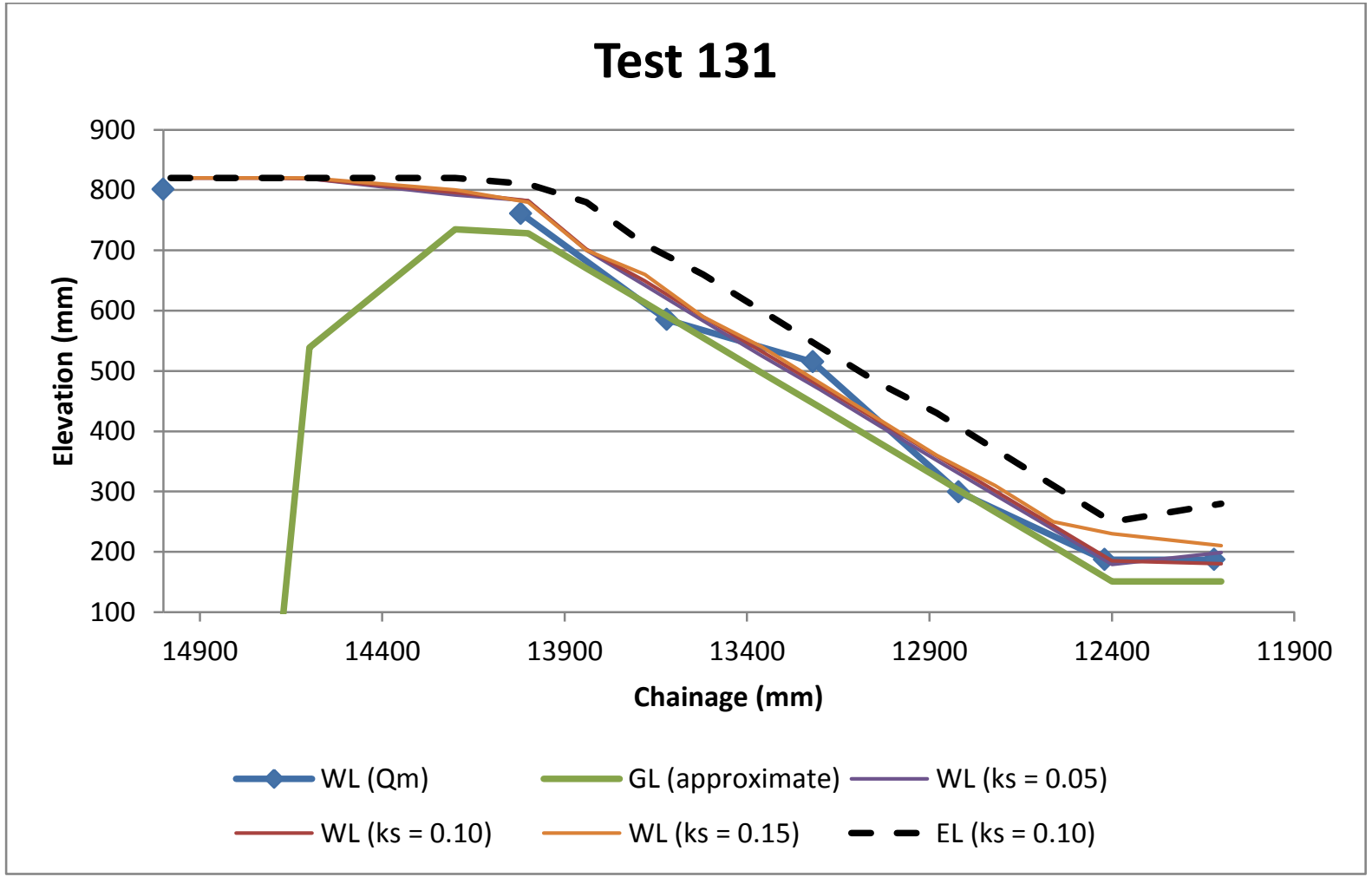

Figure D-3: Simulation results for Test 131 
Test 211

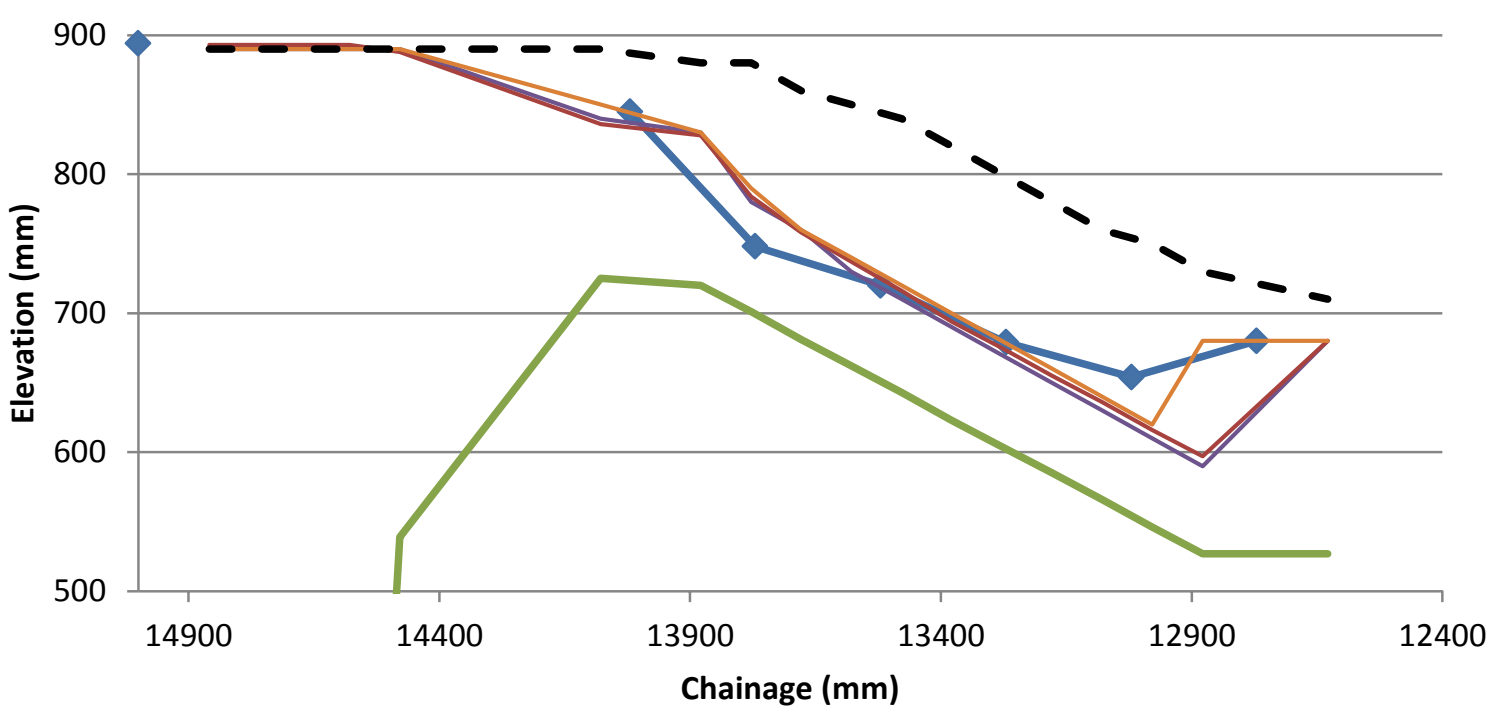
$\checkmark \mathrm{WL}(\mathrm{Qm})$
GL (Approximate)
WL $(k s=0.05)$
$\mathrm{WL}(\mathrm{ks}=0.10)$
$\mathrm{WL}(\mathrm{ks}=0.15) \quad-\quad \mathrm{EL}(\mathrm{ks}=0.10)$

Figure D-4: Simulation results for Test 211

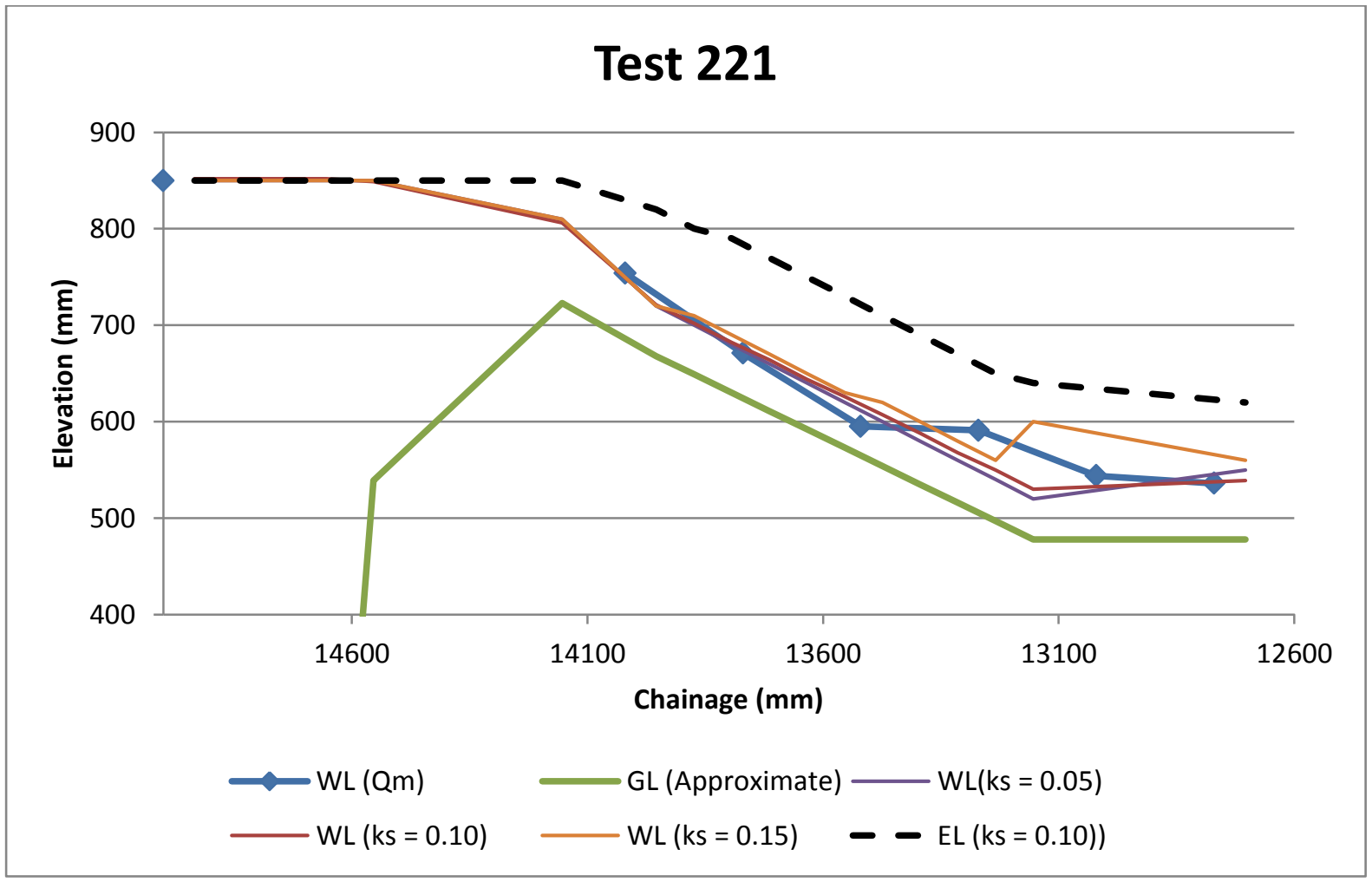

Figure D-5: Simulation results for Test 221 
Test 231

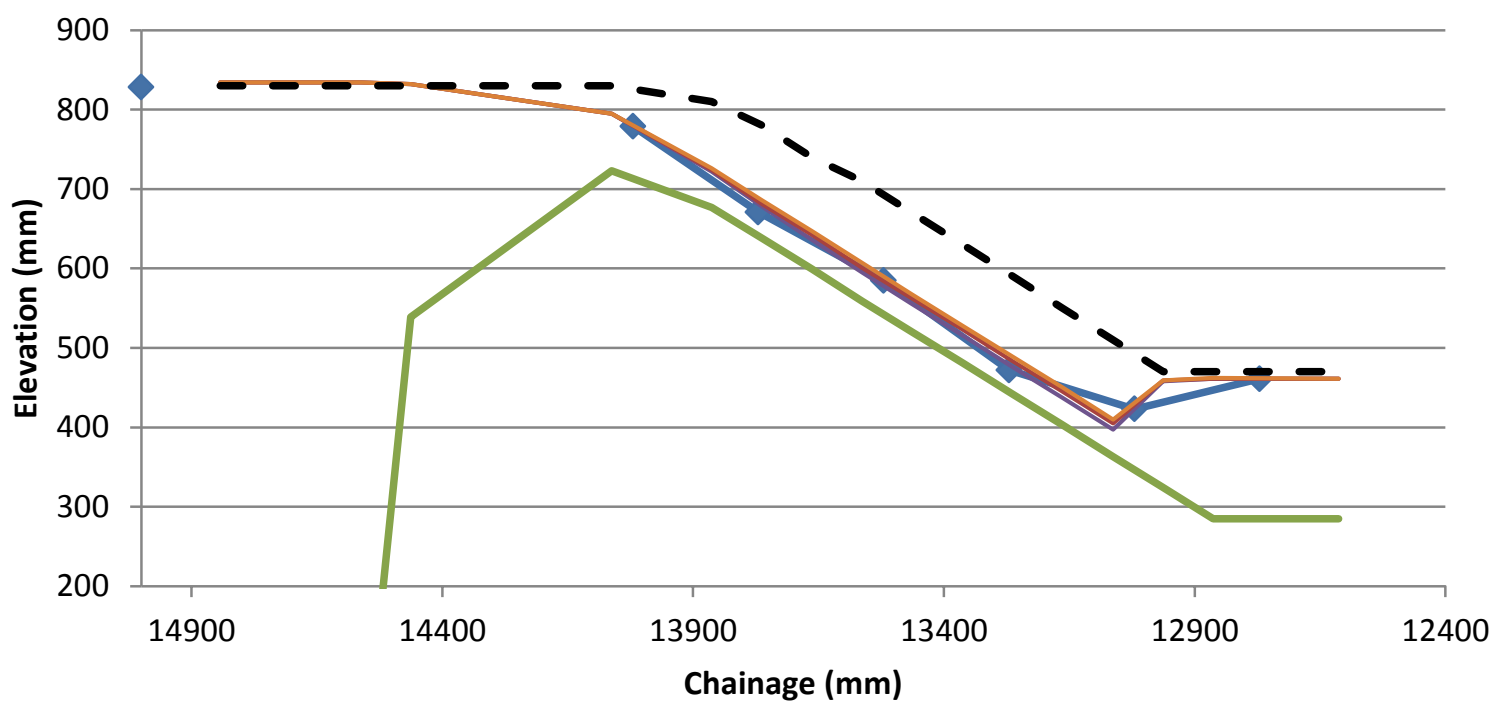
$\longrightarrow \mathrm{WL}(\mathrm{Qm})$
GL (Approximate)
$\mathrm{WL}(\mathrm{ks}=0.05)$
$\mathrm{WL}(\mathrm{ks}=0.10)$
$\mathrm{WL}(\mathrm{ks}=0.15) \quad-\quad \mathrm{EL}(\mathrm{ks}=0.10)$

Figure D-6: Simulation results for Test 231

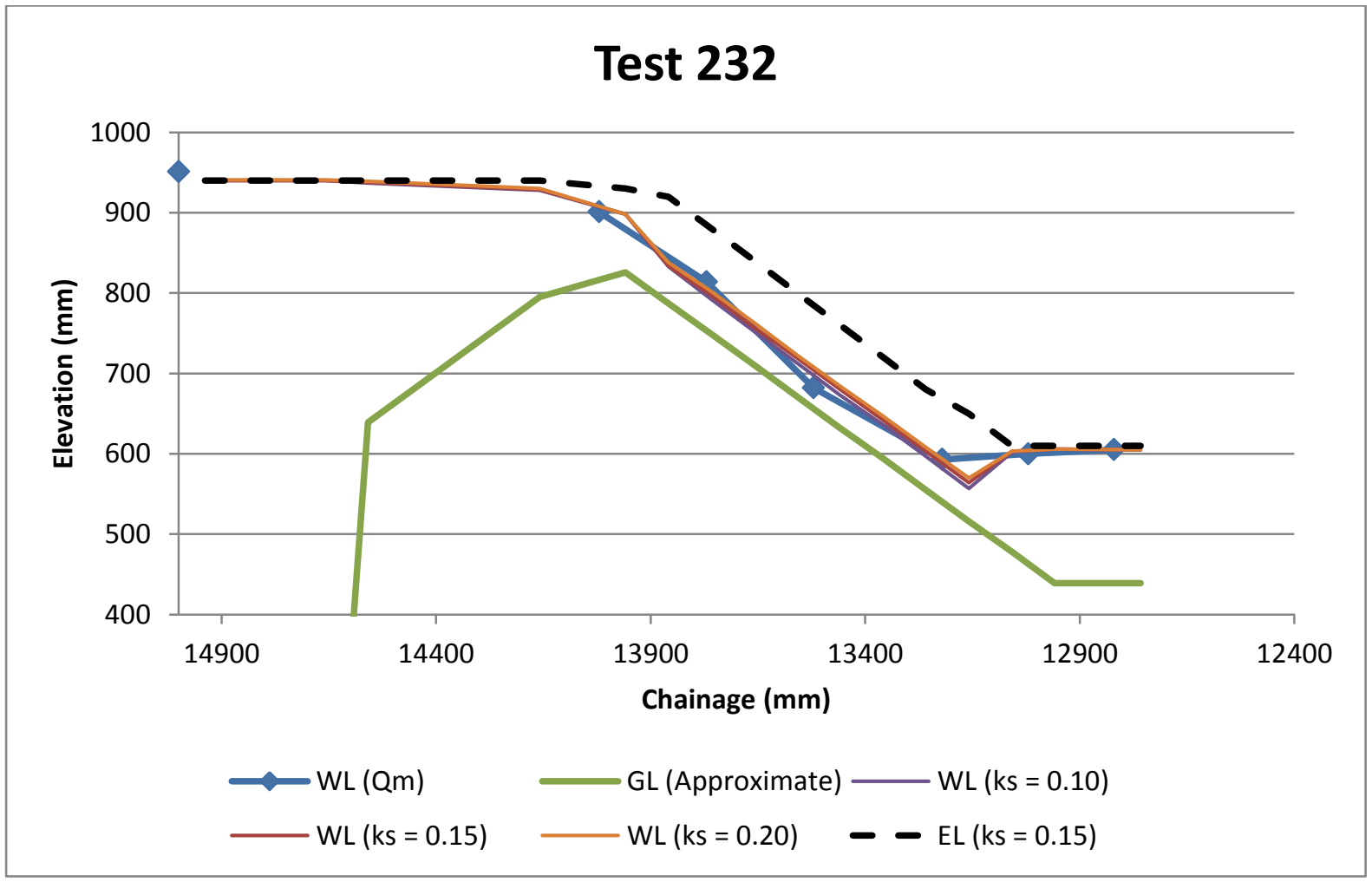

Figure D-7: Simulation results for Test 232 
Test 222

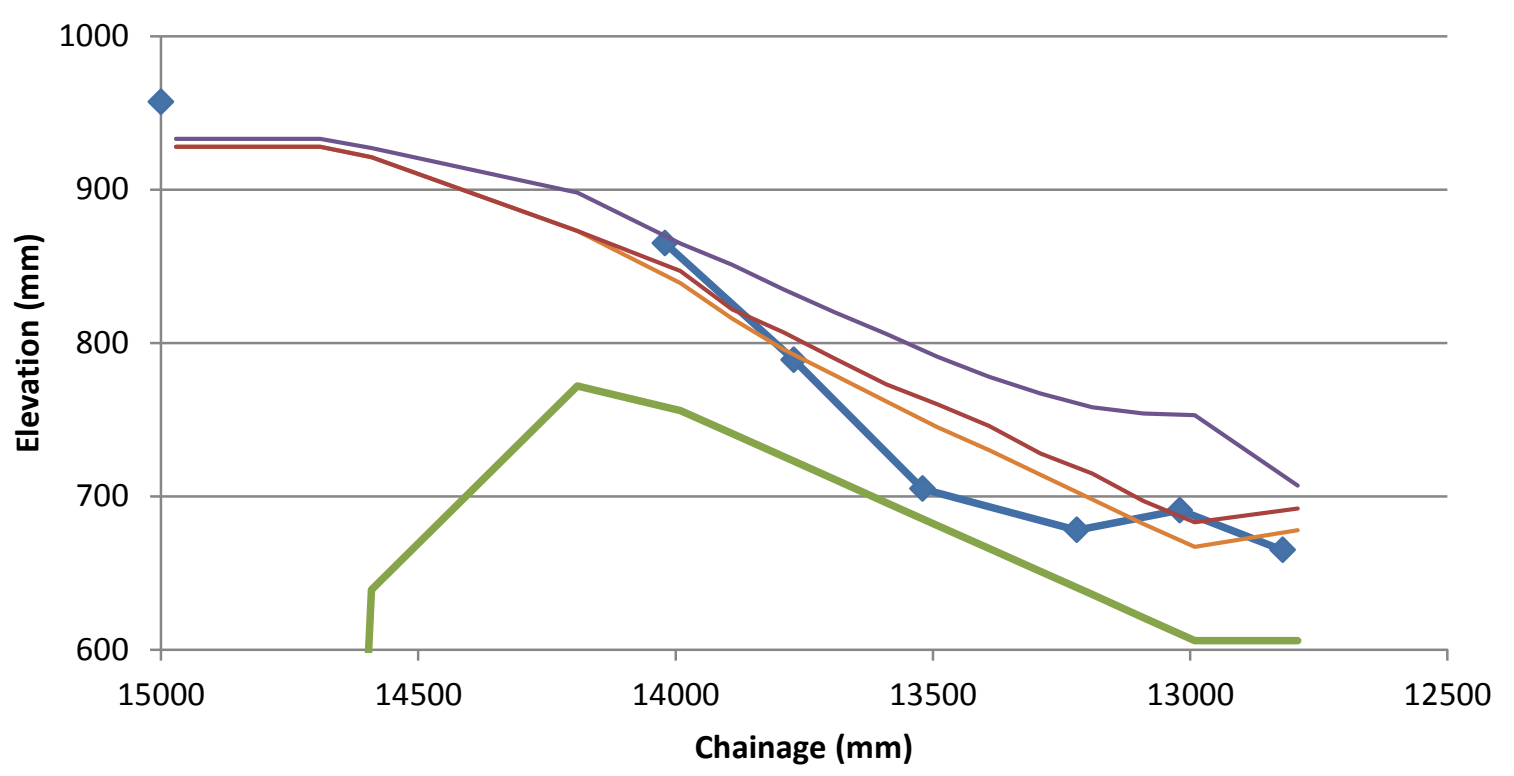

$\neg \mathrm{WL}(\mathrm{Qm}) \longrightarrow \mathrm{GL}($ Approximate) $\longrightarrow \mathrm{WL}(\mathrm{ks}=0.05) \longrightarrow \mathrm{WL}(\mathrm{ks}=0.15) \longrightarrow \mathrm{WL}(\mathrm{ks}=0.40)$

Figure D-8: Simulation results for Test 222 (inconclusive)

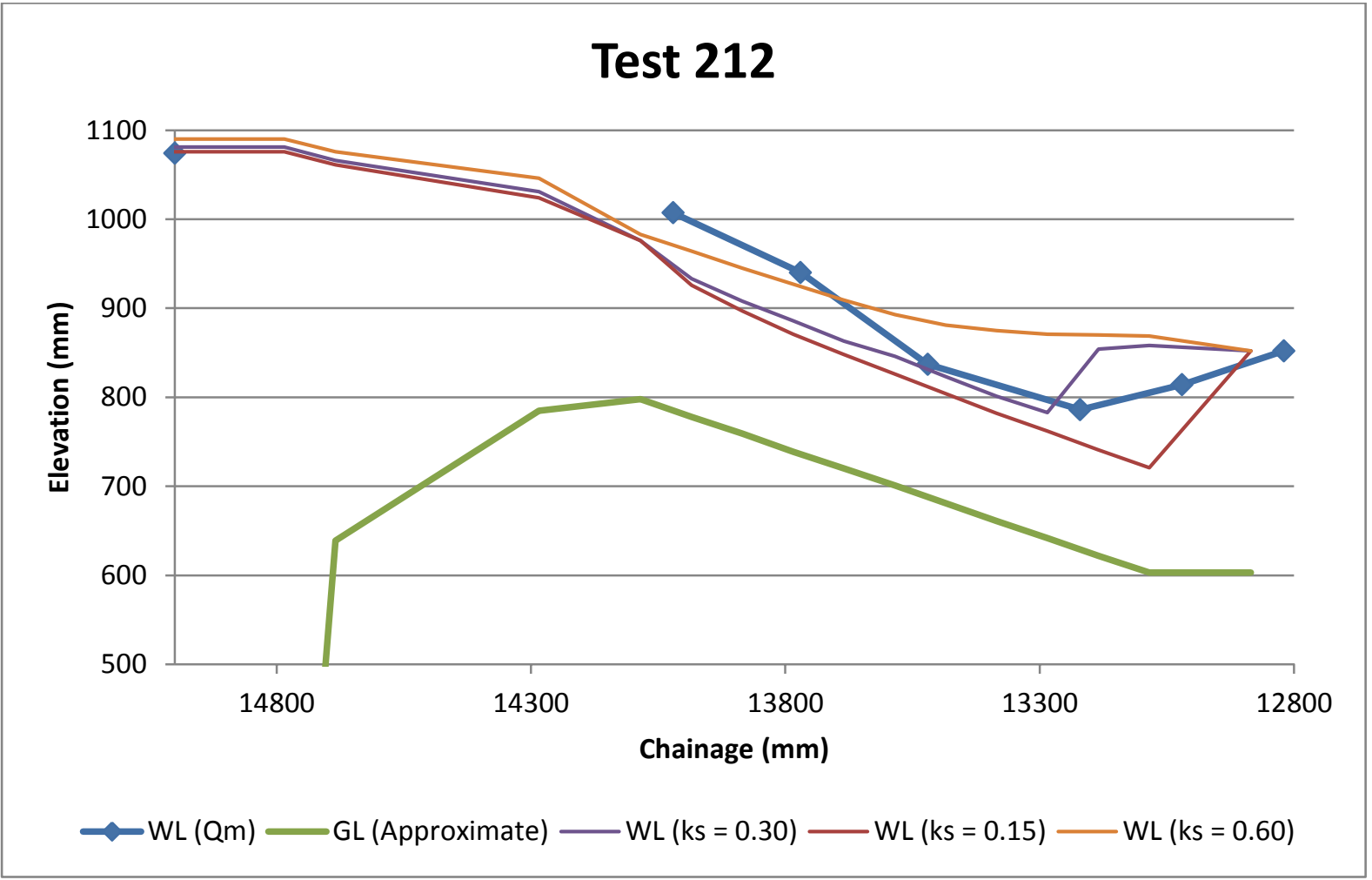

Figure D-9: Simulation results for Test 212 (inconclusive) 


\section{Test 132}

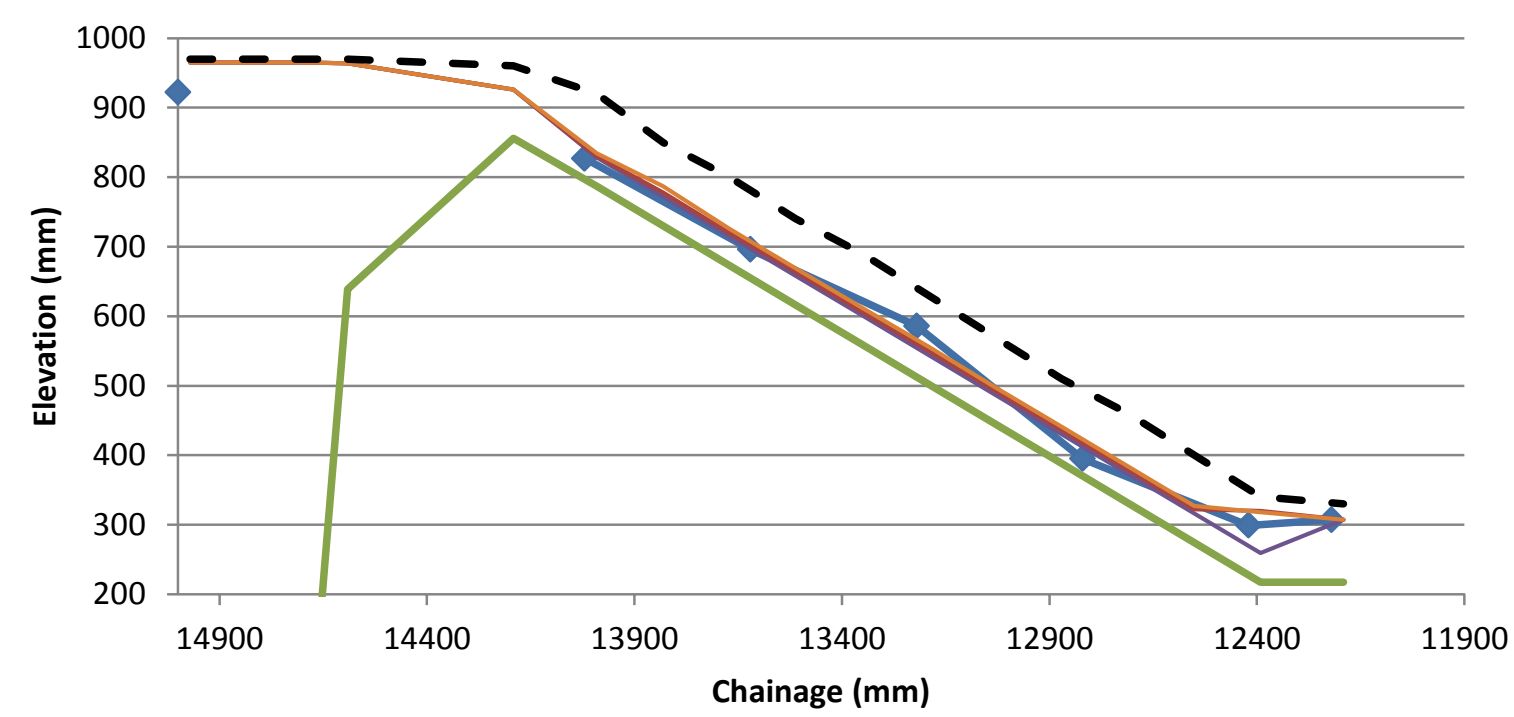
$\leadsto$ WL $(\mathrm{Qm})$
GL (Approximate)
$\mathrm{WL}(\mathrm{ks}=0.10)$
$\mathrm{WL}(\mathrm{ks}=0.15)$
$\mathrm{WL}(\mathrm{ks}=0.20) \quad-\quad-E L(k s=0.15)$

Figure D-10: Simulation results for Test 132

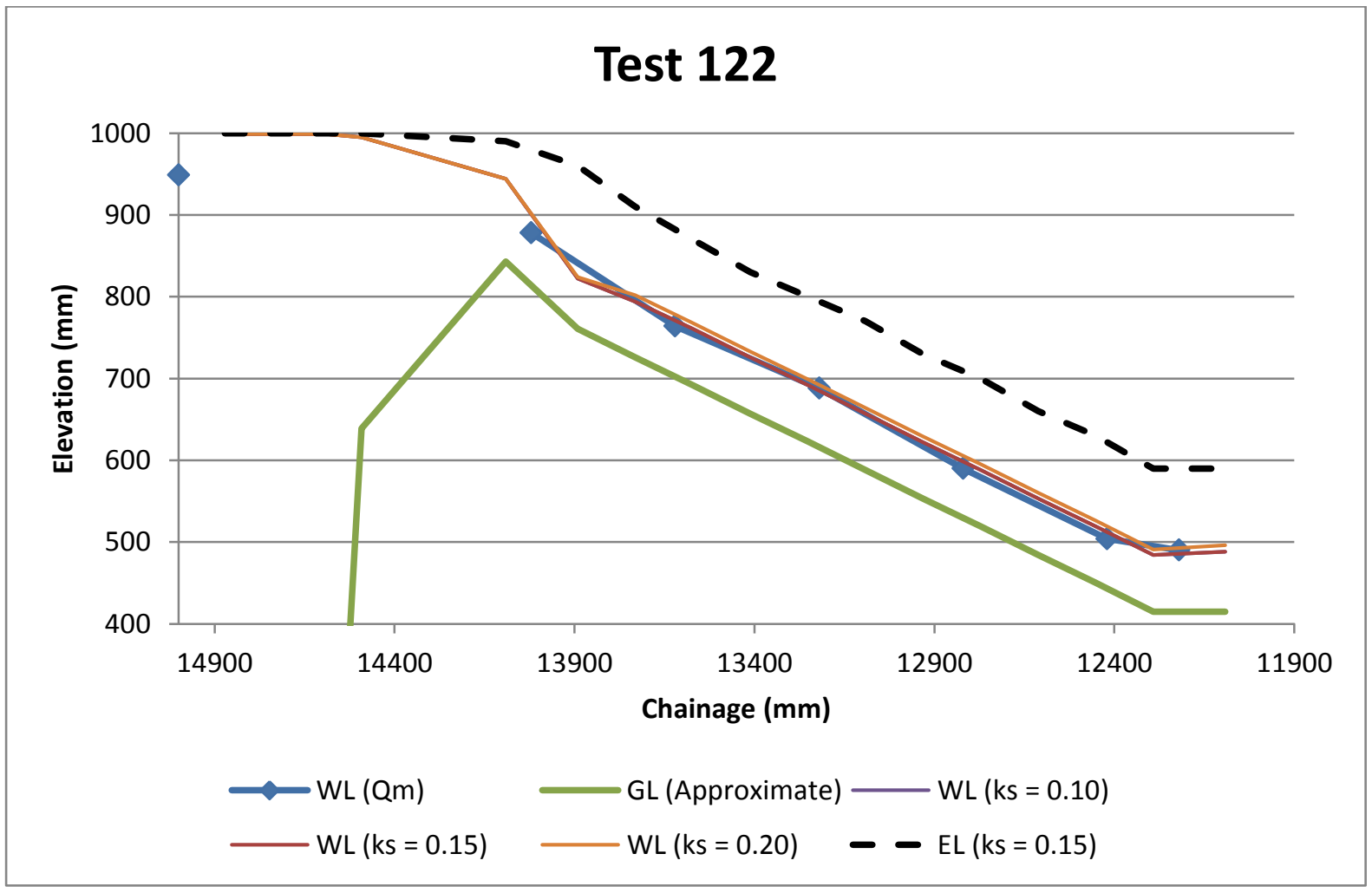

Figure D-11: Simulation results for Test 122 


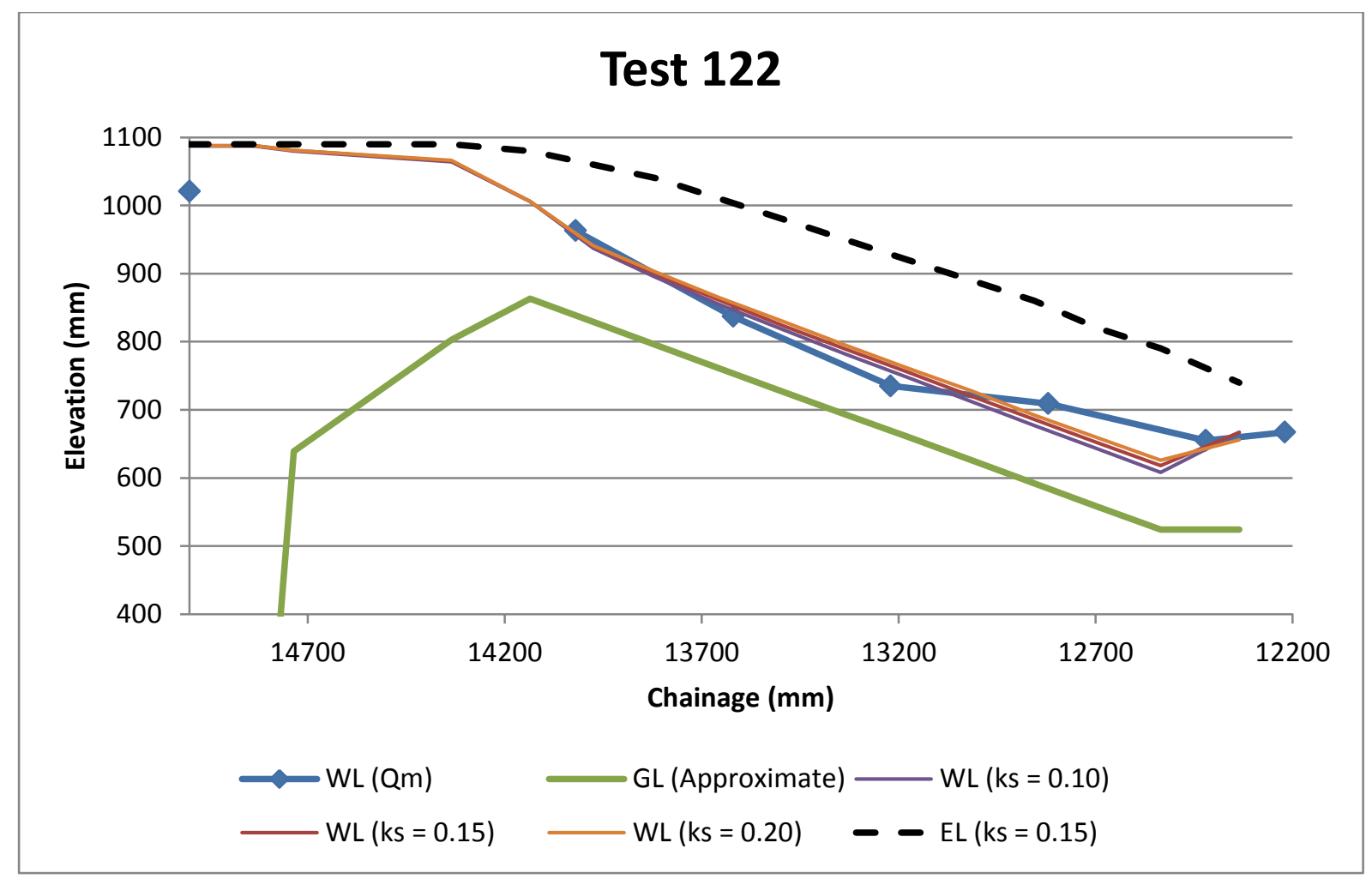

Figure D-12: Simulation results for Test 122 